\author{
UNIVERSIDADE DE SÃO PAULO \\ ESCOLA DE ENGENHARIA DE SÃO CARLOS \\ DEPARTAMENTO DE ENGENHARIA DE PRODUÇÃO
}

FELIPE BARRETO SILVA

Proposta e avaliação de um procedimento de planejamento de tempo combinado ágil e tradicional

São Carlos

2015 

FELIPE BARRETO SILVA

\section{Proposta e avaliação de um procedimento de planejamento de tempo combinado ágil e tradicional}

Dissertação de mestrado apresentada à Escola de Engenharia de São Carlos, Universidade de São Paulo, como parte dos requisitos para obtenção do Título de Mestre em Engenharia de Produção.

Área de concentração: Processos e Gestão de Operações

Orientador: Prof. Dr. Daniel Capaldo Amaral

São Carlos

2015 
AUTORIZO A REPRODUÇÃO E DIVULGAÇÃO TOTAL OU PARCIAL DESTE TRABALHO, POR QUALQUER MEIO CONVENCIONAL OU ELETRÔNICO, PARA FINS DE ESTUDO E PESQUISA, DESDE QUE CITADA A FONTE.

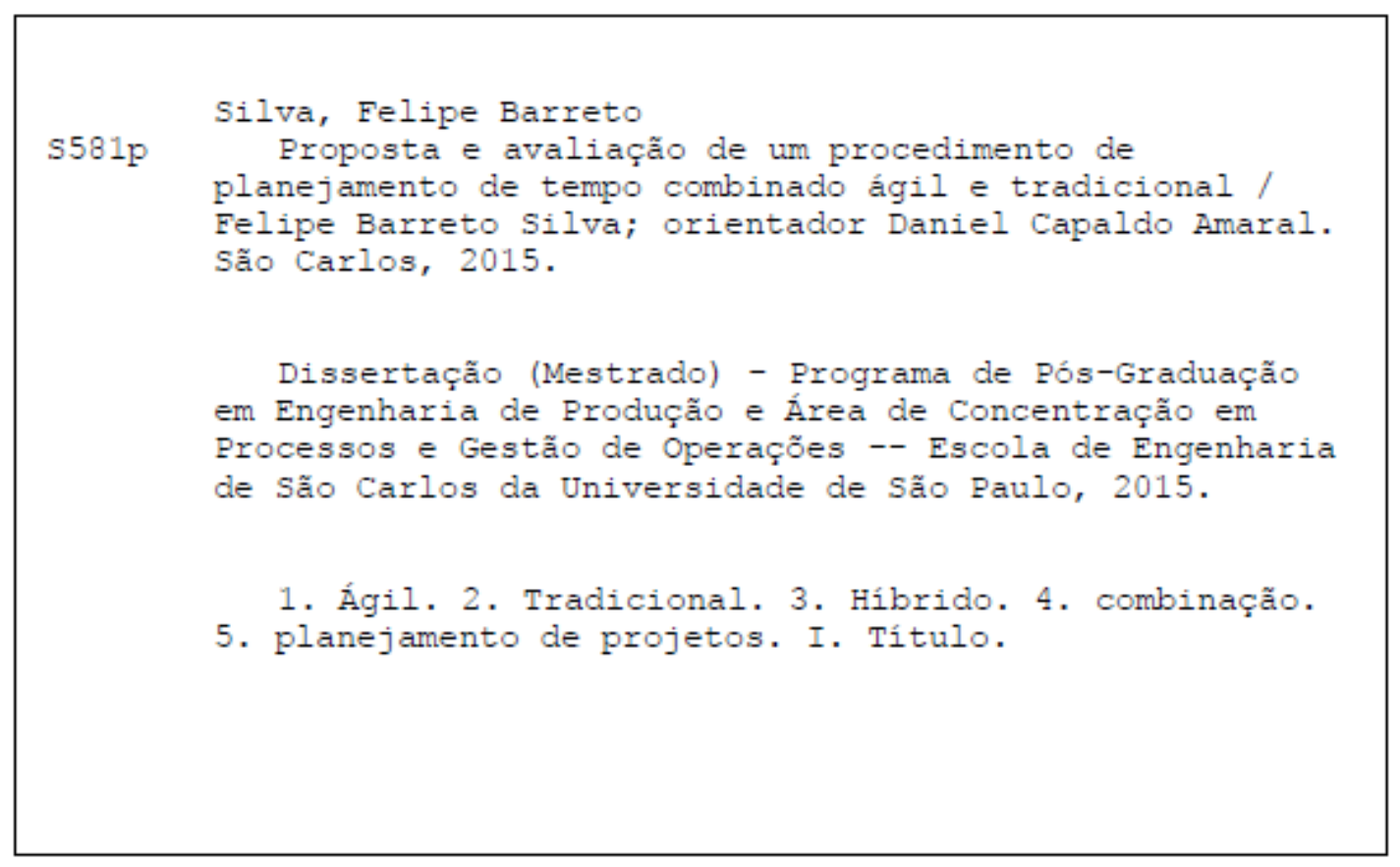


FOLHA DE JULGAMENTO

Candidato: Engenheiro FELIPE BARRETO SILVA.

Título da dissertação: "Proposta e avaliação de um procedimento de planejamento de tempo combinado ágil e tradicional".

Data da defesa: 29/06/2015

Comissão Julgadora:

Resultado:

Prof. Associado Daniel Capaldo Amaral (Orientador)

APRUVADO

(Escola de Engenharia de São Carlos/EESC)

Profa. Dra. Janaina Mascarenhas Hornos da Costa

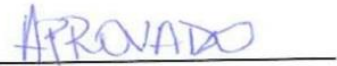

(Escola de Engenharia de São Carlos/EESC)

Dr. Claudiano Sales de Araújo Júnior

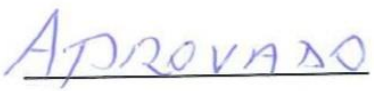

(Embraer)

Coordenadora do Programa de Pós-Graduação em Engenharia de Produção:

Profa. Associada Daisy Aparecida do Nascimento Rebelatto

Presidente da Comissão de Pós-Graduação:

Prof. Associado Paulo César Lima Segantine 


\section{AGRADECIMENTOS}

Um pouco mais de dois anos foram dedicados ao projeto desse mestrado e o resultado mudou completamente a minha vida em termos acadêmicos, pessoal e profissional. Tive a oportunidade de conhecer pessoas fantásticas, excelentes profissionais e amigos que levarei comigo pelo resto da minha vida. Sinto-me extremamente lisonjeado por ter tido essa oportunidade. Muito obrigado a todos que participaram de alguma forma desse projeto e que não mencionei nesses agradecimentos.

Tive a oportunidade de desenvolver esse mestrado sob a orientação do professor Daniel Capaldo Amaral. Gostaria de agradecer a ele pela orientação, confiança, incentivo e contribuição à minha formação acadêmica, pessoal e profissional. Aprendi lições valiosíssimas que levarei para toda a minha vida.

Quero agradecer a Deus por me abençoar durante esse período me dando saúde e guiando o meu caminho. À minha família, meu pai, minha mãe e, principalmente, a minha irmã, que sempre me apoiou nas minhas decisões e colaborou imensamente para a realização desse projeto.

Aos meus amigos de pesquisa e companheiros de Pós-graduação Lucelindo, Taís Hamamoto, Kênia, Vanessa Nappi, Gabriel Mantese, Caio Marques, Matheus, Victor Macul, Daniel Guzzo, Claudia, Miriã, Raphael Prateleira, João Guilherme, Gabriela, Lucas Portilho, Cintia, Roberta e Fausto pelo conhecimento compartilhado, amizade e bons momentos durante o mestrado.

Aos professores Henrique Rozelfeld e Janaína Costa pelo conhecimento, ensinamentos compartilhados durante o mestrado e as contribuições nesta pesquisa.

Aos meus amigos e família do Ceará, Narcisio, Onias, Abigail e a pequena Rebeca pelos momentos felizes aos finais de semana em que nos reunimos para almoçar e conversar sobre a nossa terra natal.

Aos funcionários do SEP pelo apoio administrativo.

Ao Numa e a Universidade de São Paulo pela excelente estrutura e ambiente de trabalho que possibilitaram a condução desta pesquisa. A Capes pelo apoio financeiro. 


\section{RESUMO}

As abordagens Tradicional e Ágil de gerenciamento de projetos são tidas como antagônicas, porém, há autores defendendo a combinação de práticas oriundas das duas abordagens. Por meio de uma Revisão Bibliográfica Sistemática, foram identificadas definições, benefícios esperados, fatores críticos e propostas de combinação, na forma de métodos e frameworks. Conclui-se que até o momento não há um termo comum, as definições são amplas e não auxiliam o desenvolvimento de métodos combinados. Analisou-se qualitativamente dez propostas utilizando os critérios de diferenciação identificadas em Eder et al. (2014). O resultado da análise indicou que as propostas não se diferenciavam da gestão Ágil ou não apresentavam informações para debater a combinação adotada. Identificou-se ainda duas estratégias de combinação: top-down e a bottom-up. Entre essas questões, optou-se por contribuir em duas áreas: a proposição de uma definição de abordagem híbrida ou combinada, e a recomendação de práticas para o uso dessa abordagem. O objetivo da pesquisa foi desenvolver um procedimento de planejamento de tempo combinado, baseado em uma definição nova de combinação. A concepção do procedimento utilizou a estratégia top-down e a proposta final é apresentada na forma de fluxo de atividades em um modelo de processos de negócio. Adotou-se o Estudo de Caso como método de investigação. O caso consiste em uma simulação de projeto com alunos da graduação do curso de Gestão de Projetos. Os dados foram coletados em duas dimensões, a primeira consiste na combinação de práticas, baseada nos seis critérios de Eder et al. (2014), e a segunda refere-se a usabilidade do procedimento. O resultado indicou que é viável combinar práticas. A usabilidade do procedimento pode ser considerada satisfatória para o contexto da aplicação, em termos de facilidade de uso e aprendizado. Recomenda-se como trabalhos futuros investigar a integração de outros processos de planejamento, como recursos e stakeholders, e desenvolver um procedimento considerando a estratégia bottom up.

Palavras chaves: Ágil, Tradicional, Híbrido, combinação, planejamento de projetos. 


\begin{abstract}
The Traditional and Agile project management approaches are seen as polar opposites. However, the combination of agile and traditional practices could be preferable to the isolated use of either. Through a Systematic Literature Review (RBS), definitions, expected benefits, critical factors and combination proposals, among models, methods and frameworks, were summarized. The conclusion indicates the definitions present wide meaning and do not support the development of combined proposals. A qualitative analysis of ten combination proposals uses the criteria of differentiation of agile and traditional approaches identified in Eder et al. (2014). The result of the analysis indicated the proposals do not differ from Agile or lack of information to discuss the combination adopted. In addition, the analysis identifies two combination strategies: top-down and bottom-up. This dissertation contributes in two main areas: to propose a definition of hybrid or combined approach, and recommended practices for using this approach. The objective of the research was to develop a combined time planning procedure, based on a new definition of combination. The procedure used to design top-down strategy and the final proposal is presented as flow of activities in a business processes model. The research method adopts the case study. The case consists of a project simulation with under-graduate students of project management course. Two dimensions of analysis are used to assess the data, the first is the combination of practices, based on the six criteria of Eder et al. (2014), and the second relates to the procedure usability. The result indicated that it is viable to combine practices, the procedure usability can be considered satisfactory for the application context, in terms of use and learning facility. It is recommended as future work to investigate the integration of other planning processes, as resources and stakeholders, and develop a procedure considering the bottom-up strategy.
\end{abstract}

Keywords: Hybrid; Agile; Scrum; Traditional; Plan-driven; combination; balance; project planning. 


\section{LISTA DE FIGURAS}

Figura 1 - Processos de planejamento de tempo de projeto ................................................23

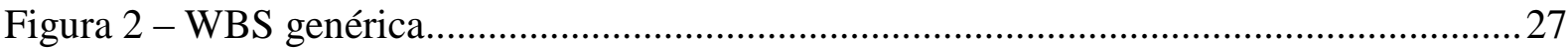

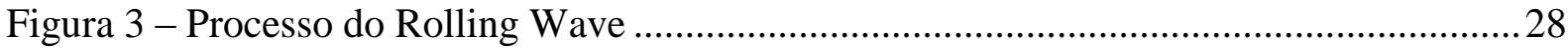

Figura 4 - Exemplo de sequenciamento de atividades utilizando o PDM ..............................28

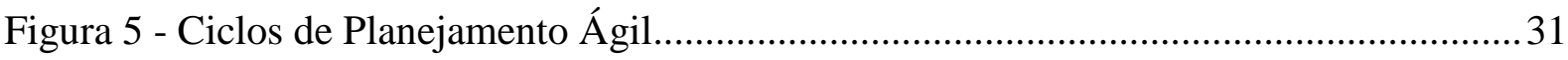

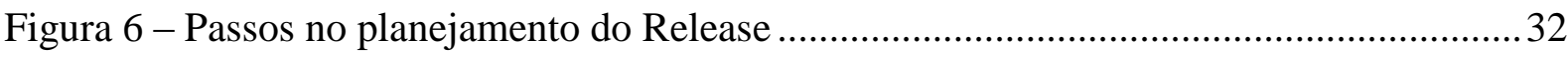

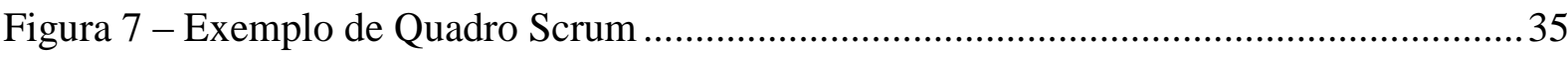

Figura 8 - Evolução da documentação e mudanças nos níveis de formalidade........................39

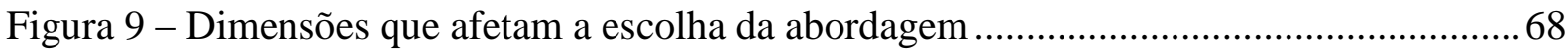

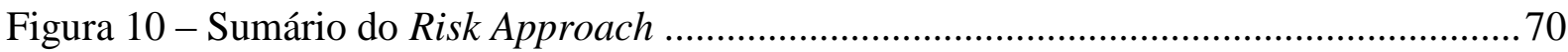

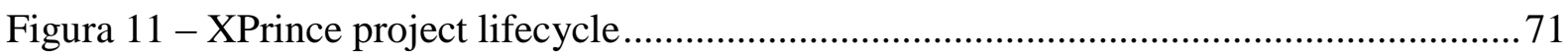

Figura 12 - Processo Híbrido de Metodologia de Design..................................................... 73

Figura 13 - Características do projeto que favorecem a abordagem Híbrida. ........................ 74

Figura 14 - Modelo Ágil de processo Hibrido Disciplinado................................................... 75

Figura 15 - Uso do modelo referencial no caso de projetos grandes ...................................... 79

Figura 16 - Diagrama proposto para o framework Tragile. ................................................. 80

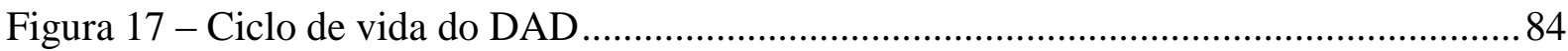

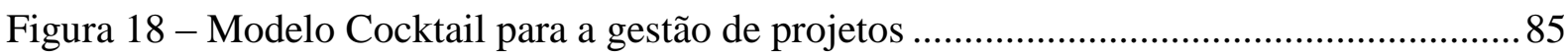

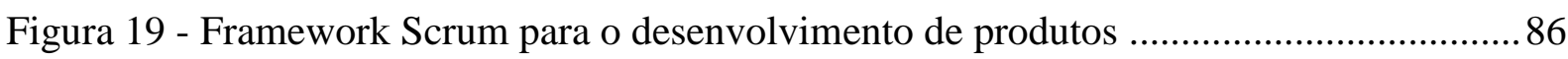

Figura 20 - Fases, atividades e resultados da pesquisa ....................................................... 99

Figura 21 - Dimensões de avaliação do procedimento ........................................................ 107

Figura 22 - Relação entre as fontes de evidências e as dimensões ........................................111

Figura 23 - Primeira proposta do fluxo de informações do procedimento ............................. 115

Figura 24 - Artefatos criados para o caso do Globo Interativo.............................................. 116

Figura 25 - Segunda proposta criada para o fluxo de informações do procedimento ...........118

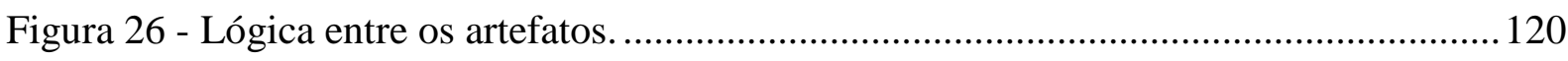

Figura 27 - Comparação entre os níveis de planejamento .................................................. 122

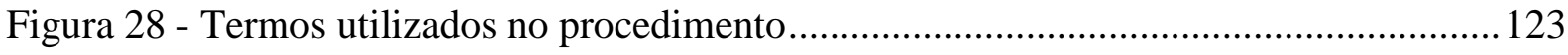

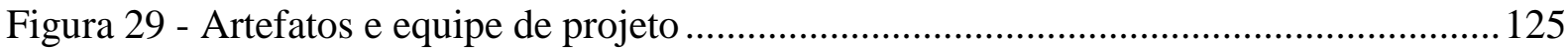

Figura 30 - Visão geral do Procedimento de planejamento de tempo combinando ...............126

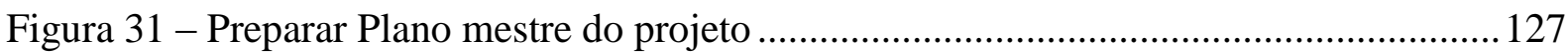




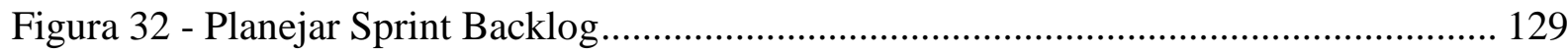

Figura 33 - Executar Sprint: repetir para cada equipe operacional (1... n) ......................... 130

Figura 34 - Realizar reunião diária............................................................................... 131

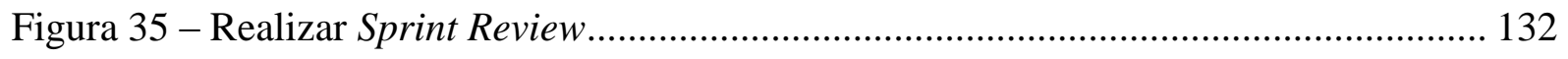

Figura 36 - Realizar Retrospective Review.................................................................... 132

Figura 37 - Implementar mudanças no Planejamento .......................................................... 133

Figura 38 - Milestone Review ………………………………………………….... 135

Figura 39 - Desafio do foguete de água …………………………………………….... 137

Figura 40 - Subsistemas do Foguete.......................................................................... 137

Figura 41 - Cronograma de atividades do treinamento ..................................................... 138

Figura 42 - Plano Mestre equipe Preta ....................................................................... 142

Figura 43 - Os subsistemas planejando os resultados finais. ................................................ 142

Figura 44 - Líderes criando o Plano Mestre .................................................................... 142

Figura 45 - Líder assumindo o papel de gerente de projetos.................................................. 143

Figura 46 - Estrutura adotada pela equipe Vermelha durante o Sprint 2 ………………..... 145

Figura 47 - Líderes da equipe Preta discutindo as interfaces do produto............................... 145

Figura 48 - Relação entre work item e resultado final, equipe Azul, Sprint 1. ...................... 147

Figura 49 - PMe da equipe Preta............................................................................... 148

Figura 50 - Equipe Azul e protótipo final. ........................................................................ 150

Figura 51 - Equipe Vermelha e protótipo final. .............................................................. 150

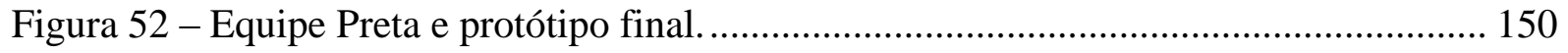

Figura 53 - Matriz Item - Entrega do exemplo ………………………………………...... 177

Figura 54- Plano do projeto para o exemplo ....................................................................... 177

Figura 55 - Quadro Scrum e as atividades do $1^{\text {a }}$ Sprint para o exemplo................................ 178

Figura 56 - Visão geral do Envisioning …………………………………………….... 181

Figura 57 - Captar necessidades (equipe e cliente) .............................................................. 182

Figura 58 - Captar necessidades (Pesquisa de mercado)..................................................... 184

Figura 59 - Elaborar Pré-concepção do produto ………………………………………….... 185

Figura 60 - Preparar Matriz Item-entrega........................................................................ 186

Figura 61 - Layout da sala de treinamento ..................................................................... 189

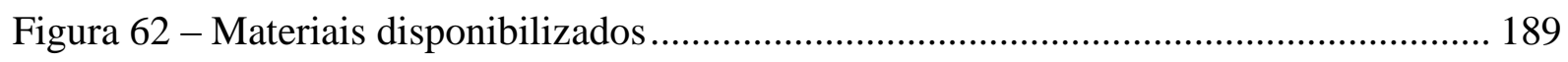

Figura 63 - Pré-concepção do Globo Interativo …………………………………….... 211

Figura 64 - Arquitetura do Software para o Globo Interativo ................................................ 211 


\section{LISTA DE QUADROS}

Quadro 1 - Métodos e ferramentas de planejamento de tempo ............................................26

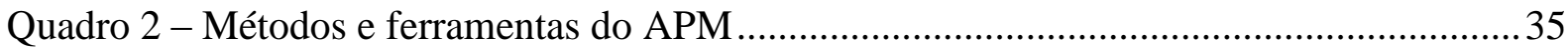

Quadro 3 - Condições de maior probabilidade de sucesso para Ágil e Tradicional ................37

Quadro 4 - Síntese dos termos e definições sobre a combinação ............................................52

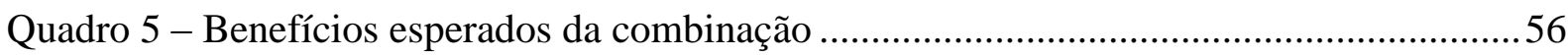

Quadro 6 - Síntese das recomendações de parâmetros de controle do projeto ..........................58

Quadro 7 - Características para identificação da abordagem de gerenciamento de projeto

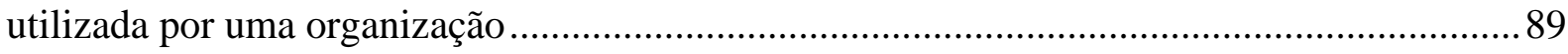

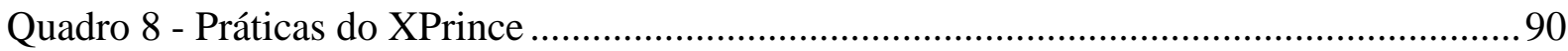

Quadro 9 - Práticas do modelo de processo híbrido de metodologia de design ....................... 90

Quadro 10 - Práticas do Framework Híbrido..............................................................................90

Quadro 11 - Práticas do Processo híbrido disciplinado ....................................................... 91

Quadro 12 - Práticas do Modelo referencial ágil para grandes projetos................................ 92

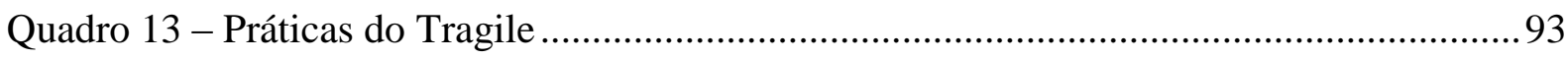

Quadro 14 - Práticas do Diciplined Agile Delivery ................................................................ 93

Quadro 15 - Práticas do Modelo Cocktail ..................................................................................94

Quadro 16 - Práticas do framework Scrum para o desenvolvimento de produtos ..................94

Quadro 17 - Síntese da análise das propostas de combinação ................................................95

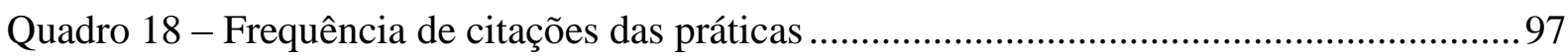

Quadro 19 - Strings de busca utilizadas na pesquisa.......................................................... 102

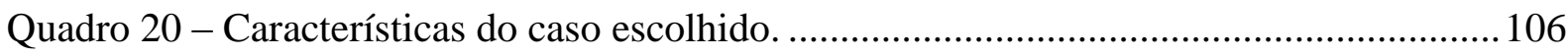

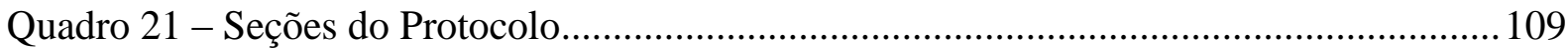

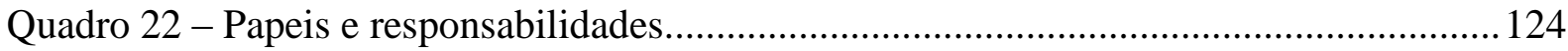

Quadro 23 - Programação planejada para o Dia 2 ................................................................ 139

Quadro 24 - Programação planejada para o Dia 3 ................................................................ 140

Quadro 25 - Programação planejada para o Dia 4 ............................................................. 140

Quadro 26 - Avaliação da experiência do usuário para cada equipe .................................... 156

Quadro 27 - Artigos lidos integramente na RBS ........................................................... 172

Quadro 28 - Materiais para a construção do foguete ............................................................. 190 


\section{LISTA DE ABREVIATURAS}

APM - Gestão Ágil de Projetos

BPMN - Business Process Management Notation

CCPM - Critical Chain Project Management

CPM - Método do Caminho Crítico

DAD - Distributed Agile Development

ISO - International Organization for Standization

PB - Product Backlog

PDM - Precedence diagramming method

PERT - Program Evaluation and Review Tecnique

PMBoK - Project Management Book of Knowledge

PMe - Plano Mestre do Projeto

RBS - Revisão Bibliográfica Sistemática

QS - Quadro Scrum

WBS - Work Breakdown Structure

$\mathrm{XP}$ - Extreme Programming 


\section{SUMÁRIO}

1 INTRODUÇÃ

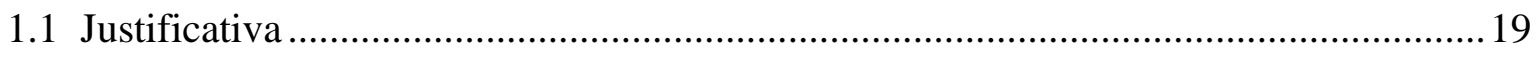

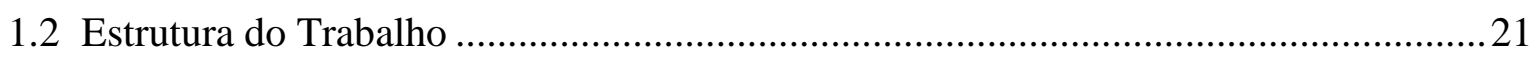

2 PLANEJAMENTO DE TEMPO DE PROJETO ............................................................ 22

2.1 Planejamento de tempo segundo a Abordagem Tradicional ...................................... 22

2.1.1 Atividades relacionadas ao planejamento de tempo de projeto .........................2 23

2.1.2 Métodos e Ferramentas para o planejamento do tempo de projeto.....................26

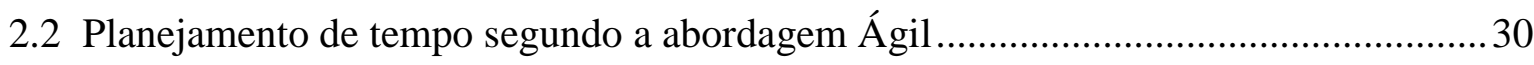

2.2.1 Atividades relacionadas com o Planejamento do tempo segundo o APM ...........32

2.2.2 Métodos e ferramentas para o planejamento de tempo .......................................35

2.3 Problemas no planejamento em Projetos Complexos ou Inovadores ............................ 36

3 COMBINAÇÃO DE PRÁTICAS ÁGEIS E TRADICINAS .....................................41

3.1 Pesquisa sobre combinação de práticas de gestão de projetos ..................................... 41

3.2 Definições e termos utilizados para a combinação de práticas de gestão de projetos .. 51

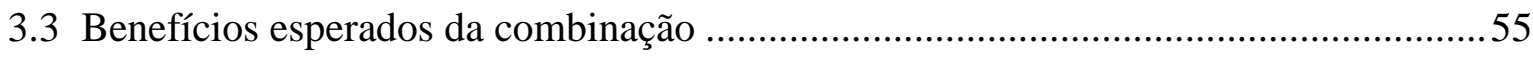

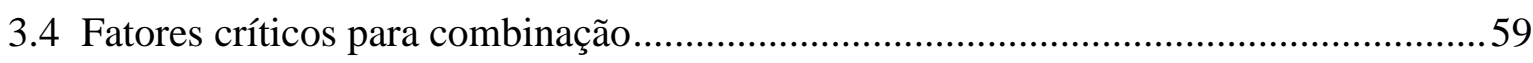

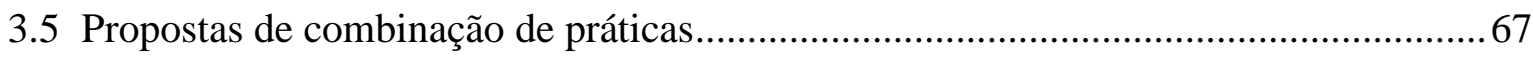

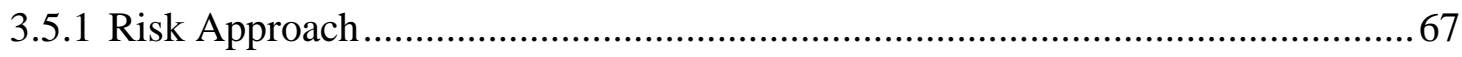

3.5.2 XPrince (Extreme Programming IN Controlled Environments) .........................71

3.5.3 Processo Híbrido de Metodologia de Design .................................................... 73

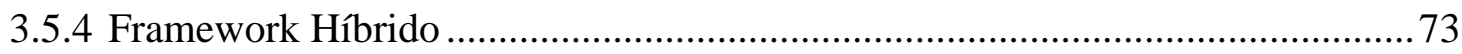

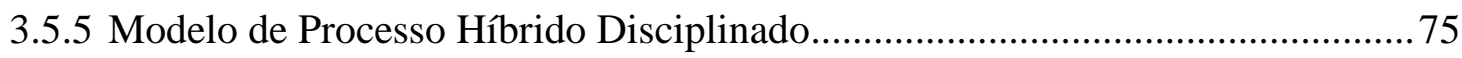

3.5.6 Modelo referencial ágil para grandes projetos ................................................ 78

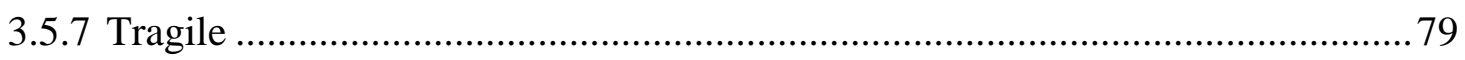

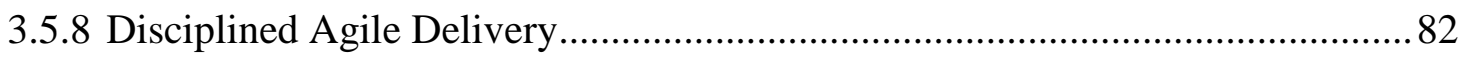


3.5.9 Modelo Cocktail para a gestão de projetos ...................................................... 85

3.5.10 Framework Scrum para o desenvolvimento de produtos ............................. 86

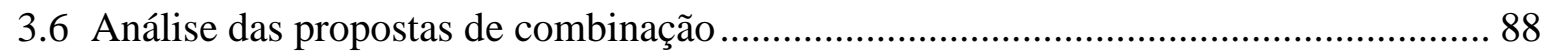

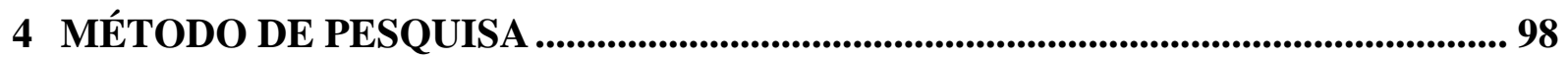

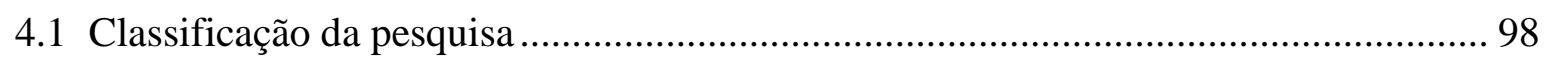

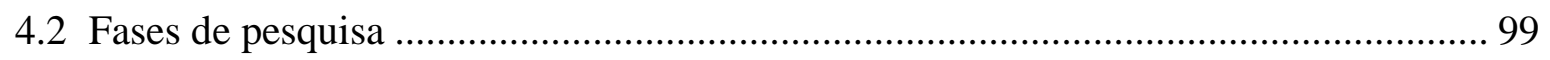

4.2.1 Atividade 1.1 - Revisão de planejamento de projetos.................................. 100

4.2.2 Atividade 1.2 - Investigar combinação de práticas ágeis e tradicionais .......... 100

4.2.3 Atividade 2.1 - Elaborar conceito do procedimento .................................... 103

4.2.4 Atividade 2.2 - Estruturar fluxo de atividades e informação do procedimento 103

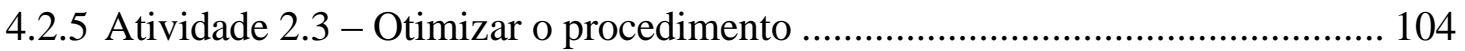

4.2.6 Atividade 3.1 - Planejar Estudo de Caso.......................................................... 105

4.2.7 Atividade 3.2 - Definir dimensões e variáveis do estudo .............................. 107

4.2.8 Atividade 3.3 - Elaborar os instrumentos de coleta de dados........................ 109

4.2.9 Atividade 3.4 - Aplicar o procedimento e coletar os dados ........................... 110

4.2.10 Atividade 3.5 - Analisar dados e artefatos coletados............................... 111

5 PROCEDIMENTO DE COMBINAÇÃO DE PRÁTICAS DE PLANEJAMENTO 114

5.1 Desenvolvimento do conceito do procedimento ................................................. 114

5.2 Elementos fundamentais para o entendimento do procedimento ............................ 121

5.3 Procedimento de planejamento de tempo combinado .......................................... 126

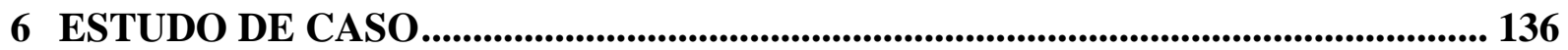

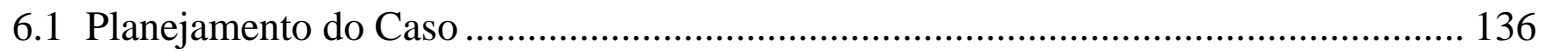

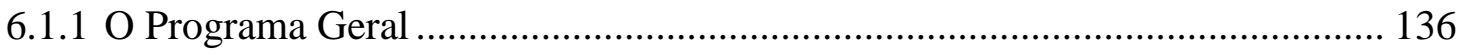

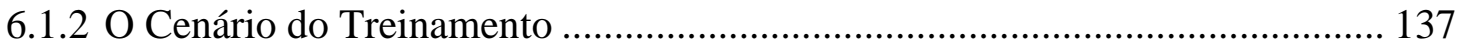

6.1.3 O Plano de Aulas e eventos principais ........................................................ 138

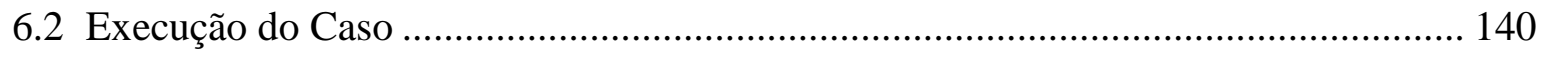

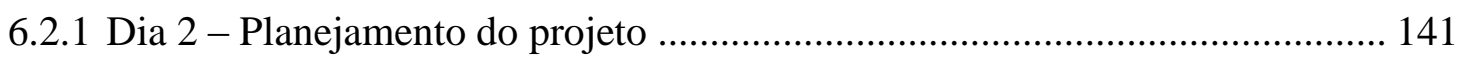


6.2.2 Dia 3 - Execução do projeto

6.2.3 Dia 4 - Finalização do projeto 146

7 ANÁLISE DOS DADOS E DISCUSSÃO.

7.1 Dimensão 1 - Combinação de práticas. 151

7.2 Dimensão 2 - Experiência do usuário. 155

7.3 Discussão sobre outras evidências decorrentes do caso 160

8 CONCLUSÕES DO TRABALHO 163

9 REFERÊNCIAS BIBLIOGRÁFICAS 166

APÊNDICE A - Trabalhos analisados pela revisão bibliográfica sistemática 172

APêNDICE B - Fatores Críticos para a COmbinação 174

APÊNDICE C - Artefatos criados para o caso exemplo do Capítulo 5 177

APÊNDICE D - Quadro de equivalência. 179

APÊNDICE E - Envisioning 181

APÊNDICE F - Dicionário de dados do procedimento 187

APÊNDICE G - Protocolo do estudo de caso 189

APÊNDICE H - Questionário de avaliação da experiência do usuário 194

APÊNDICE I - Cenário do treinamento (Visão do produto)............................................196

APÊNDICE J - Carta de consetimento..............................................................................198

APÊNDICE $L$ - Tabela com o registro dos dados coletados......................................... 199

APÊNDICE M - Cálculo do Índice de concordância ............................................................... 204

ANEXO A - Lista de classificação de práticas de gestão de projetos................................210

ANEXO B - Pré-concepção do produto e arquitetura de software para o exemplo......211

ANEXO C - Captação das necessidades do cliente ................................................................... 212

ANEXO D - Legenda do procedimento ......................................................................213

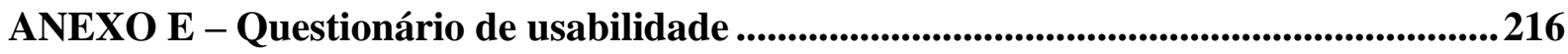


XVI 


\section{INTRODUÇÃO}

As práticas da Gestão Ágil de Projetos (APM) têm sido aplicadas em um número cada vez maior de empresas. Dentre as práticas mais utilizadas por profissionais de gestão de projetos, destacam-se: resposta rápida às oportunidades estratégicas (75\%); ciclo curtos de produção e tomada de decisão (64\%); envolver o cliente, integrar a voz do cliente (54\%) (PMI'S PULSE OF THE PROFESSION, 2012).

Projetos de produtos complexos, que abrangem hardware e software, poderiam se beneficiar de práticas do APM, porém, há barreiras para a efetivação dessas práticas, por exemplo, o tamanho da equipe, alteração rápida nos projetos e incorporação de novas funcionalidades solicitadas pelo cliente nas fases finais de desenvolvimento (BOEHM; TURNER, 2003; MISHA e MISHA, 2011;TURK; RUMPE, 2009).

Uma alternativa para solucionar essas barreiras é combinar práticas oriundas das abordagens Ágil e Tradicional, fenômeno conhecido por abordagem Híbrida ou Combinada de gestão de projetos. Por exemplo, Boehm e Turner (2005) estudaram a implementação do APM em ambientes que utilizavam predominantemente a abordagem tradicional e identificaram empresas combinando-as em um mesmo projeto. Outro exemplo é o levantamento sobre agilidade em gestão de projetos, com uma amostra de 856 profissionais, onde foram identificados de cerca 60 profissionais combinando as abordagens para gerenciar projetos (CONFORTO; REBENTISCH; AMARAL, 2014).

Outros trabalhos também defendem oportunidades e vantagens em combinar as abordagens ao invés de escolher uma determinada abordagem, como Boehm (2002), Boehm e Turner (2003), Vinekar, Slinkman e Nerur (2006), Galal-Edeen, Riad e Seyam (2007) e Batra et al. (2010).

Uma Revisão Sistemática da Literatura (RBS) foi realizada para identificar trabalhos, discutindo a combinação de práticas de gestão de projetos, resultando em um conjunto de 51 trabalhos. Todos os trabalhos identificados foram analisados segundo os critérios de termos e definições, fatores críticos, benefícios esperados e propostas de combinação, modelos, métodos, frameworks, entre outros. Também, foi possível agrupá-los em duas diferentes iniciativas ou linhas de pesquisa, o Desenvolvimento Ágil Distribuído (DAD) e a Ambidestria Organizacional. 
O Desenvolvimento Ágil Distribuído (DAD) consiste em gerenciar um projeto com times distribuídos geograficamente empregando-se o APM. No entanto, o APM é recomendado para pequenos times, co-localizados e com a presença e dedicação do cliente no projeto (BOEHM; TURNER, 2003). No contexto do DAD podem surgir problemas de comunicação e alinhamento entre os times distribuídos ou a não participação do cliente no projeto.

A segunda iniciativa é observada em trabalhos que utilizaram o termo Ambidestria Organizacional para identificar o fenômeno de combinação de abordagens. Ambidestria Organizacional é definida como a capacidade da organização de adotar e equilibrar ao mesmo tempo uma abordagem emergente com aquela deliberada, eliminando a necessidade de escolha (BODWELL; CHERMACK, 2010). A analogia com a Gestão de Projetos seria adotar uma estrutura organizacional que comporte um time de projeto Ágil e outro Tradicional (VINEKAR; SLINKMAN; NERUR, 2006).

Essa pesquisa propõe-se a investigar a combinação entre a gestão Tradicional e Ágil e contribuir para solucionar a lacuna encontrada. O problema de pesquisa consiste em "como combinar as práticas ágeis e tradicionais de gestão de projetos".

Dez propostas de combinação foram identificadas na RBS e avaliadas qualitativamente utilizando as seis características de Eder et al. (2014), que diferenciam a APM da Gestão Tradicional de projetos. O resultado da análise indicou propostas que não se diferenciavam da Gestão Ágil ou que não apresentam informações para debater a combinação adotada. Nenhuma das dez propostas de combinação apresentou um procedimento sistemático que indique como combinar as práticas de ambas as abordagens, sendo, assim, identificada uma lacuna da teoria.

O foco da pesquisa é desenvolver um procedimento de planejamento que combine as duas abordagens. Assim, o objetivo geral desse trabalho é desenvolver um procedimento de planejamento de tempo combinando práticas ágeis e tradicionais. Por desenvolver, entende-se como o processo de concepção e avaliação do procedimento.

O procedimento foi implementado em um estudo de caso, onde alunos da graduação do curso de Sistemas de Informação executaram um projeto fictício utilizando o procedimento. O caso consiste em um desafio de lançamento de foguetes de água, onde três equipes de projetos deveriam criar um protótipo do sistema foguete, plataforma de lançamento e sistema de acionamento. 
A avaliação foi realizada pelos alunos após a execução do projeto utilizando um questionário de usabilidade autoreportada e associado a duas questões de opinão. O resultado apontou que é viável combinar práticas ágeis e tradicionais de planejamento e a usabilidade do procedimento pode ser considerada satisfatória para o contexto da aplicação, em termos de facilidade de uso e aprendizado.

As contribuições principais da pesquisa consistem na síntese da literatura sobre o tema de combinação de práticas e a proposta do procedimento em diagramas de Business Process Management Notation (BPMN), apresentados no Capitulo 3 e 5, respectivamente.

\subsection{Justificativa}

Há um consenso entre uma parte dos autores que estudam a gestão ágil, de que é possível, até preferível, combinar as abordagens de forma a se obter as vantagens como um maior nível de controle e responder a mudanças no escopo do produto, características associadas ao tradicional e ágil, respectivamente (BOEHM, 2002; BOEHM e TURNER, 2003; BOEHM e TURNER, 2005; VINEKAR, SLINKMAN e NERUR, 2006; GALALEDEEN, RIAD e SEYAM, 2007; BATRA et al., 2010).

A partir da Revisão Sistemática Bibliográfica realizada e apresentada no Capítulo 3, podemos encontrar indícios em estudos de caso e autores que fazem a recomendação de combinar as práticas. Os autores sugerem benefícios em utilizar a combinação de abordagens, por exemplo, melhorar a coesão e comunicação entre os times de projeto. No entanto, não foi identificada uma forma sistemática de como combinar os processos de gestão de projetos, como planejamento, execução e controle.

Por exemplo, Boehm e Turner (2003) desenvolveram o Risk Approach, um método cujo objetivo é identificar se risco que domina o projeto é baseado em características tradicionais ou ágeis. Deste modo, é possível sugerir qual a abordagem de gestão de projetos que deve ser adotada. Quando não há uma clareza sobre quais riscos dominam, recomenda-se a utilização das duas abordagens. Todavia, os autores não debatem estratégias para combinar as abordagens e solucionar os riscos.

Vinekar, Slinkman e Nerur (2006) propõem combinar as abordagens estabelecendo um time de projeto Ágil e outro Tradicional, em uma mesma organização, porém os times devem ser separados ou isolados fisicamente. Os autores decorrem da 
possibilidade de um projeto necessitar dos dois times ao mesmo tempo, no entanto, não discutem como coordená-los nesse contexto.

Galal-Edeen, Riad e Seyam (2007) sugerem que é preciso combinar as abordagens para obter vantagens competitivas e apresentam um framework contendo fases de desenvolvimento e práticas ágeis, como o planejamento iterativo e testes de aceitação do produto. Embora apresentem um framework, este se limita a combinar as fases de desenvolvimento e a documentação dos principais artefatos, por exemplo, o product backlog, não apresentando como combinar os processos de gestão de projetos.

Batra et al. (2010) investigaram um estudo de caso em um projeto de software para navios de cruzeiro e identificaram características do desenvolvimento onde seria necessário combinar as abordagens de gestão de projetos, tais como projetos grandes, estratégicos, distribuídos geograficamente, envolvendo requisitos em evolução e mudanças imprevisíveis no ambiente. Os autores explicam que requisitos do produto em evolução é um desafio único para projetos grandes e distribuídos, onde nenhuma abordagem isoladamente pode tratar eficazmente. A investigação limita-se na contextualização da combinação e não decorrem sobre uma forma sistemática de combinação.

Conclui-se que a literatura oferece indícios claros para combinar o Ágil e Tradicional. Mas, a verificação dos benefícios não é possível, pois não foi identificada também nenhuma proposta de modelo conceitual ou procedimento que indique como combinar os métodos sistematicamente. Além disso, existem poucos relatos na literatura de modelos sobre a combinação ou híbridos (SOMMER et al., 2015).

Essa limitação impede o avanço no desenvolvimento do tema. Se não se sabe como implementar esta abordagem de forma sistemática, como utilizá-la? Que princípios, práticas e ferramentas devem ser considerados para elaborar processos de gestão de projetos? Sem mencionar a problemática da utilização dessa combinação fora do contexto de sistemas de informações ou software, na qual os autores citados se inserem.

A elaboração de procedimentos abrangendo práticas ágeis e tradicionais combinadas é o primeiro desafio para se solucionar esta questão e é fundamental para o avanço do debate. A pesquisa se justifica ainda no campo prático, trazendo implicações gerenciais que podem ser difundidas entre gerentes de projetos e auxiliar na disseminação das práticas ágeis. Será importante também para o grupo de pesquisa que vem desenvolvendo o tema desde 2005. 


\subsection{Estrutura do Trabalho}

O Capítulo 2 apresenta a contextualização sobre planejamento de projetos. O capítulo é divido em três partes. A primeira referente ao planejamento tradicional, a segunda apresenta o planejamento ágil, e a terceira apresenta-se a problemática de planejamento em projetos complexos.

O Capítulo 3 apresenta a Revisão Bibliográfica Sistemática sobre o tema de combinação de práticas tradicionais e ágeis. A discussão abrange a caracterização das definições de combinação, fatores críticos para a implementação e benefícios esperados. Também, são descritas e analisadas dez propostas de combinação.

O Capítulo 4 compreende a caracterização do método de pesquisa adotado na pesquisa. Apresenta-se a classificação da pesquisa e a descrição das fases e atividades de pesquisa.

O Capítulo 5 destina-se ao desenvolvimento do procedimento de planejamento de tempo combinado. Apresenta-se todo o processo de concepção, discussão dos elementos fundamentais e detalhamento das atividades do procedimento.

O Capítulo 6 visa descrever as etapas de planejamento e a execução do Estudo de Caso.

O Capitulo 7 apresenta a análise dos dados e discussões referentes aos dados do Estudo de Caso.

O Capítulo 8 destina-se as conclusões da pesquisa. 


\section{PLANEJAMENTO DE TEMPO DE PROJETO}

O Capítulo 2 visa apresentar uma visão geral e introduzir conceitos fundamentais sobre planejamento de tempo. Entende-se que o termo planejamento corresponde a uma atividade e o termo plano como resultado do planejamento, consistindo em documentos ou figuras que representam o momento no qual se acredita que o projeto irá se desdobrar no futuro (COHN, 2008, p.9).

O tempo é uma das variáveis mais importantes para o planejamento do projeto e existem diferenças significativas das atividades envolvidas no planejamento de tempo entre a Gestão Ágil de projetos e a Tradicional.

Na literatura encontram-se vários livros clássicos sobre Gestão de Projetos onde o planejamento de tempo é descrito com detalhes. Recomenda-se a leitura do Guia de Conhecimento de Gestão de Projetos (PMBoK) e livros como Carvalho e Rabechini Jr (2011), Wysocki (2007) e Kerner (2008) para maiores detalhes sobre a abordagem tradicional. Também os livros Amaral et al. (2011), Cohn (2008), Leffingwell (2011) e Schwaber (2004) para maiores detalhes sobre a Gestão Ágil de Projetos (APM).

\subsection{Planejamento de tempo segundo a Abordagem Tradicional}

O planejamento do projeto é um dos cinco grupos de processos de gerenciamento e envolve o escopo, tempo, qualidade, recursos humanos, riscos, stakeholders (PMI, 2013, p.61). As atividades envolvidas no planejamento de projetos empreendem esforços para identificar atividades, recursos e a melhor forma de integrá-los (ROZENFELD et al., 2006, p.150).

O tempo, custo e escopo são as variáveis principais para o planejamento e controle de projetos, associadas ao termo "triangulo de ferro". O planejamento do projeto tradicional considera o tempo e o custo variáveis e o escopo fixo (SLIGER; BRODERICK, 2008, p.68). No início do projeto há um esforço para elaborar o escopo do projeto, definir as atividades e o cronograma do projeto.

O planejamento do tempo inclui processos requeridos para gerenciar no tempo hábil a conclusão do projeto (PMI, 2013, p.141). O principal resultado do planejamento de tempo é o Plano de Gerenciamento do Tempo, que visa estabelecer as políticas, 
procedimentos e documentação para planejar, desenvolver, gerenciar, executar e controlar o cronograma do projeto, guiando a gestão do cronograma por todo o projeto (PMI, 2013, p.145). Desta forma, o gerente de projeto deve controlar a variação da duração das atividades durante a execução do projeto.

Atualizações decorrentes de mudanças aprovadas durante a execução do projeto podem causar um impacto nos planos do projeto. As atualizações do plano de gerenciamento do projeto fornecem maior precisão em relação a cronograma, custos e recursos necessários, de forma a atender ao escopo definido do projeto como um todo (PMI, 2013, p. 56).

\subsubsection{Atividades relacionadas ao planejamento de tempo de projeto}

O planejamento do tempo de projeto é organizado em cinco processos principais (CARVALHO; RABECHINI JR, 2011; PMI, 2013; WYSOCKI, 2007): (1) Definir atividades; (2) Sequenciar atividades; (3) Estimar recursos, (4) Estimar duração; e (5) Desenvolver o Cronograma. A Figura 1 apresenta a relação entre os processos envolvidos no planejamento de tempo segundo a abordagem Tradicional.

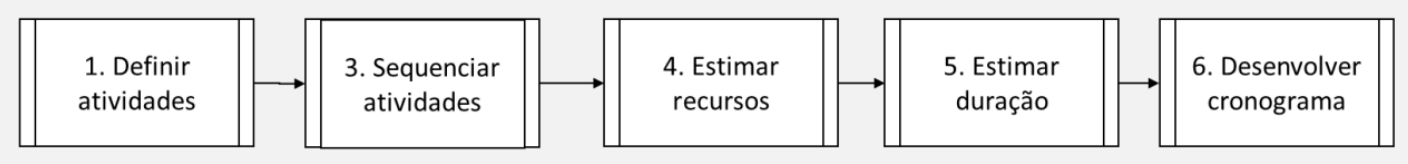

Figura 1 - Processos de planejamento de tempo de projeto Fonte: Adaptado do PMI (2013).

Definir as atividades consiste em identificar e documentar ações específicas para serem executadas para produzir as entregas do projeto (deliverables) (PMI, 2013, p.141). O benefício maior do processo é dividir o projeto em atividades, que provem uma base para estimar, executar, monitorar e controlar o trabalho do projeto (PMI, 2013, p.149).

A Decomposição da Work Breakdown Scructure (WBS) é a técnica utilizada para definir as atividades. A WBS é uma representação visual ou gráfica da hierarquia do escopo do produto, que apresenta a relação entre as entregas e pacotes de trabalho (work pakage) (PMI, 2013, p.567; WYSOCKI, 2007, p.140). Durante o planejamento do tempo, as entregas e pacotes de trabalhos presentes na WBS são decompostos ou desdobrados em atividades (PMI, 2013, p.151; WYSOCKI, 2007, p.140). Uma atividade de projeto é entendida como 
uma parcela programada do trabalho a ser executada no projeto que possui três atributos essenciais, a duração de tempo, recursos alocados e custos associados (PMI, 2013, p.526).

Os Milestones ou marcos são um tipo de especial de atividade. Consistem em pontos ou eventos significativos para o projeto (PMI, 2013, p.153) e um meio de manter o controle sobre o progresso do escopo e processo do projeto (WYSOCKI, 2007, p.289). Por exemplo, um milestone pode corresponder a uma feira de exibição do produto ou a data de entrega do produto. A lista de Milestones identifica o conjunto de todos os eventos principais de um projeto, quais são mandatórios, requeridos por contrato ou opcionais (PMI, 2013, p.153).

A lista de atividades, os atributos para cada atividade definida e a lista de Milestones do projeto são as principais saídas do processo de definição das atividades (CARVALHO; RABECHINI JR, 2011; PMI, 2013, p.153).

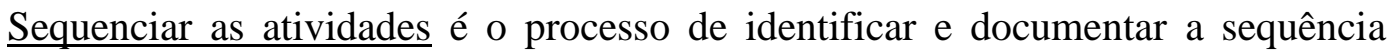
lógica de atividades necessária para entregar o projeto (PMI, 2013, p.141; WYSOCKI, 2007, p.186). A principal saída do processo é a representação gráfica da sequência lógica entre as atividades de projeto (PMI, 2013; WYSOCKI, 2007, p.186).

Estimar recursos para as atividades é o processo de identificação e estimação do tipo e quantidade de materiais, recursos humanos, equipamento ou suprimentos requeridos para executar uma atividade (PMI, 2013, p.141). Os tipos de recursos consistem em pessoas, equipamentos, estabelecimentos, investimento ou materiais (WYSOCKI, 2007, p.173).

Os recursos humanos podem ser representados pela Resource Breakdown Structure, que é uma representação hierárquica dos recursos humanos em categorias e tipos e usada para auxiliar a estimação de recursos, duração e custos do projeto (PMI, 2013, p.165; WISOCKI, 2007, p.175).

A principal saída da estimação dos recursos são os requisitos de recursos das atividades que identifica os tipos e quantidades para cada atividade nos pacotes de trabalhos e cada período de trabalho e a RBS (PMI, 2013, p.163).

Estimar duração das atividades é o processo de avaliação do número de períodos de trabalho necessários para completar atividades individuais com os recursos estimados (PMI, 2013, p.141). 
É importante diferenciar dois conceitos principais para a estimação da duração. Duração é o tempo decorrido em meses, dias ou horas de trabalho, não incluindo finais de semana ou feriados. Esforço é o trabalho requerido para completar uma atividade, por exemplo, a quantidade de homens por hora (WYSOCKI, 2007, p.164).

Três variáveis são consideradas ao estimar a duração de uma atividade, a própria duração, o total de trabalho que irá ser executado por um recurso e a porcentagem do dia disponível do recurso para executar o trabalho (WYSOCKI, 2007, p.176). Por exemplo, se uma atividade requer 40 horas para ser completada e uma pessoa devota apenas 50 por cento do dia para a atividade, a duração total da atividade será de 80 horas (WYSOCKI, 2007, p.177).

A duração pode ser estimada em função da disponibilidade de recursos, mas não existe uma relação linear entre a duração e os recursos (WYSOCKI, 2007, p.165). Por exemplo, afirma-se que ao duplicar a quantidade de recursos alocados em uma atividade a duração diminui pela metade. Existem casos onde a afirmação não é verdadeira, pois existem atividades que não podem ser divididas entre diversos recursos e, além disso, ao adicionar recursos humanos a uma atividade, aumenta-se a necessidade a coordenação e comunicação (WYSOCKI, 2007).

A principal saída do processo são as próprias estimações de durações, que representam a quantidade de períodos prováveis para completar uma atividade, por exemplo, a duração de duas semanas \pm 2 dias indica que uma atividade levará pelo menos oito dias úteis e não mais que doze para ser finalizada (PMI, 2013, p.172).

Desenvolver cronograma é o processo de analisar a sequência das atividades, durações, requisitos de recursos e as restrições para criar o cronograma do projeto (PMI, 2013, p.172). O cronograma do projeto pode ser representado por meio do Gráfico de Gantt ou Diagrama de rede (WYSOCKI, 2007, p.187). Existem várias técnicas analíticas para desenvolver o cronograma, como o Método do Caminho Crítico (CPM) e a Corrente Crítica (CCPM), que serão detalhadas na próxima seção.

As principais saídas são a linha de base do cronograma e o Cronograma do projeto. A linha de base indica as datas de início e fim das atividades e durante a fase de monitoramento e controle do projeto as datas atuais de início e fim são comparadas com as datas definidas na linha de base para comparar se ocorreram variações (PMI, 2013, p.181). O Cronograma do projeto apresenta as relações entre as atividades com as datas planejadas, 
durações, milestones e recursos associados e, no mínimo, apresenta a data planejada de início e fim de cada atividade (PMI, 2013, p.182).

\subsubsection{Métodos e Ferramentas para o planejamento do tempo de projeto}

O Quadro 1 apresenta o resumo de métodos e ferramentas associados aos processos de planejamento de tempo, definir as atividades, sequenciar atividades, estimação da duração e desenvolvimento do cronograma. Nos próximos parágrafos serão detalhados os métodos e ferramentas com implicação direta nesta pesquisa.

\begin{tabular}{|ll|}
\hline \multicolumn{1}{|c|}{ Quadro 1 - Métodos e ferramentas de planejamento de tempo } \\
Processos & Métodos e Ferramentas \\
\hline Definir atividades & $\begin{array}{l}\text { Decomposição } \\
\text { Planejamento em ondas } \\
\text { Opinião de especialista }\end{array}$ \\
\hline Sequenciar atividades & Diagrama de Precedência (PDM) \\
& Diagrama de flecha (ADM) \\
& Determinação dependência \\
& Antecipaçôes e esperas \\
\hline Estimar duração das & Estimativa Análoga \\
atividades & Estimação paramétrica \\
& Estimação de três pontos \\
& Técnica Delphi \\
& Opinião de especialista \\
\hline Desenvolver Cronograma & Análise de Rede \\
& Método do caminho crítico (CPM) \\
& Corrente Crítica (CCPM) \\
& Otimização de recursos \\
& Técnicas de modelagem \\
& Antecipações e esperas \\
& Compressão do cronograma \\
& Ferramenta de programação \\
\hline
\end{tabular}

Fonte: Adaptado do PMI (2013)

Dentre as técnicas que podem ser utilizadas para definir as atividades destacam-se duas em razão a importância para esta pesquisa, a Decomposição da WBS e o Planejamento em Ondas.

A Decomposição da WBS é usada para dividir ou subdividir o escopo do projeto e as entregas em atividades e tarefas (CARVALHO; RABECHINI JR, 2011; PMI, 2013, p.151; WYSOCKI, 2007, p.140). Duas técnicas de definição das atividades podem ser utilizadas para decompor o projeto e a Figura 2 ajuda a explica-las. A técnica Top-down há um esforço para decompor sucessivamente o projeto a partir do objetivo ou meta até o nível 2 da WBS ou 
outros níveis inferiores. A técnica Bottom-up decompõem até o nível 1 da WBS que correspondem a entregas ou pacotes de trabalho. Em outro momento, a equipe de projeto é dividida em subequipes, que listam as atividades para o nível 2 ou inferiores da WBS, que devem ser completadas para entregar o primeiro nível de atividades (WYSOCKI, 2007, p.145).

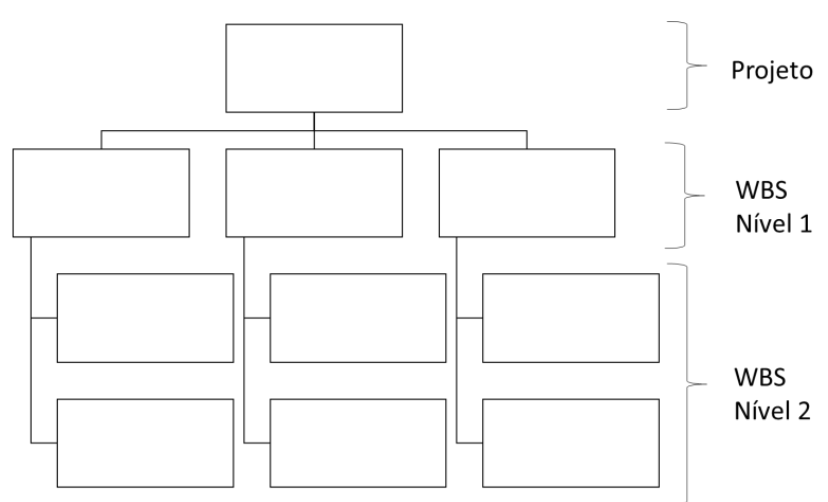

Figura 2 - WBS genérica

Fonte: Adaptado de Griffin e Somermeyer (2007, p.406).

O Planejamento em Ondas (Rolling Wave Planning) é uma técnica de planejamento iterativa na qual são detalhadas as atividades a serem executadas no curto prazo, enquanto que as atividades de longo prazo são planejadas em alto nível de detalhe (PMI, 2013, p.151; GOODPASTURE, 2004, p.210). Planejamento é realizado em vários estágios, particularmente se requisito do recurso é dependente ou condicionado as atividades de curto prazo (GOODPASTURE, 2004, p.210).

Os seis passos do Planejamento em Ondas são apresentados na Figura 3 (GRIFFIN; SOMERMEYER, 2007, p.405). O primeiro passo do planejamento em ondas é elaborar o Termo de Abertura do Projeto, onde são definidas as pessoas, requisitos e visão do projeto. O Passo número 2 consiste em detalhar o primeiro nível da WBS e definir as atividades para um horizonte de tempo de até 3 meses. No passo seguinte os pacotes de trabalho são decompostos e definidos para o nível 2 da WBS. No Passo 4, a equipe de projeto deve se comprometer com o linha de base do escopo definido no passo anterior. O Passo 5 consiste na execução das atividades definidas para a primeira onda. Por último, o Passo 6 envolve a contínua iteração das atividades das sucessivas ondas através do horizonte de planejamento. Ao final das ondas de planejamento, a equipe de projeto executa as atividades de fechamento do projeto. 


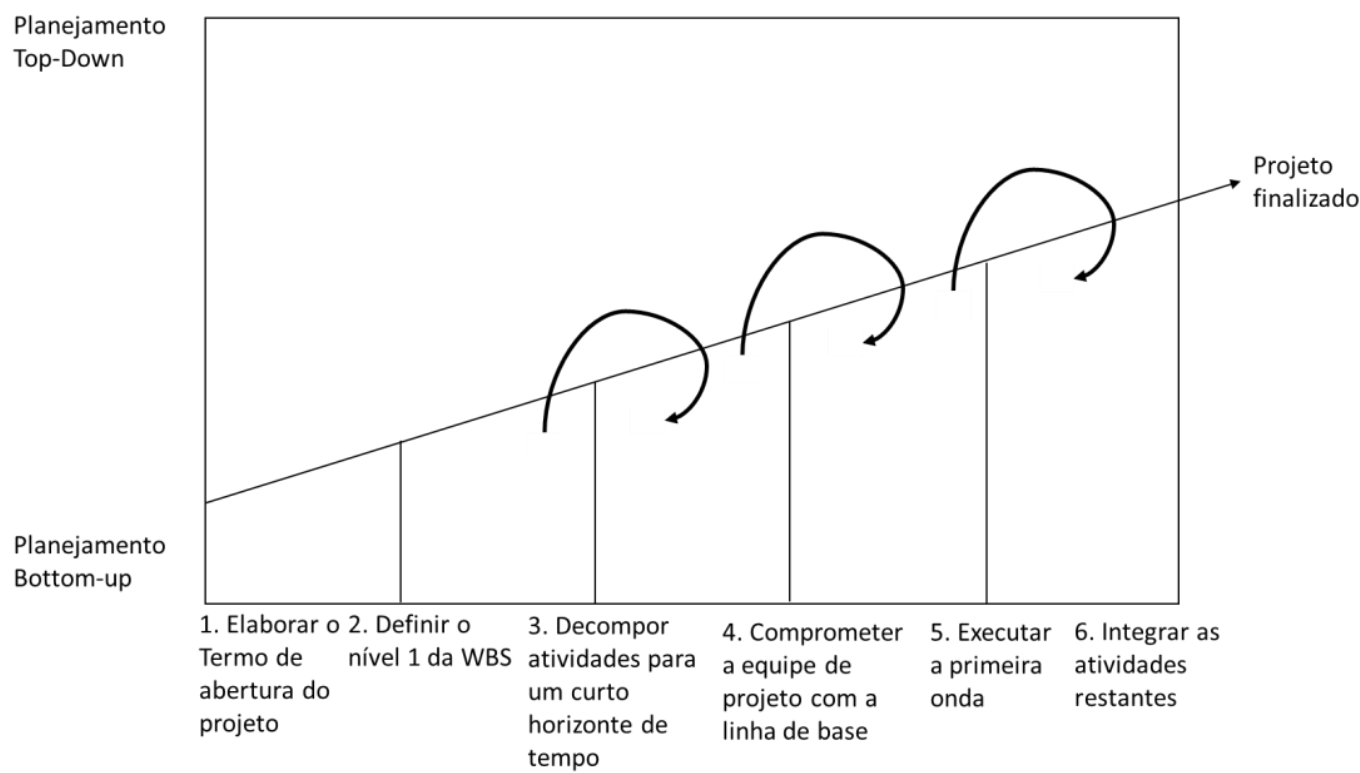

Figura 3 - Processo do Rolling Wave Fonte: traduzido de Griffin e Somermeyer (2007, p.405).

As técnicas comumente citadas para sequenciar as atividades são o Diagrama Precedência (PDM), Diagrama de flecha (ADM), Determinação da dependência e Antecipações e Esperas (Leads and Lags) (CARVALHO; RABECHINI JR, 2011; PMI, 2013, p.156; WYSOCKI, 2007, p.187). Em comum, as técnicas de sequenciamento representam a relação lógica entre as atividades sucessoras e predecessora por meio de setas e quadros ou círculos. A Figura 4 apresenta um exemplo de sequenciamento utilizando o PDM.

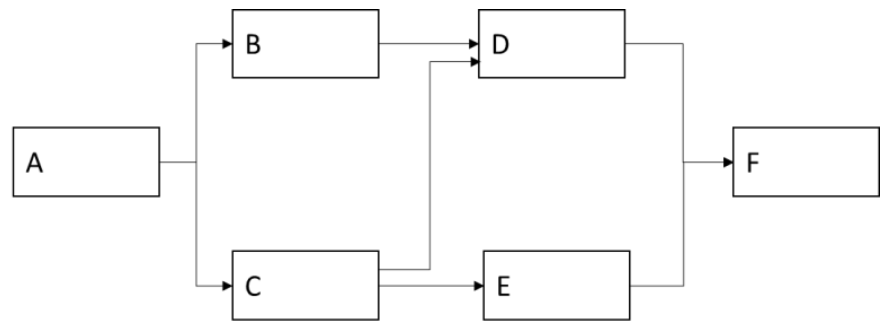

Figura 4 - Exemplo de sequenciamento de atividades utilizando o PDM

Fonte: Wysoski (2007, p.189)

As técnicas e métodos para a estimação da duração de atividades mais comuns consistem em: Estimativa Análoga ou Similaridade com outras atividades; Estimação paramétrica; Dados históricos; Técnica Delphi; Técnica de três pontos; e Opinião de especialistas (CARVALHO; RABECHINI JR, 2011, p.114; PMI, 2013, p.169; WYSOCKI, p.168). 
Quatro métodos de desenvolvimento do cronograma de projeto são os mais difundidos na prática, o Gráfico de Gantt, Método do Caminho Crítico (CPM), Program Evaluation and Review Tecnique (PERT) e a Corrente Crítica (CCPM) (CARVALHO; RABECHINI JR, 2011, p.114; PMI, 2013, p.177; WYSOCKI, p.187). Desta forma, optou-se por detalha-los nos próximos parágrafos. Os métodos não se limitam a esses quatros, por exemplo, existe a Análise de Rede, Técnicas de Otimização de recursos, Técnicas de modelagem, como Simulação e Análise de Cenários (PMI, 2013, p.176).

Gráfico de Gantt consiste em um plano onde as atividades de projeto são representadas por barras retangulares, onde o comprimento representa a duração. As atividades são organizadas através da data de início e fim na linha horizontal e a por ordem da data de início na linha vertical (PMI, 2013, p.182; WYSOCKY, 2007, p.156).

O Método do Caminho Crítico (CPM) objetiva identificar a sequência de atividades na rede com maior duração para determinar a data de entrega do projeto. A sequência é chamada de Caminho Crítico, pois qualquer atraso na execução das atividades irá impactar em um atraso na data de entrega do projeto. (WYSOCKY, 2007, p.156). O Método também é utilizado para indicar a flexibilidade da programação das atividades calculando-se a folga entre as atividades (PMI, 2013, p.176).

O CPM utiliza a lógica de programação para frente ou para trás para determinar o Caminho Crítico. Na programação para frente obtém-se a data mais cedo de início de cada atividade, parte-se do inicio do evento e determina-se a primeira data de inicio de cada atividade da rede. Na programação para trás, percorre-se o caminho inverso, obtém-se a data mais tarde de término de cada atividade, parte-se do evento término e percorre-se até a origem da rede (CARVALHO; RABECHINI JR, 2011, p.118 e 119).

O Program Evaluation and Review Tecnique (PERT) utiliza três estimações para calcular a duração das atividades, a duração mais provável de acontecer, a otimista baseada no cenário mais positivo e a pessimista baseada no cenário mais negativo. Com base nessas três estimativas é possível calcular a duração esperada da atividade utilizando a distribuição Beta de probabilidade. O PERT utiliza a premissa que a execução de uma atividade é independente das outras, ou seja, não interfere na duração de outras atividades (CARVALHO; RABECHINI JR, 2011, p.127).

A Corrente Crítica ou Critical Chain Project Management (CCPM) é uma ferramenta de otimização de recursos proveniente da Teoria das Restrições (TOC). Segundo o 
CCPM, o foco não deve ser o Caminho Crítico das atividades, onde os recursos das atividades são independentes, mas sim no caminho em que há dependência entre atividades e restrições de recursos, esse caminho é chamado de corrente crítica (WYSOCKI, 2007, p.368).

O conceito principal do CCPM é remover a contingência de cada atividade em uma sequencia. A contingência é utilizada para aumentar a duração de uma atividade para evitar problemas com as incertezas do projeto. Assim, assumindo que existem variações na duração das atividades, parte da contingência removida das atividades é inserida na rede em forma de pulmões (buffers) para evitar problemas com a escassez de recursos e incertezas do projeto (GOODPASTURE, 2004, p.211; PMI, 2013, p.178; WYSOCKY, 2007, p.373).

\subsection{Planejamento de tempo segundo a abordagem Ágil}

No Planejamento segundo a Gestão Ágil de Projetos (APM) há uma mudança no paradigma do custo, tempo e escopo. No APM, o tempo e o custo são definidos no começo do projeto, enquanto que são esperadas e abraçadas mudanças no escopo inicial (SLIGER; BRODERICK, 2008, p.68). Logo, o APM considera fixos o tempo e custo e o escopo variável ou flexível (CONFORTO, 2013). Ao final do tempo disponível para executar o projeto, a equipe entrega o produto com o máximo de requisitos solicitados pelo cliente.

Essa mudança de paradigma impacta diretamente no processo de planejamento. A ideia principal do APM é realizar um planejamento flexível que visa absorver mudanças no escopo durante o ciclo de vida do projeto e entregar mais valor para o cliente (AMARAL et al., 2011, p.114). Deste modo, os planos são revisados durante o projeto e podem ser mudados de acordo com novas descobertas, mudando o foco dos planos detalhados de longo prazo para a repetição da atividade de planejamento (COHN, 2008, p.9).

No entanto, o APM não apresenta padrões formais para os processos de planejamento, diferentemente do que ocorre na Gestão Tradicional. Existem vários métodos ágeis, tais como Scrum, Extreme Programming (XP), Crystal Methods, Dynamic Development Method (DSDM) e Feature-Driven Development (FDD), que possuem similaridades e diferenças nas práticas, ferramentas e artefatos adotados.

O Scrum se destaca dentre os métodos ágeis como o mais utilizado por profissionais de gestão de projetos e, além disso, existem aplicações onde o Scrum é utilizado 
em conjunto com o XP em razão da complementação entre os dois métodos (VERSION ONE, 2014). Portanto, a discussão referente ao planejamento tempo será focada nos dois métodos.

O Planejamento de tempo segundo o APM segue dois conceitos principais: a Iteração e os Níveis de Planejamento.

A Iteração (XP) ou Sprint (Scrum) é uma parcela ou unidade de tempo no APM. A Iteração é definida como uma parcela fixa de tempo (timebox) na qual a equipe de projeto deve entregar resultados parciais do projeto (SCHAWBER, 2004, p.142). A duração da Iteração pode variar entre 2 a 4 semanas e a equipe ágil entrega algum resultado do projeto ao final da iteração (COHN, 2008, p.24).

Os níveis ou ciclos de planejamento consistem na elaboração progressiva do plano do projeto em níveis diferentes de detalhe (COHN, 2008, p.28). A Figura 5 apresenta os seis níveis de planejamento do APM. A recomendação para utilizar o APM é planejar no mínimo os três últimos níveis, Release, Iteration, e o Daily (CONH, 2008, p. 28).

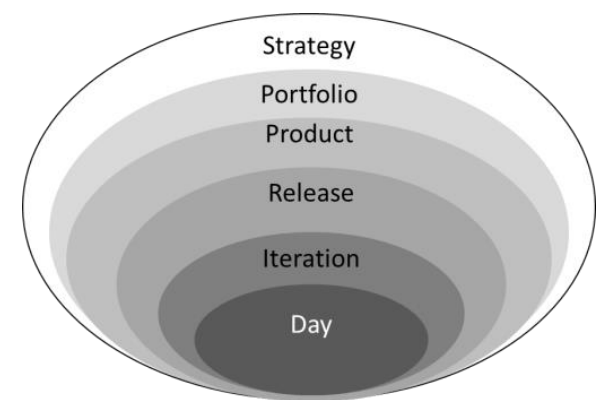

Figura 5 - Ciclos de Planejamento Ágil Fonte: Cohn (2008, p. 28)

A próxima seção discutirá em detalhes os três últimos níveis de planejamento do APM e ressalta-se a correspondência ou equivalência entre os métodos ágeis. No XP os três últimos níveis de planejamento são chamados de Release Planning, Iteration Planning e o Daily Planning. No Scrum não há um nível de planejamento que corresponde ao Release, os dois níveis inferiores são chamados de Sprint Planning e Daily Scrum Meeting. Nessa revisão optou-se por discutir os três níveis referentes ao XP por apresentar mais detalhes no processo de planejamento. O Apêndice D apresenta a equivalência entre todos o planos elaborados pelo APM e a Gestão Tradicional. 


\subsubsection{Atividades relacionadas com o Planejamento do tempo segundo o APM}

O Release Planning é um processo de criação de um plano de alto nível que abrange um período mais longo que uma iteração (COHN, 2008, p.133). Também, é definido como uma atividade periódica com o objetivo de alinhar o time de projeto com a missão comum (LEFFINGWELL, 2011, p.80).

A equipe de projeto desdobra a Visão do Produto $^{1}$ em requerimentos e user stories (estórias) durante o Release Planning (LEFFINGWELL, 2011, p.80). O user story é uma breve descrição de funcionalidade do produto, do ponto de vista do usuário ou cliente, coletados pela equipe de projeto (LEFFINGWELL, 2011, p.56; COHN, 2006, p. 25).

A Figura 6 apresenta os passos envolvidos no Release Planning (COHN, 2008, p.134). No primeiro passo, a equipe de projeto determina as condições de satisfação e identifica os critérios de sucesso ou falha nos quais o projeto será avaliado. O segundo passo corresponde a estimar os user stories em termos de pontos ou duração de tempo, para dois ou três releases. Os próximos três passos podem ser executados em qualquer sequência, determinar a duração das iterações, estimar a velocidade de entrega da equipe de projeto e priorizar os user stories. Por fim, no passo seis, são selecionados os user stories e a data de Release.

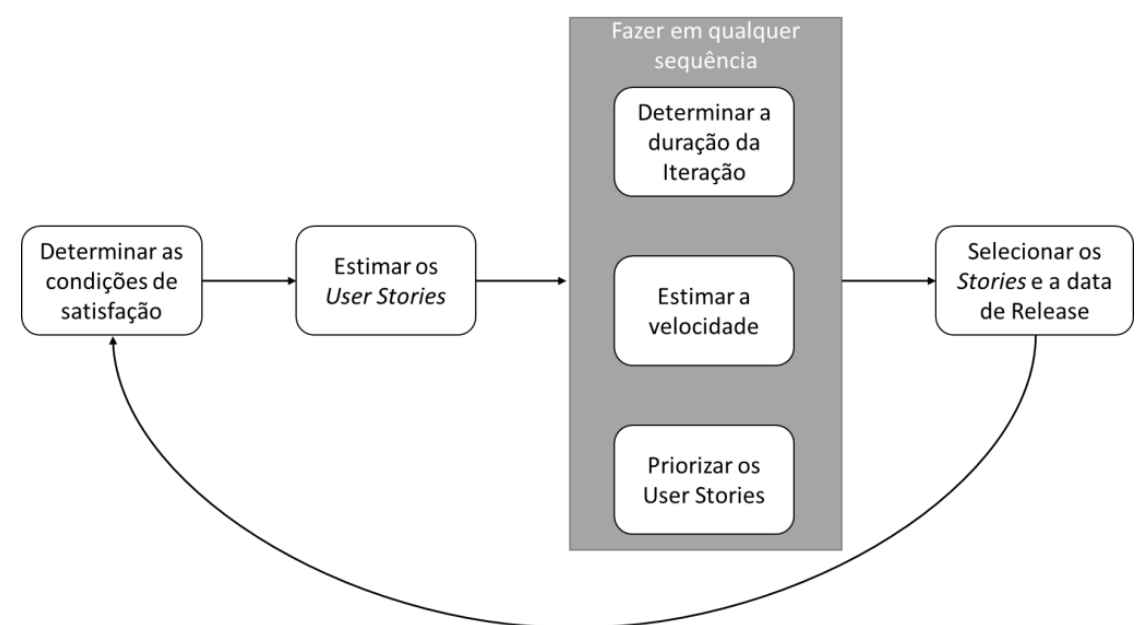

Figura 6 - Passos no planejamento do Release

Fonte: Cohn (2008, p.135), adaptado pelo autor.

${ }^{1}$ Visão do Produto é definida como um conjunto de artefatos que descrevem o resultado esperado de um projeto de produto, por meio de elementos visuais e textuais, que devem ser elaborados de maneira concisa, coletiva (por membros da equipe de projeto e o cliente), alinhados com a estratégia apoiada pelo projeto e capaz de desafiar a equipe em busca de soluções inovadoras (BENASSI, 2013, p.100). 
Um importante passo no planejamento do Release é a priorização dos user stories. A priorização consiste na atribuição de valores de importância de execução, onde user stories com maior valor são desenvolvido antes (SCWABER, 2004, p.148). A priorização pode ser realizada envolvendo o cliente do produto por meio de grupo de foco (AMARAL, 2011, p.129). No caso de impossibilidade de participação direta do cliente, o Product Owner $^{2}$ pode se basear em pesquisas de mercado para priorizar os requisitos (COHN, 2008, p.141). Três fatores podem ser utilizados para atribuir valores e auxiliar a equipe de projeto na priorização e tomada de decisão, a independência entre outros user stories, o valor para alcançar os objetivos da próxima iteração e a redução do risco (LEFFINGWELL, 2011, p.210).

As informações sobre os user stories são armazenadas no Product Backlog (PB). $\mathrm{O}$ PB consiste em uma lista priorizada de requisitos do projeto com as respectivas estimativas (SCHWABER, 2004, p.142). A lista é o resultado final do Release Planning e é importante devido a três fatores (COHN, 2008, p.133): ajuda toda a equipe de projeto a decidir o quanto deve ser desenvolvido e quanto tempo vai demorar antes de ter um produto liberável; transmite as expectativas sobre o que é susceptível de ser desenvolvido e em que prazo; e serve como guia para que a equipe de projeto possa progredir.

Durante o Release Planning não há a criação de um plano que indique os responsáveis por desenvolver os user stories, atividades ou sequência no qual o trabalho será realizado dentro de uma iteração. As decisões sobre quem trabalha sobre o quê e qual a sequência de atividades é deixada para as pessoas que irão realizar o trabalho e melhor se adiadas quanto o possível (COHN, 2008, p. 134).

O Iteration planning ou Sprint Planning consiste em uma reunião que envolve toda a equipe de projeto, onde o Product Owner apresenta os user stories com maior prioridade e os membros da equipe de projeto auxiliam na determinação de quanto do Product Backlog pode ser desenvolvimento e convertido em funcionalidades do produto (SHWABER, 2004, p.142).

Os user stories são selecionados por meio de estimativas e são decompostos em um conjunto de atividades necessárias para entregar uma funcionalidade do produto, mas sem alocar recursos para as atividades (COHN, 2008, p.152). Uma habilidade essencial para a equipe de projeto durante a iteração é refinar, codificar, testar e aprovar esse em uma um conjunto de user stories do Product Backlog (LEFFINGWELL, 2011, p.155).

\footnotetext{
${ }^{2}$ Product Owner é a pessoa responsável por gerenciar o Product Backlog e maximizar o valor do projeto. Também representa todos os Stakeholders do projeto (SCHWABER, 2004, p.142)
} 
O resultado deste nível de planejamento é o Plano da Iteração (Iteration Plan). O Plano é representado por uma planilha eletrônica ou um conjunto post-its com atividades escritas à mão (SCHWABER, 2004, p. 142). As atividades devem ser organizadas de acordo com a user story a ser implementada ao final da iteração (COHN, 2008, p.145). Os elementos centrais que constituem o Plano da Iteração são objetivo, a lista priorizada de user stories, o comprometimento da equipe de projeto com o objetivo e documentação do plano em um local visível ou de fácil acesso (LEFFINGWELL, 2011, p.163).

O Daily planning (planejamento diário) corresponde ao último nível de planejamento do APM. São reuniões diárias, onde todos os membros do time participam, com o objetivo de compartilhar informações sobre o progresso, comunicar e coordenar as atividades (COHN, 2008, p.29; LEFFINGWELL, 2011, p.165; SCHWABER, 2004, p.141). Em uma sessão de 15 minutos, os membros da equipe ágil atualizam o status, comprometemse com o trabalho e reportam os impedimentos respondendo às perguntas "o que eu fiz ontem?”, “o que farei hoje?” e “existe impedimentos?” (LEFFINGWELL, 2011, p.165).

Nas reuniões diárias, cada membro da equipe de projeto fala o que pretende fazer em seguida, baseado em negociações com o restante da equipe. Em caso de impedimentos na execução do trabalho, a pessoa anuncia para a equipe na próxima reunião (KOSKELA E HOWELL, 2002).

Ao final da Iteração, a equipe de projeto conduz duas reuniões de revisão do projeto com propósitos e audiências diferentes, o Sprint Review (Revisão da Iteração) e a Retrospective review (Revisão Retrospectiva).

O Sprint Review é uma reunião de revisão com o propósito da equipe de projeto apresentar funcionalidades desenvolvidas durante a Iteração e prontas para serem integradas ao produto (SCHWABER, 2004, p.143). A equipe de projeto discute objetivo da iteração, os resultados alcançados e o impacto dos resultados para as próximas Iterações (LEFFINGWELL, 2011, p.167). O Product Owner e os Stakeholders participam da reunião e provêm feedback sobre os resultados alcançados pela equipe de projeto (LEFFINGWELL, 2011, p.167; SCHWABER, 2004, p.143).

O propósito da Retrospective review é discutir e determinar o que pode ser mudando para tornar a próxima iteração mais produtiva e as lições aprendidas durante a iteração (LEFFINGWELL, 2011, p. 168; SCHWABER, 2004, p.142). A reunião é conduzida com participação apenas dos membros da equipe de projeto e é divida em duas partes, a 
primeira consiste em uma análise das métricas do projeto e a segunda uma análise qualitativa, com foco em melhorias para a próxima iteração (SCHWABER, 2004, p.142).

\subsubsection{Métodos e ferramentas para o planejamento de tempo}

O Quadro 2 apresenta o resumo de métodos e ferramentas utilizados nos níveis de Release Planning e Iteration Planning.

\begin{tabular}{|ll|}
\multicolumn{1}{|c|}{ Quadro 2- Métodos e ferramentas do APM } \\
\hline Processos & Métodos e Ferramentas \\
\hline Release Planning & Roadmap (Plano de releases) \\
\hline $\begin{array}{l}\text { Iteration Planning } \\
\text { (Sprint Planning) }\end{array}$ & Quadro Scrum \\
& $\begin{array}{l}\text { Planning Poker } \\
\text { Sprint Review } \\
\text { Gráfico de desempenho }\end{array}$ \\
\hline
\end{tabular}

O Roadmap ou Plano de releases é uma ferramenta utilizada no Release Planning que consiste em conjuntos de requisitos do produto, priorizados e organizados em datas planejadas de releases (LEFFINGWELL, 2011, p.272). O Plano de releases é uma visão geral de como a equipe de projeto pretende entregar o maior valor possível (COHN, 2008, p.134).

O Quadro Scrum ou Task board é uma ferramenta de gestão visual que auxilia no planejamento e controle das atividades da Iteração, elaborado ao final do Iteration Planning e utilizado nas reuniões diárias. A Figura 7 ilustra um exemplo de Quadro Scrum, que auxilia na organização do trabalho da equipe de projeto e os membros podem visualizar facilmente quais atividades estão sendo executadas e quais estão disponíveis (COHN, 2008, p.227).

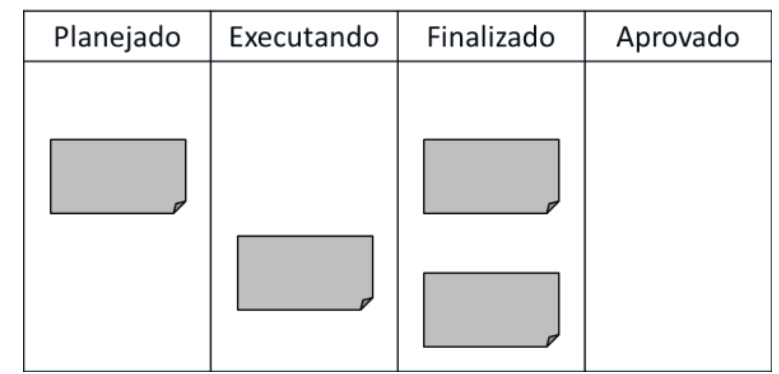

Figura 7 - Exemplo de Quadro Scrum Fonte: Leffingwell (2011, p.165).

No APM as estimações de duração podem ser em relação ao tempo ou pontos, sendo o segundo modo o mais recomendado (COHN, 2008, p.58). O Planning Poker é um método de estimação por pontos de duração dos user stories e utilizado para estimar um 
conjunto inicial de user stories antes do início oficial do projeto ou durante as primeiras estimações (COHN, 2008, p.58).

O método é composto por seis passos e envolve toda a equipe de projeto $(\mathrm{COHN}$, 2008, p.58). O primeiro passo é preparar o baralho de cartas, onde cada carta possui um valor de estimativa, por exemplo, 0, 1, 2, 3, 5, 8, 13, 20, 40 e 100. O segundo passo é escolher um moderador dentre os membros da equipe. $\mathrm{O}$ moderador, então, inicia o passo três lendo a descrição de um user story a ser estimado. Os outros membros fazem perguntas em relação ao user story e o Product Owner ajuda a responder. Após, no quarto passo, cada membro escolhe uma carta com o valor atribuído para a estimativa do user story sem revelar para os outros. No quinto passo, todas as cartas são apresentadas ao mesmo tempo. As pessoas que escolheram a maior e menor estimativa explicam o porquê do valor atribuído. Inicia-se, então, a discussão sobre o user story e a estimativa, que deve durar por alguns minutos. Depois, no sexto passo, os membros são convidados à re-estimar a duração do user story e reiniciar a discussão. Os passos são repetidos até haver uma convergência nas estimativas atribuídas pelos membros que, normalmente, ocorre já na segunda rodada do Planning Poker.

O Gráfico de desempenho mede o trabalho realizado versus o planejado por iteração (AMARAL et al., 2011, p.134) e mostra quantidade de trabalho remanescente através do tempo (SCHWABER, 2004, p.11). No APM é importante medir o progresso meio das entregas realizadas ou produto funcionando e o gráfico do tipo Burndown é o mais indicado quando é possível planejar todas as iterações do projeto e possuir uma visão sobre a quantidade de entregas (AMARAL et al., 2011, p.134).

\subsection{Problemas no planejamento em Projetos Complexos ou Inovadores}

O Quadro 3 apresenta o conjunto de condições sob as quais cada abordagem de gestão de projetos possui maior probabilidade de ter sucesso. As condições auxiliam os gerentes de projetos a escolherem a abordagem mais indicada para o desenvolvimento do projeto. 
Quadro 3 - Condições de maior probabilidade de sucesso para Ágil e Tradicional

\begin{tabular}{|lll|}
\hline Condição & \multicolumn{1}{c|}{ Ágil } & \multicolumn{1}{c|}{ Tradicional } \\
Desenvolvedores & $\begin{array}{l}\text { Áconhecedor, co- } \\
\text { localizado, experiente e } \\
\text { colaborativo }\end{array}$ & $\begin{array}{l}\text { Orientado para o plano, } \\
\text { habilidades adequadas, acesso ao } \\
\text { conhecimento externo }\end{array}$ \\
\hline Clientes & $\begin{array}{l}\text { Dedicado, conhecedor, } \\
\text { co-localizado }\end{array}$ & $\begin{array}{l}\text { Acesso ao conhecimento, } \\
\text { colaborativo e representativo }\end{array}$ \\
\hline Requisitos & $\begin{array}{l}\text { Em grande parte emergente } \\
\text { e mudanças rápidas }\end{array}$ & $\begin{array}{l}\text { Em grande parte estáveis e } \\
\text { conhecíveis cedo }\end{array}$ \\
\hline Arquitetura & $\begin{array}{l}\text { Projetado para os requisitos } \\
\text { atuais }\end{array}$ & $\begin{array}{l}\text { Projetado para os requisitos atuais } \\
\text { e previsíveis }\end{array}$ \\
\hline Retrabalho & Pouco dispendioso & Dispendioso \\
\hline Tamanho & Times e produtos pequenos & Times e produtos grandes \\
\hline $\begin{array}{l}\text { Objetivo } \\
\text { primário }\end{array}$ & Entrega rápida de valor & Elevada segurança \\
\hline
\end{tabular}

Fonte: Boehm e Turner (2003)

O problema de escolha das abordagens de gestão de projetos ocorre quando um determinado projeto possui condições entre o Ágil e Tradicional. Por exemplo, no contexto de projeto complexo, que envolve grandes equipes de projeto e distribuição geográfica, entrega rápida de valor para o cliente e requisitos que mudam com o progresso da equipe de projeto, nenhuma das abordagens sozinha é eficaz para lidar com os desafios do projeto (BATRA et al., 2011).

A complexidade é entendida nessa pesquisa como as dificuldades e incertezas impostas pelo número de tecnologias, componentes e funções nos esforços de desenvolvimento e natureza organizacional das atividades que os indivíduos e organizações encaram ao desenvolver novos produtos (KIM e WILEMON, 2003).

No contexto de projetos complexos surgem problemas relacionados ao planejamento do projeto utilizando a abordagem tradicional. Por exemplo, quando os clientes encontram dificuldades em declarar completamente todos os requisitos no início do projeto (HASS, 2007). A declaração do escopo no inicio é uma condição para a definição as atividades e elaborar o cronograma. A falta de definição do escopo do produto impossibilita a elaboração de uma WBS precisa e confiável, resultando em dificuldades para definir a linha de base em termos de custo e tempo, que são estimadas diretamente baseadas nos requisitos, impossibilitando a elaboração do cronograma devido à ausência de uma WBS (KOSKELA; HOWELL, 2002). 
A falta de flexibilidade para lidar com mudanças nos requisitos consiste em outro problema no planejamento tradicional (NERUR, MAHAPATRA, MANGALARAJ, 2005). A abordagem Tradicional minimiza as mudanças através de uma rigorosa coleta de requisitos antes do início do projeto e controle de cronograma e resultados (VINEKAR, SLINKMAN; NERUR, 2006). As mudanças no escopo do projeto podem impactar negativamente a elaboração da documentação do projeto, resultando em retrabalho e perda de valor.

A abordagem Ágil, por outro lado, é recomendada para ambientes de projetos onde os requisitos do produto são variáveis ou estão em evolução com o progresso da equipe de projeto. O APM possui métodos, práticas e ferramentas mais simples caldados na flexibilidade ou agilidade para lidar com a mudança durante o projeto (AMARAL et al. 2011).

As vantagens de utilizar o APM consistem no foco na necessidade do cliente, adaptação a mudanças nos requisitos e tempo rápido de desenvolvimento (BARLOW et al., 2011). Entretanto, existem limitações ao adotar a abordagem Ágil em projetos complexos, como a integração e dependências entre as funções do produto, dificuldade de gerenciar ambiente multi-equipes.

A mudança excessiva de requisitos pode levar a erros e retrabalho. No caso de projetos complexos, pode gerar ainda um aumento nos custos em projeto cujo produto possui funções muito integradas ou dependentes, dificultando entregas de forma incremental (TURK; RUMPE, 2009).

A APM é desenvolvido e operado melhor em projetos pequenos e com uma equipe de projeto co-localizada (LEE; DELONE; ESPINOSA, 2006). Em projetos grandes, complexos e distribuídos o planejamento, controle e coordenação são críticos para o sucesso do projeto, sendo recomendado a utilização de práticas tradicionais (BATRA et al., 2010).

A coordenação e comunicação entre várias equipes de projeto é um fator importante para projetos complexos devido à necessidade de gerenciar as dependências entre as equipes e sincronizar a tomada de decisão e outras atividades (LAANTI, 2008 apud MISHA e MISHA, 2011).

A gestão informal da informação torna-se um obstáculo para a implementação do APM em projetos complexos no contexto de coordenação e comunicação de varias equipes de projeto. Existe a tendência de quanto maior a empresa e os projetos, maior a necessidade de 
formalização da documentação e comunicação (KERNER, 2002, p.454) e o APM promove a comunicação informal e a baixo esforço na documentação do projeto (BARLOW et al., 2011).

A Figura 8 apresenta um resumo sobre a gestão formal e informal de projetos. A Gestão formal é baseada na excessiva documentação do projeto, reuniões contínuas e autoridade do gerente de projetos e a gestão informal fundamentada na confiança, cooperação e trabalho em equipe (KERZNER, 2002, p.454).

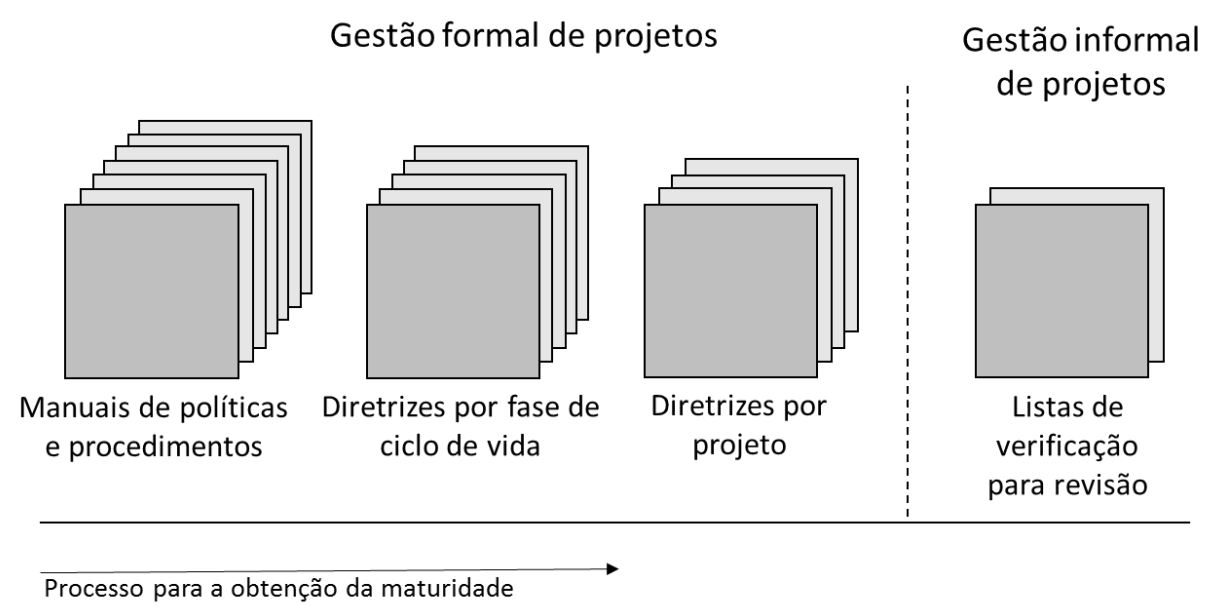

Figura 8 - Evolução da documentação e mudanças nos níveis de formalidade Fonte: adaptado de Kezner (2002, p.454).

$\mathrm{Na}$ literatura encontra-se a discussão sobre a escolha entre as abordagens de gestão de projetos. Acredita-se que não há uma abordagem que se sobressaia sobre a outra a depender do contexto de desenvolvimento e é comum os autores se referirem ao assunto utilizando o termo no silver bullet ou one size does not fit all (BOEHM; TURNER, 2003; SHENRAR, 2001).

Duas abordagens discutem o tema de escolha e, em comum, visam definir um conjunto de princípios e práticas para um determinado tipo de projeto e correspondem a abordagem contingencial e a abordagem Híbrida ou combinada de gestão de projetos.

A abordagem contingencial consiste em escolher um conjunto específico de princípios para diferentes tipos de projetos (SHENHAR, 2001; SAUSER; REILLY; SHENHAR, 2009). Essa abordagem inicia-se no estudo da tipologia do projeto, por exemplo, projetos de baixa tecnologia, que utiliza tecnologias conhecidas, e alta tecnologia, que integra novas tecnologias, porém, conhecidas (SHENRAR, 2001). 
O aumento da integração de novas tecnologias no produto afeta, por exemplo, o número de ciclos de design, a necessidade de prototipagem e testes e a frequência e complexidade das decisões de trade-off. Além disso, deve-se ter mais atenção nas atividades de planejamento e controle necessárias para gerenciar o projeto (SHENRAR, 2001).

A abordagem Híbrida ou combinação entre o Ágil e o Tradicional é o foco desta pesquisa. O desafio de combinar as duas abordagens é saber como orquestrar as práticas de gestão de projetos (FERNANDEZ; FERNANDEZ, 2008). No próximo capítulo será discutida em detalhes a combinação entre as praticas ágeis e tradicionais. 


\section{COMBINAÇÃO DE PRÁTICAS ÁGEIS E TRADICINAS}

O objetivo desse capítulo é apresentar a Revisão Bibliográfica Sistemática (RBS) sobre os trabalhos que propõem a combinação de práticas ágeis e tradicionais de gestão de projetos.

\subsection{Pesquisa sobre combinação de práticas de gestão de projetos}

A pesquisa sobre combinação das abordagens Tradicional e Ágil iniciou-se desde os primeiros trabalhos que descreviam a abordagem ágil. $\mathrm{O}$ trabalho com maior ênfase foi o de Boehm (2002). O autor compara as abordagens e lista as características do projeto onde cada obtém maior vantagem. Como resultado da comparação, o autor defende que a combinação das abordagens é possível e preferível as outras abordagens isoladamente, embora não decorra de como realizá-la.

No trabalho de Boehm (2002), há a indicação de duas iniciativas de combinação de abordagens, Highsmith (2000, p.24) e em Fowler (2001).

Highsmith (2000) propõe o método Adaptive Software Development (ADS), que utiliza princípios ágeis como ciclos iterativos, adaptação às mudanças, auto-gestão, entrega de resultados parciais e emergentes e, também, práticas de abordagens tradicionais, tais como:

- Elaboração de uma lista de atividades em cada ciclo de planejamento;

- Utilização do Quality Function Deployment (QFD) para analisar trade-off no design do produto, por exemplo, a segurança e manutenção em sistemas geralmente são conflituosas;

- Elaboração do cronograma de projeto, contendo datas comprometidas pelo time após as seções de planejamento e não datas estabelecidas como estimativas; e

- Análise de risco do projeto e monitoramento do escopo e cronograma do ciclo.

Embora apresente práticas tradicionais como a elaboração do cronograma do projeto, ao analisar o texto segundo os princípios ágeis da seção 2.2, entende-se, porém, que o ADS deve ser caracterizado como um método Ágil e não uma combinação. 
Fowler (2001) recomenda o uso dos diagramas do UML (Unified Modeling Language) com o XP (Extreme Programming). A UML é uma linguagem para especificar software e não uma abordagem de gestão de projetos, portanto o trabalho não é considerado uma forma de combinação entre as abordagens Ágil e Tradicional.

Para apresentar a revisão da literatura, optou-se por agrupar os autores encontrados em três grupos distintos. Os grupos foram identificados a partir das palavraschaves utilizadas pelos autores para identificar o fenômeno de combinação de práticas. $\mathrm{O}$ intuito do agrupamento é facilitar a compreensão sobre as ideias identificadas sobre combinação de abordagens de gestão de projetos. O primeiro grupo consiste em autores da Gestão Ágil de Projetos (APM). O segundo grupo são autores do Desenvolvimento Ágil Distribuído (DAD). O terceiro grupo de autores utiliza o termo Ambidestria Organizacional para indicar a combinação entre as abordagens.

O primeiro grupo consiste em autores da APM que discutem a implementação da abordagem ágil em ambientes que utilizaram predominantemente a abordagem tradicional de gestão de projetos. Griffiths (2004) apresenta sugestões para conciliar os processos de gestão de projetos provenientes do PMBoK com as práticas ágeis. Na Iniciação e Fechamento é recomendado utilizar as práticas tradicionais conforme são descritas pelo PMBoK. O processo de Planejamento deve ser modificado para ser iterativo e desdobrado por todo o projeto, sendo guiado pelo feedback da performance atual do projeto. Na Execução devem ser a utilizadas práticas ágeis, como a iteração e métricas simples. O processo de Controle também é indicado práticas ágeis, como as reuniões de revisão da iteração e controle do fluxo. Contudo, o autor restringe-se a sugestões para combinar as abordagens de gestão de projetos, não se aprofundando na discussão sobre práticas, princípios e ferramentas que deveriam ser consideradas.

Boehm e Turner (2005) estudaram a implementação do APM em empresas que utilizavam primordialmente a gestão tradicional de projetos e identificaram projetos combinando ambas as abordagens ou um híbrido. $\mathrm{O}$ resultado são recomendações em três elementos considerados críticos para o gerenciamento de projetos:

1. Processo de Desenvolvimento: realizar preparação do up-front; elaborar o processo ao invés de implementá-lo de uma vez; definir funcionalidades e responsabilidades especificas para cada abordagem; desenvolver arquiteturas 
de alto nível; realinhar os milestones tradicionais; e, avaliar os riscos para determinar o nível de agilidade.

2. Processo de Negócio: testar o impacto do ágil em processos tradicionais para verificar problemas de Recursos Humanos; aplicar o throughput ao invés da contabilidade de custos; desenvolver a gestão e práticas de arquitetura; investigar e atualizar as práticas de contratos; identificar incompatibilidade de pressupostos entre os métodos; conduzir estudos empíricos para descobrir classes de mudanças mais imprevisíveis; e, estabelecer guias de compatibilidade com os processos ágeis.

3. Pessoas: Entender como a comunicação ocorre entre os times; orientar os stakeholders para o novo processo; enfatizar o valor; selecione os excelentes e premie os resultados alcançados; e, reoriente o sistema de recompensas para reconhecer tanto as contribuições do time e individuais.

Karlostrom e Runeson (2005) estudaram a integração entre o APM e o modelo de desenvolvimento Stage-Gate ${ }^{\circledR}$ em três grandes empresas de software, entre elas, a Ericsson Microwave Systems. Os resultados apontam pontos de conflito entre as abordagens, como a documentação do projeto, possível isolamento da equipe ágil e o baixo suporte aos planos de longo prazo ao utilizar o APM na execução do projeto. Também, benefícios como melhoras na comunicação entre os times de projeto e na coordenação do projeto. No entanto, não foi identificado detalhes específicos em modificações necessárias no Stage-Gate ${ }^{\circledR}$ pata integrar práticas ágeis, por exemplo, na avaliação do projeto nos gates e na integração do desenvolvimento iterativo.

Fernandez e Fernandez (2008) investigaram as principais diferenças entre as abordagens de Gestão de Projetos. Os autores concluem o trabalho defendendo a combinação entre as vantagens da flexibilidade e adaptabilidade provenientes do ágil com a estrutura tradicional. No entanto, restringem-se a dizer que o desafio consiste em identificar a combinação apropriada, sem se aprofundarem no tema. Portanto, não especificam como combinar as abordagens de gestão de projetos e nem mesmo os desafios.

Port e Bui (2009) realizaram uma simulação com o objetivo de comparar quatro estratégias de priorização de requisitos de gestão de projetos, tradicional, ágil e duas combinadas. A estratégia tradicional consiste em implementar os requisitos de maior custobenefício primeiro. A estratégia ágil visa entregar valor rápido e focar na necessidade do cliente, permitindo alterações na priorização dos requisitos. E duas estratégias combinadas, a 
primeira consiste em introduzir o conceito de custo-benefício à estratégia ágil, e outra combina as estratégias tradicional com a ágil, considerando o custo-benefício de adicionar um novo requisito e variando o tamanho das iterações, sendo denominada de abordagem híbrida. O modelo utilizou como variáveis dados de custo e valor do requisito e pressupostos como o tempo de desenvolvimento é desconhecido e a inclusão de novos requisitos segue uma distribuição de Poison. O resultado indicou que as estratégias combinadas obtiveram melhores performances quando o modelo utilizou porcentagens médias e altas de dinamismo ou mudanças de requisitos por iteração, por exemplo, $15 \%$ e $200 \%$ respectivamente.

Embora os resultados sejam condizentes com a teoria, que em ambientes de alto dinamismo é vantajoso combinar as estratégias, Port e Bui (2009) utilizam a premissa que o custo-benefício dos requisitos seja conhecido para planejar o projeto, difícil de ocorrer no início do projeto, onde são priorizados os requisitos e entregas do projeto, por exemplo, e não consideram outras variáveis como o tamanho do time de projeto que, segundo Boehm e Turner (2003), influencia na escolha da abordagem de gestão de projetos.

Zaki e Moawad (2010) propuseram um modelo para combinar as práticas ágeis e tradicionais. O modelo utiliza a abordagem Ágil como base para o desenvolvimento e o processo é divido em seis fases distintas. Na fase de avaliação iterativa, é sugerido algumas práticas tradicionais como solução para problemas com o APM. Por exemplo, requisitos em evolução e alta frequência de mudanças são problemas ágeis que podem causar prejuízos ao projeto e dificultar a identificação do real escopo. É recomendado sign-off do cliente para os requisitos da iteração, dividir o projeto em fases, estabelecendo contratos específicos para cada, ou precificar o esforço por homem hora. Entende-se que as recomendações transgredem o princípio ágil de incorporar as mudanças, pois criam barreiras para evitar novas mudanças no escopo do projeto, e não foi identificado esse nível de discussão no trabalho. Todavia, excluindo essa fase e as recomendações, o modelo utiliza essencialmente práticas Ágeis, como o backlog, story cards e a iteração, não deixando claro quais as práticas tradicionais são incorporadas ao modelo.

Barlow et al. (2011) investigaram a implementação do APM em projetos grandes e complexos e defendem que para esse tipo de projeto a solução consiste em combinar o ágil e o tradicional, ou uma metodologia híbrida. A combinação consiste em decompor tarefas do projeto em módulos, de forma mais independente possível. Deste modo, as técnicas tradicionais são utilizadas para o(s) módulo(s) com tarefas com interdependências 
sequenciais, ou seja, tarefas que devem ser executadas em um lógico e fluxo linear de trabalho. As técnicas ágeis são utilizadas para o(s) módulo(s) com interdependência reciproca, ou seja, tarefas que dependem mutualmente umas das outras. Analisando a proposta dos autores, assume-se que todas as entregas e respectivas atividades e tarefas são conhecidas previamente e que é possível agrupá-las em módulos. Na impossibilidade de decompor ou o agrupar as tarefas, a proposta torna-se inviável. Também, não é discutido como as interfaces são gerenciadas para evitar problemas de incompatibilidades entre módulos diferentes.

Cobb (2011, p.69) defende que a transformação de uma empresa do tradicional para o ágil começa com o desenvolvimento de uma abordagem híbrida ou combinada. A abordagem é sugerida nos casos em que não faz sentido a empresa adotar o Scrum ou XP, tais como cultura organizacional não suportar princípios ágeis, ambiente de riscos e regulatório de operação exigir controle do projeto, grau de incerteza não justificar a implementação do ágil e migração gradual e incremental em virtude do nível da mudança necessária. O autor sugere alternativas para a combinação entre abordagens:

- Utilizar a iteração para quebrar grandes projetos em partes menores;

- Desenvolver requisitos de alto nível e planejar o up-front, depois continuar a refinar os requisitos e planos em cada iteração;

- Priorizar os requisitos para garantir que os mais essenciais sejam desenvolvidos primeiros;

- Desenvolver o engajamento de alto nível do negócio para a supervisão do esforço de desenvolvimento;

- Integrar os testes de QA (Quality Assurance) para verificar a entrega de valor;

- Eliminar os documentos e artefatos que não provem valor para a organização;

- Utilizar práticas ágeis como o pair programming, integração contínua, code refactoring e iteração para melhorar a produtividade do desenvolvimento; e

- Criar uma cultura organizacional para sustentar a abordagem ágil como treinar o pessoal, desenvolver a parceria entre os usuários, enfatizar os resultados alcançados entre os membros do time de projeto, criar times multifuncionais e co-localizados.

Cobb (2011, p.87) também indica que a combinação possui as seguintes características: 
- Gerenciamento de projetos: iterações com duração pequenas e médias; documentação de requisitos orientados ao risco; controlar o processo pelo valor entregado;

- Processo de Desenvolvimento: escolhas de design orientado ao risco e valor; construção diária; testes funcionais contínuos, maior parte automatizado; $80 \%$ de cobertura de testes; e

- Colaboração: colaboração multigrupos por meio de frequentes checkpoints; equipes multifuncionais; auto-gestão; reuniões diárias.

A analisando as características propostas por Cobb (2010, p.87), observa-se que todas são práticas ágeis, tais como, desenvolvimento iterativo, entrega de valor, equipes multifuncionais, auto-gestão e reuniões diárias. Considera-se, assim, que o autor não traz novas práticas que indicariam uma combinação.

Spundak (2014) defende a existência da combinação entre as abordagens ágil e tradicional. A combinação deve levar em consideração características do projeto e do ambiente organizacional, sendo assim possível combinar o ágil e o tradicional em um mesmo projeto. $\mathrm{O}$ autor também defende que o debate deve ser estendido para outros contextos fora do desenvolvimento de software e sistemas de informação. No entanto, não discute em detalhes as características do projeto e não apresenta uma forma de combinar as abordagens, por exemplo, não decorre sobre quais práticas devem ser combinadas, limitando-se a defender a ideia da combinação.

O segundo grupo onde existe o debate sobre combinação é a de Desenvolvimento Ágil Distribuído (DAD). Trata-se de um grupo de autores que discutem as práticas empregadas por equipes de projeto distribuídas geograficamente, trabalhando com o gerenciamento ágil de projetos em ciclos 24 horas de trabalho, em diferentes fusos horários e culturas organizacionais (RAMESH et al., 2006; BATRA et al., 2010)

A distribuição geográfica de times de projeto gera desafios que dificultam a coordenação e aumentam a complexidade do gerenciamento. Os maiores desafios nesse contexto são: sincronizar os times de projeto; colaboração entre membros de times diferentes; canais de comunicação; ferramentas de suporte; grandes times de desenvolvimento e múltiplas unidades de desenvolvimento (HOSSAIN; BABAR; PAIK, 2009). 
Os desafios apresentados impõem restrições à implementação do APM no desenvolvimento distribuído (HOSSAIN; BABAR; PAIK, 2009). Os princípios de comunicação informal e conhecimento tácito são conflitantes com o contexto em razão da dificuldade de compartilhar informações e diferenças culturais entre os membros do projeto (LEE; DELONE; ESPINOSA, 2006). A comunicação frente-a-frente entre equipes e clientes não é possível, porque em ambientes distribuídos eles não estão na mesma localização, limitando as ações de suporte dessa abordagem nesse contexto (TURK; RUMPE, 2009). Reunir o time de projeto para as reuniões diárias ou de revisão torna-se uma atividade complexa, em alguns casos é impossível, em razão das diferenças de fuso horário e limitações de comunicação e compartilhamento de informações.

Ramesh et al. (2006) investigaram como os times de projeto implementaram as práticas ágeis em um desenvolvimento distribuído e solucionaram os desafios impostos por esse contexto. A investigação foi conduzida em três estudos de casos, empresas de desenvolvimento de software que utilizavam equipes distribuídas. O resultado encontrado indicou a combinação de práticas de ágeis e tradicionais, sendo denominadas de "práticas ágeis disciplinas", que correspondem à:

1. Ajustar o processo continuadamente: planejar iterações para finalizar os requisitos e design; Documentar os requisitos em diferentes níveis de formalidade;

2. Facilitar o compartilhamento de conhecimento: manter um repositório de informações comum; focar no entendimento das funcionalidades ao invés de novas e críticas; ciclos de desenvolvimento curtos, mas não iterativo.

3. Melhorar a comunicação; sincronizar horas de trabalho; utilizar de canais de comunicação formais; balancear a coordenação nas atividades dos times de projeto; enfatizar a constante troca de informações;

4. Criar coesão entre os times;

5. Confiar no trabalho desenvolvido, mas verificar a qualidade do produto.

Yadav et al. (2009) apresentam características de uma abordagem chamada de Flexible Global Software Development - FGSD (Desenvolvimento Flexível e Global de Software) após uma revisão da literatura. A abordagem teria características intermediarias entre o Ágil e o Tradicional, tais como a abrangência da comunicação formal e informal, importância igual para as pessoas e processos, média documentação do projeto, requisitos são 
emergentes e há o uso de protótipos para capturar os requisitos, equipe de projeto grande dividida em sub-equipes com até 10 pessoas. Entretanto, não foi identificado o processo utilizado pelos os autores para elaborar a proposta dessa abordagem. A revisão não apresentada informações para suportar a proposta do FGSD, deixando dúvidas se a proposta apresenta outras características além das citadas.

Batra et al. (2010) propõem a combinação entre o tradicional e ágil a partir de três elementos identificados em um estudo de caso. O primeiro elemento consiste em características do desenvolvimento onde seria necessário combinar as abordagens. Por exemplo, projetos grandes, estratégicos, distribuídos e envolvendo requisitos em evolução e mudanças no ambiente imprevisíveis. O segundo são dois fatores de sucesso, alcançar os requisitos dos clientes e controlar o orçamento e cronograma. O terceiro corresponde aos princípios: os tradicionais são responsáveis pela base do projeto, provendo estrutura para o planejamento, controle e coordenação entre os times de projeto; os ágeis ajudariam a lidar com a descoberta, aprendizagem e mudança, funcionando de forma iterativa e entregando valor rapidamente. Todos os elementos foram sintetizados em um framework que chamaram de abordagem Híbrida, o qual será apresentado em maiores detalhes na seção 3.5.4.

O terceiro grupo é observado em trabalhos que utilizaram a teoria da Ambidestria Organizacional para indicar a combinação de abordagens. Ambidestria Organizacional é definida como a capacidade da organização de adotar e balancear ao mesmo tempo uma abordagem emergente com aquela deliberada, eliminando a necessidade de escolha (BODWELL; CHERMACK, 2010). A analogia com a Gestão de Projetos seria uma empresa implementar dois times de projetos, um ágil e outro tradicional, e separá-los fisicamente, porém mantê-los na mesma estrutura organizacional (VINEKAR; SLINKMAN; NERUR, 2006). Cada time de projeto é responsável por desenvolver a respectiva abordagem, adotando os princípios, práticas, ferramentas e sistemas de recompensas. O objetivo é alavancar os benefícios de ambas as abordagens em uma organização para prover adaptação as necessidades emergentes e manter a estabilidade do projeto (VINEKAR; SLINKMAN; NERUR, 2006).

A separação dos times de projeto, tradicional e ágil, proposta pela Ambidestria, traz alguns desafios organizacionais. Por exemplo, ao adotar cada abordagem isoladamente, limita-se a colaboração e aprendizagem entre times diferentes, transgredindo o princípio ágil de colaboração e comunicação. Criar duas dois times distintos para a gestão de projetos requer 
investimento em recursos humanos e treinamento em cada abordagem que poucas as empresas poderia arcar, inviabilizando a proposta dos autores. A proposta ambidestra pode ser inapropriada quando um projeto necessitar da colaboração dos dois times ao mesmo tempo, por exemplo, o caso do Desenvolvimento Ágil Distribuído (DAD) (RAMESH; MOHAN; CAO, 2012). O problema ocorre em virtude dos conflitos entre comunicação, alinhamento, controle de processo e compartilhamento de documentos e que são críticos para o desenvolvimento com equipes de projeto distribuídas (RAMESH; MOHAN; CAO, 2012).

Outros autores da Ambidestria discutem a ideia de práticas relacionadas aos times de projeto. Lee, Delone e Espinosa (2006) pesquisaram como times distribuídos aprimoram a disciplina nas atividades do desenvolvimento de software e constroem flexibilidade e agilidade para responder a mudanças externas. A disciplina é entendia como a utilização de práticas tradicionais, como a documentação e padronização do projeto, e a flexibilidade e agilidade são entendidas como provenientes de práticas ágeis, como a iteração ou sprint. Os autores utilizaram entrevistas semiestruturadas, com 22 gerentes de projeto globais de desenvolvimento de software, provenientes de sete diferentes empresas. O questionário envolvia questões "Como os limites globais e barreiras afetam os projetos?" e "Qual estratégia é a mais efetiva para mitigar os efeitos negativos do desenvolvimento distribuído?”. O resultado foi uma lista de estratégias denominadas de "estratégias ambidestras":

- Plataforma comum de compartilhamento de informações;

- Organização dos times em designar atividades através do globo;

- Inclusão de atividades de entendimento e conhecimento;

- Prontidão da tecnologia para ser utilizada;

- Aumento na frequência e intensidade das atividades e processos;

- Conhecer o que cada time faz e construir confiança entre eles; e

- Adaptar o uso da melhor tecnologia para cada atividade.

O debate presente em Lee, Delone e Espinosa (2006) restringe-se em identificar as estratégias. Faltam informações de como coordenar as estratégias identificadas e não é avaliado se as estratégias levantadas são eficazes em mitigar os efeitos negativos da distribuição geográfica.

Ramesh, Mohan e Cao (2012) examinaram como de equipes de projetos desenvolvem a ambidestria para lidar com o conflito entre a flexibilidade e alinhamento ao implementar o Ágil em ambientes distribuídos, em três estudos de caso. A conclusão consiste 
em defender que o desenvolvimento distribuído de software requer o uso de processos formais provenientes da abordagem tradicional, assim como a flexibilidade para lidar com mudanças rápidas proporcionadas pela abordagem ágil. Os autores também fazem uma relação entre práticas de gestão de projetos e os conflitos. As práticas são denominadas de "práticas balanceadas" e são divididas com foco na operação e relacionamento, tais como:

- Estruturas formais, mas com flexibilidade, como canais de comunicação e coordenação formal limitada;

- Assimilar o processo antes de entregar valor rapidamente;

- Construir confiança, mas com verificação de qualidade; e

- Promover a coesão do time, mas manter a distribuição utilizando a sincronização e permitir a visita frequente entre times e clientes.

Todavia, não foi identificado como utilizar as "práticas balanceadas" para os processos gerenciamento de projetos, limitando a discussão ao nível de times de projetos. Os autores investigaram a ambidestria em três estudos de casos de desenvolvimento de software, restringindo a abrangência dos resultados encontrados para outros contextos de desenvolvimento, por exemplo, produtos manufaturados. As práticas testadas foram identificadas em um estudo anterior, Ramesh et al. (2006), e podem não refletir a lista de todas as práticas que levam a ambidestria, como os próprios autores citam.

A pesquisa identificou o debate e a hipótese de combinação entre abordagens de gestão de projetos, no entanto, não foram identificadas informações detalhadas necessárias para se estabelecer a combinação entre o Ágil e o Tradicional. Institivamente ao pensar em combinar as duas abordagens, pensa-se em "Como denominá-la e defini-la?"; "Quais os fatores críticos e benéficos esperados?; e "Quais as práticas devem ser combinadas?, por exemplo, para se elaborar um procedimento de planejamento nesse contexto.

Conclui-se que o estudo da combinação das abordagens ágil e tradicional é debatido sob três rótulos distintos: gestão ágil de projetos; gerenciamento ágil distribuído; e abordagem ambidestra para gerenciamento de projetos. $\mathrm{O}$ debate é divido sob três aspectos, fatores críticos, benefícios esperados e propostas de combinações. Nas próximas seções, descreve-se em detalhe cada um dos aspectos, sintetizando o conteúdo encontrado nas pesquisas. Antes, aborda-se em mais detalhe as definições e termos utilizados. 


\subsection{Definições e termos utilizados para a combinação de práticas de gestão de projetos}

As definições são importantes, pois proporcionam diretrizes, práticas, dentre outras características que permitem a elaboração de modelos e métodos e práticas combinadas. Os termos permitem identificar e rotular o fenômeno de combinação na literatura.

Todos os termos e definições empregados e os respectivos autores identificados na Revisão Bibliográfica Sistemática (RBS) foram organizados e apresentados em ordem alfabética dos autores no Quadro 4. Na coluna 3 do Quadro 4, classifica-se as definições considerando o grau de informação fornecido pelo autor em três rótulos: definições limitadas ou redundantes; combinação entre abordagens; combinação de princípios e práticas.

As "definições limitadas ou redundantes" apresentam dois erros técnicos, limitada, pois não apresentam informações suficientes para explicar o fenômeno de combinação, e redundante, pois expressam um fenômeno com termos sinônimos e, portanto, não permitem uma clara compreensão (SUDADDABY, 2010). No contexto da pesquisa, são definições que não apontam o que é comum e diferente entre a combinação e as duas outras formas de se gerenciar projetos. Por exemplo, Boehm e Turner (2002) utilizam o termo abordagem híbrida e a definem como "Mix" do Ágil e Tradicional. A palavra "Mix" significa mistura, mesmo sentido que a palavra "híbrido". Portanto, são sinônimas e não é possível interpretá-las. Desta forma, não acrescentam conhecimento, pois não permitem responder precisamente quais as propriedades e características presentes em uma abordagem Híbrida. Este tipo de definição não contribui para a teoria, conforme apresentado por Suddaby (2010), e não possui sentido prático para a pesquisa.

As definições classificadas como "combinação de abordagens" induzem a considerar a combinação todos os princípios, práticas, técnicas e ferramentas presentes no Ágil e Tradicional. Os autores não explicam como combinar práticas com funções semelhantes. Por exemplo, como combinar a elaboração do escopo de projeto tradicional e criação da visão ágil. Logo, considera-se que essas definições apresentam alto nível de abstração ou subjetividade e não explicam do fenômeno. 
Quadro 4 - Síntese dos termos e definições sobre a combinação

\begin{tabular}{|c|c|c|c|}
\hline Termo & Definição & Classificação & Autor \\
\hline $\begin{array}{l}\text { Metodologia } \\
\text { Híbrida }\end{array}$ & $\begin{array}{l}\text { Decompor tarefas do projeto em módulos, de forma } \\
\text { mais independente possível. Utilizar técnicas } \\
\text { tradicionais para o(s) módulo(s) com tarefas com } \\
\text { interdependências sequenciais, e técnicas ágeis para } \\
\text { o(s) módulo(s) com interdependência reciproca. }\end{array}$ & $\begin{array}{l}\text { Combinação de } \\
\text { práticas e } \\
\text { princípios }\end{array}$ & $\begin{array}{l}\text { Barlow et al. } \\
\qquad(2011)\end{array}$ \\
\hline $\begin{array}{l}\text { Abordagem } \\
\text { Híbrida }\end{array}$ & $\begin{array}{l}\text { Princípios Tradicionais responsáveis pela disciplina } \\
\text { atuam como um guarda-chuva para o } \\
\text { desenvolvimento ágil }\end{array}$ & $\begin{array}{l}\text { Combinação de } \\
\text { práticas e } \\
\text { princípios }\end{array}$ & $\begin{array}{l}\text { Batra et al. } \\
\quad(2010)\end{array}$ \\
\hline $\begin{array}{l}\text { Abordagem } \\
\text { Híbrida }\end{array}$ & $\begin{array}{l}\text { Combinação da Gestão Ágil com a estrutura global } \\
\text { da ISO21500 - Guia de Gestão de Projetos }\end{array}$ & $\begin{array}{l}\text { Combinação de } \\
\text { práticas e } \\
\text { princípios }\end{array}$ & $\begin{array}{l}\text { Binder, Aillaud } \\
\text { e Schilli (2014) }\end{array}$ \\
\hline Projeto Híbrido & $\begin{array}{l}\text { Aplicação seletiva de métodos ágeis dentro de uma } \\
\text { estrutura de plano global para enfrentar os riscos do } \\
\text { plano orientado e combinar a rápida mudança, a } \\
\text { necessidade de uma resposta rápida e as exigências } \\
\text { emergentes. }\end{array}$ & $\begin{array}{l}\text { Combinação de } \\
\text { práticas e } \\
\text { princípios }\end{array}$ & $\begin{array}{l}\text { Boehm e Turner } \\
\text { (2003) }\end{array}$ \\
\hline Projeto Híbrido & Mix do Ágil e Tradicional & $\begin{array}{l}\text { Definição } \\
\text { limitada ou } \\
\text { redundante }\end{array}$ & $\begin{array}{l}\text { Boehm e Turner } \\
\qquad(2005)\end{array}$ \\
\hline $\begin{array}{l}\text { Mix Tradicional } \\
\text { e Ágil }\end{array}$ & $\begin{array}{l}\text { Equilibrar a necessidade de criatividade com a } \\
\text { disciplina requerida para lançar o produto e manter o } \\
\text { sucesso dos produtos }\end{array}$ & $\begin{array}{l}\text { Definição } \\
\text { limitada ou } \\
\text { redundante }\end{array}$ & $\begin{array}{c}\text { Chin } \\
(2004, \text { p. 16) }\end{array}$ \\
\hline $\begin{array}{l}\text { Abordagem } \\
\text { Hibrida }\end{array}$ & $\begin{array}{l}\text { Compromisso entre um ambiente orientado ao plano } \\
\text { tradicional e um ágil puro. }\end{array}$ & $\begin{array}{l}\text { Definição } \\
\text { limitada ou } \\
\text { redundante }\end{array}$ & $\begin{array}{c}\text { Cobb } \\
(2011, \text { p.68) }\end{array}$ \\
\hline $\begin{array}{l}\text { Abordagem } \\
\text { Hibrida }\end{array}$ & Ambas as práticas Tradicionais e Ágeis & $\begin{array}{l}\text { Definição } \\
\text { limitada ou } \\
\text { redundante }\end{array}$ & $\begin{array}{l}\text { Fernandez e } \\
\text { Fernandez } \\
(2008) \\
\end{array}$ \\
\hline $\begin{array}{l}\text { Abordagem } \\
\text { Híbrida }\end{array}$ & $\begin{array}{l}\text { Combinação das abordagens para encontrar um meio } \\
\text { termo que combine as vantagens e corrija as } \\
\text { deficiências do Tradicional e Ágil }\end{array}$ & $\begin{array}{l}\text { Combinação de } \\
\text { abordagens }\end{array}$ & $\begin{array}{l}\text { Galal-edeen, } \\
\text { Riad e Seyam } \\
\quad(2007)\end{array}$ \\
\hline $\begin{array}{l}\text { Abordagem } \\
\text { Híbrida ou } \\
\text { WetAgile }\end{array}$ & Combinação da abordagem Waterfall com o Ágil. & $\begin{array}{l}\text { Definição } \\
\text { limitada ou } \\
\text { redundante }\end{array}$ & Pieczko (2010) \\
\hline $\begin{array}{l}\text { Abordagem } \\
\text { Híbrida }\end{array}$ & $\begin{array}{l}\text { A combinação das estratégias de priorização de } \\
\text { requisitis do Plan-based (ou tradicional) com a ágil, } \\
\text { considerando o custo benefício de adicionar um novo } \\
\text { requisito e variando o tamanho das iterações. }\end{array}$ & $\begin{array}{l}\text { Combinação de } \\
\text { práticas e } \\
\text { princípios }\end{array}$ & $\begin{array}{l}\text { Port e Bui } \\
\text { (2009) }\end{array}$ \\
\hline $\begin{array}{l}\text { Metodologia } \\
\text { Híbrida de } \\
\text { Design }\end{array}$ & $\begin{array}{l}\text { A combinação entre ASD (Adaptive Software } \\
\text { Development) e o NPD (New Product Development). }\end{array}$ & $\begin{array}{l}\text { Combinação de } \\
\text { práticas e } \\
\text { princípios }\end{array}$ & $\begin{array}{c}\text { Rahimian e } \\
\text { Ramsin (2007) }\end{array}$ \\
\hline $\begin{array}{l}\text { Abordagem } \\
\text { Ambidestra }\end{array}$ & $\begin{array}{l}\text { Incorporar metodologias Plan-driven e Ágil para } \\
\text { facilitar a distribuição e flexibilidade (Alinhamento e } \\
\text { Adapdalidade) }\end{array}$ & $\begin{array}{l}\text { Combinação de } \\
\text { práticas e } \\
\text { princípios }\end{array}$ & $\begin{array}{l}\text { Ramesh, Mohan } \\
\text { e Cao (2012) }\end{array}$ \\
\hline $\begin{array}{l}\text { Tragile ou } \\
\text { Abordagem } \\
\text { Híbrida } \\
\end{array}$ & $\begin{array}{l}\text { Combinação de diretrizes e práticas do Tradicional } \\
\text { com práticas e princípios Ágeis. }\end{array}$ & $\begin{array}{l}\text { Combinação de } \\
\text { práticas e } \\
\text { princípios }\end{array}$ & $\begin{array}{l}\text { Seyam e Galal- } \\
\text { Edeen (2011) }\end{array}$ \\
\hline $\begin{array}{l}\text { Abordagem } \\
\text { Ambidestra }\end{array}$ & $\begin{array}{l}\text { Combinação de uma unidade Ágil e outra unidade } \\
\text { Tradicional. }\end{array}$ & $\begin{array}{l}\text { Definição } \\
\text { limitada ou } \\
\text { redundante }\end{array}$ & $\begin{array}{c}\text { Vinekar, } \\
\text { Slinkman e } \\
\text { Nerur (2006) } \\
\end{array}$ \\
\hline Modelo Híbrido & $\begin{array}{l}\text { A estrutura Ágil e problemas correspondentes são } \\
\text { disciplinados com práticas tradicionais. }\end{array}$ & $\begin{array}{c}\text { Combinação de } \\
\text { práticas e } \\
\text { princípios }\end{array}$ & $\begin{array}{c}\text { Zaki e Moawad } \\
(2010)\end{array}$ \\
\hline
\end{tabular}


As definições que indicam a "combinação de princípios e práticas" demostram um nível de subjetividade menor que as definições que recomendam a combinação de abordagens. Isso se deve ao fato que práticas e princípios podem ser incorporados em uma abordagem para avaliação segundo determinado critério de desempenho. Por exemplo, o princípio ágil de planejamento iterativo pode ser incorporado a gestão tradicional e avaliar se a equipe de projeto entrega funcionalidades do produto dentro de uma iteração. Essas definições são o foco dessa pesquisa e quatro definições destacam-se pela forma de combinação sugerida: Batra et al. (2010); Boehm e Turner (2003); Seyam e Galal-Edeen (2011); e Zaki e Moawad (2010).

As duas primeiras definições em destaque sugerem utilizar princípios tradicionais para o planejamento e controle do projeto e a execução por meio de princípios ágeis. Para Batra et al. (2010) os princípios Tradicionais atuam de forma a manter a previsibilidade e ordem no projeto por meio dos processos de planejamento, controle e coordenação, e os princípios e práticas ágeis são empregados na execução para responder as mudanças emergentes. Identificou-se que os autores recomendam a priorização dos requisitos com a utilização do product backlog, mas não explicam como a esta se relaciona com os planos tradicionais. Boehm e Turner (2003) sugerem a aplicação seletiva de métodos ágeis em uma estrutura de plano global para enfrentar os riscos do projeto orientado ao plano e combinar a necessidade de responder rapidamente as exigências emergentes. Nos dois trabalhos, portanto, as práticas ágeis devem interagir com a estrutura tradicional para atualização dos planos e gerenciamento do projeto. Identificou-se em ambos a recomendação do desenvolvimento iterativo.

As outras duas definições em destaque sugerem utilizar a abordagem Ágil e combinar princípios ou práticas tradicionais para solucionar problemas como, por exemplo, a falta de documentação de requisitos fundamentais. Zaki e Moawad (2010) recomendam o Ágil como estrutura para elaborar o modelo de processo, este contendo seis fases distintas, e os problemas correspondentes ao Ágil são “disciplinados” ou solucionados utilizando práticas tradicionais, possibilitando a customização do processo. Seyam e Galal-Edeen (2011) definem a combinação de diretrizes e práticas do Tradicional com práticas e princípios Ágeis. Os autores propõem o framework Tragile, combinando uma base Ágil e a adicionando fases de desenvolvimento e maior nível de documentação, por exemplo, artefatos importantes como o product backlog. 
Logo, foi possível identificar duas formas distintas de combinação de práticas e princípios. Batra et al. (2010) e Boehm e Turner (2003) convergem para a ideia de utilizar princípios tradicionais como a base e o Ágil como ferramenta iterativa para lidar com o dinamismo e incertezas de requisitos e ambiente, sendo visto como um procedimento topdown. Zaki e Moawad (2010) e Seyam e Galal-Edeen (2011) divergem e sugerem utilizar os princípios Ágeis como base para o desenvolvimento e introduzir práticas tradicionais para mitigar os problemas dessa abordagem, sendo classificado como um procedimento bottom-up.

Apesar de terem sido identificadas algumas definições com maior grau de informações, por exemplo, Batra et al. (2010) e Zaki e Moawad (2010), pode-se concluir da análise que elas precisam ser aprimoradas para indicar um objetivo para combinar as práticas.

Neste referencial teórico, opta-se pelo termo "combinação de práticas" ao invés de abordagem Híbrida para se referir à combinação de práticas tradicionais e ágeis de gestão de projetos. Embora o termo abordagem híbrida seja o mais comum dentre os apresentados no Quadro 4 e utilizado pelos autores mais relevantes do tema Boehm e Turner (2005) (MAGDALENO; WERNER; ARAUJO, 2011), acredita-se que a palavra abordagem tem um sentido amplo, abrangendo princípios, práticas e também benefícios, conforme apresenta a definição de Amaral et al. (2011) para o $\mathrm{APM}^{3}$. Desta forma, evita-se confusão com os termos e simplifica o entendimento.

O termo abordagem Ambidestra foi descartado em virtude da duplicidade de sentidos identificado e. O primeiro sentido corresponde a duas subunidades de gestão de projetos separadas (VINEKAR; SLINKMAN; NERUR, 2006). O segundo consiste em uma habilidade do time em utilizar práticas ágeis e tradicionais para mitigar os conflitos de flexibilidade e controle (RAMESH; MOHAN; CAO, 2012). Além disso, o termo possui baixa frequência de citação dentre os termos apresentados no Quadro 4.

$\mathrm{Na}$ próxima seção serão apresentados os benefícios esperados ao implementar a combinação ou abordagem Híbrida. Os benefícios são compreendidos como o desempenho a ser melhorado ao combinar princípios e práticas das abordagens de gestão de projetos e são utilizados pelos autores como justificativa para cria-la.

${ }^{3} \mathrm{O}$ APM é definido como uma abordagem fundamentada em um conjunto de princípios, cujo o objetivo é tornar o processo de gerenciamento mais simples, flexível e iterativo, de forma a obter melhores resultados em desempenho (custo, tempo e qualidade), menor esforço em gerenciamento e maiores níveis de inovação e agregação de valor ao cliente. 


\subsection{Benefícios esperados da combinação}

O principal benefício defendido ao combinar princípios e práticas das abordagens de gestão de projetos consiste em obter, ao mesmo tempo, as vantagens associadas ao Ágil e Tradicional e solucionar as limitações de cada abordagem isoladamente (BARLOW et al., 2011; BINDER; AILLAUD; SCHILLI, 2014; BOEHM; TURNER, 2003; SEYAM; GALALEDEEN, 2011; PORT; BUI, 2009; ZAKI; MOAWAD, 2010).

A afirmação anterior sugere que todas as vantagens do Ágil e todas do Tradicional são incorporadas ao combiná-las e que ambas se completam mitigando as limitações. Esse benefício é entendido como subjetivo e amplo em significado, pois os autores não identificam como as vantagens do Ágil mitigariam limitações do Tradicional e vice-versa.

A literatura apresenta outros benefícios esperados para a combinação. Todos os benefícios identificados foram listados e agrupados no Quadro 5, consistem em: coesão do time de projeto; comunicação entre times; satisfação do cliente; entrega do produto no tempo certo; proporcionar flexibilidade; e, manter controle.

A coesão convém para aumentar a percepção de equipes geograficamente distribuídas de pertencerem à mesma equipe de desenvolvimento, sendo criada ao visitar frequentemente as outras equipes geograficamente separadas (RAMESH et al., 2006). Entende-se que a coesão atua como a percepção comum entre membros do projeto de pertencerem à mesma equipe de projeto.

A comunicação entre times e gerentes é melhorada ao incorporar práticas ágeis em ambientes que utilizam a gestão tradicional (KARLOSTROM; RUNESON, 2005; RAMESH et al., 2006; SOMMER et al., 2015). Esse benefício seria alcançado por meio da constante comunicação entre os times, sincronizando trabalho entre diferentes times de projeto, mantendo um repositório de dados comum, focando no entendimento das funcionalidades ao invés de adicionar novas e realizando revisões periódicas como toda a equipe de desenvolvimento (RAMESH et al., 2006).

Satisfação do cliente. Durante os testes de aceitação do produto, o cliente avalia se o produto atende as necessidades. A quantidade de modificações solicitadas pelo cliente e o impacto dessas no projeto são um indicador para medir a satisfação do cliente e o foco do time do projeto (SEYAM; GALAL-EDEEN, 2011). 
Entrega do produto no tempo certo, ou seja, o consumidor não lida com atrasos do time de desenvolvimento. Ao introduzir a prática ágil de entregas parciais, o consumidor pode iniciar a utilização de partes do produto sem ter que esperar este ser terminado completamente (SEYAM; GALAL-EDEEN, 2011).

Quadro 5 - Benefícios esperados da combinação

\begin{tabular}{|c|c|c|}
\hline Categoria & Benefícios sugeridos & Autores \\
\hline $\begin{array}{l}\text { Coesão do time de } \\
\text { projeto }\end{array}$ & $\begin{array}{l}\text { - Percepção de membros de diferentes times de } \\
\text { pertencerem ao mesmo time de desenvolvimento }\end{array}$ & $\begin{array}{l}\text { Ramesh et al. } \\
\quad \text { (2006) }\end{array}$ \\
\hline \multirow[t]{2}{*}{ Comunicação } & $\begin{array}{l}\text { - A comunicação entre times de projeto é melhorada ao } \\
\text { incorporar práticas ágeis em ambientes que utilizam a } \\
\text { gestão tradicional }\end{array}$ & $\begin{array}{l}\text { Karlostrom e } \\
\text { Runeson (2005) } \\
\text { Ramesh } \text { et al. } \\
\quad(2006) \\
\text { Sommer } \text { et al. } \\
\quad(2015)\end{array}$ \\
\hline & $\begin{array}{l}\text { - Melhorar a comunicação por meio da sincronização do } \\
\text { trabalho }\end{array}$ & $\begin{array}{l}\text { Ramesh et al. } \\
\quad \text { (2006) }\end{array}$ \\
\hline Satisfação do cliente & $\begin{array}{l}\text { - Apenas pequenas modificações são solicitadas nos testes } \\
\text { de aceitação }\end{array}$ & $\begin{array}{c}\text { Seyam e Galal- } \\
\text { Edeen (2011) }\end{array}$ \\
\hline \multirow[b]{2}{*}{$\begin{array}{l}\text { Entrega do produto } \\
\text { no tempo certo }\end{array}$} & - Entrega do produto no prazo estabelecido & \multirow[b]{2}{*}{$\begin{array}{l}\text { Seyam e Galal- } \\
\text { Edeen (2011) }\end{array}$} \\
\hline & $\begin{array}{l}\text { - O consumidor pode iniciar a utilização de partes do } \\
\text { produto sem ter que esperar o time de projeto termina-lo } \\
\text { completamente. }\end{array}$ & \\
\hline \multirow[t]{2}{*}{$\begin{array}{l}\text { Proporcionar } \\
\text { flexibilidade }\end{array}$} & $\begin{array}{l}\text { - Documentação dos artefatos críticos e o Quality } \\
\text { Assurance (QA) distribuído permitem a organização a } \\
\text { manter um nível de controle essencial. O objetivo é } \\
\text { satisfazer normas e políticas organizacionais ao mesmo, } \\
\text { tempo prover a flexibilidade necessária para o projeto }\end{array}$ & $\begin{array}{l}\text { Ramesh et al. } \\
\quad \text { (2006) }\end{array}$ \\
\hline & $\begin{array}{l}\text { - Responder as mudanças dentro de um projeto grande, } \\
\text { estratégico, distribuído e terceirizado. }\end{array}$ & \multirow{2}{*}{ Batra et al. 2010} \\
\hline \multirow[b]{2}{*}{ Controle do projeto } & $\begin{array}{l}\text { - Estabelecer controle e agilidade para alcançar desafios e } \\
\text { metas dinâmicas. }\end{array}$ & \\
\hline & $\begin{array}{l}\text { - Ajudar o desenvolvimento a ser bem gerenciado e de } \\
\text { forma organizada, enquanto preserva a flexibilidade do } \\
\text { processo. }\end{array}$ & $\begin{array}{l}\text { Seyam e Galal- } \\
\text { Edeen (2011) }\end{array}$ \\
\hline
\end{tabular}

A flexibilidade ${ }^{4}$ é entendida como a capacidade adaptação as mudanças, em especial, aquelas que incidem sobre os requisitos do produto. A flexibilidade é proporcionada

${ }^{4}$ Recomenda-se a leitura do trabalho de Conforto (2013) para maiores informações sobre flexibilidade e agilidade no APM. 
ao utilizar práticas ágeis como a priorização de itens no Product Backlog, por exemplo, (BATRA et al., 2010). Ramesh et al. (2006) e Seyam e Galal-Edeen (2011) também defendem a inclusão da flexibilidade no projeto, embora não decorram de como alcançá-la.

O controle do projeto é relacionado com práticas tradicionais segundo os autores que defendem a combinação, por exemplo, Batra et al. (2010). Entende-se que práticas tradicionais são provenientes de guias e manuais de gestão de projetos como o PMBoK. De acordo com o PMI (2013), o controle de projetos integra cinco parâmetros: escopo; cronograma; custo; técnicos; e, qualidade. Logo, é necessário definir quais os parâmetros de controle os quais os autores estão sugerindo para gerenciar o projeto.

Ramesh et al. (2006) explicam que a documentação dos artefatos críticos e o Quality Assurance ${ }^{5}$ (QA) permitem que a organização mantenha um nível de controle mínimo, satisfazendo normas e políticas organizacionais e, ao mesmo tempo, provendo flexibilidade necessária para o projeto. Essa afirmação levanta alguns questionamentos. Qual o nível mínimo de controle para o projeto? Que tipo de controle deve ser realizado? Quais as políticas e normas que devem ser consideradas? Como controla-las durante a execução do projeto? Essas questões são importantes para entendermos como estabelecer o controle do projeto. Comparando os parâmetros de controle do PMBoK (2013) e com os indicados pelos autores, identificou-se a qualidade do produto, por meio do QA, e técnicos, relacionados com a documentação.

Batra et al. (2010) propõem que o controle é necessário para administrar as atividades de empresas terceirizadas. No estudo de caso apresentado pelos autores, é relatado que o time de projeto utilizou o planejamento iterativo para estabelecer controle, por meio de práticas como a priorização de itens do product backlog, estimativas de custos tempo para as atividades a serem executadas durante a iteração. Entende-se, então, que os parâmetros de controle aos quais os autores se referem são escopo, custos e cronograma.

Seyam e Galal-Edeen (2011) apontam no estudo de caso investigado que o controle foi estabelecido por meio de atividades direcionadas para monitorar o progresso do projeto, como as reuniões diárias, onde é verificado as estimativas de tempo e progresso da equipe de projeto. Entende-se, assim, que os parâmetros a serem controlados são o cronograma e escopo de projeto.

\footnotetext{
${ }^{5}$ Quality Assurance (QA) são testes de qualidade nos requisitos do sistema. Pode incluir testes de performance, confiabilidade, conformidade com o padrão da indústria, entre outros (LEFFINGWELL, 2011, p.72)
} 
Outros autores apresentam também sugestões para controlar projetos que utilizam a combinação. Para Binder, Aillaud e Schilli (2014), o controle do escopo deve ser flexível para permitir mudanças nos requisitos que são apoiados por uma análise de impacto e aprovado pelos principais Stakeholders. O cronograma deve ser controlado no início de cada iteração, por meio da comparação do plano de alto nível com a duração das atividades executadas e a duração estimada das remanescentes. O controle dos custos é realizado no início de cada iteração, por meio da comparação do orçamento de alto nível com o total de custo das atividades executadas e o custo estimado as remanescentes. A qualidade do projeto provém do princípio ágil de atenção com a excelência técnica e bom design e monitorado por meio de outro, software funcionando é a medida primária de progresso. Os autores não debatem como obter a qualidade por meio dos princípios ágeis, limitando-se a argumentar a possibilidade de se controlar por meio desses princípios. Apesar das limitações na investigação dos autores, entende-se que os todos os parâmetros de controle são citados pelos autores.

Toda a análise das recomendações de controle de projeto dos autores que defendem a combinação e a relação com os parâmetros de controle do PMI (2013) estão sintetizados no Quadro 6.

Quadro 6 - Síntese das recomendações de parâmetros de controle do projeto

\begin{tabular}{lccccc}
\cline { 2 - 6 } & \multicolumn{5}{c}{ Parâmetros de Controle } \\
\cline { 2 - 6 } & Custo & Cronograma & Escopo & Técnicos & Qualidade \\
\hline Ramesh et al. (2006) & & & & $\mathrm{X}$ & $\mathrm{X}$ \\
\hline Batra et al. (2010) & $\mathrm{X}$ & $\mathrm{X}$ & $\mathrm{X}$ & & \\
\hline Seyam e Galal-Edeen (2011) & & $\mathrm{X}$ & $\mathrm{X}$ & & $\mathrm{X}$ \\
\hline Binder, Aillaud e Schilli (2014) & $\mathrm{X}$ & $\mathrm{X}$ & $\mathrm{X}$ & $\mathrm{X}$ & $\mathrm{X}$ \\
\hline
\end{tabular}

Observa-se no Quadro 6 que os dois parâmetros de controle mais comuns são o cronograma e o escopo. Portanto, nessa pesquisa assume-se que a combinação entre práticas de gestão de projetos deve proporcionar controle do cronograma e escopo.

Em resumo, foram identificadas seis categorias de benefícios esperados ao combinar as práticas de gestão de projetos. Ao analisar e comparar esses benefícios com os esperados ao implementar gestão ágil, foi identificado que os que defendem a combinação estão propondo os mesmos benefícios do ágil, como a resposta a mudança, melhoria na comunicação e maior integração da equipe de projeto. Esse fato importante permite concluir que o principal foco desses autores é obter o mesmo benefício da gestão ágil, talvez na 
suposição de que a combinação serviria para obter as mesmas vantagens em ambientes que a implementação do APM poderia ser inadequada para a gestão do projeto, por exemplo, em projetos complexos, onde é necessário um maior nível de controle do projeto em razão da complexidade da gestão do projeto.

As sínteses das seções 3.2 e 3.3 permitem propor uma definição para a combinação de práticas de gestão de projetos, incluindo os benefícios como um dos pontos importantes para a combinação:

Uso combinado de práticas provenientes da teoria do gerenciamento Ágil e Tradicional, em um mesmo projeto, que objetiva melhorar o desempenho em coesão, comunicação, satisfação do cliente, tempo e flexibilidade, mantendo, porém, grau mais elevado de controle de projeto.

\subsection{Fatores críticos para combinação}

Na teoria de gestão de projetos, os fatores críticos de sucesso (FCS) tratam do sucesso do projeto como um todo, por meio da identificação e gerenciamento de fatores que podem impactar no custo, prazo, escopo, qualidade, ou mesmo gerar um risco para a execução e conclusão do projeto (SHENHAR et al., 2002). Os FCS podem ser definidos como os fatores que devem estar presentes para um projeto ter sucesso (CHOW; CAO, 2006). Ou podem ser definidos como aspectos indispensáveis para atender as necessidades do cliente, por exemplo, o cumprimento da programação, atendimento ao orçamento e concretização da qualidade (KERZNER, 2008, p.43).

Os fatores críticos de sucesso são debatidos em vários trabalhos na literatura de gerenciamento de projetos em razão da complexidade de identificá-los e medi-los na prática. Por exemplo, Shenhar et al. (2002) apresentam uma investigação para identificar os FCS, utilizando um modelo com 170 variáveis derivadas de uma revisão da literatura em uma amostra de 127 projetos.

A combinação de práticas de gestão de projetos é um fenômeno recente na literatura, sendo o marco inicial o trabalho de Boehm (2002). Deste modo, fatores críticos de sucesso, como definido anteriormente, são inexistentes ou limitam-se a contextos específicos 
de alguns estudos de casos. A principal discussão dos autores que defendem a combinação, e com nível maior de detalhes, são recomendações gerais do tipo problemas, conflitos potencializados pela combinação, aspectos que merecem ser observados na utilização ou até práticas recomendadas pelos autores. Essa lista foi denominada de fatores críticos para a combinação.

Todos os fatores críticos identificados foram listados e classificados em quatorze categorias no Apêndice B: (1) arquitetura de alto nível; (2) Up-front de desenvolvimento; (3) desenvolvimento iterativo; (4) documentação mínima do projeto; (5) medição do processo; (6) melhorar a produtividade do desenvolvimento; (7) milestones; (8) gestão dos requisitos do produto; (9) qualidade; (10) divisão de atividades de projeto; (11) Estrutura organizacional; (12) Comunicação (13) gerenciamento da mudança; e (14) processo de desenvolvimento. Apresenta-se a discussão sobre as recomendações dos autores.

Arquitetura $^{6}$ de alto nível (1), termo da Engenharia de Software para se referir à descrição dos elementos do sistema, a qual indica a forma como os seus elementos (componentes e interfaces) se relacionam. Para o Processo de Desenvolvimento de Produtos, arquitetura corresponde ao arranjo e interação dos elementos funcionais do produto físico (ROZENFELD et al., 2006).

Três propósitos em utilizar a Arquitetura foram identificados. Arquitetura de alto nível promove uma informação essencial da visão geral do projeto (BOEHM; TURNER, 2004, p.89). Visa estabelecer características e padrões que permitam separar componentes estáveis daqueles em evolução de requisitos e ambiente (BOEHM; TURNER, 2005). Associada com a visão do produto, a arquitetura ajuda a equipe de projeto na avaliação do escopo e aumenta a comunicação entre as subequipes e usuários (HUO et al., 2004).

Up-front de Desenvolvimento (2) consiste em uma fase de planejamento de desenvolvimento de produtos, onde existe grande esforço para prever as atividades operacionais, demandando informações precisas para a elaboração do cronograma, por exemplo. O Up-front é recomendado para ambientes estáveis, onde há pouca ou nenhuma mudança nos requisitos do produto, pois em ambientes dinâmicos, com muitas mudanças, as

\footnotetext{
${ }^{6}$ Arquitetura de software é uma estrutura de componentes de um programa/sistema, os relacionamentos entre esses componentes, os princípios e diretrizes que governam os projetos e a evolução dos softwares. Os blocos de construção (ou seja, os componentes) de uma arquitetura são constituídos de unidades que desempenham o comportamento do sistema; são constituídos também de conexões que mostram essas unidades transmitem informações e de conexões que mostram como as várias operações do programa são atividades sequenciais ou concorrentemente (NAKAGAWA, 2006, p.28)
} 
informações iniciais tornam-se imprecisas afetando a acurácia do cronograma e prejudicando o controle do projeto, sendo considerado como uma fonte de retrabalho (BOEHM; TURNER, 2003).

A combinação do Up-front e práticas ágil requer modificações. Uma sugestão é focar na compreensão das funcionalidades iniciais ao invés de introduzir novas funcionalidades críticas (RAMESH et al., 2006). Objetiva-se fomentar o aprendizado da equipe de projeto e clientes por meio do entendimento das funcionalidades iniciais e conhecimento dos processos, atividades e ferramentas aplicadas ao desenvolvimento.

Outra sugestão é utilizar o Up-front para reduzir a ambiguidade do escopo do projeto e estabelecimento de funcionalidades a serem entregues, sendo alcançada obtendo-se os requisitos do usuário da melhor forma possível (BATRA et al., 2010). O objetivo é identificar oportunidades ou novas funcionalidades no início, mesmo que estes sejam instáveis e dinâmicos. Entretanto, os autores não especificam métodos ou ferramentas para obter os requisitos do usuário. O Up-front deve incluir atividades de conhecimento e entendimento (LEE; DELONE; ESPINOSA, 2006), que auxiliam o time de projeto a aumentar o conhecimento sobre os desafios do projeto.

Uma forma de aumentar o conhecimento sobre o produto do projeto é utilizar a prática ágil de Visão do produto (AMARAL et al., 2011; SOMMER et al., 2015). Por exemplo, Sommer et al. (2015) recomendam a prática para refinar a ideia do produto e criar o Product Backlog inicial.

A última recomendação é desenvolver os requisitos de alto nível no Up-front e continuar a refinar os requisitos e os planos em cada iteração (COBB, 2011, p.87). O desenvolvimento de requisitos de alto nível é entendido como uma atividade semelhante a criação da Visão do Produto, pois objetiva identificar as entregas e partes principais do produto.

Portanto, conclui-se que o Up-front requer modificações no sentido de reduzir as atividades de elaboração de planos, como o cronograma de projeto, e aumentar as atividades relacionadas ao entendimento e conhecimento dos requisitos do projeto. Além disso, deve-se considerar a incorporação de práticas ágeis como a Visão do produto.

Desenvolvimento iterativo (3) é um dos elementos centrais do APM e vários trabalhos recomendam incluir essa prática ao indicar a combinação (AMARAL et al., 2011; AMBLER, 2013; BATRA et al., 2010; COBB, 2011; NAWROCKI et al., 2006; RAMESH et 
al., 2006; SEYAM; GALAL-EDEEN, 2011; SOMMER et al., 2015). Desses trabalhos foram destacadas duas recomendações principais. A primeira consiste em adotar ciclos de desenvolvimento curtos, mas não iterativo no sentido do ágil convencional, pois, os ciclos iterativos são aplicados com sucesso em times co-localizados, mas não funcionam com times distribuídos em razão da falta de coesão entre os times e desconhecimento das necessidades do cliente (RAMESH et al.,2006). A outra recomendação é utilizara iteração com duração de tempo pequena ou média e, também, utilizar o desenvolvimento iterativo para quebrar os projetos em partes menores (COBB, 2011). Logo, apesar das contradições nas recomendações de como dividir o tempo das interações, pode-se concluir que os autores são unânimes em citar esta prática.

Documentação mínima do projeto (4). Os autores da teoria ágil criticam o excesso de burocracia e documentação advinda da abordagem tradicional, sendo essa prática desconsiderada e incentivado conhecimento tácito e compartilhamento informal de informações. Porém, na combinação deve-se enfatizar a documentação mais que no gerenciamento ágil. Neste caso, são considerados os artefatos, deliverables e processos críticos ao final do ciclo de desenvolvimento (RAMESH et al., 2006). Por exemplo, requisitos minimamente documentados trazem mais benefícios ao desenvolvimento do que a comunicação informal para o compartilhamento de informações entre times de projeto (RAMESH et al., 2006). A documentação, mesmo sendo mínima, cria uma figura global do projeto e auxilia no gerenciamento do conhecimento nos casos de rotatividade de membros do time, fato comum em grandes times de projetos (BATRA et al., 2010).

Recomenda-se eliminar os documentos e artefatos requeridos por processos tradicionais que não agregam valor e documentar os requisitos orientados ao risco (COBB, 2011, p.69 e 87). O objetivo é simplificar o processo de desenvolvimento sem deixar de atender as demandas que exigem documentação, por exemplo, normas regulamentadoras. Também, recomenda-se utilizar templates para coletar, documentar e organizar toda a informação produzida no projeto (CONFORTO; AMARAL, 2010).

A documentação deve ser entendida como uma atividade de projeto (KARLOSTROM; RUNESON, 2005). Nesse caso, modelos de referência de desenvolvimento de produtos podem auxiliar a identificação das atividades que devem ser documentadas (CONFORTO; AMARAL, 2011), mas pode haver conflitos em se manter a mínima documentação e a grande quantidade de documentação requerida pelos modelos de 
desenvolvimento (KARLOSTROM; RUNESON, 2005). Logo, a combinação requer uma racionalização das práticas tradicionais de documentação.

Medição do processo (5). Há relatos de problemas de que a implementação do desenvolvimento iterativo e entregas incrementais resultam em conflitos com as práticas de controle de processo tradicionais (BOEHM; TURNER, 2005). Alguns autores recomendam a utilização de métricas simples e relevantes alinhadas com a meta do desenvolvimento, por exemplo, métricas baseadas nas funcionalidades entregues e tempo restante de projeto, normalmente utilizadas pelo APM (GRIFFITHS, 2004). Recomenda-se também utilizar o throughput, proveniente da Teoria das Restrições, ao invés da contabilidade de custos tradicional para medir o processo de desenvolvimento (BOEHM; TURNER, 2005). Controlar o processo pelo valor entregue, priorizando as ações do time de projeto (COBB, 2011, p.87). Portanto, surge a recomendação de que os gerentes de projetos deveriam optar por um sistema de medição de processo de desenvolvimento mais rigoroso que o APM, com controle de custos, e ao mesmo tempo mais simples que os tradicionais, com o intuito de reduzir os conflitos citados e manter o controle sobre o projeto.

Melhorar a produtividade do desenvolvimento (6). Recomenda-se a utilização de técnicas ágeis como programação em pares, a integração contínua, code refactoring e a iteração para melhorar a produtividade do desenvolvimento (COBB, 2011, p.69), mas não se identificou a justificativa do porquê utilizá-las ou como beneficiaram a combinação. Neste sentido, não se vê diferença para as duas abordagens já existentes.

Milestones (7). Defende-se que é necessário adaptar as práticas de revisão de projeto tradicionais para integrá-los ao desenvolvimento iterativo. Elaborar pontos de revisão e balanço para garantir que o projeto está sobre controle (RAMESH et al., 2006). Por exemplo, o design review ${ }^{7}$ deve ser alterado para acomodar a avaliação protótipos do desenvolvimento iterativo (BOEHM; TURNER, 2005). Os critérios de avaliação nos milestones requerem definição cuidadosa para evitar descompassos com o processo de desenvolvimento iterativo (BOEHM; TURNER, 2004, p.89).

Gestão dos requisitos do produto (8). A gestão Ágil lida com as mudanças nos requisitos, mesmo em momentos finais do desenvolvimento. Desta forma, ao combinar as práticas, a gestão dos requisitos do produto deve ser realizada pela equipe de projeto para controlar as mudanças ocorridas durante o projeto. $\mathrm{O}$ objetivo principal é evitar impactos

\footnotetext{
${ }^{7}$ Processo de revisão detalhada de aspectos técnicos do produto por meio de critérios de avaliação ligados a fase do desenvolvimento em questão (ROZENFELD et al., 2006, p.74)
} 
significantes no custo e cronograma do projeto (BATRA et al., 2010). No entanto, não foram identificadas diferenças da recomendação para práticas tradicionais de gerenciamento de escopo de projeto e a recomendação de Batra el al. (2010).

Existe, também, a recomendação de priorizar requisitos, que consiste em sequenciar funcionalidades dentro de uma iteração, conforme as práticas ágeis. A priorização convém para acelerar a entrega das funcionalidades mais essenciais para o cliente e agregar valor (COBB, 2011, p.69). Os requisitos mais importantes devem ser desenvolvidos primeiramente e não são permitidos atrasos na execução desses, os outros requisitos são agendados para o final do projeto ou abandonados (KARLOSTROM; RUNESON, 2005).

Qualidade (9). Introduzir práticas para inspecionar a qualidade do processo e do produto com o objetivo de provar a entrega de valor. Recomenda-se estabelecer o nível de controle que permita gerenciar a qualidade do processo de desenvolvimento e a flexibilidade para as mudanças, incorporando o QA (Quality Assurance) para testes e inspeção de qualidade (RAMESH et al., 2006; COBB, 2011, p.69).

Divisão de atividades de projeto (10). Para projetos com muitas equipes, ou equipes distribuídas, as interfaces do produto e as dependências entre as atividades de projeto podem dificultar a divisão das atividades entre as sub-equipes de projeto, o estabelecimento e controle das entregadas e a execução de práticas ágeis como a priorização dos requisitos, por exemplo. A sugestão para contornar esse problema é minimizar as dependências delegando atividades independentes para um mesmo time (LEE; DELONE; ESPINOSA, 2006). Também, decompor o projeto em módulos de atividades independentes, e coordenar as ações das sub-equipes (BARLOW et al., 2011).

Estrutura organizacional (11). Ao combinar práticas e princípios ágeis e tradicionais é importante analisar impacto na estrutura organizacional do projeto. Por exemplo, como integrar na estrutura as funções do Gerente de projeto e Product Owner e como será divida a responsabilidade para a tomada de decisão.

No tradicional existem dois papeis responsáveis pela tomada de decisão. O Steering committees é responsável por decisões estratégicas, o gerente de projeto é responsável por todas as decisões táticas e operacionais e a equipe de projeto desenvolvem as atividades do projeto (SOMMER; DUKOVSKA-POPOVSKA; STEGER-JENSEN, 2014).

No Scrum, por exemplo, as decisões de projeto são compartilhadas entre o Product Owner, Cliente e equipe de projeto. Além disso, a equipe de projeto assume 
responsabilidades administrativas e participam do planejamento, controle e monitoramento do projeto, sendo chamadas de equipes auto-geridas (self-organizing team) (SCHWABER, 2004; AMARAL et al., 2011).

Nawrocki et al. (2006) apresentam a estrutura organizacional combinada entre Prince2 e o XP. Alta administração do projeto (Project Board) é formada pelo Usuário sênior (Senior User), que coordena os usuários e foca na usabilidade, Executivo, que representa o investidor e possui autoridade para cancelar o projeto, e o Fornecedor sênior (Senior Supplier), que representa o fornecedor da organização. O nível intermediário possui dois papeis principais. O Gerente de projeto é responsável pelo contato com a alta administração, direcionar a equipe de projeto e motivar os desenvolvedores. O Arquiteto (Architect) é mais orientado aos conhecimentos técnicos e atua na equipe de projeto como um Sênior designer. E os desenvolvedores representam o último nível, sendo os responsáveis por executar as atividades de projeto.

Batra et al. (2010) apresentam a estrutura organizacional adotada no estudo de caso investigado. A alta administração do projeto é representada pelo Steering Committee e formada pelos gerentes sêniores (senior managers). A principal responsabilidade é a tomada de decisão estratégica, como a adição de requisitos ao produto e aprovação do orçamento, de forma rápida e em um período de 24 horas. O Gerente de projetos é responsável por decidir quais as atividades serão desenvolvidas na próxima Iteração, baseando-se em uma lista de itens priorizados pelo custo e estimativas de tempo. E as equipes auto-geridas, formadas pelos desenvolvedores e responsáveis por desenvolver as atividades de projeto.

Sommer, Dukovska-Popovska, Steger-Jensen (2014) e Sommer et al. (2015) propõem um modelo de estrutura organizacional, que combina papeis da gestão tradicional e ágil. O modelo é uma síntese das descobertas do estudo em cinco empresas, onde o desenvolvimento de produtos tradicional foi adaptado para incluir o método Scrum. A estrutura possui uma alta administração, representada pelo Steering Committee, formada pelos gerentes e principais stakeholders e responsável pelas decisões estratégicas como mudanças no escopo e alocação de recursos. O nível intermediário é formado pelo gerente de projetos, que assume a função do Product Owner e é responsável pela comunicação entre a equipe de projeto e a alta administração, e os Scrum Masters, membros da equipe de projeto treinados para facilitar a organização do projeto. No último nível estão as Equipes auto-geridas que desenvolvem as atividades de projeto. 
Em síntese, a estrutura organizacional é composta pela Alta administração do projeto, representada por gerentes e os principais stakeholders e responsáveis por decisões estratégicas, pelo nível intermediário, representado principalmente pelo Gerente de projetos e líderes das equipes de projeto, responsáveis pelas decisões táticas do projeto, e o nível operacional, representado pelas equipes auto-geridas que utilizam as práticas ágeis.

Comunicação (12). A abordagem ágil enfatiza a comunicação informal e o conhecimento tácito e compartilhado, enquanto que o tradicional preza por formalidade e documentação do conhecimento. Essas diferenças geram conflitos e transformam esse quesito em um fator crítico para o desenvolvimento. Deve-se entender como a comunicação ocorre entre os times para remover os conflitos e barreiras (BOEHM; TURNER, 2005). Melhorar a comunicação por meio da sincronização do trabalho entre os times, equilíbrio de coordenação e responsabilidades entre os membros e utilização de múltiplos canais de comunicação para manter constante a troca de informações (RAMESH et al., 2006). E reforçar o feedback e colaboração por meio de frequentes checkpoints (COBB, 2011, p.87). Neste caso não foi possível encontrar uma diferença entre o híbrido e as demais abordagens em prática.

Gerenciamento da mudança (13), os princípios ágeis podem não ser aceitos por membros time de projeto em virtude das diferenças nos estilos de gerenciamento e aumento das responsabilidades individuais, principalmente em ambientes tradicionais. Gerenciar as mudanças culturais e os comportamentos dos indivíduos com a nova abordagem é fundamental para a implementar o APM em ambientes tradicionais (BOEHM; TURNER, 2005). Ao propor um processo que integre o ágil e o tradicional, os interessados devem conduzir uma análise significativa nos processos existentes para identificar incompatibilidades nos requisitos e expectativa do processo proposto. Também, treinar gerentes e equipe de projeto no APM para auxiliar na implementação e aceitação dessa abordagem em conjunto com a tradicional (KARLOSTROM; RUNESON, 2005).

Processo de Desenvolvimento (14) deve ser revisado para a implementação de práticas ágeis. Há autores que, apesar de desenvolverem um modelo direcionado para a abordagem ágil, sugerem o uso de modelo de referência de desenvolvimento combinado com o desenvolvimento iterativo (AMARAL et al., 2011). Outra possibilidade é criar um processo de ajuste contínuo para atender às necessidades do projeto (RAMESH et al., 2006). Os ajustes auxiliam na implementação de práticas ágeis e que esse suporte os processos existentes ou as novas prioridades organizacionais (BOEHM; TURNER, 2005). O processo pode ser 
construído gradualmente ao invés de ser implementado de uma só vez (BOEHM; TURNER, 2005). Recomenda-se testes funcionais contínuos, maior parte automatizado e fazer as escolhas de design orientado ao risco e valor (COBB, 2011, p.87). Dessa forma, garante-se a entrega de valor para o usuário. As informações do projeto devem ser mantidas em um repositório comum e de fácil acesso ao time de desenvolvimento (AMARAL et al., 2011; LEE; DELONE; ESPINOSA, 2006; RAMESH et al., 2006). Assim, conclui-se que o processo de desenvolvimento de produto deve ser racionalizado para integrar práticas ágeis.

Os quatorze fatores críticos identificados indicam recomendações que se sabe até o momento para a combinação das práticas de gestão de projetos. As recomendações mostram práticas do ágil (iteração, documentação mínima, priorização de requisitos e comunicação) e tradicionais (definição de responsabilidade, Up-front ou planejamento inicial, milestones, qualidade, indicadores, medição do processo) que deveriam ser adaptadas com alterações de ênfase ou objetivo. Indicam também aspectos que mereceriam mais atenção do gerente se comparado com as abordagens Ágil e Tradicional, como o desenvolvimento da arquitetura, compreensão dos requisitos iniciais e comunicação.

\subsection{Propostas de combinação de práticas}

Durante a Revisão Bibliográfica Sistemática foram identificados trabalhos que apresentaram propostas de combinação entre as práticas de gestão de projetos. As propostas identificadas consistem em um conjunto de todos os modelos, métodos e frameworks identificados. Nas próximas subseções, a discussão foca em dez propostas de combinação, apresentadas em ordem cronológica visando mostrar a evolução do tema até o momento, que consistem em: Boehm e Turner (2003 e 2004), Nawrocki et al. (2006), Rahimian e Ramsin (2007), Batra et al. (2010), Zaki e Moawad (2010), Amaral et al. (2011), Seyam e GalalEdeen (2011), Ambler (2013); Binder, Aillaud e Schilli (2014); e Sommer et al. (2015).

\subsubsection{Risk Approach}

O Risk Approach ou Abordagem de Risco é um método utilizado para a escolha entre as abordagens Ágil e Tradicional e elaborar estratégias para lidar com os riscos associados ao ambiente de projeto. É proposto por Boehm e Turner (2003) e, mais detalhadamente, em Boehm e Turner (2004). O método possui dois passos principais. 
O primeiro passo consiste em caracterizar o ambiente de projeto para auxiliar a escolha da abordagem em uma situação em particular. Utiliza-se uma classificação em cinco dimensões críticas que representam o resumo dos home-grounds, características do projeto onde cada abordagem possui maior probabilidade de sucesso e correspondem:

- Tamanho. Número de pessoas destinadas ao projeto;

- Criticidade. Perda devido ao impacto dos defeitos;

- Dinamismo. Consiste em um quociente da mudança de requisitos por mês;

- Pessoal. Relaciona as habilidades necessárias para gerenciar projetos ágeis e tradicionais; e

- Cultura. Relaciona se a cultura organizacional preza por regras definidas e procedimentos claros ou maior grau de liberdade para os indivíduos.

O resultado da classificação é apresentado no gráfico polar ilustrado na Figura 9. O exame das cinco dimensões críticas em conjunto permite identificar qual a abordagem a ser utilizada. No caso em que as pontuações no gráfico estiverem próximas do centro, há maior probabilidade de sucesso adotando o APM. Se ocorrerem na periferia do gráfico, recomendase o tradicional. A combinação advém quando não há uma predominância das pontuações, algumas incidindo mais ao centro e outras mais periféricas.

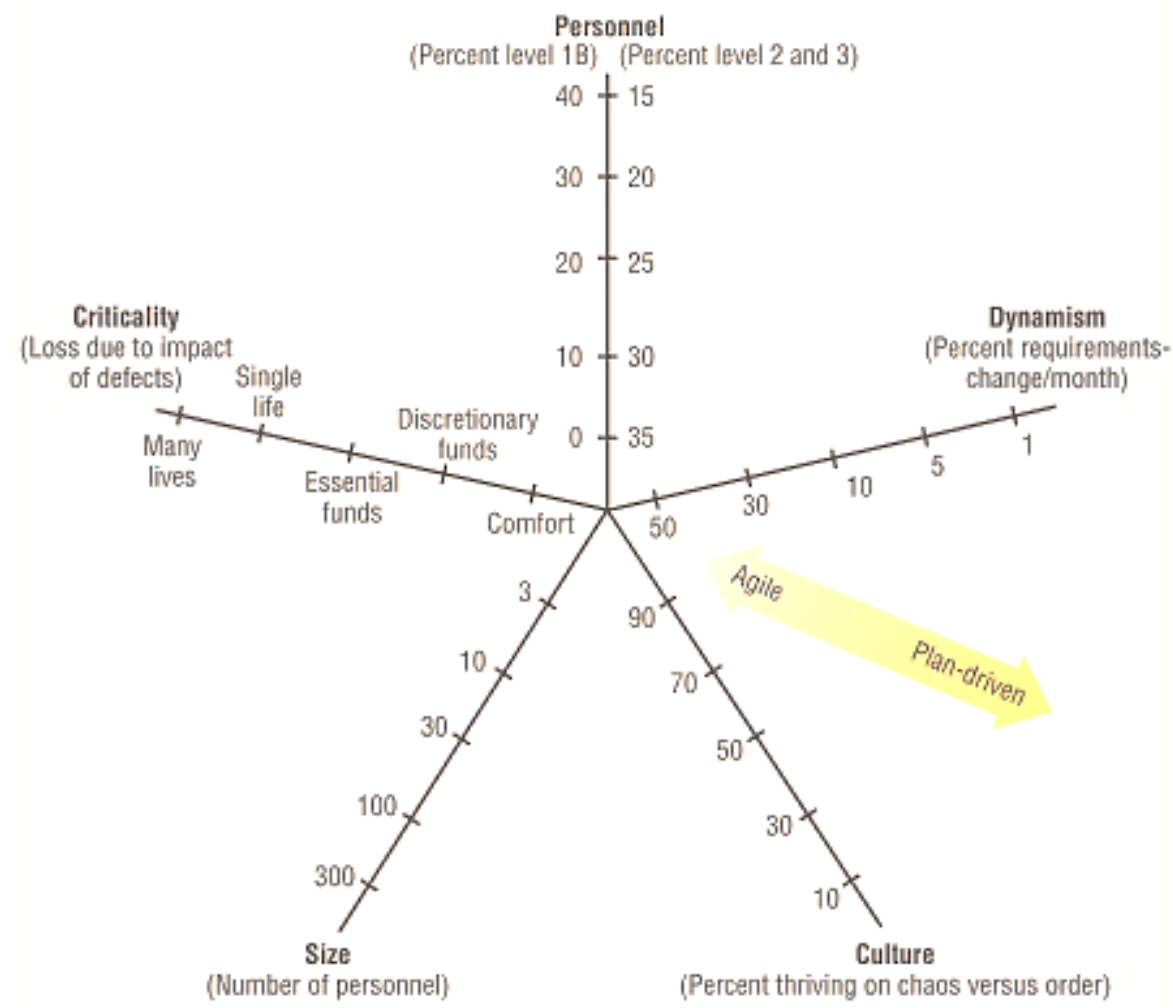

Figura 9 - Dimensões que afetam a escolha da abordagem 
Fonte: Boehm e Turner (2004, p.56).

O segundo passo consiste em executar cinco etapas conforme o fluxograma apresentado na Figura 10. O objetivo é elaborar estratégias para mitigar os riscos que dominam o projeto. $\mathrm{O}$ resultado é um plano para solucionar os riscos e escolher a abordagem adequada.

Etapa 1, Análise dos riscos. Consiste em identificar os riscos associados com as abordagens, classificá-los e ponderá-los para facilitar a análise do projeto. Boehm e Turner (2004, p.102) classificam os riscos em três categorias específicas:

- Riscos ambientais. Resultantes do contexto geral do projeto, como incertezas na tecnologia e complexidade de sistemas;

- Riscos ágeis. Específicos no uso de métodos ágeis, como criticidade e escalabilidade, uso de design simples e $\mathrm{YAGNI}^{8}$, turnover e falta de pessoas com habilidade em métodos ágeis; e

- Riscos tradicionais. Específicos no uso de métodos tradicionais, como mudanças rápidas, necessidade de entregar resultado rápido, requerimentos emergentes e falta de pessoas com habilidade em métodos tradicionais.

As informações sobre os riscos provêm uma base para auxiliar a tomada de decisão sobre a abordagem de gestão de projetos a ser adotada nos casos onde há muitas incertezas sobre o projeto. A equipe de projeto deve aumentar o conhecimento geral do projeto por meio da coleta de informações e criação de protótipos, banco de dados, dentre outros, caso houver muitas incertezas associadas aos riscos. O resultado dessa etapa é o entendimento do sobre o ambiente de projeto e das capacidades organizacionais necessárias para desenvolvê-lo.

Etapa 2, Comparação dos riscos. Avalia-se os resultados da etapa anterior para determinar qual a abordagem a ser adotada. Por exemplo, se os riscos tradicionais dominam, deve-se adotar a abordagem tradicional e monitorar os riscos ágeis identificados, e vice-versa. Se não houver clareza em indicar a abordagem, deve-se executar a Etapa 3, caso contrário, ir para a Etapa 4.

${ }^{8}$ Acrômio para You Aren't Going to Need It (você não vai precisar disso). Principio Ágil que dita que os membros da equipe de projeto não devem fazer trabalho extra para antecipar requisitos ou funções do produto em uma iteração (BOEHM, 2002). 


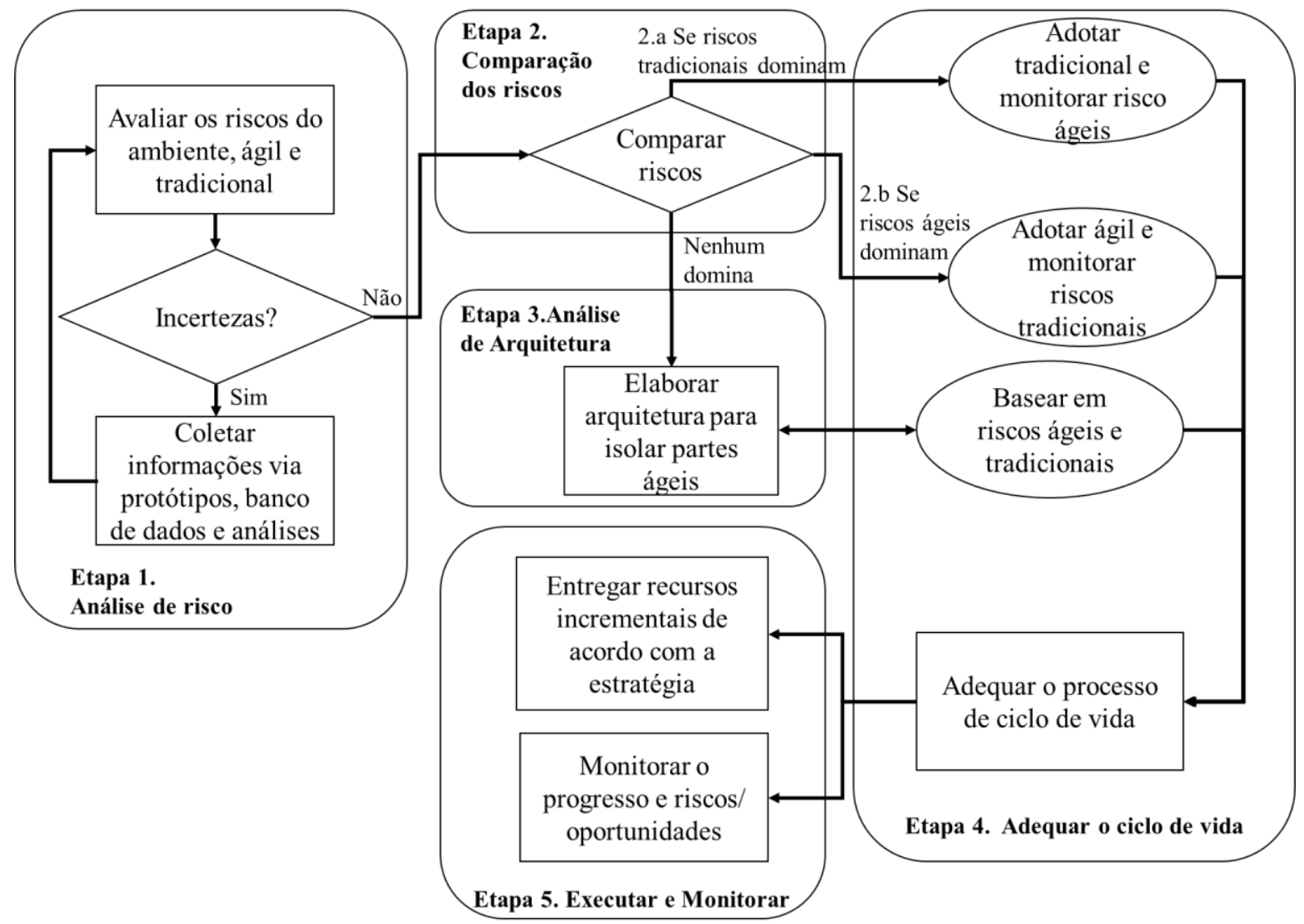

Figura 10 - Sumário do Risk Approach

Fonte: Boehm e Turner (2004, p.101), traduzido pelo autor.

Etapa 3, Análise da arquitetura. Os riscos identificados nas etapas anteriores requerem a combinação entre as abordagens para mitigá-los. A recomendação é a elaboração de uma arquitetura que suporte o uso das duas abordagens. O intuito é identificar as interfaces, isolar as partes que possuem maior probabilidade de mudanças para serem gerenciadas pela abordagem Ágil e, assim, minimizar os riscos. Nos casos de impossibilidade de elaboração da arquitetura, a sugestão é utilizar os métodos tradicionais como padrão de execução e feedback de trabalho.

Etapa 4, Adequar o ciclo de vida. Consiste em elaborar soluções para cada risco individualmente e integrá-los em uma estratégia global de projeto para serem monitorados na fase seguinte. O resultado é um mapa de estratégias contendo ações necessárias para o desenvolvimento do projeto.

Etapa 5, Executar e Monitorar. O time de gerenciamento deve constantemente monitorar e reavaliar as estratégias desenvolvidas na etapa anterior. Pode ser necessário ajustar os níveis entre ágil e tradicional em casos onde o método e as estratégias estabelecidas 
inicialmente não apresentem o resultado esperado ou novas informações sobre o projeto sejam descobertas.

Boehm e Turner (2003) apresentam uma recomendação de combinação entre abordagens nos casos onde existe a impossibilidade de assumir quais os riscos que dominam o projeto. Os autores indicam a criação da arquitetura do software para identificar partes ágeis e tradicionais. O pressuposto é assumir a possibilidade de dividir a arquitetura e identificar essas partes, que exige maior grau de detalhe nos requisitos do produto para isolar as partes no início do desenvolvimento, onde as informações normalmente carecem de detalhes ou estão indisponíveis em virtude das incertezas do projeto. Também, não há o debate sobre como gerenciar o projeto quando se adota as duas abordagens para desenvolver o software.

Conclui-se que a relevância do método consiste em caracterizar os riscos associados ao projeto e indicar se é necessário adotar a combinação. Embora alguns trabalhos citem o Risk Approach como uma forma de combinação (GALAL-EDEEN; RIAD; SEYAM, 2007; BARLOW et al., 2011), entende-se que o Risk Approach não é uma proposta de combinação, mas um método de diagnostico que serviria para indicar quando combinar práticas de gestão de projetos.

\subsubsection{XPrince (Extreme Programming IN Controlled Environments)}

O XPrince é uma proposta de desenvolvimento de software que visa balancear a agilidade do Extreme Programming (XP) e a disciplina dos métodos Tradicionais, combinando as abordagem de gestão de projetos (NAWROCKI et al., 2006).

A Figura 11 apresenta a proposta, que contém um ciclo de vida de projeto de cinco fases distintas baseadas no XP, PRINCE2 e o Rational Unified Process (RUP): Starting up a Project, Initiating a Project, Elaboration, Release e Closing.

\begin{tabular}{|c|c|c|c|c|c|c|c|c|c|c|}
\hline \multirow{2}{*}{$\begin{array}{l}\text { Starting } \\
\text { up a } \\
\text { Project }\end{array}$} & \multirow[b]{2}{*}{$\begin{array}{c}\text { Initianting } \\
\text { a project }\end{array}$} & \multirow[b]{2}{*}{$\begin{array}{l}\text { Elabo- } \\
\text { ration }\end{array}$} & \multicolumn{3}{|c|}{ Release 1} & & \multicolumn{3}{|c|}{ Release K } & \multirow{2}{*}{$\begin{array}{c}\text { Closing } \\
\text { a } \\
\text { project }\end{array}$} \\
\hline & & & $\begin{array}{c}\text { Increment } \\
1.1\end{array}$ & $\begin{array}{c}\text { Increment } \\
1.2\end{array}$ & $\begin{array}{c}\text { Transition } \\
1\end{array}$ & & $\begin{array}{c}\text { Increment } \\
\text { K. } 1\end{array}$ & $\begin{array}{c}\text { Increment } \\
\text { K. } 2\end{array}$ & $\begin{array}{c}\text { Transition } \\
\text { K }\end{array}$ & \\
\hline
\end{tabular}

Figura 11 - XPrince project lifecycle

Fonte: Nawrocki et al. (2006).

Starting up a Project consiste no inicio o ciclo de vida de projeto do XPrince, onde dois objetivos principais são executados. O primeiro objetivo é indicar as pessoas que constituíram o time de gerenciamento, como o gerente de projetos, desenvolvedores e analista 
de arquitetura. O segundo objetivo é produzir o documento da visão do projeto, de modo semelhante ao indicado pelo PRINCE2, elaborando o project brief, o project approach e a versão inicial do business case do projeto.

Initiating a Project objetiva-se em criar o plano e ambiente organizacional para o projeto. Os principais objetivos são: (1) entender o que deve ser desenvolvido; (2) propor a arquitetura inicial, que consiste em uma descrição de alto nível para prover informação para o planejamento do projeto; (3) Planejar todo o projeto e refinar o business case. O plano deve especificar todos os releases e funcionalidades para os releases, deste modo provendo uma perspectiva mais ampla do projeto; e, (4) configurar os canais de comunicação e o ambiente de gerenciamento de projetos, que inclui a periocidade das reuniões, documentação e reportes.

Elaborarion consiste na fase de planejamento da arquitetura do projeto. Objetivase por selecionar os mecanismos de desenvolvimento, checar os riscos e criar um framework para ser utilizado pelos desenvolvedores. O Analista de arquitetura e o Gerente de projetos utilizam essa fase para refinar os requisitos e o plano de projeto.

$\underline{\text { Release }}$ consiste principalmente em incrementos e na transição, onde o código é escrito, os testes são executados e há avaliação de aceitação pela gerencia do projeto, de forma similar ao XP.

Closing é a ultima fase de desenvolvimento e objetiva-se na avaliação do projeto e identificação de ações de acompanhamento. O projeto é finalizado e a equipe desfeita, assemelhando-se com a fase de fechamento descrita no PRINCE2.

Foram identificados dois diferenciais principais na proposta que indicam a combinação entre as abordagens de gestão de projetos. O primeiro diferencial é a indicação de uma fase inicial de planejamento, onde os autores recomendam a criação de um plano de projeto indicando todos os releases e funcionalidades principais e análise da arquitetura a ser desenvolvida, característica considerada como tradicional. O segundo diferencial é o desenvolvimento iterativo e entregas parciais por meio dos releases, sendo caracterizado como proveniente gestão Ágil. Portanto, entende-se que o XPrince apresenta uma forma de combinação de abordagens de gestão de projetos. 


\subsubsection{Processo Híbrido de Metodologia de Design}

O Processo Híbrido de Metodologia de Design, ilustrado na Figura 12, foi elaborado combinando as ideias do Adaptative Software Development (ASD), um método ágil, e as fases de Desenvolvimento de Novos Produtos (NPD) (RAHIMIAN; RAMSIN, 2007).

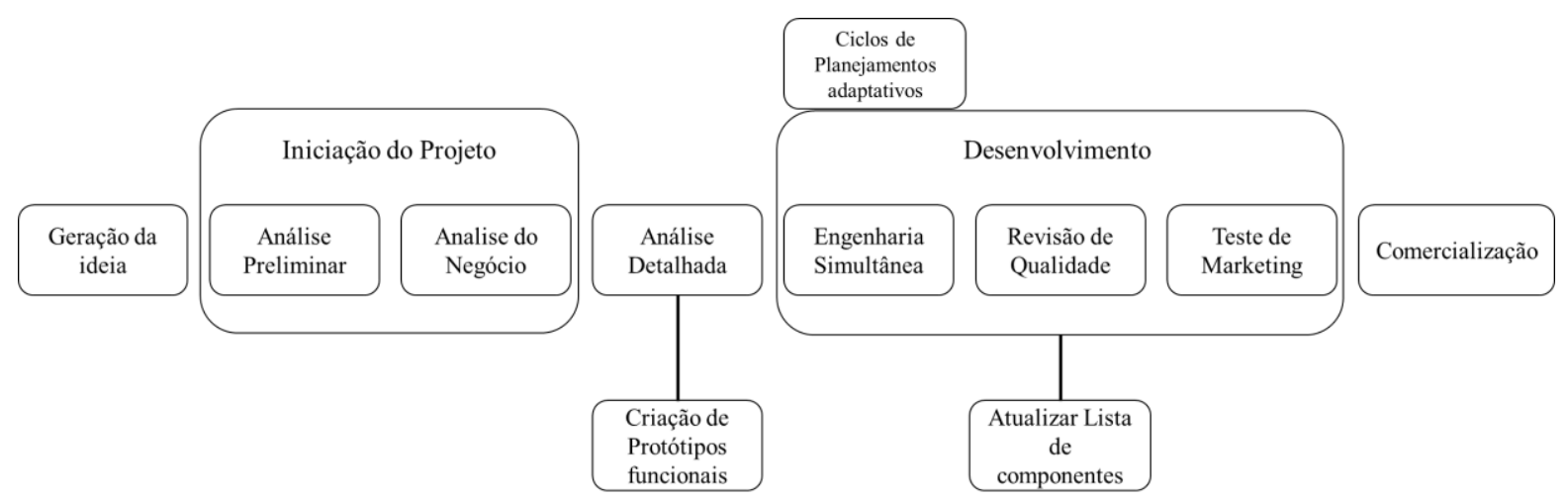

Figura 12 - Processo Híbrido de Metodologia de Design

Fonte: Rahimian e Ramsin (2007), traduzido pelo autor.

O trabalho apresenta a proposição do processo de fases necessárias para desenvolver o software para celulares. Faltam detalhes de atividades específicas, práticas e ferramentas para serem utilizadas nos processos de gestão, que auxiliariam a pesquisa. Também, não é testado em um estudo de caso para analisar a performance de desenvolvimento de software.

Foi possível identificar que o método utiliza essencialmente elementos da abordagem Ágil, como o planejamento iterativo e priorização de requisitos. A diferença para a gestão Ágil consiste em integrar atividades recorrentes do NPD como a geração de ideias no início do desenvolvimento, os testes de marketing ao final do processo e estabelecer um ciclo de vida. Práticas tradicionais são citadas como características de um desenvolvimento ideal, como o suporte para reutilização, ou modularidade, e inclusão de pontos de revisão. Entretanto, não foi identificada a relação destes com o processo elaborado.

\subsubsection{Framework Híbrido}

O Framework Híbrido é o resultado de um estudo de caso onde foi investigado quando e onde é necessário combinar as abordagens no contexto do Desenvolvimento Ágil Distribuído (DAD) (BATRA et al., 2010). conforme é esquematizado na Figura 13. 


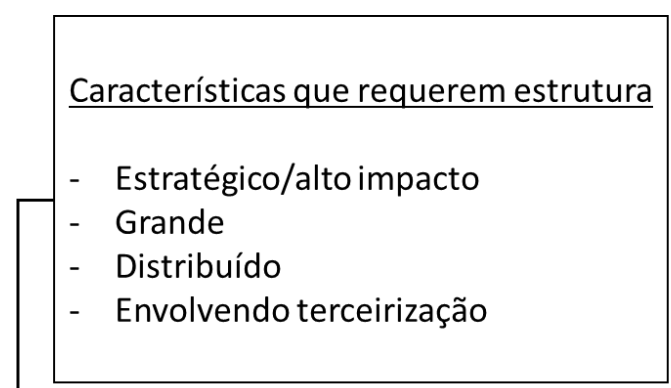

Características que requerem agilidade

- Requisitos de usuários em evolução

- Descoberta de novas funcionalidades

- Mudanças organizacionais e tecnológicas imprevistas

- Necessidade de entregas parciais e incrementais

Abordagem Tradicional fornece um contexto de planejamento

controle, coordenação para a capacidade resposta das iterações

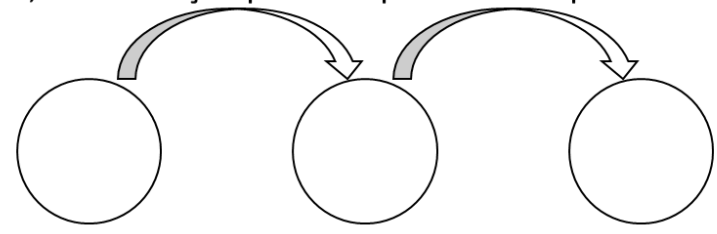

Métodos ágeis fornecem retorno rápido e senso de resposta através das iterações
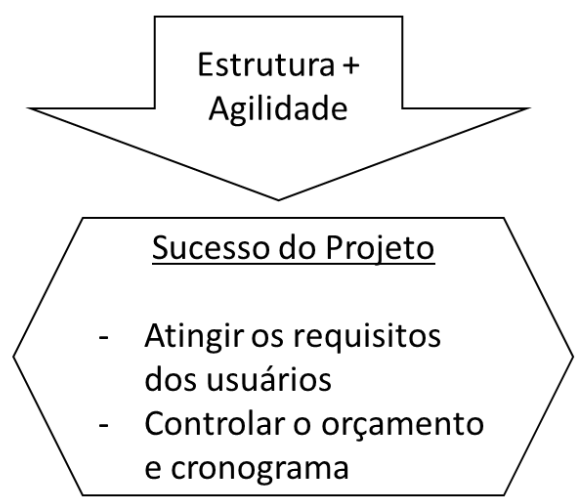

Figura 13 - Características do projeto que favorecem a abordagem Híbrida.

Fonte: Batra et al. (2010), traduzido pelo autor.

Projetos grandes, estratégicos, distribuídos, envolvendo terceirização são características que requerem a estrutura advinda de métodos tradicionais como coordenação e controle e comunicação entre times. Requisitos em evolução, mudanças organizacionais, tecnológicas imprevistas e descoberta de novas funcionalidades são características que necessitam métodos ágeis por permitirem a adaptação às mudanças. Esse conjunto de características trazem desafios que nenhuma abordagem isoladamente pode tratar eficazmente (BATRA et al., 2010).

A estratégia para lidar com os desafios impostos por esse conjunto de características consiste em utilizar princípios tradicionais para o planejamento, controle e coordenação, que são críticos para o desenvolvimento distribuído. Os princípios ágeis atuam de forma iterativa como veículo de resposta para o dinamismo e incertezas dos requisitos e projetos. 
Uma forma de combinação apresentada na proposta consiste no gerenciamento dos requisitos do usuário estabelecido no estudo de caso. Requisitos insuficientemente definidos na fase inicial de planejamento frequentemente causam custos de retrabalho. Mudanças nos requisitos nas fases finais de implementação criam problemas difíceis de lidar. Logo, o gerenciamento dos requisitos é importante e pode trazer implicações significantes ao custo e cronograma do projeto caso não existir (BATRA et al., 2011). A solução encontrada no estudo de caso foi a alta administração do projeto apenas aprovar o escopo adicional quando este apresentou benefícios estratégicos.

O estudo de caso também indicou que o custo e cronograma do projeto também foram ajustados para serem atualizados ao longo do tempo e de forma iterativa. As estimativas iniciais eram irreais e não foram utilizadas como medida de desempenho do projeto. Fundos adicionais acompanhavam estimativas suplementares de tempo onde o Steering committee avaliava o pedido ao mesmo tempo em que os stakeholders eram informados das decisões.

Entretanto, no framework Híbrido faltam detalhes de como proceder com os processos de gestão de projetos, como, por exemplo, a realização do planejamento, controle e coordenação por meio de práticas tradicionais e como sincroniza-las com a execução utilizando práticas ágeis. Faltam elementos para caracterizar a elaboração os planos de projetos e como atualizá-los com as entregas incrementais. Também, como relacionar os requisitos priorizados o planejamento e planos.

\subsubsection{Modelo de Processo Híbrido Disciplinado}

O Modelo de Processo Híbrido Disciplinado, ilustrado na Figura 14, consiste em método de seis fases que se desenvolve desde a iniciação do projeto até a comercialização. Foi elaborado por Zaki e Moawad (2010) no contexto do desenvolvimento de software.

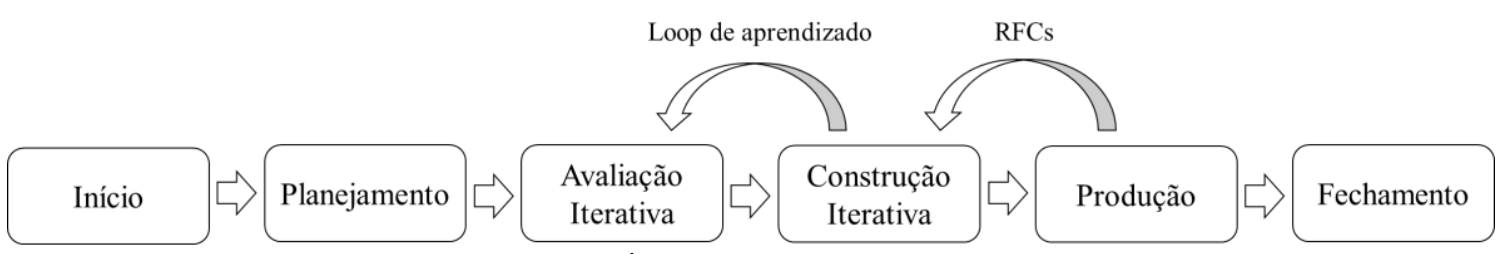

Figura 14 - Modelo Ágil de processo Hibrido Disciplinado Fonte: Zaki e Moawad (2010), traduzido pelo autor. 
A primeira fase consiste no Início, as atividades estão relacionadas com o conhecimento sobre as necessidades do projeto como elaboração da missão, objetivo e premissas e restrições do negócio. Há a especificação da coleta das estórias do usuário ( user stories), elaboração do product backlog e o desenvolvimento da arquitetura de alto nível, práticas pertencentes a gestão ágil, associado à construção de protótipos com as funções principais. A elaboração do Project Charter e a Visão do projeto são mencionadas, mas não há detalhamento desses.

A fase de Planejamento visa estabelecer os limites do projeto e deve ser executada ao início de cada iteração. As atividades são: a estimação em grupo de todas as stories coletadas; definição de prioridades dos user stories em conjunto com os clientes; e, estabelecimento da data para o primeiro release, todas práticas associadas à gestão Ágil.

A terceira fase é a Avaliação Iterativa na qual 16 pontos críticos de implementação da Gestão Ágil são avaliados. Os pontos críticos do ágil são relacionados causa e efeito entre quatro principais aspectos do desenvolvimento de software, Organização, Software, Time de projeto e Cliente. As práticas tradicionais são propostas para solucionar as causas identificadas. Destacam-se seis pontos críticos e as respectivas sugestões de solução, tais como:

- Mudança nos requisitos, causada pela evolução na maturidade do cliente. Sugestão, pedir a aprovação do cliente para os requisitos da iteração;

- Custo contínuo de testes. Causado pela complexidade do software e habilidades técnicas do time. Sugestão é realizar testes intensivos no final da fase ao invés de cada iteração ou Sprint;

- Falta de estrutura. O falta de clareza nas necessidades do cliente causa instabilidade e desestruturação da arquitetura do produto devido a mudanças. É recomendado determinar detalhes necessários no design inicial de acordo com a natureza do projeto;

- Falta de documentação. Causada pelo foco no produto e frequentes releases. A sugestão é negociar com cliente e organização a documentação como atividade a ser realizada;

- Falta de previsibilidade. Causada pela falta de clareza e conhecimento do cliente sobre o produto. Propõe-se a utilização de ferramentas estatísticas para os relatórios; e 
- Perda de controle. Causada pela comunicação informal entre as pessoas. Recomenda-se fazer reuniões de status semanais e de release.

A fase de Construção Iterativa consiste em desenvolver os itens do backlog escolhidos na fase de planejamento para a iteração específica. As atividades são: especificar o responsável para cada user story; integração do sistema; realizar as reuniões diárias; liberar documentação; e executar a reunião de retrospectiva.

A quinta fase é a Produção, o produto é liberado para o usuário e submetido a testes intensivos. O feedback do usuário é coletado e os pedidos de mudanças (RFCs) são analisados e incorporados ao produto.

O Fechamento do projeto é a última fase e consiste nas atividades de encerramento. O projeto encontra-se nessa fase quando não há mais users story para serem desenvolvidos, por exemplo. Finaliza-se a documentação pendente do produto para suporte e manutenção atuarem.

O modelo apresenta limitações referentes à combinação das práticas. Não há explicação de como foi elaborada a lista com os 16 pontos críticos do Ágil, quais critérios e metodologias cientificas foram utilizados para identificá-los. Também, não há uma discussão sobre como as práticas tradicionais solucionariam os pontos críticos levantados. Por exemplo, como o uso de ferramentas estatísticas e relatórios podem solucionar o problema de falta de previsibilidade. Entende-se que as recomendações são superficiais, além de não serem testadas no estudo de caso apresentado no trabalho.

Os autores explicam que a fase de planejamento deve ocorrer ao início de cada iteração para definir o backlog, mas o modelo apresenta o planejamento como uma fase especifica, sem loops de aprendizado, semelhante ao que acontece nas fases posteriores. Isso deixa dúvida sobre a intenção dos autores na fase de planejamento, pois no tradicional esta é uma única grande fase no início do desenvolvimento e no APM uma ação repetida em intervalos iguais de tempo.

Observou-se que o modelo utiliza essencialmente práticas ágeis e, deste modo, não se diferencia de outros métodos ágeis. Foram identificas práticas ágeis como o desenvolvimento iterativo, e artefatos, como o user stories e backlog. Mas, com a exceção das fases de desenvolvimento e da documentação do projeto, não foram encontradas outras práticas tradicionais que permitiram discutir a combinação. 


\subsubsection{Modelo referencial ágil para grandes projetos}

Amaral et al. (2011) elaboraram um modelo referencial para a abordagem de gerenciamento ágil para ser aplicado para produtos manufaturados, além do software. Apesar de ser um modelo assumido como ágil, os autores propõem o uso deste modelo de maneira combinada com um processo de planejamento tradicional nos casos em que o produto é complexo como grandes equipamentos, automóveis, entre outros.

Nesta proposta de destaca-se, primeiro, a recomendação de elaborar a visão do produto e, posteriormente, a utilizar um planejamento em vários níveis. Propõe-se que uma equipe gerencial do projeto empregue ferramentas tradicionais de cronograma para preparar o plano completo contendo o produto final e as principais entregas, elaborados para possuir o maior grau de independência possível e interfaces bem delimitadas. Os membros da equipe gerencial devem ser alocados para a coordenação de equipes operacionais.

Também, a divisão das entregas entre as equipes ágeis. Cada entrega deve ser desenvolvida por uma equipe ágil, sendo desdobra em atividades e descritas em um plano iterativo.

Em suma, a proposta dos autores é combinar equipes ágeis com os métodos e técnicas tradicionais, como o modelo de referência para o desenvolvimento de produtos e a decomposição do projeto por meio da Work Breakdown Structure (WBS), conforme representada esquematicamente na Figura 15.

Utilizar duas equipes traz desafios para o desenvolvimento que não são debatidos pelos autores. O pressuposto do modelo é que as entregas podem ser identificadas e dividas para equipes ágeis e tradicionais de acordo com o nível de incerteza ou a probabilidade de mudança. Essa divisão nem sempre é possível nas fazes iniciais do projeto, porque requer informações precisas sobre os pacotes de trabalho normalmente não disponíveis.

Os autores não citam como gerenciar as diferenças entre as equipes de projeto. Caso ambos times ágeis e tradicionais estiverem desenvolvendo o mesmo produto, eles podem entregar artefatos totalmente diferentes que podem não ser fáceis de integrar (BOEHM; TURNER, 2005). Isso poderia gerar retrabalho e conflitos entre as equipes. 


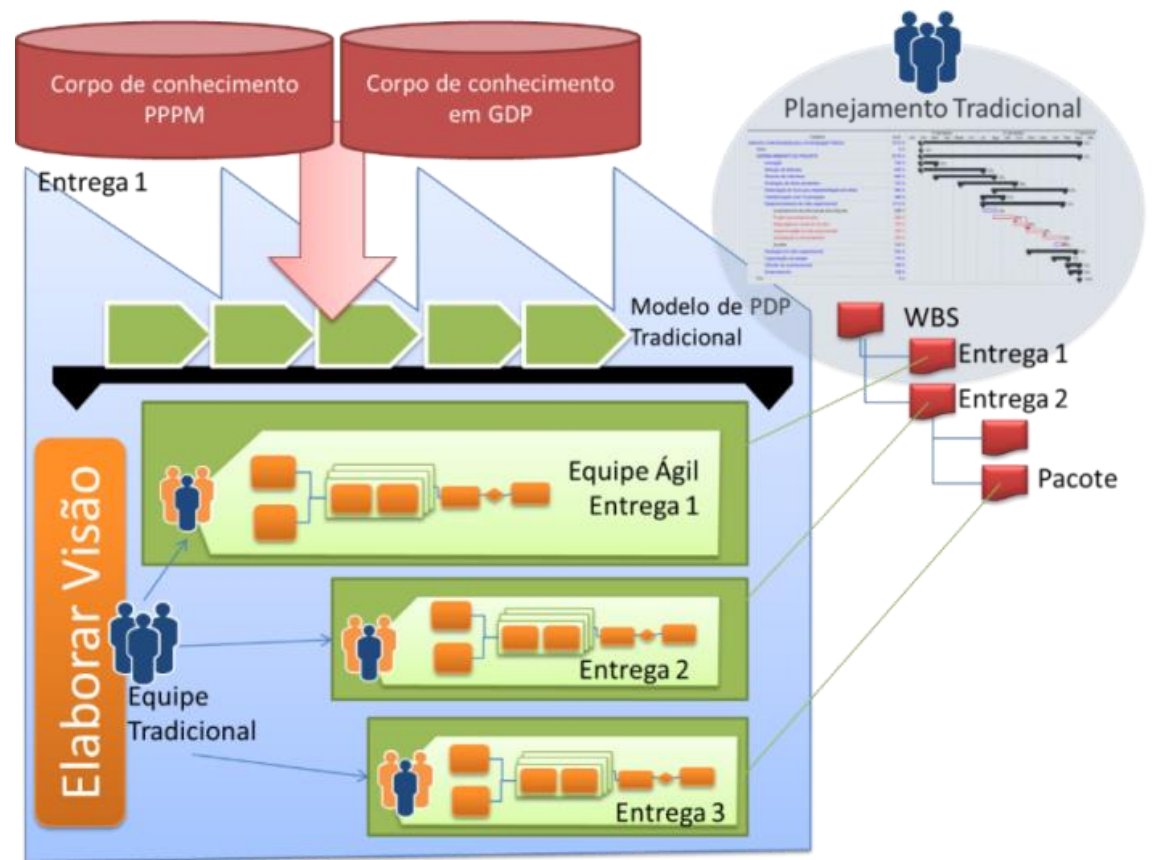

Figura 15 - Uso do modelo referencial no caso de projetos grandes Fonte: Amaral et al. (2011, p.52)

Outra limitação é que não há detalhes de como construir os planos de projeto. Os autores sugerem utilizar o modelo de referência e a WBS no início do projeto, mas não detalham o procedimento de criação dos planos. Também, não há a discussão de como atualizar esses planos, visto que as equipes ágeis e tradicionais podem gerar resultados diferentes dificultando a atualização e controle do projeto.

\subsubsection{Tragile}

Seyam e Galal-Edeen (2011) propõem um framework como o intuito de combinar diretrizes e práticas do Tradicional com práticas e princípios Ágeis apresentada na Figura 16.

A primeira fase consiste na Seleção da Metodologia. Os autores incorporam o Risk Approach, Boehm e Turner (2003), com o objetivo de aprimorar o conhecimento da situação do projeto e organização e ajudar na escolha da abordagem de desenvolvimento, tradicional, ágil ou híbrida. Uma vez identificado o híbrido, executa-se o próximo passo do framework. 


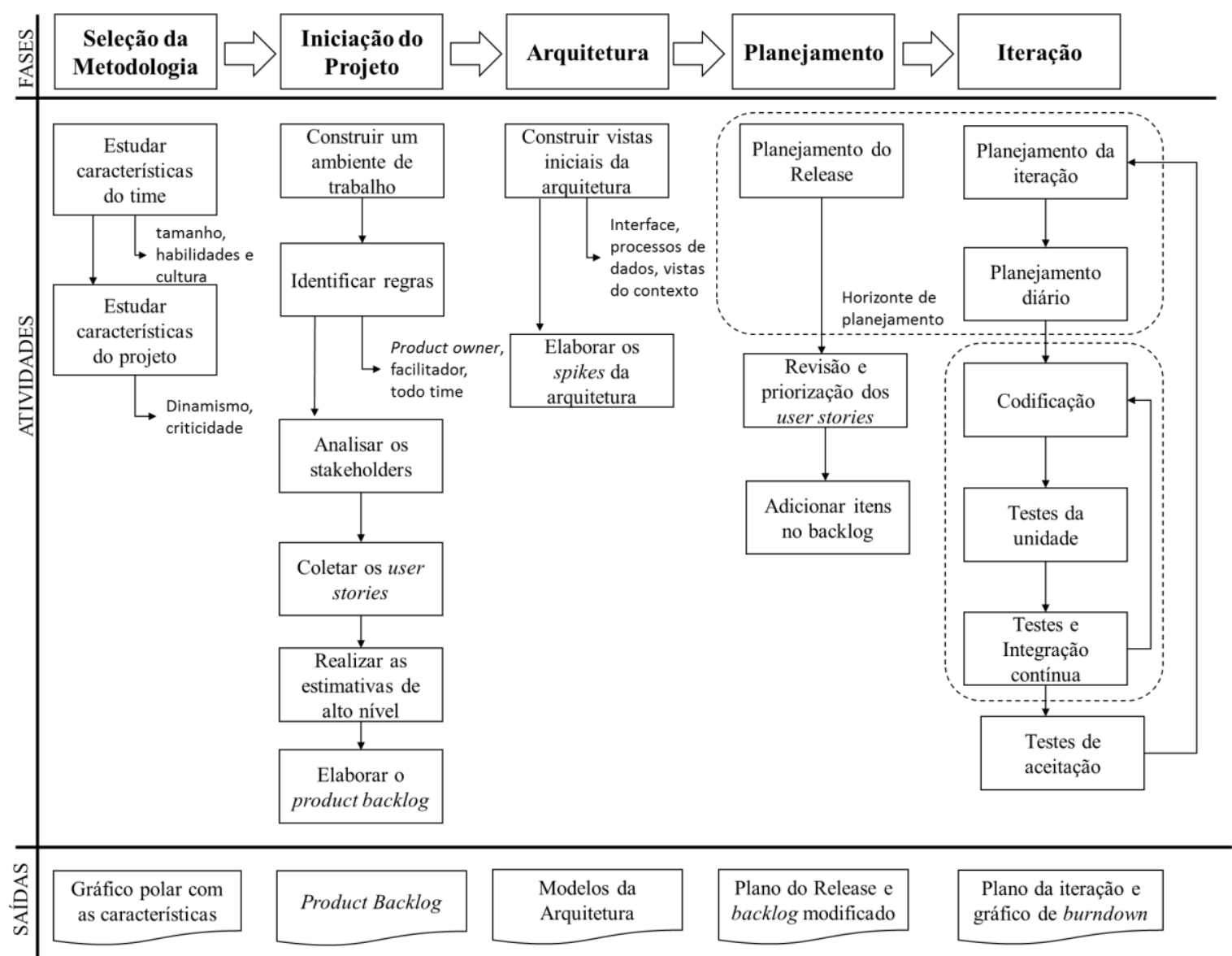

Figura 16 - Diagrama proposto para o framework Tragile. Fonte: Seyam e Galal-Edeen (2011), traduzido pelo autor.

A fase de iniciação do projeto consiste na execução das atividades preliminares. Construir ou organizar o ambiente de físico de trabalho. Identificar regras dos participantes do processo de desenvolvimento como o Product Owner e o facilitador das atividades. Analisar os stakeholders utilizando o personas, onde existe a representação de um grupo específico para definir os usurários do sistema e os respectivos requisitos. Coletar os user stories que devem incluir os requisitos que representam o valor do negócio para o usuário da forma mais simples possível. Realizar as estimativas de alto nível para esclarecer o escopo dos requisitos escritos em forma de user stories. E elaborar o product backlog onde todos os requisitos são listados e priorizados.

$\mathrm{Na}$ fase de Arquitetura, todo o time elabora um simples modelo que contêm os requisitos do sistema. Recomenda-se utilizar quadros brancos ou páginas Wiki para construíla com o intuito de garantir a simplicidade e permitir modificações e atualizações posteriormente no desenvolvimento. 
O Planejamento é dividido em três níveis, Release, Iteração e o Diário. Os autores explicam que nessa fase existe a elaboração do roadmap com as atividades ao longo de todo o desenvolvimento.

O planejamento do Release inclui duas atividades principais. A primeira é revisar e priorizar os user stories, onde decide-se quais stories serão desenvolvidos levando em consideração a entrega de valor. O segundo é adicionar itens ao backlog, quando identificados pela equipe e clientes. A principal saída é a descrição de alto nível do backlog incluindo as estimativas sobre o tempo e esforço de cada item e o plano de alto nível do produto.

O equipe de projeto prossegue para o planejamento da Iteração. Nesse há o desmembramento dos itens selecionados do product backlog em atividades de desenvolvimento. As estimativas feitas no Release são revisadas, sendo elaboradas estimativas mais precisas para cada atividade quando necessário. As atividades são elaboradas para no máximo para duas iterações. A entrega principal é o plano de iteração contendo as atividades da iteração.

O planejamento Diário utiliza as mesmas três perguntas do Scrum para monitorar o progresso e verificar impedimentos no desenvolvimento, conforme o mostrado na seção 2.2.

Logo, não há muitas em diferenciação para o Ágil no planejamento. A exceção é a sugestão de utilizar uma duração de iteração flexível e decidida pelo time, ou seja, pode variar de acordo com a necessidade do projeto. O APM adota durações iguais para todas as iterações.

Após o planejamento, executa-se as atividades operacionais do desenvolvimento. Na codificação, emprega-se padrões de códigos, refactoring e o pair programming para melhorar a qualidade. Os testes são realizados em três etapas. Na unidade para assegurar que um modulo particular cumpra a função pretendida. Na integração entre os módulos. Por fim, na aceitação, onde a funcionalidade de todo o sistema é avaliada pelo product owner e cliente.

O framework proposto é implementado em um estudo de caso. A empresa escolhida é pioneira e líder do ramo de sistemas e tecnologia para a língua Arábica. O projeto analisado consistia na criação de uma ferramenta para auxiliar os desenvolvedores internos a lidar com as palavras Arábicas. O time de desenvolvimento era composto de quatro pessoas.

O Risk Approach foi utilizado na primeira etapa para avaliar o ambiente de projeto. O time de desenvolvimento não atingiu o nível necessário para adotar o Ágil em razão da necessidade de habilidades específicas para esta abordagem. A cultura foi avaliada e 
caracterizada como tradicional em virtude da hierarquização do processo de desenvolvimento. O Risk Approach possui outras três dimensões críticas a serem medidas, tamanho, criticidade para a organização e dinamismo do ambiente, mas não foi identificada a discussão dessas outras três dimensões.

A principal crítica ao Tragile é que foram identificadas apenas diferenças sutis para o APM. A incorporação de uma arquitetura de alto nível, a documentação de importantes artefatos e a sugestão de utilizar durações diferentes para as iterações são elementos diferenciais desse método.

Os autores justificam a escolha do Tragile apenas nas duas primeiras dimensões, não decorrem de outras características do projeto para a escolha do híbrido. Portanto, os resultados e problemas levantados pelos autores são questionáveis para trazer indícios concretos para a combinação de práticas ágeis e tradicionais.

\subsubsection{Disciplined Agile Delivery}

O Disciplined Agile Delivery que consiste em um método que combina elementos de métodos ágeis como XP, Scrum, Lean Software Develpment, entre outros, com um ciclo de vida de desenvolvimento (AMBLER, 2013). O método é ilustrado na Figura 17 e apresenta três fases: Inception, Construction e Transition.

A fase Inception assemelha-se como o Up-front que inicia os projetos de forma geral com uma ou mais iterações. Os objetivos estabelecidos para essa fase consistem em: formar o time inicial; desenvolver a visão comum do projeto; alinhar o projeto com a direção do negócio; explorar o escopo inicial; identificar a estratégia técnica inicial; desenvolver o plano de release inicial; formar o ambiente de trabalho; identificar os riscos; e, garantir financiamento.

A fase de Construção (Constrution) é similhar ao Sprint Backlog do método Scrum e não foram encontradas diferenças entre os dois. Os objetivos dessa fase são: produzir uma solução potencialmente consumível; melhorar a qualidade; verificar a arquitetura cedo; identificar mudanças nas necessidades dos stakeholders.

A fase final do método consiste na Transição (Transition). Esta fase possui dois objetivos principais: garantir a solução está de acordo com os requisitos do cliente; e, implementar solução. 
Ao analisar o método, foram identificadas quatro diferenças principais entre o método e a gestão Ágil. A primeira é a definição do ciclo de vida de desenvolvimento com fases e objetivos claros. A segunda diferença apresenta-se na fase de Inception, que se assemelha com o Up-front de desenvolvimento tradicional, iniciando o projeto, estabelecendo o time de projeto, a visão comum, identificando de riscos e explorando o escopo inicial. A terceira diferença é a consideração da documentação como entrega do projeto, por exemplo, toda a documentação necessária para satisfazer uma lei regulatória. A quarta diferença é a formalização da governança do projeto por meio do estabelecimento de responsabilidades, autoridade, comunicação e suporte para a estratégia da empresa. 


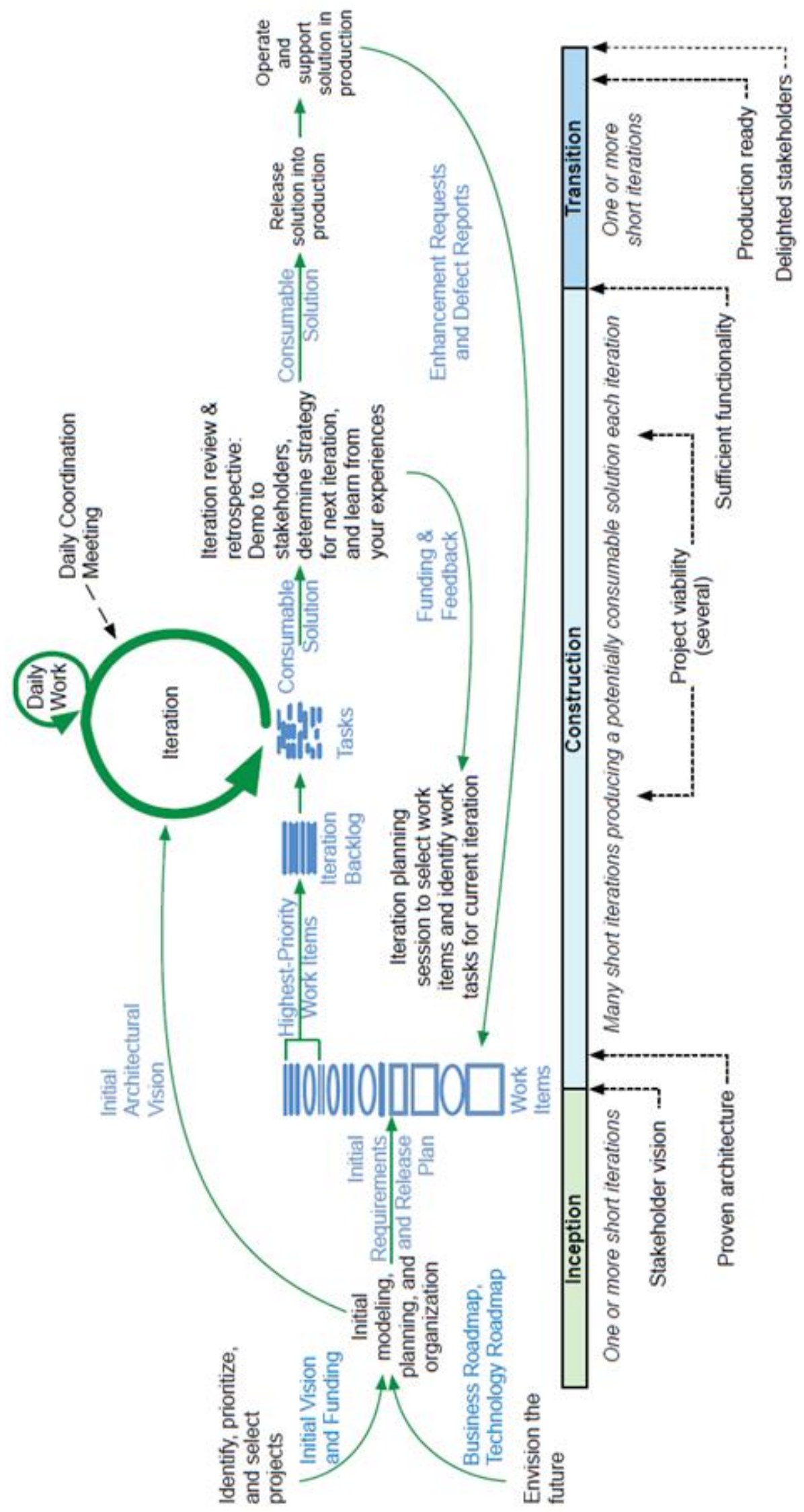

Figura 17 - Ciclo de vida do DAD

Fonte: Ambler (2013) 


\subsubsection{Modelo Cocktail para a gestão de projetos}

O modelo Cocktail para a gestão de projetos é o resultado de uma correlação entre os cinco grupos de processos, iniciação, planejamento, implementação, controle e fechamento, da ISO 21500 de gestão de projetos e princípios contidos do Manifesto Ágil (BINDER; AILLAUD; SCHILLI, 2014). A Figura 18 apresentada o modelo, que combina a gestão tradicional, baseado no modelo de desenvolvimento de software Waterfall, e a gestão ágil de projetos.

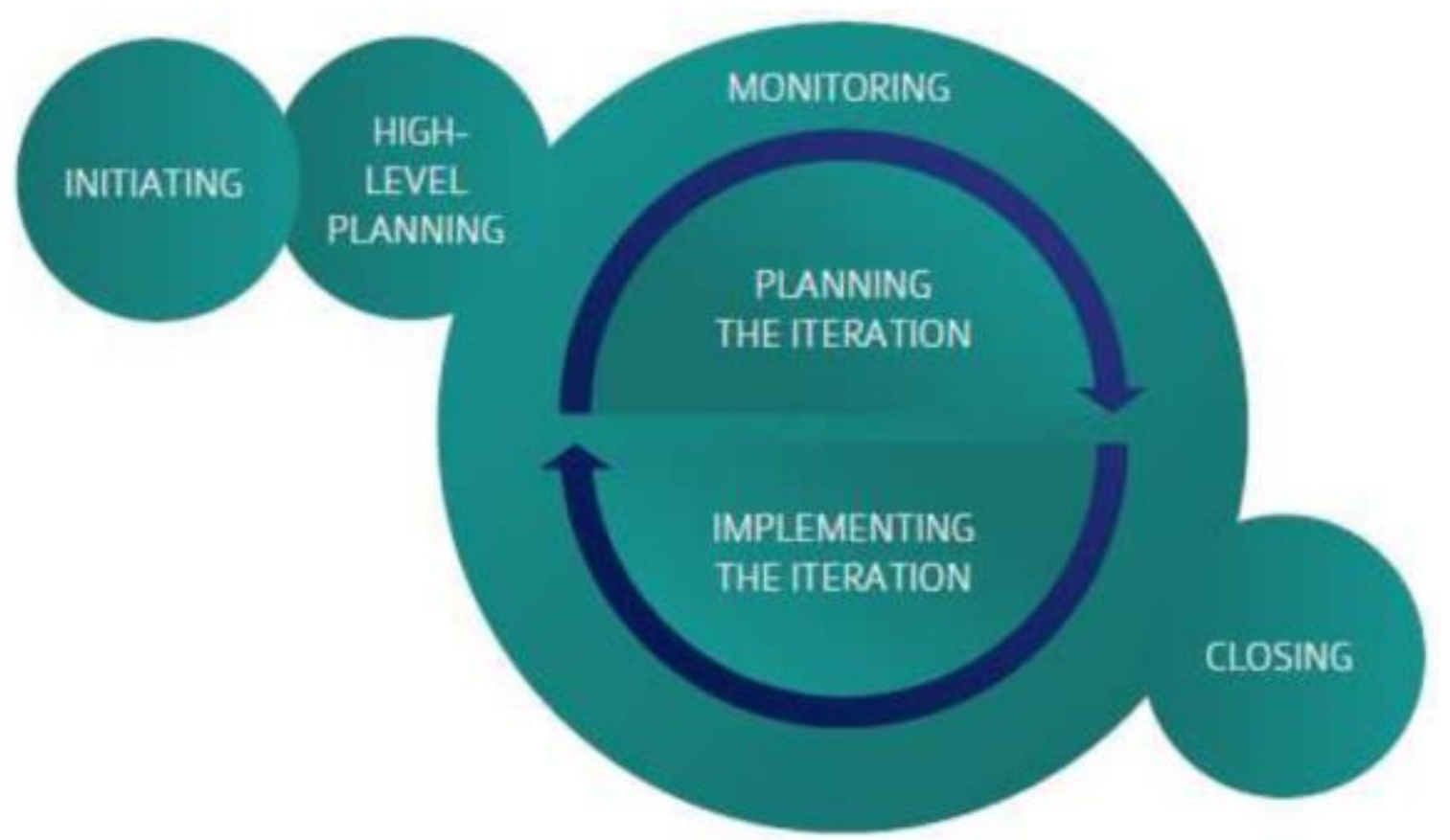

Figura 18 - Modelo Cocktail para a gestão de projetos Fonte: Binder, Aillaud e Schilli (2014).

No modelo destacam-se duas diferenças principais que remetem a combinação das práticas ágeis e tradicionais, sendo que a primeira ocorre na fase de iniciação e planejamento de alto nível (initiating e high-level planning) e a outra na planejar e implementar a iteração (planning the iteration e implementing the iteration).

Na fase de iniciação e de planejamento de alto nível, há a recomendação de utilizar técnicas tradicionais para a elaboração do plano inicial, como definição do escopo, criação da WBS, estimação de recursos e custos, sequenciamento de atividades e elaboração do cronograma. A diferença consiste em elaborar o plano inicial de alto nível de detalhamento ao invés de detalhar o plano de projeto no inicio, como ocorre no tradicional. Por exemplo, a elaboração do cronograma de projeto leva em consideração os principais marcos ou 
milestones, principais funcionalidades e o escopo de alto nível. A definição das atividades de projeto também ocorre em alto nível.

Nas fases de planejar e implementar a iteração, é indicado adotar o desenvolvimento iterativo e entregas parciais do produto. As atividades identificadas inicialmente em alto nível são priorizadas e detalhadas durante as iterações. Não foi identificado diferenças para as práticas da gestão Ágil. No entanto, o plano de projeto é atualizado em cada iteração e verifica-se a consistência deste com o status do projeto.

Binder, Aillaud e Schilli (2014) apresentam várias recomendações para combinar as práticas, no entanto não apresentam o como implementar as recomendações de forma sistemática. O modelo apresenta as fases, mas, por exemplo, não trata como o cronograma de alto nível se relaciona com as atividades desenvolvidas durante as iterações. Além disso, não foi identificado como atualizar o planejamento do projeto no caso do plano de alto nível não for condizente com a realidade ou houver mudanças no escopo do produto, por exemplo.

\subsubsection{Framework Scrum para o desenvolvimento de produtos}

O framework é o resultado de uma investigação sobre a implementação do Scrum em cinco empresas industriais, por exemplo, turbinas de vento e válvulas e sensores (SOMMER et al., 2015). A Figura 19 apresenta o framework, onde a proposta é combinar a estrutura de fases de desenvolvimento de produtos Stage-Gate ${ }^{\circledR}$ com a execução do projeto por meio do Scrum.

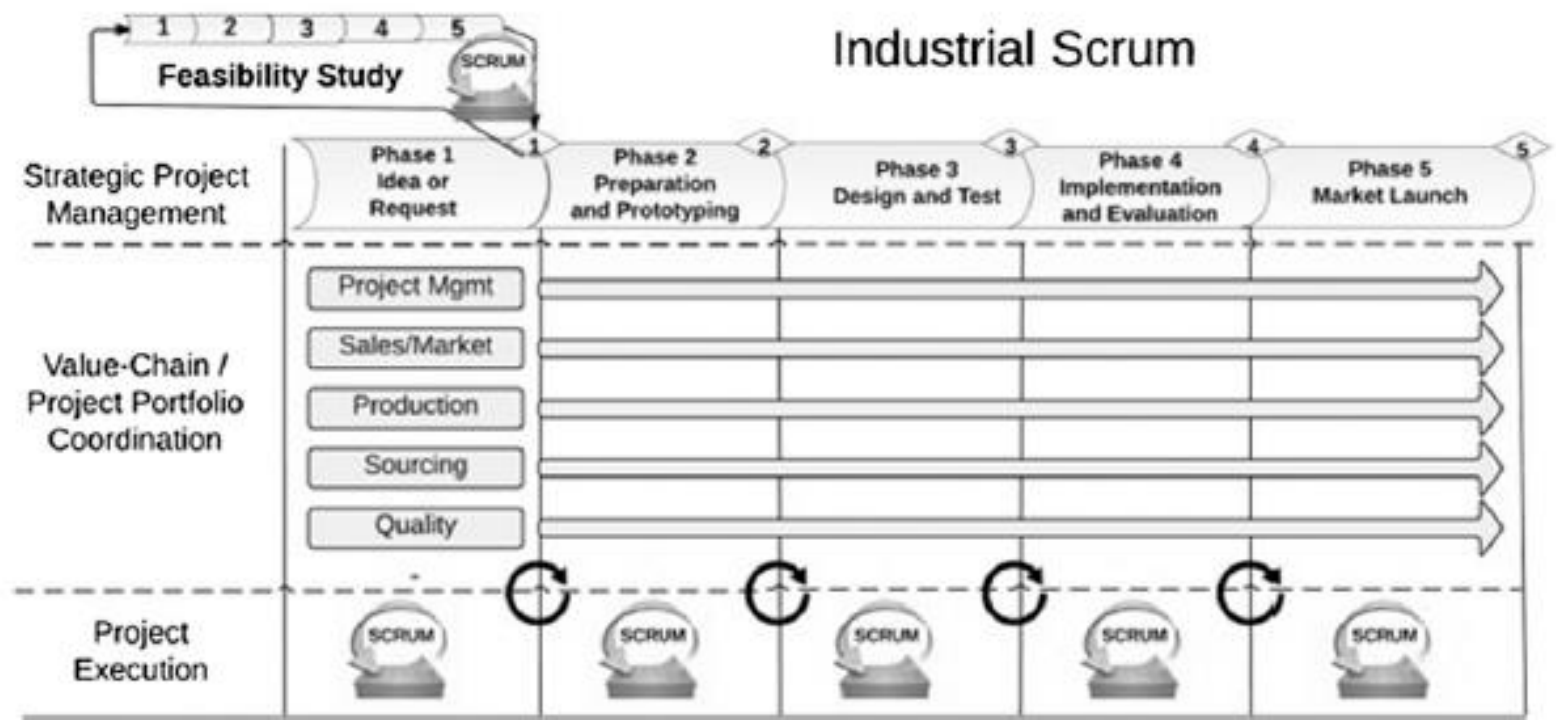

Figura 19 - Framework Scrum para o desenvolvimento de produtos Fonte: Sommer et al. (2015) 
Destacam-se três pontos fundamentais relacionados com a combinação de práticas ágeis e tradicionais: (1) três níveis de planejamento; (2) estudo de viabilidade; e (3) estrutura organizacional.

O framework apresenta três níveis de planejamento. A gestão estratégica do projeto é o primeiro nível que corresponde à gestão do portfolio do produto e é coordenado pelo Steering Committee. O Value-Chain/project portfolio coordination é o nível intermediário. O foco é o planejamento de recursos do projeto e compartilhamento de conhecimentos entre os times de projeto. A coordenação dos recursos entre os times de projeto é realizada por meio de quadros visuais. O terceiro nível é a execução do projeto usando o método Scrum.

No inicio do desenvolvimento do produto, o processo chamado de estudo de viabilidade (Feasibility Study) é executado pelo time Scrum em conjunto com os principais stakeholders dos departamentos. O processo objetiva a aumentar o entendimento sobre o produto, refinando a Visão e desenvolvendo o Product Backlog inicial e protótipos. Após a criação da visão, inicia-se o planejamento para as outras fases do desenvolvimento.

O framework apresenta uma recomendação de estrutura organizacional do time de projeto. Os principais papeis são (SOMMER et al., 2015):

- Steering committee: responsável pela tomada de decisão estratégica do projeto, que incluem o orçamento do projeto, mudanças no escopo do produto e alocação de recursos;

- Gerente de projetos: responsável pela comunicação com todos os participantes, solicitar recursos para os stakeholders do projeto e prover inputs para o time Scrum;

- Business manager: atua com a voz do consumidor, provendo conhecimentos detalhados sobre as necessidades do consumidor e comunica-se diretamente com os consumidores envolvidos no projeto.

- Time de projeto: responsável pela execução de ações direcionadas pelas decisões estratégicas feitas pelo Steering committee.

- Grupo de gestão de portfolio de projetos: responsável pela distribuição estratégica dos recursos dentre os projetos do portfolio.

No framework foram identificadas praticas ágeis, tais como a Visão do produto, elaboração do Product Backlog, o desenvolvimento iterativo e quadros visuais, e práticas 
tradicionais como o Steering committee, gestão de recursos, Modelo de referência. No entanto, não foi identificado como é realizada a integração entre os níveis de planejamento para a atualização do projeto, por exemplo, e como o cliente é envolvido nas fases de desenvolvimento, com exceção do estudo de viabilidade. Também, não há uma definição de quais práticas ágeis devem ser adotadas e como estas interagem com os outros níveis de planejamento.

\subsection{Análise das propostas de combinação}

O objetivo dessa seção é discutir as propostas de combinação descritas na seção 3.5 em um nível maior de detalhes, utilizando uma análise qualitativa para identificar o conjunto de práticas ágeis e tradicionais recomendadas em cada proposta.

A análise qualitativa adotou o trabalho de Eder et al. (2014) como critério de avaliação. O trabalho apresenta uma RBS para classificar as práticas recomendadas em cada abordagem em ferramentas, ações e técnicas, resultando na lista apresentada no Anexo A. Também, investigaram as principais diferenças entre as abordagens. $\mathrm{O}$ resultado é a lista de seis características primordiais que diferem as abordagens, indicadas no Quadro 7.

A análise qualitativa utilizou a lista de práticas e as seis características. A lista de práticas foi usada para caracterizar as ações, ferramentas e técnicas apresentadas em cada proposta. As seis características foram empregadas como critérios para analisar as propostas de combinação, distinguir quais as práticas que estavam sendo combinadas e classificar as práticas em ágil ou tradicional. Assim, descreve-se a análise de cada proposta.

O Risk Approach foi compreendido como um método de diagnóstico cujo objetivo é identificar riscos associados ao ambiente de desenvolvimento do projeto e escolha da abordagem de gestão. Deste modo, o Risk Approach não apresenta detalhes sobre como combinar as abordagens de gestão de projetos. 
Quadro 7 - Características para identificação da abordagem de gerenciamento de projeto utilizada por uma organização

\begin{tabular}{|c|c|c|}
\hline CARACTERÍSTICA & TRADICIONAL & ÁGIL \\
\hline $\begin{array}{l}\text { 1) Elaboração do plano do projeto } \\
\text { (Plano) }\end{array}$ & $\begin{array}{l}\text { Único plano de projeto, que } \\
\text { abrange o tempo total do projeto e } \\
\text { contêm os produtos, entregas, } \\
\text { pacotes de trabalho e atividades. }\end{array}$ & $\begin{array}{l}\text { Há dois planos de projeto: a) plano } \\
\text { geral que considera o tempo total } \\
\text { de duração do projeto e apenas os } \\
\text { produtos principais; b) plano de } \\
\text { curto prazo que contém apenas as } \\
\text { entregas e atividades referentes a } \\
\text { uma fração de tempo do projeto } \\
\text { (iteração). }\end{array}$ \\
\hline $\begin{array}{l}\text { 2) forma como se descreve o } \\
\text { escopo do projeto (Escopo) }\end{array}$ & $\begin{array}{l}\text { Descrição exata do resultado final } \\
\text { por meio de texto com normas do } \\
\text { tipo contratuais, números objetivos } \\
\text { e indicadores de desempenho. }\end{array}$ & $\begin{array}{l}\text { Descrição do resultado final de } \\
\text { maneira abrangente, desafiadora, } \\
\text { ambígua e metafórica. }\end{array}$ \\
\hline $\begin{array}{l}\text { 3) nível de detalhe e padronização } \\
\text { com que cada atividade do projeto } \\
\text { é definida (Atividades) }\end{array}$ & $\begin{array}{l}\text { As atividades são descritas de } \\
\text { maneira padronizada e organizadas } \\
\text { em listas do tipo WBS. Contêm } \\
\text { código e são classificadas em } \\
\text { conjuntos de pacotes de trabalho, } \\
\text { entregas e produto do projeto. }\end{array}$ & $\begin{array}{l}\text { Não há um padrão para a descrição } \\
\text { das atividades, que podem ser } \\
\text { escritas na forma de estórias, } \\
\text { problemas, ações ou entregas. E } \\
\text { não há uma tentativa de } \\
\text { organização, apenas a priorização } \\
\text { do que deve ser executado no } \\
\text { momento. }\end{array}$ \\
\hline $\begin{array}{l}\text { 4) horizonte de planejamento das } \\
\text { atividades da equipe de projeto } \\
\text { (Horizonte) }\end{array}$ & $\begin{array}{l}\text { As listas de atividades são válidas } \\
\text { para o horizonte total do projeto. }\end{array}$ & $\begin{array}{l}\text { As listas de atividades são válidas } \\
\text { para uma iteração, que é definida } \\
\text { como uma fração do tempo total do } \\
\text { projeto. }\end{array}$ \\
\hline $\begin{array}{l}\text { 5) estratégia utilizada para o } \\
\text { controle do tempo do projeto } \\
\text { (Tempo) }\end{array}$ & $\begin{array}{l}\text { Empregam-se relatórios com } \\
\text { indicadores de desempenho, } \\
\text { documentos escritos, auditorias e } \\
\text { análises de transições de fase. As } \\
\text { reuniões da equipe não são } \\
\text { frequentes. }\end{array}$ & $\begin{array}{l}\text { Empregam-se dispositivos visuais } \\
\text { que indicam entregas físicas do } \\
\text { resultado final (cartazes, auto- } \\
\text { adesivos etc.). As reuniões são } \\
\text { curtas e frequentes. }\end{array}$ \\
\hline $\begin{array}{l}\text { 6) estratégia utilizada para a } \\
\text { garantia do atingimento do escopo } \\
\text { do projeto (Garantia) }\end{array}$ & $\begin{array}{l}\text { O gerente de projeto avalia, } \\
\text { prioriza, adiciona ou altera as } \\
\text { atividades do projeto para que os } \\
\text { resultados estejam em } \\
\text { conformidade com o escopo do } \\
\text { projeto assinado com o cliente. }\end{array}$ & $\begin{array}{l}\text { O cliente avalia, prioriza, adiciona } \\
\text { ou altera o produto final do projeto, } \\
\text { conforme a experiência com os } \\
\text { resultados alcançados. A equipe } \\
\text { altera as atividades para obter os } \\
\text { resultados propostos pelo cliente. }\end{array}$ \\
\hline
\end{tabular}

Fonte: Eder et al. (2014)

XPrince apresentou três características, duas classificadas como tradicionais e outra ágil. O método indica que o plano de projeto deve apresentar todos os releases, funcionalidades principais, prover uma perspectiva ampla do projeto e o responsável pela elaboração do plano é o gerente de projeto. Deste modo, o Plano e o horizonte de planejamento foram classificados como tradicionais. Na fase de Release e o código é escrito, os testes são executados e há avaliação de aceitação pela gerencia do projeto, de forma similar ao XP. A partir disso, a estratégia de controle de tempo foi entendida como ágil. Não foram identificados detalhes sobre como definir o escopo, definir as atividades de projeto e como garantir o escopo. Outras práticas identificadas no método estão apresentadas no Quadro 8. 
Quadro 8 - Práticas do XPrince

\begin{tabular}{|ccc|}
\hline Prática & Tipo & Classificação \\
\hline $\begin{array}{c}\text { Identificar trabalho } \\
\text { necessário para o projeto }\end{array}$ & Ação & Ambas \\
\hline Business Case & Técnica & Tradicional \\
\hline Arquitetura do produto & Técnica & Ágil \\
\hline
\end{tabular}

O processo híbrido de metodologia de design não apresentou informações em relação às seis características, impossibilitando concluir a natureza da abordagem utilizada. As práticas apresentadas no Quadro 9 consistem na priorização de requisitos e arquitetura do produto, ambas classificadas como ágeis. Não há mais detalhes de atividades específicas, técnicas e ferramentas que auxiliariam a investigação sobre combinação.

Quadro 9 - Práticas do modelo de processo híbrido de metodologia de design

\begin{tabular}{|ccc|}
\hline Prática & Tipo & Classificação \\
\hline Priorizar requisitos & Ação & Ágil \\
\hline Arquitetura do produto & Técnica & Ágil \\
\hline
\end{tabular}

O framework Híbrido não apresentou informações sobre as três primeiras características, Plano, Escopo e Atividades, e as outras três foram assinaladas como ágeis. O estudo de caso utilizou um curto horizonte para o planejamento das atividades do projeto. A reunião diária foi utilizada como a estratégia de controle, conforme prescreve o método Scrum. A estratégia de atingimento do escopo foi a avaliação e feedback do cliente. Foram identificados, conforme Eder et al. (2014) e apresentado no Quadro 10, a técnica de Product Backlog, a ação de priorização de requisitos, ambos classificados como ágeis, e a técnica tradicional de reunião chamada de Steering committee. Assim, conclui-se que o framework apresenta características da Gestão Ágil. Faltam detalhes para afirmar se consiste ou não em uma combinação entre abordagens, como, por exemplo, a elaboração de planos de projeto e a atualização por meio de entregas incrementais.

Quadro 10 - Práticas do Framework Híbrido

\begin{tabular}{|ccc|}
\hline Prática & Tipo & Classificação \\
\hline $\begin{array}{c}\text { Controlar mudanças do } \\
\text { Escopo }\end{array}$ & Ação & Ágil \\
\hline Priorizar requisitos & Ação & Ágil \\
\hline Product Backlog & Técnica & Ágil \\
\hline Daily Scrum Meeting & Técnica & Ágil \\
\hline Reunião & Técnica & Ambas \\
\hline
\end{tabular}


No modelo de Processo híbrido disciplinado todas as características foram identificadas e classificadas como ágeis. Procedeu-se com a classificação das práticas para tentar identificar a proposta dos autores de combinação, conforme é apresentado no Quadro 11. Foram identificadas a ação de priorização de requisitos e as técnicas user stories, product backlog, daily meeting, arquitetura de alto nível do produto reunião retrospectiva, todos, também, ágeis. A ação de declaração problema ou oportunidade e estimar duração tempo e esforço, foram classificadas em ambas as abordagens. Logo, trata-se de uma abordagem ágil em virtude de todas as características apresentadas.

Quadro 11 - Práticas do Processo híbrido disciplinado

\begin{tabular}{|clc|}
\hline Prática & Tipo & Classificação \\
\hline Priorizar requisitos & Ação & Ágil \\
\hline $\begin{array}{c}\text { Declarar problema/ } \\
\text { oportunidade }\end{array}$ & Ação & Ambas \\
\hline $\begin{array}{c}\text { Estimar duração } \\
\text { tempo e esforço }\end{array}$ & Ação & Ambas \\
\hline User stories & Técnica & Ágil \\
\hline Product Backlog & Técnica & Ágil \\
\hline $\begin{array}{c}\text { Daily Scrum } \\
\text { meeting }\end{array}$ & Técnica & Ágil \\
\hline $\begin{array}{c}\text { Arquitetura do } \\
\text { Produto }\end{array}$ & Técnica & Ágil \\
\hline $\begin{array}{c}\text { Reunião } \\
\text { Retrospectiva }\end{array}$ & Técnica & Ágil \\
\hline
\end{tabular}

No modelo referencial ágil para grandes projetos todas as características foram identificadas. Os autores sugerem a elaboração de um único plano de projeto, conforme o tradicional. A ação de definição do escopo é realizada por meio da Visão do produto, de forma semelhante ao ágil. As atividades são definidas utilizando o padrão do modelo de referência baseado no Processo de Desenvolvimento de Produtos e WBS, característica associada ao tradicional. Os três últimos critérios foram classificados como ágeis. $\mathrm{O}$ planejamento é realizado de forma iterativa, com o detalhamento de atividades no curto horizonte de tempo. O controle do tempo é obtido por meio de reuniões curtas e frequentes. E a verificação atingimento do escopo é realizada utilizando o feedback do progresso e avaliação do cliente. As práticas mencionadas pelos autores estão sumarizadas no Quadro 12. 
Quadro 12 - Práticas do Modelo referencial ágil para grandes projetos

\begin{tabular}{|ccc|}
\hline Prática & Tipo & Classificação \\
\hline $\begin{array}{c}\text { Declarar problema/ } \\
\text { oportunidade }\end{array}$ & Ação & Ambas \\
\hline Definir atividades & Ação & Ambas \\
\hline $\begin{array}{c}\text { WBS/ } \\
\text { decomposição }\end{array}$ & Técnica & Ambas \\
\hline Quadros & Ferramenta & Ambas \\
\hline
\end{tabular}

Apesar de apresentar dois critérios tradicionais, não é possível inferir sobre a combinação das abordagens no modelo referencial ágil para grandes projetos. Os autores sugerem essa adaptação do modelo para utilizar as práticas ágeis em ambientes complexos, mas falta a descrição sobre como combinar. Mesmo assim, classifica-se a definição de pacotes de atividades como ação tradicional, a declaração do problema ou oportunidade e a decomposição das atividades/WBS como presente em ambas às abordagens.

No Tragile todas as características foram identificadas e classificadas como ágeis. As práticas foram identificadas no Quadro 13 e condizem a ação de priorizar requisitos e as técnicas user stories, product backlog, daily meeting e arquitetura de alto nível, e classificados como ágeis. A ferramenta de quadros, a ação de estimar duração tempo e esforço e a técnica de decomposição dos user stories, foram classificados como advindos de ambas as abordagens. Os quadros são recomendados pelos autores para a esquematização das arquiteturas visando permitir modificações e adições nas funcionalidades levantadas incialmente pela equipe de projeto.

Logo, foram identificadas apenas diferenças sutis entre o Tragile e o APM, realçadas com a classificação de Eder et al. (2014). A incorporação de uma arquitetura de alto nível, a documentação de importantes artefatos e a sugestão de utilizar durações diferentes para as iterações são elementos diferenciais desse método, o que não parece suficiente para trata-lo como algo diferente de um método ágil. 
Quadro 13 - Práticas do Tragile

\begin{tabular}{|ccc|}
\hline Prática & Tipo & Classificação \\
\hline Priorizar requisitos & Ação & Ágil \\
\hline $\begin{array}{c}\text { Estimar duração } \\
\text { tempo e esforço }\end{array}$ & Ação & Ambas \\
\hline User stories & Técnica & Ágil \\
\hline Product Backlog & Técnica & Ágil \\
\hline $\begin{array}{c}\text { Daily Scrum } \\
\text { meeting }\end{array}$ & Técnica & Ágil \\
\hline $\begin{array}{c}\text { Arquitetura do } \\
\text { Produto }\end{array}$ & Técnica & Ágil \\
\hline $\begin{array}{c}\text { Reunião } \\
\text { Retrospectiva }\end{array}$ & Técnica & Ágil \\
\hline $\begin{array}{c}\text { WBS/ } \\
\text { decomposição }\end{array}$ & Técnica & Ambas \\
\hline Quadro & Ferramenta & Ambas \\
\hline
\end{tabular}

O Diciplined Agile Delivery apresentou todas as seis características e classificadas como ágeis. Foram identificados outros elementos que diferem o método da gestão Ágil, a incorporação de ciclo de vida de projeto, documentação e formalização da governança do projeto. Apesar desses elementos, foi considerado que não há a indicação de combinação entre abordagens de gestão de projetos. O Quadro 14 apresenta as práticas identificadas no método.

Quadro 14 - Práticas do Diciplined Agile Delivery

\begin{tabular}{|ccc|}
\hline Prática & Tipo & Classificação \\
\hline $\begin{array}{c}\text { Definir escopo do } \\
\text { projeto }\end{array}$ & Ação & Ambas \\
\hline Sprint Backlog & Técnica & Ágil \\
\hline Product Backlog & Técnica & Ágil \\
\hline $\begin{array}{c}\text { Arquitetura do } \\
\text { Produto }\end{array}$ & Técnica & Ágil \\
\hline $\begin{array}{c}\text { Daily Scrum } \\
\text { Meeting }\end{array}$ & Técnica & Ágil \\
\hline $\begin{array}{c}\text { WBS/ } \\
\text { decomposição }\end{array}$ & Técnica & Ambas \\
\hline
\end{tabular}

No modelo Cocktail foram identificadas cinco características, duas ágeis e três tradicionais, indicando a combinação. O plano, o escopo e as atividades são definidos a partir de técnicas tradicionais como definição do escopo, criação da WBS, estimação de recursos e custos, sequenciamento de atividades e elaboração do cronograma. No modelo há a recomendação que as mudanças no escopo, por exemplo, que devem ser aprovadas pelos principais stakeholders e ocorre a priorização das atividades durante a iteração, ambas 
ocorrem de forma semelhante ao ágil. Assim, o controle do tempo e a garantia do escopo foram considerados ágeis. Não foram identificados detalhes referentes ao horizonte de planejamento do projeto. O Quadro 15 apresenta a síntese das práticas recomendadas no modelo.

Quadro 15 - Práticas do Modelo Cocktail

\begin{tabular}{|clc|}
\hline Prática & Tipo & Classificação \\
\hline $\begin{array}{c}\text { Definir o escopo } \\
\text { do projeto }\end{array}$ & Ação & Ambas \\
\hline $\begin{array}{c}\text { Estimas recursos } \\
\text { das atividades }\end{array}$ & Ação & Ambas \\
\hline $\begin{array}{c}\text { Sequenciar as } \\
\text { atividades }\end{array}$ & Ação & Tradicional \\
\hline $\begin{array}{c}\text { Desenvolver o } \\
\text { cronograma }\end{array}$ & Ação & Tradicional \\
\hline $\begin{array}{c}\text { WBS/ } \\
\text { decomposição }\end{array}$ & Técnica & Ambas \\
\hline
\end{tabular}

Framework Scrum para o desenvolvimento de produtos apresenta três características. Os três níveis de planejamento é uma combinação entre o processo tradicional, com Gates e planejamento de recursos, e o planejamento do Sprint. Logo, o Plano possui práticas relacionadas tanto com o tradicional quanto com o ágilm, sendo, assim, classificado como um mix. Durante o estudo de viabilidade, o escopo do produto é descrito usando a Visão do produto, assim permite classificar o Escopo como ágil. Após definir a visão, o Product Backlog é desenvolvido com a lista inicial de atividades do projeto, deste modo, a definição das Atividades é classificada como ágil. Por outro lado, o framework não apresenta como priorizar o Product Backlog e nem como envolver o cliente no processo. Também, não apresenta informações sobre o Horizonte, Tempo e Garantia. O Quadro 16 apresenta a síntese das práticas recomendadas no framework Scrum.

Quadro 16 - Práticas do framework Scrum para o desenvolvimento de produtos

\begin{tabular}{|ccc|}
\hline Prática & Tipo & Classificação \\
\hline $\begin{array}{c}\text { Estimar os recursos } \\
\text { das atividades }\end{array}$ & Ação & Ambas \\
\hline Product Backlog & Técnica & Ágil \\
\hline Sprint Backlog & Técnica & Ágil \\
\hline Reunião & Técnica & Ambas \\
\hline Quadro & Ferramenta & Ambas \\
\hline Protótipo & Ferramenta & Ambas \\
\hline
\end{tabular}


A Quadro 17 apresenta a síntese da análise relacionando as nove propostas de combinação e as seis características de Eder et al. (2014). A análise do quadro permite concluir que as propostas de Boehm e Turner (2003), Nawrocki et al. (2006), Batra et al. (2010) e Rahimian e Ramsin (2007) descrevem poucas características que não possibilita inferir como combinar práticas de gestão de projetos. As propostas de Zark e Moawad (2010), Seyam e Galal-Edeen (2011) e Ambler (2013) pouco se diferenciam da gestão ágil, sendo as principais diferenças dessas propostas a incorporação de um processo de desenvolvimento e a documentação de importantes artefatos. Amaral et al. (2011) e Binder, Aillaud e Schilli (2014) e Sommer et al. (2015) trazem uma recomendação mais específica, onde utiliza-se o plano de projeto tradicional e o planejamento iterativo ágil, embora as propostas não apresentem detalhes sobre como combinar.

Portanto, de maneira geral, considera-se que as propostas estão em uma fase conceitual. Nenhuma das dez propostas de combinação apresentou um procedimento sistemático que indique como combinar as práticas de ambas as abordagens. Os autores não estabelecem exatamente os passos, ordem ou quais práticas combinar. Além disso, não foram encontradas referências que descrevam a aplicação das propostas. Portanto, existe uma lacuna em relação aos procedimentos que combinam o Ágil e Tradicional.

Quadro 17 - Síntese da análise das propostas de combinação

\begin{tabular}{|c|c|c|c|c|c|c|}
\hline & \multirow{2}{*}{\multicolumn{6}{|c|}{ Seis características de EDER et al. (2014) }} \\
\hline & & & & & & \\
\hline & Plano & Escopo & Atividades & Horizonte & Tempo & Garantia \\
\hline \multicolumn{7}{|l|}{ Risk Approach (BOEHM; TURNER, 2003) } \\
\hline XPrince (NAWROCKI et al., 2006) & $\mathrm{T}$ & & & $\mathrm{T}$ & A & \\
\hline \multicolumn{7}{|l|}{$\begin{array}{l}\text { Processo hibrido de metodologia de Design } \\
\text { (RAHIMIAN; RAMSIN, 2007) }\end{array}$} \\
\hline Framework Híbrido (BATRA et al., 2010) & A & A & A & & & \\
\hline $\begin{array}{l}\text { Modelo de Processo Híbrido Disciplinado } \\
\text { (ZAKI; MOAWAD, 2010) }\end{array}$ & A & A & A & A & A & A \\
\hline $\begin{array}{l}\text { Modelo referencial ágil para grandes projetos } \\
\text { (AMARAL et al., 2011) }\end{array}$ & $\mathrm{T}$ & A & $\mathrm{T}$ & A & A & A \\
\hline Tragile (SEYAM; GALAL-EDEEN, 2011) & A & A & A & A & A & A \\
\hline Disciplined Agile Delivery (AMBLER, 2013) & A & A & A & A & A & A \\
\hline $\begin{array}{l}\text { Cocktail model for project management } \\
\text { (BINDER et al., 2014) }\end{array}$ & $\mathrm{T}$ & $\mathrm{T}$ & $\mathrm{T}$ & & A & A \\
\hline $\begin{array}{l}\text { Framework Scrum para o desenvolvimento de } \\
\text { produtos (SOMMER et al., 2015) }\end{array}$ & $\mathrm{M}$ & A & A & & & \\
\hline
\end{tabular}


A lacuna impede o progresso do tema. Quais ações, técnicas e ferramentas devem ser consideradas para elaborar processos combinados de gestão de projetos? Somando a isso, tem-se a problemática da utilização dessa combinação fora do contexto de sistemas de informações ou desenvolvimento de software na qual a maioria dos autores citados se insere.

A pesquisa permite concluir também que existem duas estratégias para o planejamento do projeto combinado. A estratégia bottom-up consiste combinar a gestão ágil e um processo de desenvolvimento, contendo fases definidas e as principais entregas, conforme Zark e Moawad (2010), Seyam e Galal-Edeen (2011), Ambler (2013) e Sommer et al. (2015). A estratégia top-down considera a elaboração de um plano de projeto tradicional e a execução por meio de iterações ou sprints, conforme é apresentado em Nawrocki et al. (2006), Batra et al. (2010), Amaral et al. (2011) e Binder, Aillaud e Schilli (2014).

Conclui-se também que a característica principal da combinação, presente na estratégia top-down, é a presença concomitante de um plano de projeto tradicional, baseado em cronograma, com os planos simplificados propostos na abordagem do gerenciamento ágil de projetos: Product Backlog e Spring Backlog. A questão é como coordenar o conteúdo desses planos e trabalha-los conjuntamente. Falta pesquisa nesta área e um passo importante para o desenvolvimento das abordagens combinadas pode ser como estabelecer um mecanismo de interação entre esses planos.

Outra conclusão interessante é sobre quais práticas devem ser utilizadas para combinar as práticas. O Quadro 18 apresenta a lista completa com todas as citações das práticas identificadas nas propostas. Dentre as práticas mais citadas, destacam-se o Product Backlog, Priorizar requisitos, WBS/ decomposição, Daily Scrum Meeting e Arquitetura do produto. Isso leva a concluir que para combinar o APM e o tradicional deve-se levar em consideração essas cinco práticas.

Visto a lacuna identificada e as informações apresentadas no Capítulo 3, a pesquisa desenvolveu um procedimento planejamento a partir das análises realizadas para propor uma forma de combinar, especificamente no aspecto planejamento de tempo. $\mathrm{O}$ procedimento é o foco da discussão do Capítulo 5. 
Quadro 18 - Frequência de citações das práticas

\begin{tabular}{|lr|}
\hline Práticas & Frequência \\
\hline Ágil & \\
Product Backlog & 5 \\
Arquitetura do produto & 5 \\
Daily Scrum Meeting & 4 \\
Priorizar requisitos & 4 \\
Sprint Backlog & 2 \\
User stories & 2 \\
Reunião Retrospectiva & 2 \\
Controlar mudanças do Escopo & 1 \\
Tradicional & \\
Business Case & 1 \\
Sequenciar as atividades & 1 \\
Desenvolver o cronograma & 1 \\
Ambas & \\
WBS/ decomposição & 4 \\
Quadros & 3 \\
Declarar problema/ oportunidade & 2 \\
Definir escopo do projeto & 2 \\
Reunião & 2 \\
Estimar duração tempo e esforço & 2 \\
Estimar recursos das atividades & 2 \\
Definir atividades & 1 \\
Protótipo & 1 \\
Identificar trabalho necessário para o projeto & 1 \\
\hline Total Geral & \\
\hline & \\
\hline
\end{tabular}




\section{MÉTODO DE PESQUISA}

\subsection{Classificação da pesquisa}

A revisão da literatura indicou que o fenômeno de combinação de práticas ágeis e tradicionais teve início paralelo ao desenvolvimento da gestão ágil de projeto, com o trabalho de Boehm (2002), porém, não se desenvolveu da mesma maneira. Não houve evolução significativa do fenômeno nos últimos anos, os autores ainda buscam definições, benefícios e elaboram propostas de combinação. Em especial, faltam detalhes nas recomendações sobre como combiná-las. Portanto, a pesquisa sobre a combinação está no início do desenvolvimento.

Entende-se que este fenômeno pode ser considerado uma inovação gerencial. A inovação gerencial é definida como a invenção e implementação de práticas, processos, estruturas ou técnicas de gestão que são novas para o estado da arte e destinados a aumentar as metas organizacionais (BIRKINSHAW; HAMEL; MOL, 2008).

A inovação gerencial deve ser legitimada por dois grupos de agentes: agentes internos, empregados da organização que fazem uso do conhecimento em suas atividades; e, agentes externos, consultores ou acadêmicos com o interesse de legitimar a eficácia da nova prática, e atuam na sua disseminação (BIRKINSHAW; HAMEL; MOL, 2008). O procedimento proposto nesta pesquisa deve ser avaliado segundo a legitimidade interna, avaliando a viabilidade de combinar as práticas e na perspectiva do usuário.

A pesquisa é classificada como um Estudo de Caso em razão do tipo de questão de pesquisa a que se propõe a responder. A questão de pesquisa desse trabalho consiste em “Como combinar a gestão Tradicional e Ágil?". Questões correspondentes ao tipo “como” ou "por que" conduzem o pesquisador escolher entre a estratégia de estudo de caso, experimento ou pesquisa histórica (YIN, 2005, p.25).

O Estudo de caso é definido quando se seleciona um caso ou uma pequena quantidade de casos, no contexto real, e se analisa geralmente de modo qualitativo (DUL; HAK, 2008, p.4). O estudo de caso é classificado de dois modos de acordo com o objetivo geral (DUL; HAK, 2008, p.31). Orientado para a prática possui o objetivo de contribuir com o conhecimento de um ou mais interessados. Orientada para a teoria contribui para o desenvolvimento da teoria em si. O objetivo dessa pesquisa é desenvolver um procedimento 
de planejamento de tempo combinado teórico. Deste modo, a pesquisa é classificada como um estudo de caso orientado para a teoria.

O teste do procedimento proposto em um caso real permitirá entender desafios, problemas e gerar hipóteses para o avanço da teoria, assim como investigar a legitimidade interna do procedimento.

\subsection{Fases de pesquisa}

A execução da pesquisa foi planejada em três fases conforme ilustra a Figura 20: Fase 1 - Revisão da literatura; Fase 2 - Elaboração do Procedimento; Fase 3 - Aplicação do procedimento. Nas próximas subseções são descritas cada atividade presente nas Fases para a execução da pesquisa, assim como os procedimentos científicos adotados.

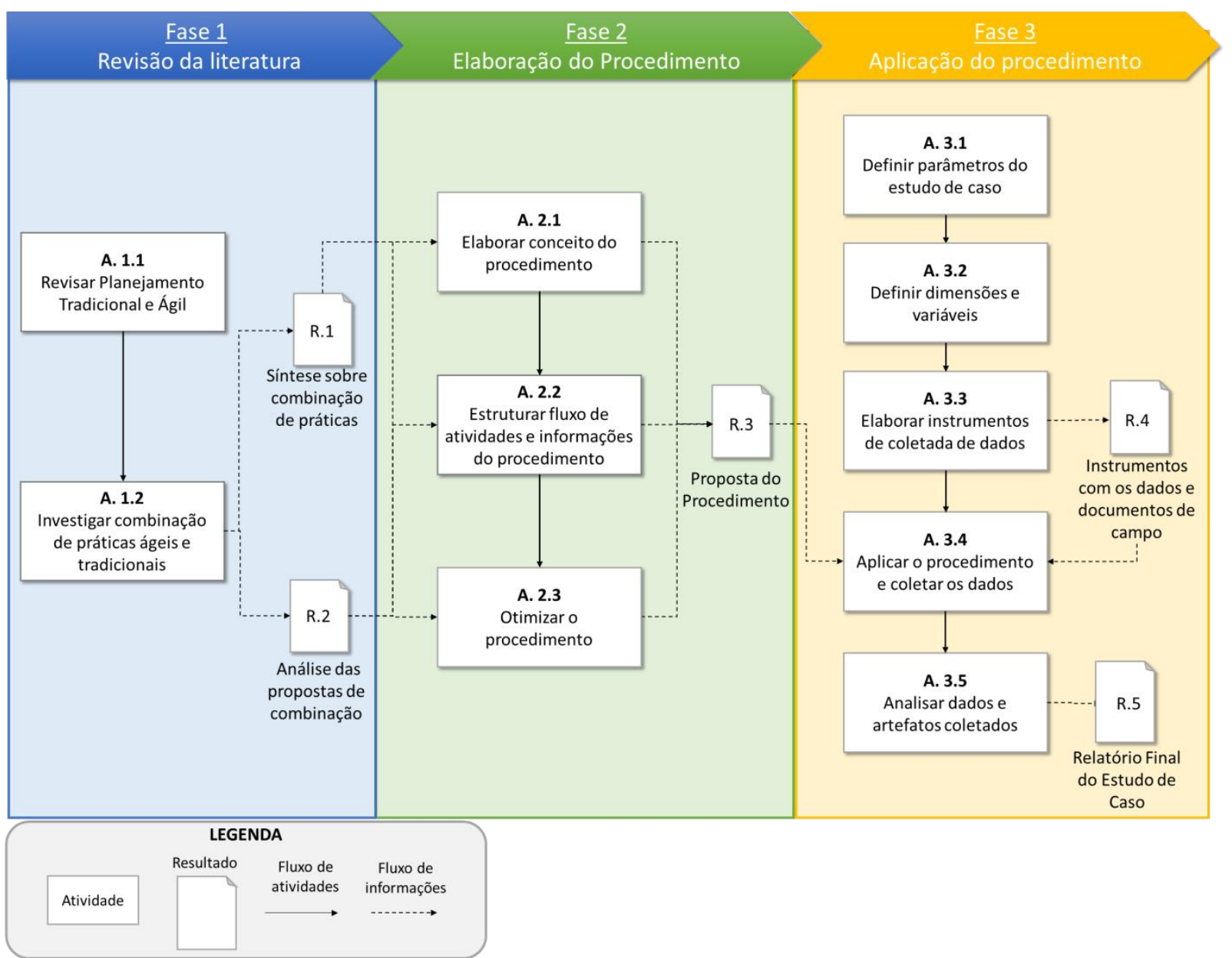

Figura 20 - Fases, atividades e resultados da pesquisa 


\subsubsection{Atividade 1.1 - Revisão de planejamento de projetos.}

Os procedimentos de planejamento da gestão de projetos Tradicional e Ágil foram caracterizados por meio de uma revisão dos autores que sintetizam e são consideradas referências principais na disseminação dos métodos. Os principais autores da gestão tradicional de projetos, por exemplo, PMI (2013) e Wysocki (2007), e da gestão ágil de projetos, tais como Cohn (2011) e Schwaber (2004). Os procedimentos de planejamento estão apresentados no Capítulo 2 deste trabalho.

\subsubsection{Atividade 1.2 - Investigar combinação de práticas ágeis e tradicionais}

A investigação sobre a combinação de práticas ágeis e tradicionais de projetos utilizou duas ferramentas de pesquisa: uma Revisão Inicial; e Revisão Bibliográfica Sistemática (RBS). Os resultados da investigação foram apresentados no Capítulo 3. Nessa seção, apresenta-se o procedimento adotado nas duas revisões.

Dado o problema de pesquisa “Como combinar a gestão Tradicional e Ágil?”, a Revisão Inicial buscou identificar artigos, trabalhos e livros que tratavam do assunto. Para isso, o problema de pesquisa foi desdobrado em quatro perguntas norteadoras, que foram estabelecidas para guiar a busca, tais como:

1. Quais as definições de combinação de abordagens de gestão de projetos?

2. Quais são os benefícios esperados ao combiná-las?

3. Quais são os fatores críticos na combinação? e

4. Existem propostas de combinação?

O primeiro artigo encontrado na Revisão Inicial foi o trabalho de Vinekar, Slinkman e Nerur (2006). A partir desse artigo, foi possível fazer a análise da rede de citações para frente e para trás na Web of Science ${ }^{\circledR}$ e, deste modo, identificar outros trabalhos, por exemplo, Boehm e Turner (2003).

Após agregar um conjunto inicial de artigos, iniciou-se a leitura desses buscando identificar o fenômeno estudado. A leitura permitiu identificar palavras chaves a partir de como os autores denominavam a combinação e das palavras chaves utilizadas nos trabalhos. Um conjunto inicial de palavras chaves foi estabelecido, tais como agile traditional approach, agile hydrid approach, combine agile traditional, combine agile plan-driven, agile ambidexterity. 
A busca procedeu para as bases de dados da Web of Science® e Google Scholar® utilizando as palavras-chaves estabelecidas. Foi realizada a leitura do título e resumo dos artigos para identificar se os autores debatiam a combinação. Dentre os selecionados, realizou-se a leitura da introdução e conclusão buscando identificar definições, benefícios, fatores críticos e modelos de combinação. No total foram identificados 28 artigos. Realizou-se a busca em livros de gerenciamento de projetos tradicionais e ágeis para identificar o debate sobre o tema, no total de quatro livros foram identificados.

A Revisão Inicial possibilitou adquirir alguns aprendizados sobre o tema estudado. Os artigos mais citados dentre os 28 artigos identificados corresponderam aos trabalhos de Boehm (2002) e Boehm e Turner (2003 e 2005), são trabalhos que introduziram o debate sobre a combinação, Ramesh et al. (2006) e Vinekar, Slinkman e Nerur (2006), discutem a ambidestria para gestão de projetos. Também possibilitou perceber que o conjunto de palavras chaves utilizada não ajudou a identificar um conjunto maior de artigos. A maior parte dos artigos foi identificado com a análise da rede de citações. Logo foi necessário melhorar as palavras chaves de busca para a RBS.

A RBS foi elaborada e conduzida a partir do roteiro de Conforto, Amaral e Silva (2011). O roteiro prescreve os seguintes passos: (1) declarar problema de pesquisa; (2) estabelecer fontes primárias de informação sobre o fenômeno estudado; (3) criar palavras chaves de busca; (4) definir critérios de inclusão na revisão; e (5) ler os artigos.

Não houve alterações do problema de pesquisa e das perguntas norteadoras da Revisão Inicial para a RBS. Objetivou-se identificar a discussão do fenômeno nos trabalhos, termos, definições, benefícios e fatores críticos ao combinar as práticas, assim como propostas de combinação de práticas ágeis e tradicionais de projetos entre modelos, métodos, frameworks, ferramentas, entre outros.

Os trabalhos mais citados sobre o tema, tais como Boehm (2002), Boehm e Turner (2003 e 2005) e Vinekar, Slinkman e Nerur (2006) foram utilizados como fontes primárias. O trabalho de Ramesh et al. (2006) não foi utilizado como fonte primária, pois não está indexado na base consultada.

As palavras-chaves foram revisadas e modificadas para a RBS. Notou-se que os artigos, invariavelmente, citavam um dos métodos ágeis, Scrum ou Extreme Programming, por exemplo, e citavam um termo de contraposição aos métodos ágeis, Tradicional, PMBOK ou Plan-driven. Portanto, um artigo de interesse para a pesquisa precisava citar os dois, por 
exemplo, Scrum e Plan-driven. Outras palavras-chaves foram identificadas em Magdaleno, Werner e Araujo (2011) que remetiam a gestão tradicional, como CMMI, waterfall e discipline. Assim, as strings de busca formadas a partir das palavras chaves estão no Quadro 19.

Quadro 19 - Strings de busca utilizadas na pesquisa

\begin{tabular}{|c|l|l|}
\hline ID & String & Justificativa \\
\hline 1 & $\begin{array}{l}\text { (Agile or "Agile project management" or Scrum } \\
\text { or "Extreme Programming") }\end{array}$ & $\begin{array}{l}\text { Identificam artigos que trataram de } \\
\text { gerenciamento ágil de projetos }\end{array}$ \\
\hline 2 & $\begin{array}{l}\text { AND (Traditional or "plan-driven" or warterfall } \\
\text { or discipline or CMM or CMMI or PMBoK) }\end{array}$ & Identificar nome de contraposição ao Ágil \\
\hline 3 & $\begin{array}{l}\text { AND (Model or procedure or framework or } \\
\text { method or approach or methodology or process or } \\
\text { practice or technique) }\end{array}$ & $\begin{array}{l}\text { Identificar propostas de combinação } \\
\text { or "healthcare") }\end{array}$ \\
\hline 4 & $\begin{array}{l}\text { Remover artigos sobre manufatura ágil, } \\
\text { supply chain e healthcare }\end{array}$ \\
\hline
\end{tabular}

Fonte: Elaborado pelo autor

As strings foram aplicadas na base de dados da Web of Science ${ }^{\circledR}$ e o resultado retornou 317 artigos. Ao iniciar a leitura dos títulos e resumos, foi identificado que o resultado abrangeu trabalhos de outras áreas fora do gerenciamento de projetos, por exemplo, agile manufacturing, supply chain e healthcare. Deste modo, foi necessário criar a string de ID número quatro para filtrar esses artigos. O novo resultado retornou 274 artigos.

Os critérios de inclusão (IC) dos artigos na pesquisa foram estabelecidos a partir das quatro perguntas norteadoras:

- IC1 - Discutir a combinação entre as abordagens Ágil e Tradicional

- IC2 - Decorrer sobre os benefícios esperados ao combiná-las

- IC3 - Pontuar fatores críticos para combinar as abordagens

- IC4 - Apresentar modelo, método, framework ou uma proposta de combinação.

A leitura dos artigos iniciou-se pelo título e resumo dos 274 artigos e buscou-se identificar o debate sobre a combinação entre as abordagens. Desta forma, 55 passaram pelo primeiro critério de inclusão, desses foram selecionados 32 artigos após a leitura da introdução e conclusão. A leitura completa dos 32 artigos considerou o segundo e terceiro critério de inclusão e o resultado final indicou 24 artigos, dos quais oito apresentavam propostas combinação.

Um modelo foi encontrado por meio da indicação de um dos autores, Grifftins 2004, questionando o autor via email. O Modelo corresponde ao trabalho de Ambler (2013). 
A busca também contemplou livros sobre gestão de projetos tradicional e ágil, onde foi identificado mais um modelo. Portanto, o resultado final da pesquisa totalizou dez propostas de combinação de abordagens de gerenciamento de projetos, todas descritas na seção 3.5 .

A busca de propostas de combinação, a pesquisa analisou e comparou as propostas utilizando os critérios de Eder et al. (2014). Assim, foi possível identificar as ações, práticas e ferramentas adotadas pelos autores e diferenciar os modelos das abordagens ágil e tradicional, permitindo detalhar cada proposta. O resultado R.2 é discutido na seção 3.6 onde se apresenta a análise completa das propostas.

\subsubsection{Atividade 2.1 - Elaborar conceito do procedimento}

O resultado R.2 indicou duas estratégias utilizadas pelos autores para combinar as práticas ágeis e tradicionais, denominadas nessa pesquisa de top-down e bottom-up. A estratégia top-down foi escolhida em razão de um maior nível de detalhamento nas recomendações de práticas que devem ser combinadas.

Os artefatos, como o Plano de projeto e o Product Backlog foram escolhidos a partir das recomendações dos autores. A primeira providência foi estabelecer uma ordem lógica de fluxo de informações entre os artefatos escolhidos para planejar um projeto. Por exemplo, o nível de detalhe presente em cada artefato e como atualizá-los.

Após estabelecer uma lógica para o fluxo de informações entre os artefatos, o caso exemplo, apresentado no Anexo A, foi usado para simular o planejamento e execução do projeto. A lógica para o fluxo de informações foi verificada a e melhorada, chegando, assim, a um conceito do procedimento. Todo o processo de criação é descrito em detalhes na seção 5.1 .

\subsubsection{Atividade 2.2 - Estruturar fluxo de atividades e informação do procedimento}

A análise das propostas de combinação apresentada na seção 3.6 indicou que nenhuma das dez propostas apresentou uma sistematização, ou ordem, de como combinar as práticas ágeis e tradicionais.

Assim, a partir da definição da lógica para o fluxo de informações e a escolha dos artefatos, foi necessário estruturar o fluxo de atividades de planejamento. Para isso, foi utilizado o método de modelagem Business Process Management Notation (BPMN). O 
BPMN possibilitou organizar o procedimento em forma de fluxograma de processo, apresentando as entradas e saídas das atividades de planejamento. O software Bizagi ${ }^{\circledR}$, que utiliza o BPMN, foi escolhido em razão da necessidade de sistematizar o procedimento e de uma maior familiaridade.

O processo de estruturação do procedimento e todos os passos e atividades necessárias para realizar o planejamento do projeto estão descritos detalhadamente nas seções 5.3 e 5.4 .

\subsubsection{Atividade 2.3 - Otimizar o procedimento}

A otimização do procedimento foi necessária para simplificar e corrigir eventuais falhas no fluxo de atividades e informações. Ao total, quatro ciclos de otimização foram adotados na pesquisa para chegar a um nível de maturidade do procedimento considerado adequado para ser utilizado no Estudo de Caso.

Nos dois primeiros ciclos de otimização, o procedimento foi apresentado a um especialista em Gestão Ágil de Projetos, que analisou os fluxos de atividades e identificando inconsistências e melhorias na modelagem em BPMN do procedimento.

No terceiro ciclo, o procedimento foi apresentado para especialistas e alunos da Pós-graduação em Desenvolvimento de Produtos da Escola de Engenharia de São Carlos (EESC). Uma dinâmica de grupo foi conduzida com o objetivo de aumentar a percepção dos especialistas e estudantes sobre as práticas ágeis e tradicionais combinadas no procedimento e, assim, melhorar o feedback em relação inconformidades e oportunidades de melhoria. As seis características de Eder et al. (2014) foram apresentadas aos participantes e estes, em grupos, foram solicitados a identificá-las no procedimento, possibilitando, desta forma, um debate aprofundado sobre as práticas combinadas.

O último ciclo consistiu a uma revisão do procedimento com uma especialista em BPMN. O objetivo foi verificar possíveis inconformidades, melhorar e simplificar o fluxo de atividades e informações do procedimento proposto.

A proposta final do procedimento de planejamento de tempo combinado, teórico e em forma de fluxo de atividades, consiste no resultado R.4 e está apresentado no Capítulo 5. 


\subsubsection{Atividade 3.1 - Planejar Estudo de Caso}

Para planejar do Estudo de Caso foi necessário especificar três parâmetros da pesquisa como as questões de estudo, proposições e unidade de análise (YIN, 2005, p.44).

A questão de estudo foi estabelecida previamente na revisão da literatura e consiste em como combinar as práticas ágeis e tradicionais de gestão de projetos.

A proposição formulada para a investigação do caso é que possível combinar as práticas ágeis e tradicionais utilizando o cronograma de projeto tradicional e o planejamento iterativo ágil, conforme indica a estratégia top-down.

A pesquisa estabeleceu como unidade de análise o "projeto". Em razão da dificuldade de acesso a projetos reais e dos riscos envolvidos em implementar o procedimento proposto sem um teste prévio, optou-se por realizar um caso único. O caso permitirá um maior aprofundamento e riqueza de informações e ocorrerá com a participação ativa do pesquisador para observar as questões de estudo (KARLSSON, 2009, p.170).

O tipo de caso é outro parâmetro importante para ser estabelecido, pois o tipo deve apresentar certas características desejáveis para a pesquisa (MIGUEL et al., 2012, p. 136). O enquadramento do caso na pesquisa deve ser feita a partir das características do projeto indicadas na literatura. Foram identificadas quatro características principais onde a combinação das práticas é recomendada: Projeto complexo; Mudanças nos requisitos do produto; Várias equipes de projeto; Entrega rápida (AMARAL et al., 2011; BATRA et al., 2011; BOEHM; TURNER, 2004; SOMMER et al. 2015).

A complexidade pode ser definida como as dificuldades e incertezas, representadas pelo número de tecnologias/componentes/funções nos esforços de desenvolvimento e da natureza das atividades organizacionais que os indivíduos e organizações enfrentam no desenvolvimento de produtos (KIM; WILEMON, 2003). A complexidade pode ser vista por duas dimensões, a complexidade do produto e interface com o cliente (AMARAL et al., 2011). Nas duas definições a complexidade do produto possui como componente quantidade de funções inerentes ao produto a ser desenvolvido. Exemplos de projetos complexos são automobilísticos e aeronáuticos. Nesse contexto, a recomendação é adotar a gestão de projetos tradicional (BATRA et al., 2011; BOEHM; TURNER, 2003).

As mudanças no escopo do produto durante a execução do projeto podem ser associadas ao grau de novidade tecnológica do produto, que impacta diretamente na a complexidade do projeto (KIM; WILEMON, 2003; SHENRAR et al., 2001). Nesses casos, 
definir o escopo do produto no inicio do projeto é inviável em razão das mudanças. Desta forma, são recomendadas práticas ágeis para executar o projeto, visando manter a flexibilidade para lidar com as mudanças (AMARAL et al., 2011; BATRA et al., 2011; BOEHM; TURNER, 2003).

Projetos complexos podem envolver várias equipes de projeto e diversos tipos de especialistas (AMARAL et al., 2011), formando, assim, uma grande equipe de projeto. A gestão tradicional é recomendada para a coordenação de projetos com grandes equipes, por outro lado, o APM é recomendado para equipes multidisciplinares (BOEHM; TURNER, 2003). Além disso, quando há mudanças no escopo do produto, criam-se desafios de coordenação e atualização de atividades entre equipes e membros, que são críticos para projetos complexos (BATRA et al., 2011). O compartilhamento do conhecimento entre várias equipes de projeto também é afetado. A combinação permitia flexibilidade Ágil para lidar com as mudanças no projeto utilizando práticas ágeis e coordenação das equipes usando práticas tradicionais (BATRA et al., 2011).

A entrega rápida de requisitos para o cliente é outra característica associada ao projeto que envolveria a combinação das práticas. A entrega rápida está associada a alcançar de vantagens estratégicas com o projeto (BATRA et al., 2011). Práticas ágeis de entrega parciais do produto auxiliam a equipe de projeto a direcionar o desenvolvimento para obter a vantagem competitiva associada a entrega dos requisitos do produto para o Cliente final (BATRA et al., 2011). O Quadro 20 apresenta a síntese das características do caso a ser escolhido pela pesquisa.

Quadro 20 - Características do caso escolhido.

\begin{tabular}{|l|l|}
\hline Característica & Descrição \\
\hline $\begin{array}{l}\text { Complexidade do } \\
\text { projeto }\end{array}$ & $\begin{array}{l}\text { Quantidade de funções inerente ao produto desenvolvido e a } \\
\text { interdependência entre as funções. }\end{array}$ \\
\hline $\begin{array}{l}\text { Várias equipes de } \\
\text { projeto }\end{array}$ & $\begin{array}{l}\text { Desafios de coordenação e atualização de atividades entre equipes e } \\
\text { membros, que são críticos para projetos complexos. O compartilhamento do } \\
\text { conhecimento entre várias equipes de projeto também é afetado. }\end{array}$ \\
\hline $\begin{array}{l}\text { Mudanças nos } \\
\text { requisitos do produto }\end{array}$ & $\begin{array}{l}\text { O grau de novidade do produto causa mudanças nos requisitos do produto } \\
\text { durante a execução do projeto. }\end{array}$ \\
\hline Entrega rápida & $\begin{array}{l}\text { Visa obter vantagens competitivas para a empresa que executa o projeto e } \\
\text { para o Cliente final. }\end{array}$ \\
\hline
\end{tabular}

A pesquisa selecionou, intencionalmente, um caso de projeto fictício envolvendo alunos de graduação da Universidade de São Paulo (USP) da disciplina de Gestão de Projetos. 
A seleção foi necessária para testar o procedimento em um ambiente de projeto devidamente controlado para o pesquisador analisar as características de Eder et al. (2014). O caso é detalhado no Capítulo 6 e envolveu duas características para a seleção do caso, o projeto complexo e várias equipes de projeto.

\subsubsection{Atividade 3.2 - Definir dimensões e variáveis do estudo}

A pesquisa adotou o termo dimensões para se referir a um conjunto de variáveis a serem medidas em campo. Duas dimensões foram definidas a partir da literatura e criadas para avaliar o procedimento, ambas apresentadas na Figura 21: Dimensão 1 (D1) Combinação de Práticas; e Dimensão 2 (D2) - Experiência do usuário.

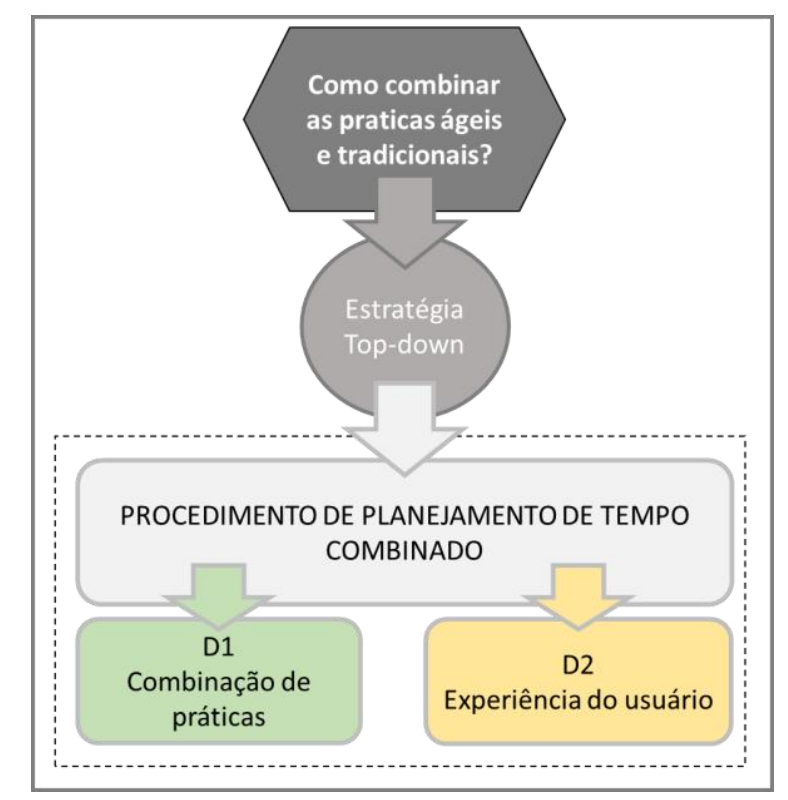

Figura 21 - Dimensões de avaliação do procedimento

Dimensão 1 (D1) - Combinação de práticas. A investigação deve seguir as proposições teóricas que conduziram a pesquisa ao Estudo de Caso (YIN, 2005, p.140). Para essa pesquisa, as proposições teóricas advém do trabalho de Eder et al. (2014). Logo, as variáveis desta dimensão foram definidas a partir das seis características utilizadas para analisar as propostas de combinação na seção 3.6. Cada variável corresponde a uma característica a ser observada no campo e, visando auxiliar o pesquisador, foram desdobradas em questões e inseridas nas questões de estudo, seção 3 do Apêndice H. As seis variáveis foram codificadas da seguinte forma: 
- D1.A - Elaboração do plano;

- D1.B - Descrição do escopo do projeto;

- D1.C - Definição das atividades;

- D1.D - Horizonte de planejamento das atividades;

- D1.E - Controle do tempo; e

- D1.F - Verificação e controle do escopo.

A Dimensão 2 (D2) é denominada de experiência dos usuários. A dimensão consiste na avaliação do usuário ao conduzir um projeto utilizando o procedimento. Justificase em razão do procedimento referir-se a uma inovação gerencial, adquirindo legitimidade quando sua credibilidade e validade são compartilhadas por seus usuários (BIRKINSHAW; HAMEL; MOL, 2008). A Dimensão foi desdobrada em duas variáveis: a usabilidade e percepção de qualidade.

A usabilidade é um conceito que advêm da área de conhecimento de sistemas computacionais e foi adaptado para esta investigação. Pode ser definida como a "medida na qual um produto pode ser usado por usuários específicos para alcançar objetivos específicos com eficácia, eficiência e satisfação em um contexto específico de uso" (ISO 9241-11 apud ARAÚJO, 2012).

A pesquisa adotou o modelo do questionário de Brooke (1996) apud Araujo (2012), System Usability Scale (SUS) (Anexo D) para avaliar a usabilidade. O questionário apresenta métricas de usabilidade autoreportadas, onde um indivíduo julga dez afirmações, sendo cinco positivas e cinco negativas, sobre a experiência global em relação ao procedimento (TULLIS; ALBERT, 2008 apud ARAUJO, 2012, p.45). O Questionário de experiência do usuário utilizado nesta pesquisa está presente no Apêndice H.

A percepção de qualidade consiste no julgamento do usuário em relação à qualidade apresentada no procedimento considerando o planejamento do projeto $\mathrm{e} o$ entendimento comum (BENASSI, 2013). A pesquisa adaptou as perguntas semiabertas referentes ao apoio ao planejamento onde o usuário responde as duas questões e justifica ou explica as respostas dadas (BENASSI, 2013). As duas questões fazem parte do Questionário de experiência do usuário. 


\subsubsection{Atividade 3.3 - Elaborar os instrumentos de coleta de dados.}

Os instrumentos de coleta de dados elaborados nesta pesquisa consistem em um diário de campo e um questionário. A atividade também contempla a elaboração do protocolo do estudo de caso.

O diário de campo corresponde ao registro de evidências do pesquisador sobre o estudo de caso. O pesquisador observou e registrou evidências utilizando uma prancheta e folhas A4, uma para cada equipe, durante a condução do caso. O registro das evidências utilizou a codificação apresentada para as variáveis da Dimensão 1, na seção anterior, para identificar dos dados e auxiliar na análise posterior. Por exemplo, a forma elaboração dos planos, código D1.A.

O questionário foi elaborado a partir das duas dimensões de estudo e está presente no Apêndice H. O questionário foi divido em duas partes, a primeira consiste nas 10 afirmações sobre a usabilidade, cuja métrica é dada em escala Linkert, de um a cinco pontos, abrangendo desde o discordo totalmente até o concordo totalmente, e a segunda parte condiz a duas perguntas abertas para captar a opinião do usuário.

O Protocolo do estudo de caso foi concebido de acordo com as recomendações de Yin (2005, p. 95) para a elaboração de cada seção. As seções e o conteúdo são apresentados no Quadro 21. O protocolo, também, contém os instrumentos de pesquisa e as regras gerais para indicar como estes devem ser utilizados (VOSS; TSIKRIKTSIS; FROHLICH, 2002; YIN, 2005, p. 92). O protocolo pode ser consultado no Apêndice G.

\begin{tabular}{|l|l|}
\hline Título & Quadro 21 - Seções do Protocolo \\
\hline $\begin{array}{l}\text { Seção 1 - Visão geral do projeto do } \\
\text { estudo de caso }\end{array}$ & $\begin{array}{l}\text { Resumidamente, apresenta os objetivos, as pessoas } \\
\text { envolvidas, as intenções teóricas do estudo. }\end{array}$ \\
\hline Seção 2 - Procedimentos de campo & $\begin{array}{l}\text { Acesso e organização do local, agenda de coleta de dados, } \\
\text { lista de materiais, fontes de informações e advertências. }\end{array}$ \\
\hline Seção 3 - Questões de estudo de caso & Parâmetros a serem observados durante a condução do caso \\
\hline $\begin{array}{l}\text { Seção } 4 \text { - Guia para o relatório do } \\
\text { estudo de caso }\end{array}$ & $\begin{array}{l}\text { Esboço, formato para os dados, uso e apresentação de } \\
\text { outras documentações e informações bibliográficas. }\end{array}$ \\
\hline
\end{tabular}

Fonte: Yin (2005), adaptado pelo autor. 


\subsubsection{Atividade 3.4-Aplicar o procedimento e coletar os dados}

A atividade contempla a implementação do procedimento em campo e a observação participativa do pesquisador, onde o pesquisador participa ativamente dos eventos estudados (YIN, 2005, p.121).

Para aplicar o procedimento, o pesquisador realizou um treinamento com alunos de graduação da turma de gerenciamento de projetos, do curso de Sistema de Informações, com cerca de 30 pessoas da Universidade de São Paulo. A idade dos alunos variava entre 20 a 30 anos, e um aluno possuía 45 anos. Dentre os alunos, 5 pessoas já possuíam experiência prática em gestão de projetos, além disso uma dessas trabalhava em uma empresa que utilizava a Gestão Ágil de Projetos (APM).

O professor responsável pela administração do curso de gerenciamento de projetos também é orientador dessa pesquisa. Isso facilitou o planejamento do treinamento com os alunos e o contato inicial com os alunos, justificando, assim, a escolha desta turma.

O curso de gerenciamento de projetos visava ensinar aos alunos os conceitos fundamentais de gestão de projetos, planejamento, execução, controle e fechamento. Durante o curso, os alunos aprenderam a utilizar o Ms Project ${ }^{\circledR}$, software de gestão de projetos. Também, como requisito para aprovação do curso, os alunos planejam e executam um projeto.

No momento da pesquisa e aplicação do treinamento, as últimas aulas estavam sendo administradas. O professor responsável abordaria o APM nessas últimas aulas. Desde modo, o pesquisador ficou responsável pelo conteúdo teórico sobre APM. O conteúdo envolveu a comparação com a Gestão Tradicional de Projetos, a combinação as práticas de ágeis e tradicionais e o procedimento de planejamento de tempo combinado.

Em um segundo momento, os alunos foram divididos em equipes para conduzir um projeto fictício utilizando o procedimento. O pesquisador acompanhou a implementação do procedimento e as equipes de projeto durante o estudo de caso.

A coleta de dados contemplou várias fontes de evidências (YIN 2005, p.125), dentre elas, o registro fotográfico da execução do treinamento, armazenamento dos artefatos físicos gerados durante o treinamento, anotações da observação do pesquisador e o questionário de experiência do usuário. A Figura 22 ilustra a relação entre as fontes e as dimensões de pesquisa. 


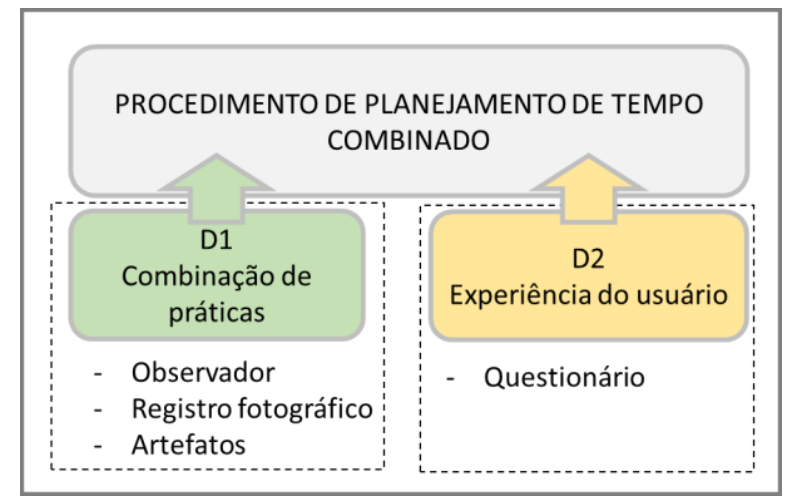

Figura 22 - Relação entre as fontes de evidências e as dimensões

As fontes de evidências possibilitaram ao pesquisador realizar a triangulação de dados na análise dos dados. A triangulação consiste no uso e combinação de diferentes métodos para estudar o mesmo fenômeno (VOSS; TSIKRIKTSIS; FROHLICH, 2002; YIN, 2005, p.125) e objetiva analisar várias perspectivas do estudo de caso. A combinação de várias fontes de evidências, considerando o mesmo fato ou fenômeno, permite classificar a triangulação adotada na pesquisa como triangulação de fontes de dados (YIN, 2005; JACK; RATURI, 2006). Deste modo, a triangulação auxiliou o pesquisador a prover inferências sobre a viabilidade do procedimento considerando as duas dimensões, conforme é apresentado na análise dos dados.

Todo o procedimento para aplicação e condução do treinamento e instruções para a coleta de dados estão descritos no protocolo do estudo de caso no Apêndice G.

\subsubsection{Atividade 3.5 - Analisar dados e artefatos coletados}

Os dados obtidos por meio do questionário de avaliação da experiência do usuário foram analisados e visam responder a questão sobre a viabilidade de combinar as práticas por meio do procedimento. Apresenta-se as estratégias escolhidas para analisar a Dimensão 1 e a Dimensão 2.

A estratégia adotada para a análise dos dados da Dimensão 1 foi baseada nas proposições teóricas que levaram ao estudo de caso, como objetivos, questões de pesquisa e hipóteses feitas a partir da revisão da literatura (YIN, 2005, p.140). As proposições da Dimensão 1 advém das seis características de Eder et al. (2014), que auxiliaram a identificar a estratégia de combinação top-down e as recomendações dos autores, utilizadas para elaboração da proposta do procedimento. O objetivo, agora, é analisar os dados coletados para confirmar ou declinar as recomendações. 
O plano do projeto ajuda a exemplificar e entender a estratégia adotada para a análise. Binder, Aillaud e Schilli (2014) recomendam elaborar o plano de projeto (variável D1.A) apresentando as entregas principais e milestones. A triangulação de fonte de evidências auxiliou a confirmar a recomendação. Por exemplo, as observações de campo (eg. os alunos elaboraram o plano de acordo com a recomendação sem dificuldades), o registro fotográfico dos alunos criando o plano e a análise do artefato físico são evidências que confirmariam a recomendação do autor. Deste modo, o pesquisador faz inferências sobre a recomendação, concluindo sobre a confirmação, declínio ou apresentando sugestões para melhorá-la.

A Dimensão 2 foi desdobrada na variável usabilidade e percepção de qualidade. Descreve-se os procedimentos adotados para analisar os dados coletados via Questionário de experiência do usuário (Apêndice $\mathrm{H}$ ) para as duas variáveis.

A variável usabilidade foi avaliada por meio de dez afirmações presentes no questionário. A técnica estatística de Índice de concordância (IC) foi aplicada para analisar os dados coletados. O IC analisa o julgamento de um indivíduo e a concordância entre vários em relação a um determinado aspecto questionado (JAMES; DEMAREE; WOLF, 1984). Toda a teoria envolvida para o cálculo do IC foi embasada no trabalho de LeBreton e Senter (2008), onde os autores realizaram uma extensa revisão sobre o assunto e apresentam o procedimento para calcular o IC. Toda a teoria envolvida e o procedimento utilizado para o cálculo das variâncias, médias e Índices de concordâncias é apresentado no Apêndice M.

A interpretação dos valores para o IC utiliza, tradicionalmente, o valor 0,7 como ponto de corte para diferenciar entre o alto e baixo nível de concordância (LEBRETON; SENTER, 2008). Isso significa atribuir 30\% de erro de variância entre as avaliações dos juízes para resposta aleatória, que pode ser inconsistente com o tipo de questão de pesquisa a ser respondida (LEBRETON; SENTER, 2008).

Deste modo, a interpretação dos valores encontrados utilizou a média das avaliações dos juízes em conjunto com o valor encontrado para o IC. A média auxilia o pesquisador a entender o que representa o valor do IC. Valores altos de média e $r_{W G}$ significam que houve total consenso entre os juízes sobre uma métrica ou variável em particular. Por outro lado, um valor alto de $r_{W G}$ e valor baixo de média significam que houve total discordância. Carvalho, Costa e Amaral (2015) apresentam critérios de interpretação de dados que consideram o IC e a média que facilitam a discussão dos resultados obtidos. Por isso, a pesquisa adota os critérios dos autores que são: 
- $\underline{\text { Totalmente atendido }}\left(r_{W G}>0.70\right.$ and $\left.\mu>3.0\right)$. Os juízes concordaram que o procedimento possui um efeito positivo;

- Ausente $\left(r_{W G}>0.70\right.$ and $\left.\mu<3.0\right)$. Os juízes concordam que o método não possui o efeito, definido como $70 \%$ da escala; e

- Indeterminado $\left(r_{W G}<0.70\right)$. Não há concordância e não é possível afirmar se qual é a percepção dos juízes.

A variável percepção de qualidade foi analisada a partir de duas questões para esboçar opinião presentes no Questionário de experiência do usuário. A variável auxilia o pesquisador a fazer inferências sobre a experiência do usuário. Por exemplo, os juízes de um determinada equipe concordaram que não há inconsistências no procedimento (Item 6), no entanto, muitos poderiam relatar oportunidades de melhoria na elaboração do planejamento do projeto ou no entendimento comum do projeto. Desta forma, as duas dimensões se completam, ajudando o pesquisado a fazer as inferências.

O relatório final do estudo de caso, apresentado no Capítulo 7, contêm todos os resultados alcançados e conclusões do pesquisador compondo, assim, o resultado R.6. 


\section{PROCEDIMENTO DE COMBINAÇÃo dE PRÁTICAS DE PLANEJAMENTO}

O Capítulo 5 apresenta o processo de desenvolvimento do procedimento. A estratégia top-down foi escolhida para ser detalhada nessa pesquisa, pois os trabalhos que delinearam essa estratégia apresentam um nível maior de informações e recomendações, permitindo a elaboração de um procedimento de planejamento tempo combinado.

\subsection{Desenvolvimento do conceito do procedimento}

Uma equipe de pesquisadores composta por três pessoas, autor, orientador e um aluno de iniciação científica, foi formada para desenvolver o conceito do procedimento. Ao total, a equipe executou três passos para desenvolvê-lo: escolha dos artefatos e definição do fluxo de informações; criação do fluxo de atividades em BPMN; e os ciclos de otimização com os especialistas. Descreve-se todos os passos executados.

O primeiro passo consistiu na escolha dos artefatos a serem utilizados para o planejamento de projetos de acordo com a estratégia top-down. A escolha dos foi realizada com base na síntese da literatura apresentada no Capítulo 3. Por artefato, refere-se aos documentos gerados pelo processo que descrevem de modo textual ou por meio de imagens as informações do projeto (BENASSI, 2013, p. 96).

O primeiro artefato escolhido foi o plano de projeto tradicional, representado pelo Gráfico de Gantt. Segundo a síntese da literatura, o plano de projeto é elaborado no início do projeto, possuindo alto nível de detalhamento das informações, limitando-se a estabelecer as entregas e milestones principais para todo o horizonte de tempo do projeto (NAWROCKI et al., 2006; AMARAL et al., 2011; BINDER; AILLAUD; SCHILLI, 2014).

Outros três artefatos foram escolhidos por estarem associados ao planejamento iterativo ágil, citado comumente entre os autores que recomendam a estratégia top-down para a execução do projeto (NAWROCKI et al., 2006; AMARAL et al., 2011; BINDER; AILLAUD; SCHILLI, 2014). Deste modo, foram escolhidos o Plano das interações (Release Plan), Product Backlog e Quadro Scrum.

Uma vez escolhidos os artefatos, a próxima ação dos pesquisadores foi criar uma lógica entre o artefato tradicional e os três ágeis. A lógica representa o fluxo de informações 
de planejamento do projeto. A Figura 24 apresenta a primeira proposta do fluxo de informações do procedimento criado pelos pesquisadores.

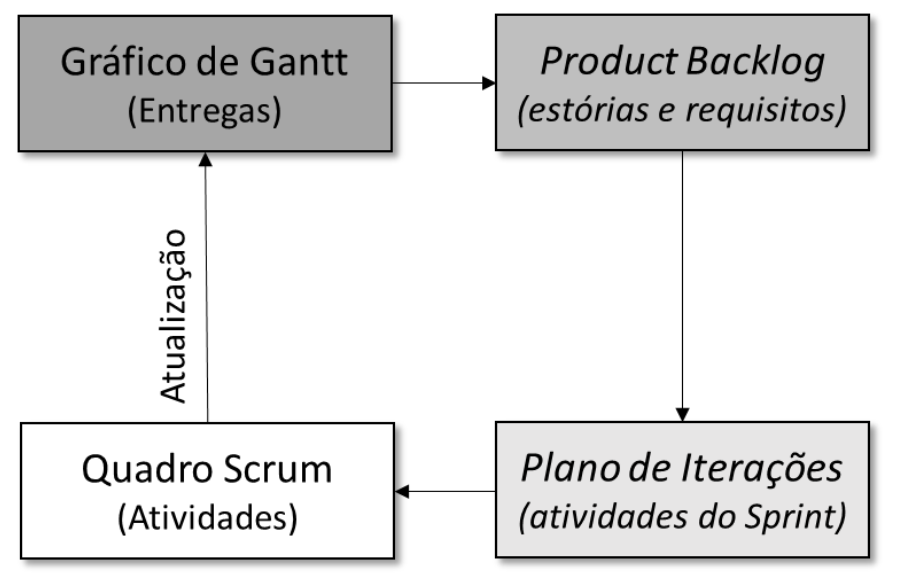

Figura 23 - Primeira proposta do fluxo de informações do procedimento

Para aumentar o conhecimento e entendimento sobre o fluxo de informações entre os artefatos, os pesquisadores optaram por adotar um projeto fictício e planejar as atividades necessárias para entregar esse projeto, simulando, assim, um projeto e a criação e atualização dos artefatos.

O caso proposto por Araujo (2012) foi adotado para ser o projeto fictício. O caso foi escolhido porque apresentou características para a escolha de estudo de caso, conforme definido na subseção 4.2.6, como um produto complexo, com interfaces software entre hardware, e o envolvimento de diversos especialistas com conhecimento diferente. Na visão dos pesquisadores, este caso permitiu identificar dificuldades no planejamento do projeto e possíveis melhorias no fluxo de informações.

O caso consiste no desenvolvimento de um produto chamado de "Globo Interativo", que deveria interagir com o usuário, mostrando informações sobre o país indicado com o toque do usuário, por exemplo, população e densidade demográfica. O Globo é destinado ao Museu local, onde deveria destacar a entrada, atrair a atenção do público e interagir com os visitantes.

O desafio do desenvolvimento do Globo Interativo era entregar o hardware e o sistema de software do produto. O Hardware consiste em um sistema de projeção de imagens e o globo físico do produto. O Software equivale ao modulo central de controle e processamento de informações e o mecanismo de procura das informações sobre os países na internet. 
Araujo (2012) utilizou o conceito de Visão do produto em razão das características inovadoras do produto e da dificuldade em estabelecer o escopo do produto utilizando práticas tradicionais. $\mathrm{O}$ autor elaborou os artefatos para definir a Visão do Produto como o Formulário de captação das necessidades do cliente (Anexo C), a Pré-concepção do produto e Arquitetura de software (Anexo B).

A Figura 24 apresenta a relação entre todos os artefatos criados para o Caso do Globo Interativo, Visão do Produto, Gráfico de Gantt, Plano iterativo e o Quadro Scrum.

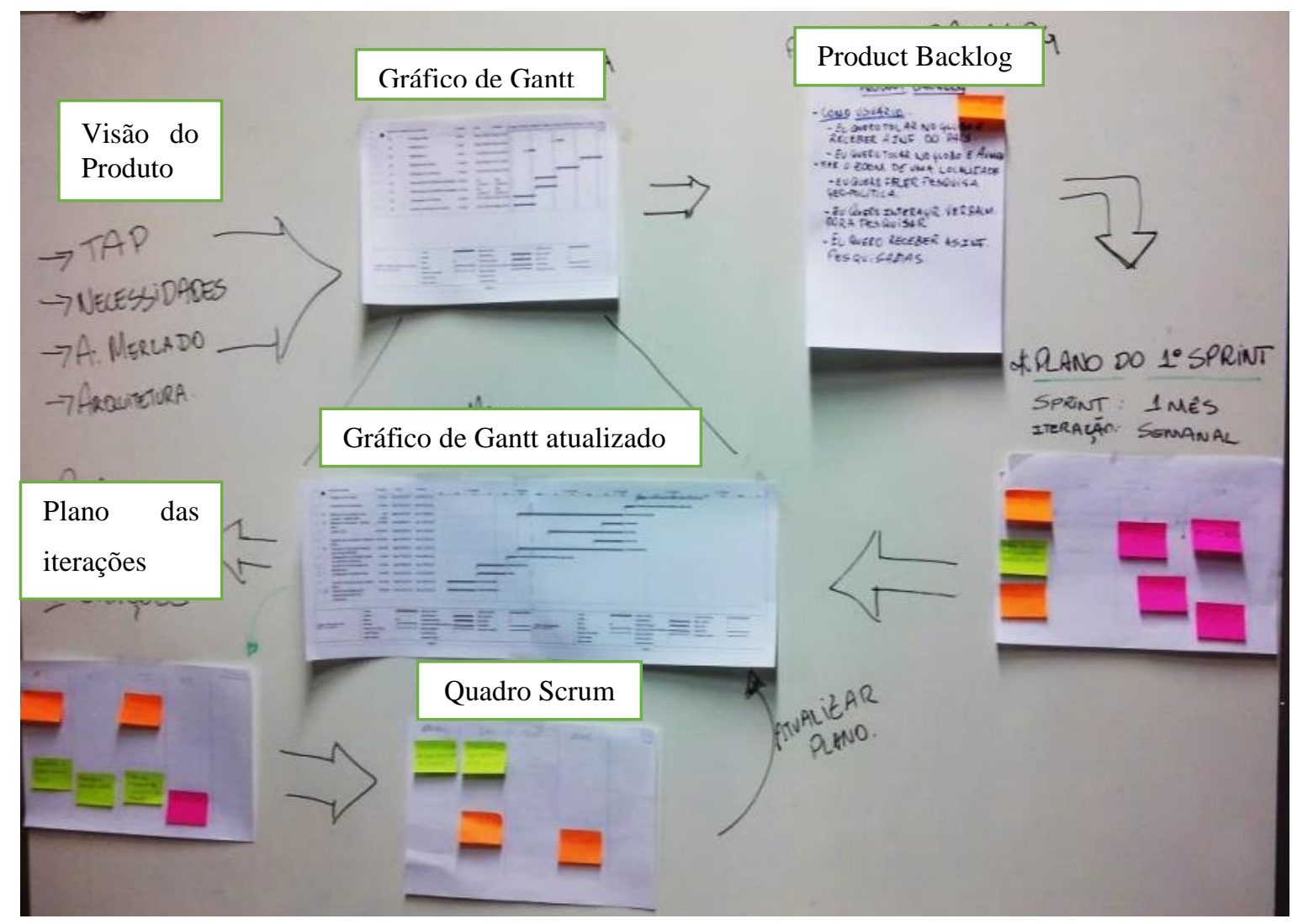

Figura 24 - Artefatos criados para o caso do Globo Interativo.

A Figura 24 mostra a Visão do Produto fornecendo de informações de entrada para a criação do Gráfico de Gantt. Isso permitiu definir as entregas principais do projeto, como, por exemplo, Globo físico, módulo de interação com usuário, concepção do globo, validação do protótipo e programa de testes.

Utilizou-se o software Microsoft Project® para elaborar o Gráfico de Gantt e estabelecer a ordem das entregas. O software foi programado para realizar o sequenciamento de traz para frente, iniciando da data de entrega do produto. Sequenciar de traz para frente foi necessário, pois os pesquisadores seguiram a recomendação do APM de fixar o tempo para a execução do projeto. Isso facilitou a elaboração do Gantt e analisar todas as entregas 
necessárias para finalizar o projeto. Definiu-se um total de 12 meses para desenvolver o projeto e 12 Sprints mensais para o planejamento do Globo Interativo. O Gráfico de Gantt resultante encontra-se no Apêndice C.

Após a definição das entregas principais e elaboração do Gantt, os pesquisadores desdobraram as entregas em atividades. Por exemplo, definir a tecnologia para o Globo Físico. Também foram elaboradas estórias do usuário para o caso. Um exemplo de estória do usuário foi "como visitante, eu gostaria de tocar em um país e receber as informações daquele país”. As atividades juntamente com as estórias do usuário (user story) e casos de uso (user cases) formaram a primeira versão do Product Backlog.

Imaginou-se que a equipe de projeto responsável pelo Globo Interativo deveria executar um primeiro Sprint com o intuito de aumentar o conhecimento sobre o projeto e finalizar os requisitos críticos do projeto, conforme é recomendado na literatura (RAMESH et al., 2006). A partir das novas informações, a equipe de projeto seria capaz de detalhar as entregas listadas no Gráfico Gantt, ou melhorar as estimativas de tempo, e criar o Plano das Interações identificando outras atividades de projeto.

Os pesquisadores observaram que a equipe de projeto do Globo poderia ser divida em duas subequipes, uma responsável pelas entregas relacionadas ao Software e outra com o Hardware do produto. Assim, cada subequipe de projeto definiria as atividades para serem executadas durante o Sprint e listá-las no Quadro Scrum. As atividades seriam priorizadas mediante aos principais stakeholders, que, no caso, poderia ser um responsável do museu pelo projeto do Globo e gerentes de projeto.

Durante a execução do Sprint, os membros da subequipe executariam a reunião diária para atualizar as atividades no Quadro Scrum conforme o status de progresso: não iniciado; executando; concluído; aprovado (LEFFINGWELL, 2011, p. 165).

Ao finalizar o Sprint, as duas subequipes de projeto se reuniriam no Sprint Review para apresentar os resultados alcançados e atualizar o Gráfico de Gantt, indicando o status de progresso das entregas principais. Caso for necessário acrescentar ou modificar alguma atividade em virtude do maior conhecimento sobre o problema, o Gráfico de Gantt pode ser mudado para descartar ou incluir novas entregas.

Neste ponto, o primeiro ciclo de planejamento da proposta é finalizado. Outros ciclos devem ser executados pela equipe de projeto até concluir o projeto e entregar o produto ao Museu. 
Ao criticar essa primeira proposta, os pesquisadores identificaram dois pontos de possíveis melhorias para o fluxo de informações do procedimento. O primeiro ponto foi a utilização das estórias do usuário para forma o Product Backlog. A técnica de estórias do usuário do APM foi utilizada para a coleta de requisitos de software. No contexto do caso do Globo, as estórias abrangeram apenas os requisitos para o software e não fez sentido em utilizá-la também para a coleta de requisitos de hardware. Deste modo, o Product Backlog não seria mais elaborando, sendo removido da proposta. $\mathrm{O}$ segundo ponto de melhoria foi a remoção da atividade de detalhamento do Gráfico Gantt, após o primeiro Sprint. O Gantt consiste em um artefato de alto nível de detalhe, utilizado para indicar os milestones e as entregas principais. Além disso, o detalhamento adiciona mais uma atividade de planejamento, assim, ao removê-la, foi possível simplificar a proposta.

Então, uma segunda proposta do fluxo de informações entre os artefatos foi criada considerando as melhorias identificadas. A Figura 25 ilustra a segunda proposta. O Product Backlog foi substituído pela Matriz Item-Entrega, outro artefato criado para elaborar a Visão do Produto (BENASSI, 2013, p. 100). A matriz relaciona as principais entregas, auxilia na análise das interfaces entre as entregas e possui uma coluna para definir os responsáveis pelas entregas. A matriz criada para o caso do Globo Iterativo encontra-se no Apêndice C.

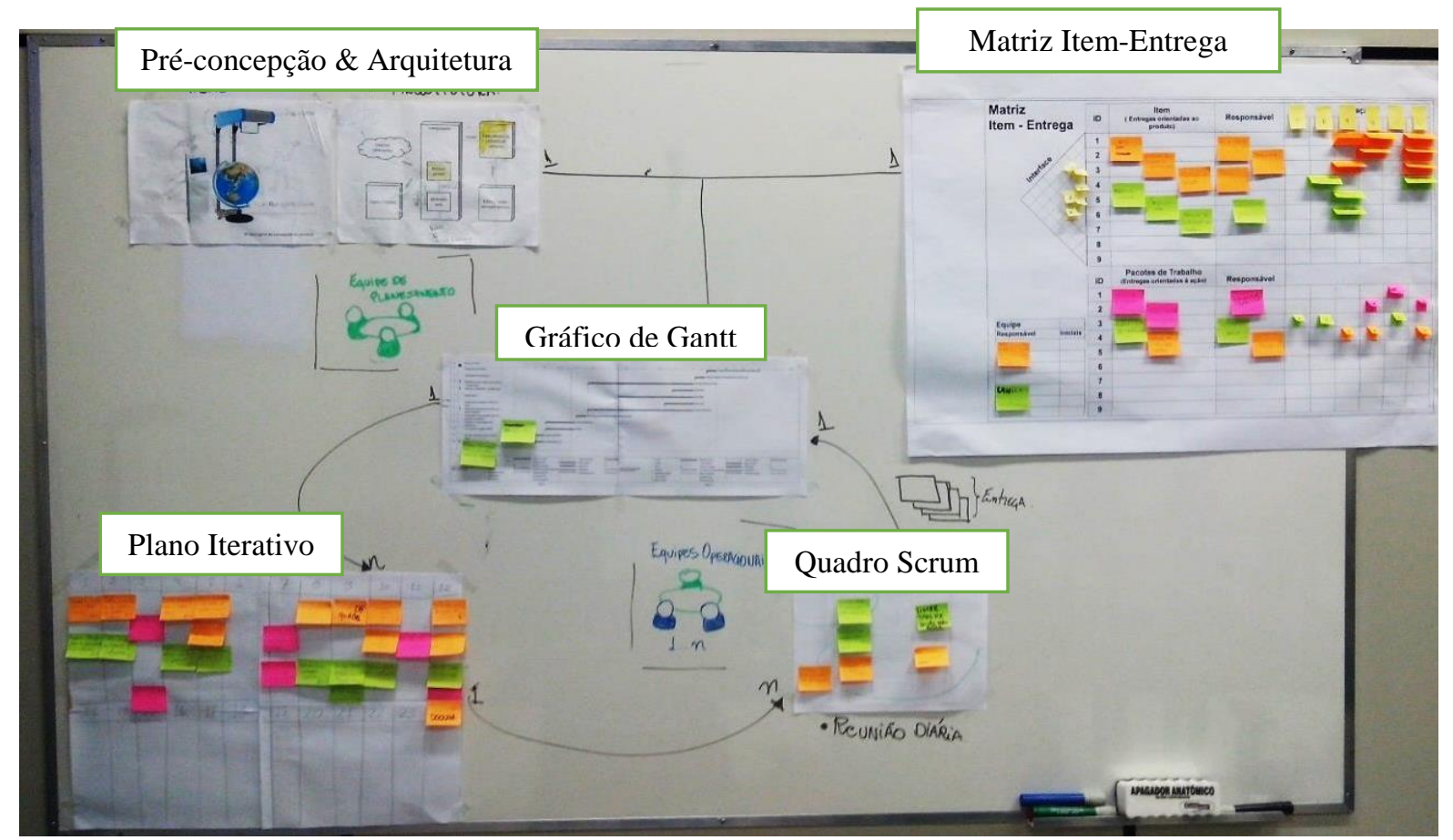

Figura 25 - Segunda proposta criada para o fluxo de informações do procedimento

As entregas e interfaces identificadas na matriz Item-Entrega permitiram a elaboração do Gráfico de Gantt. As atividades, estórias e casos seriam sequenciados no Plano 
Iterativo tendo como base a sequência das entregas no Gráfico de Gantt. As atividades seriam executadas pela respectiva subequipe e monitoradas por meio do Quadro Scrum. No Apêndice C encontra-se o exemplo de Quadro Scrum e as atividades para a primeira iteração do Globo Interativo.

Ao finalizar a segunda proposta, foi identificada uma melhoria que auxiliaria na simplificação do conceito, a remoção do Plano Iterativo. O Plano Iterativo é utilizado no APM como um instrumento listar de estórias do usuário que serão desenvolvidas durante o projeto e representa a visão do projeto no curto prazo, um ou dois Sprints (COHN, 2008, p.145). Nesse caso, o Gráfico de Gantt apresentava a visão geral do desenvolvimento do projeto para os 12 meses de execução. A criação do Plano adiciona mais uma atividade de planejamento, que foi vista como uma atividade que não agregou valor ao procedimento. Desta forma, o Plano Iterativo foi considerado desnecessário e removido do conceito. Imaginou-se que o Product Backlog poderia ser utilizado como um repositório de atividades de planejamento, substituindo, assim, o Plano Iterativo. Deste modo, a equipe definiria as atividades do Sprint armazenando-as no Product Backlog e atualizando-as ao final do Sprint.

A Pré-concepção, Arquiterura e Matriz equivalem a Visão do Produto para o caso do Globo Interativo. O processo de criação da Visão do produto é definido em Benassi (2013) e não é intenção dessa pesquisa contribuir para o avanço desse tema em específico. Desta forma, o conceito do procedimento presume que a equipe de projeto já elaborou a Visão e está iniciando o processo de planejamento do projeto.

Deste modo, o foco principal da pesquisa está nas atividades de planejamento. A lógica final do conceito, considerando os artefatos escolhidos, é apresentada na Figura 26. O Gráfico de Gantt estabelece as Entregas e a sequência destas no tempo disponível para desenvolver o projeto. O Product Backlog armazena as atividades identificadas pela equipe de projeto e priorizadas pelo Cliente. O Quadro Scrum estabelece e monitora as atividades definidas para o Sprint. Ao final, a equipe atualiza o Gráfico de Gantt com as informações provenientes das subequipes de projeto. 


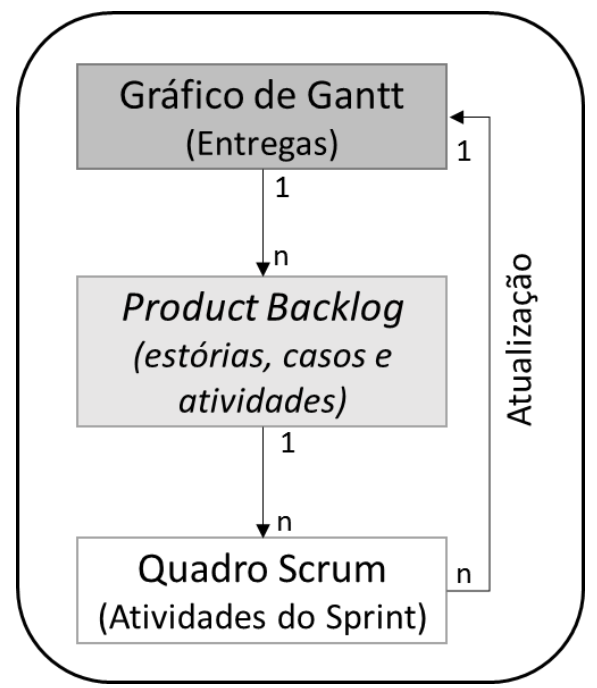

Figura 26 - Lógica entre os artefatos.

Após definir a lógica entre os artefatos, os pesquisadores passaram para o segundo passo de desenvolvimento do procedimento, a definição das atividades de planejamento. $\mathrm{O}$ fluxo de informações permitiu aos pesquisadores conceber um fluxo de atividades utilizando Business Process Managament Notation (BPMN), por meio do software Bizagi®.

O ultimo passo dos pesquisadores consistiram em quatro ciclos de otimização do fluxo de atividades, visando simplificar e melhorar o procedimento.

Os dois primeiros ciclos consistiram na revisão do fluxo de atividades em BPMN por um especialista em Gestão Ágil de Projetos. O especialista analisou todas as atividades definidas no BPMN, criticando e identificando inconsistências e melhorias no fluxo. Exemplo de melhoria foram atividades repetidas, sem sentido ou simplificação do fluxo de atividades. Deste modo, os pesquisadores alcançaram uma proposta madura de fluxo de atividades.

O terceiro ciclo de otimização compreendeu na apresentação do fluxo de atividades para outras pessoas criticar e identificar possíveis melhorias. Deste modo, o fluxo de atividades foi apresentado para especialistas em Gestão de Projetos e alunos da PósGraduação em Desenvolvimento de Produtos da Engenharia de São Carlos (EESC), que, ao total corresponderam a 12 pessoas.

Os pesquisadores elaboraram uma dinâmica de grupo. A dinâmica abordou uma breve explicação teórica sobre práticas ágeis e tradicionais, que visava aumentar a percepção dos especialistas e alunos sobre o tema de combinação de práticas ágeis e tradicionais. Em um segundo momento, foram apresentadas as seis características de Eder et al. (2014) aos participantes da dinâmica. Eles foram separados em quatro equipes com três pessoas. Foram 
solicitados a identificar as seis características no procedimento e classificá-las em ágeis e tradicionais. Isso possibilitou aos participantes um entendimento aprofundado do fluxo de atividades e o debate detalhado sobre as práticas combinadas. Assim, várias melhorias foram identificadas, como a simplificação de atividades e melhoria na apresentação do fluxo de atividades.

O quarto e último clico de otimização consistiu em uma revisão do fluxo de atividades com uma especialista em BPMN. O objetivo foi verificar possíveis inconformidades, melhorar e simplificar o fluxo de atividades e informações do procedimento proposto.

Deste modo, foi possível chegar a uma proposta final do fluxo de atividades e terminar o desenvolvimento do procedimento de planejamento. O procedimento é descrito nas duas próximas duas seções, divididas em elementos fundamentais para o entendimento do procedimento e o procedimento em BPMN. Decreve-se, na próxima seção, os três elementos fundamentais do procedimento: os níveis de planejamento; o desdobramento e nomenclatura; e a estrutura organizacional da equipe de projeto.

\subsection{Elementos fundamentais para o entendimento do procedimento}

Ressalta-se, inicialmente, que todas as definições dos elementos adotados no procedimento de planejamento estão descritos no Dicionário de dados, que pode ser consultado no Apêndice F.

As abordagens de gestão de projetos possuem modos diferentes para planejar o projeto. No Tradicional há um único nível de planejamento que representa todo o projeto, onde são definidas todas as entregas, pacotes de trabalho, atividades e criado o Gráfico de Gantt ou Cronograma mestre (PMI, 2013). No APM existe o conceito de níveis de planejamento. Por exemplo, no XP existem três níveis, Release planning, Iteration planning e Daily planning (CONH, 2008), que consideram o horizonte de planejamento para o Projeto, Iteração (Sprint) e o Diário respectivamente.

Ao combinar as práticas ágeis e tradicionais para planejar o projeto também são considerados os níveis de planejamento. O melhor exemplo é representado pelo Framework Scrum (SOMMER et al.,2015), apresentado na seção 3.5.10. No framework existem três níveis de planejamento, Estratégico, Projeto, e Sprints. No nível Estratégico e Projeto, 
recomenda-se utilizar práticas tradicionais como modelos de referência e gestão de recursos. No nível de Sprint, adota-se práticas ágeis provenientes do método Scrum.

O conceito do procedimento apresentado na seção anterior indicou a combinação entre o Gráfico de Gantt, Product Backlog e Quadro Scrum. Os três artefatos representam três níveis de planejamento, Projeto, Sprint e Diário. O nível Projeto consiste no planejamento tendo em vista todo o tempo disponível para executar o projeto e é representado pelo Gráfico de Gantt, que contêm as entregas e milestones principais. O nível Sprint (Iteração) é representado pelo Product Backlog, que contêm as atividades, casos e estórias. O nível Diário corresponde às atividades planejadas, executadas e monitoradas pelas subequipes de projeto.

A Figura 27 compara os níveis de planejamento tradicional, ágil e combinado e relaciona os artefatos utilizados em cada nível.

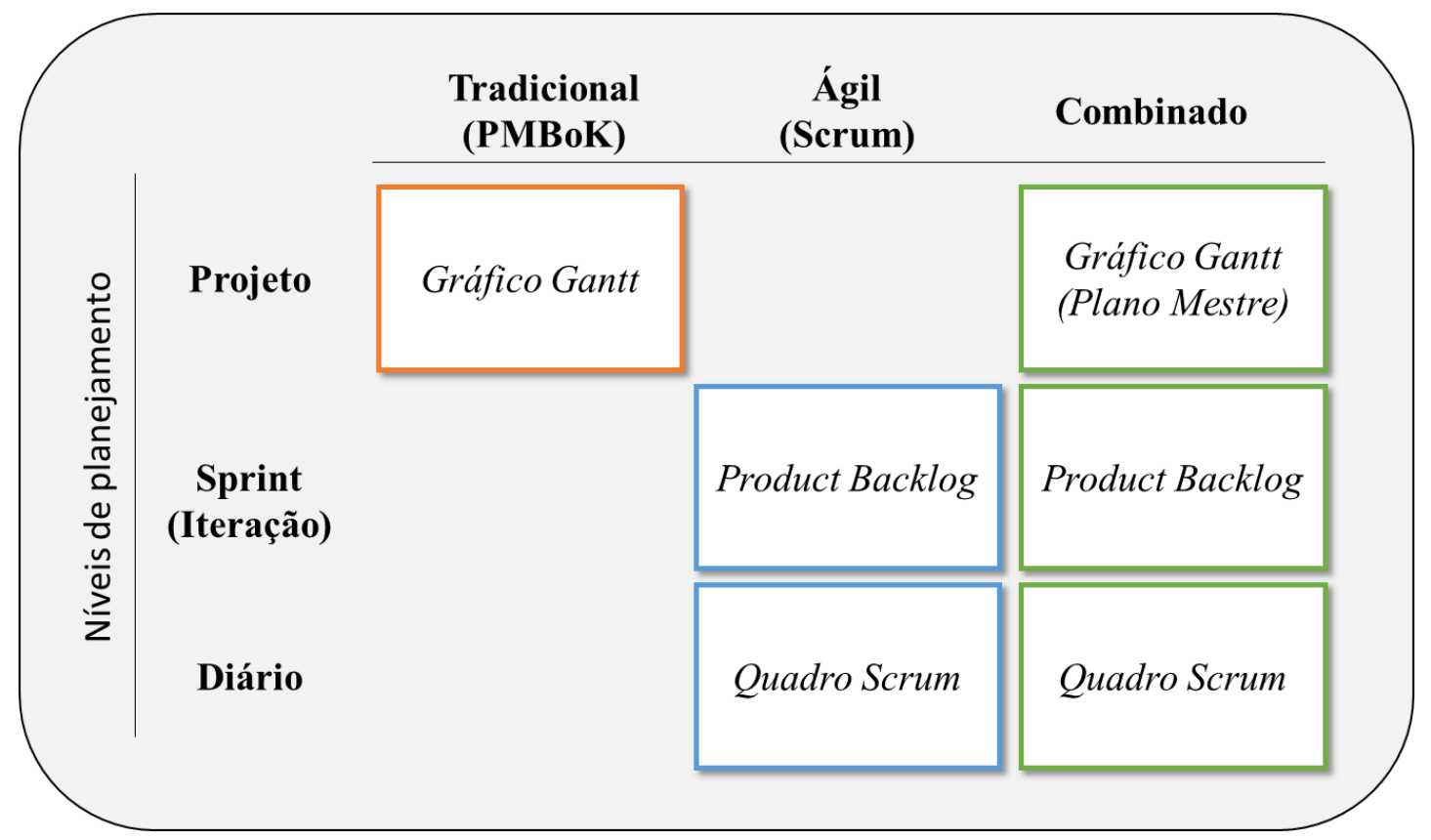

Figura 27 - Comparação entre os níveis de planejamento

No procedimento, o Gráfico de Gantt foi nomeado de Plano Mestre, apenas com o intuído de diferenciar os artefatos. O Plano Mestre é definido como o plano que apresenta as principais entregas, os milestones fundamentais, baseado nas necessidades do cliente, visão do produto e cronograma de alto nível (BINDER; AILLAUD; SCHILLI, 2014).

Recomenda-se a leitura do quadro de equivalência entre as abordagens apresentado no Apêndice D para um maior entendimento entre os níveis de planejamento e os planos gerados pela abordagem ágil e tradicional. 
O desdobramento do projeto consiste em subdividir o projeto em partes menores, de forma semelhante a uma WBS. No entanto, foram adotados dois componentes principais para indicar o desdobramento. Resultado final representa as entregas e pacotes de trabalho identificados pela equipe de projeto e necessários para finalizar o projeto. Work items (itens de trabalho) correspondem ao conjunto de todas as atividades, funções, requisitos do produto e estórias (user stories), identificados pelo time. A Figura 27 mostra a relação entre os Resultados finais e Work Items com o Produto do projeto.

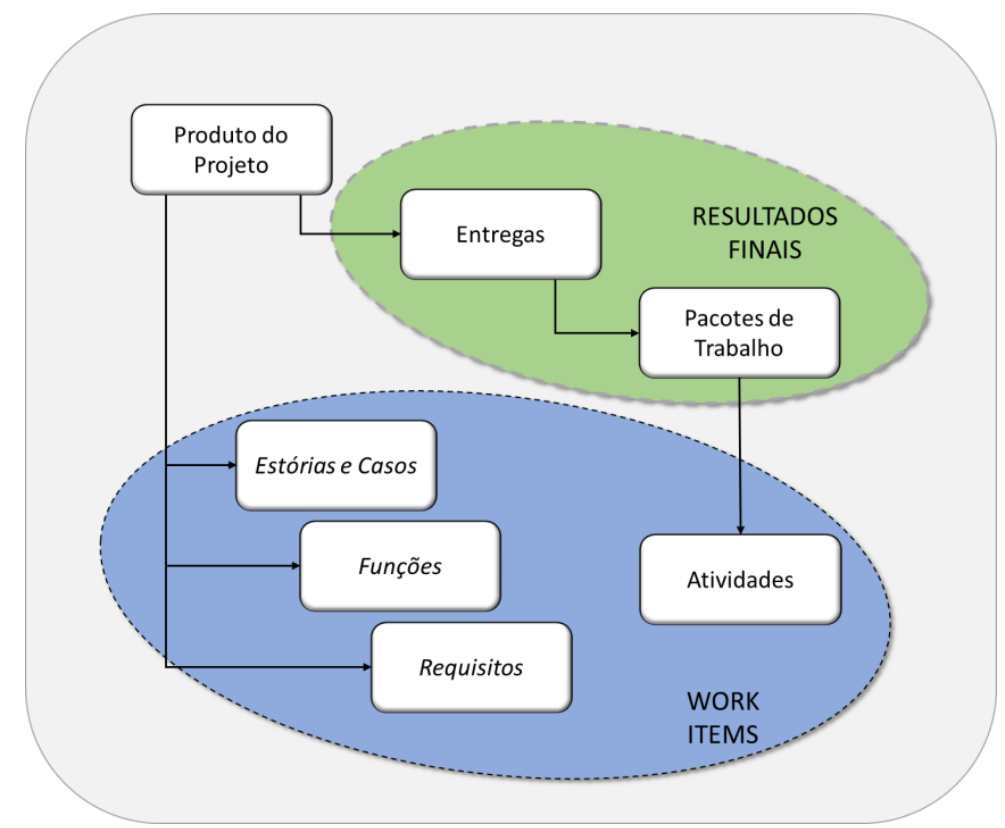

Figura 28 - Termos utilizados no procedimento

Os Resultados finais e Work Items estão diretamente relacionados com os três níveis de planejamento. Os Resultados finais são indicados no Plano Mestre do projeto, que representa o nível Projeto. Os Work items são relacionados no Product Backlog e no Quadro Scrum, representado o nível de planejamento Sprint e Diário.

Outra questão importante a ser considerada ao combinar práticas e princípios ágeis e tradicionais são as mudanças na estrutura organizacional do projeto. Na seção 3.4 foi discutido que a estrutura organizacional é composta pela Alta administração do projeto, representada por gerentes e os principais stakeholders, e responsável por decisões estratégicas, por um nível intermediário, representado principalmente pelo Gerente de projetos e líderes das equipes de projeto, responsáveis pelas decisões táticas do projeto, por um nível operacional, representado pelas Equipes auto-geridas que utilizam as práticas ágeis.

A pesquisa adota a estrutura organizacional onde existem duas equipes principais. A equipe de planejamento representa a Alta administração do projeto, composta pelo Product 
Owner, Stakeholders e Líderes das equipes operacionais. A equipe operacional representa a Equipe auto-geridas e é composta por um Líder e os Membros. O Quadro 22 descreve as responsabilidades de cada dos papeis.

\begin{tabular}{|l|l|}
\hline \multicolumn{2}{|c|}{ Quadro 22 - Papeis e responsabilidades } \\
\hline Papel & Responsabilidade \\
\hline Product Owner & $\begin{array}{l}\text { Gerenciar o produto e maximizar o valor do projeto (SCHWABER, 2004). } \\
\text { Assume responsabilidades do gerente de projetos, como a gestão de conflitos. }\end{array}$ \\
\hline Líder & $\begin{array}{l}\text { Pessoas, organizações, patrocinadores, que estejam envolvidos no projeto ou } \\
\text { cujos interesses possam ser afetados de forma positiva ou negativa pela } \\
\text { execução do projeto (PMI, 2013). }\end{array}$ \\
\hline Membro & $\begin{array}{l}\text { São os representantes das equipes operacionais na equipe de planejamento. } \\
\text { São pessoas escolhidas para serem treinadas como Scrum Master e } \\
\text { responsáveis por direcionar a entrega das atividades estabelecidas, prover } \\
\text { feedback para aos membros e auxiliar a estabelecer as atividades do Sprint. } \\
\text { Também, reportam os resultados alcançados no Sprint para a equipe de } \\
\text { planejamento e auxiliam na atualização do Plano Mestre. }\end{array}$ \\
\hline & $\begin{array}{l}\text { Especialista em um determinado conhecimento técnico. As responsabilidades } \\
\text { envolvem a execução das atividades do projeto e auxilio nas atividades } \\
\text { administrativas do projeto. }\end{array}$ \\
\hline
\end{tabular}

A equipe de planejamento é responsável por analisar e integrar todo o projeto por meio da elaboração e atualização do Plano Mestre. Desta forma, essa equipe mantem o nível de planejamento Projeto.

A equipe operacional é responsável por elaborar e atualizar o Product Backlog, que lista os work items identificados e priorizados para entregar o projeto. Também, é responsável pela elaboração do Quadro Scrum, identificando e selecionando os work items para serem executados durante o Sprint. Deste modo, a equipe é responsável pelos níveis de planejamento Sprint e Diário.

A Figura 29 sintetiza a relação entre as equipes de planejamento e operacional e os respectivos artefatos gerados. 


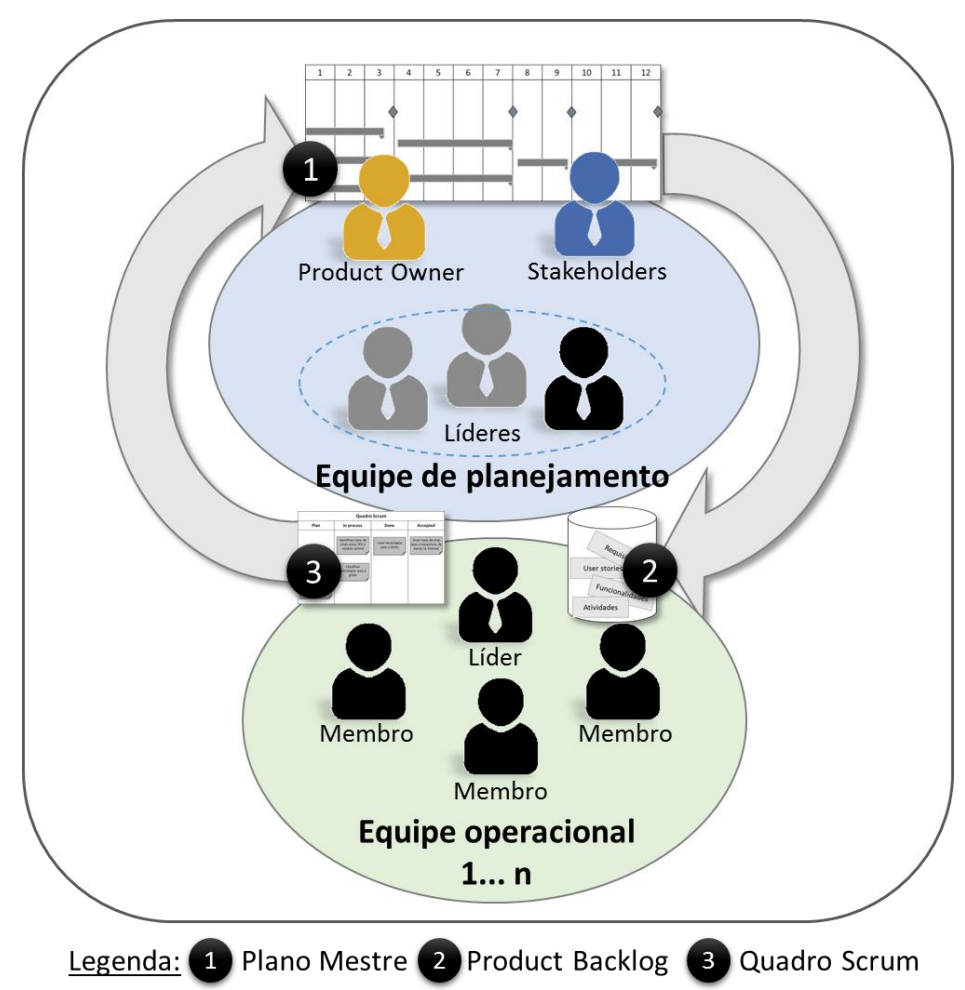

Figura 29 - Artefatos e equipe de projeto

A partir dos três elementos fundamentais apresentados nessa seção, níveis de planejamento, o desdobramento do projeto e a estrutura organizacional, é possível entender o fluxo de atividades e de informações para executar o procedimento.

Um pressuposto importante para o procedimento é que há a elaboração prévia da Visão do produto pela equipe de planejamento com auxilio da equipe operacional. Por motivos de foco e simplificação, os passos para elaboração da Visão do produto foram omitidos do procedimento apresentado na próxima seção. Para auxiliar os interessados em criar a Visão do produto, os passos apresentados por Benassi (2013) foram transformados em fluxo de atividades utilizando o BPMN e estão apresentados no Apêndice E. Mesmo assim, recomenda-se a leitura do trabalho de Benassi para maiores informações sobre a Visão.

Os diagramas representando o modelo BPMN serão apresentados na próxima seção. A legenda para interpretar os símbolos presentes nas figuras do procedimento encontrase no Anexo D. Os diagramas foram coloridos em três camadas para facilitar o entendimento e visualização do procedimento. A primeira camada colorida em roxo representa os quatro etapas principais. A camada intermediária colorida de azul corresponde às atividades. A terceira camada equivale às tarefas e está colorida em laranja. 


\subsection{Procedimento de planejamento de tempo combinado}

O procedimento é composto por quatro etapas principais: 1. Preparar o Plano mestre; 2. Planejar Sprint Backlog; 3. Executar Sprint; e, 4. Milestone Review. A Figura 30 ilustra a visão geral do procedimento, apresentando a sequência de execução das quatro etapas e os três artefatos, Plano Mestre, Product Backlog e o Quadro Scrum.

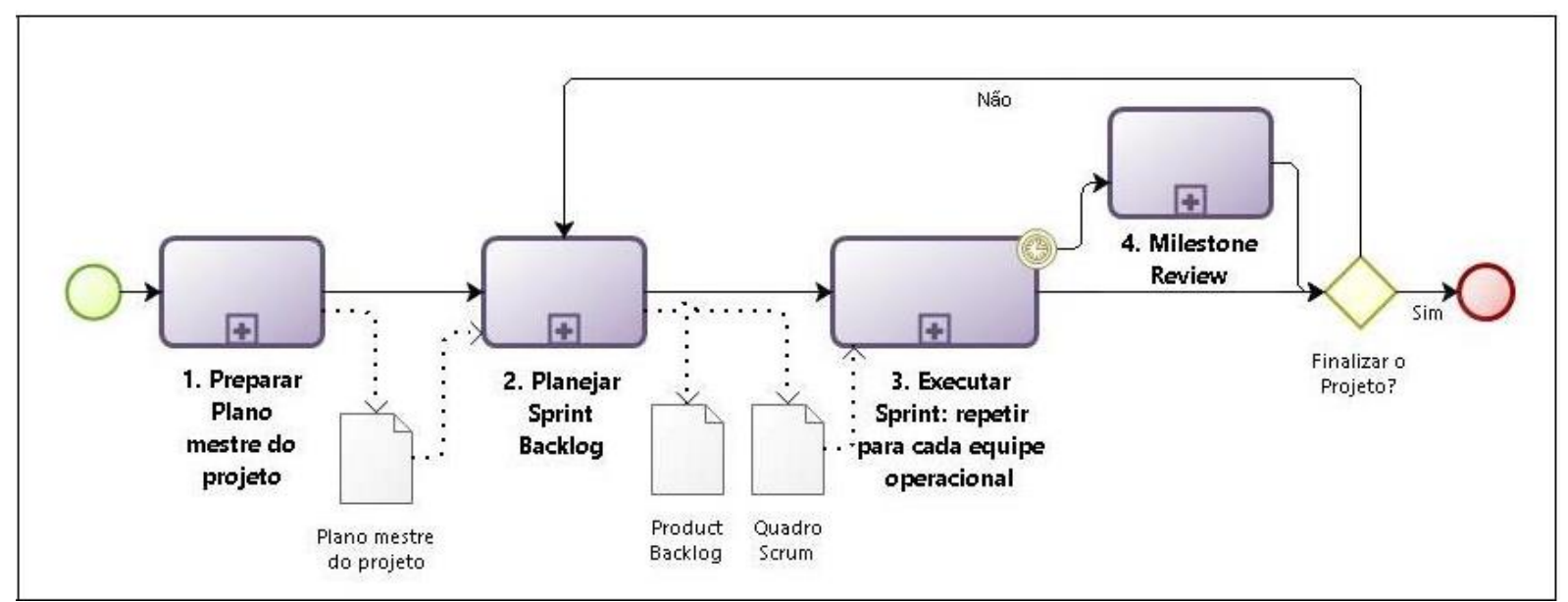

Figura 30 - Visão geral do Procedimento de planejamento de tempo combinando

A primeira etapa do procedimento é 1. Preparar Plano Mestre do projeto. A etapa foi concebida com base no roteiro presente Wysocki (2004, p.189) para a elaboração do Gráfico Gantt e considerou as recomendações de Binder, Aillaud e Schilli (2014) definir o conteúdo do Plano Mestre. A Figura 31 ilustrada as dez atividades de planejamento definidas para Preparar o Plano Mestre.

A atividade 1.1 consiste em configurar o software de gestão de projetos para sequenciar os resultados finais a partir da data final de entrega. Recomenda-se o software como ferramenta de criação e suporte do Plano Mestre. A equipe de planejamento pode optar por criá-lo utilizando um quadro branco ou outras ferramentas gráficas. O pressuposto desta atividade é que sequenciar os resultados finais a partir da data final, pois foi adotada a recomendação do APM de fixar o tempo de execução do projeto e permitir a variação no escopo do produto. Assim, qualquer ferramenta a ser utilizada pela equipe deve seguir esse pressuposto para utilizar o procedimento. 


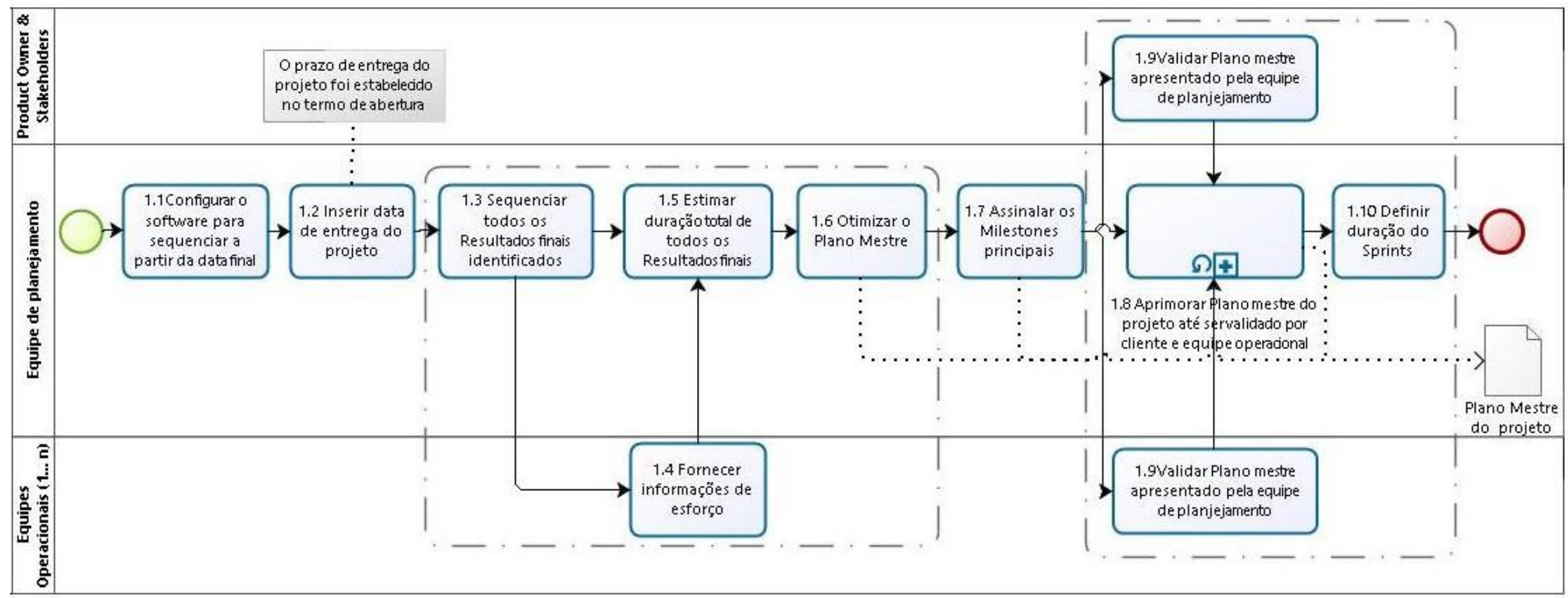

Figura 31 - Preparar Plano mestre do projeto 
A data final de entrega do projeto é inserida no software na atividade 1.2. Presume-se que a data final foi definida e documentada pela equipe de projeto e o cliente no Termo de Abertura do projeto. Deste modo, um membro da equipe de planejamento deve inserir a data final no software para iniciar a elaboração do Plano Mestre.

A seguir, a equipe de planejamento realiza o ciclo de sequenciamento, estimação e otimização do Plano Mestre, executando as atividades 1.3, 1.4, 1.5 e 1.6 em conjunto. Na atividade 1.3, os Resultados finais identificados são inseridos no software e o sequenciamento leva em consideração as interfaces e as dependências entre os Resultados finais. Na atividade 1.4, a equipe operacional analisa o esforço necessário para executar os resultados. Isso auxilia equipe de planejamento a estimar a duração de tempo dos Resultados finais na atividade 1.5. a equipe de planejamento realiza a otimização do Plano Mestre, identificando possíveis melhorias e analisando as interfaces entre os resultados finais na atividade 1.6. Nesta atividade, pode ocorrer a revisão das estimativas de duração e esforço, assim como a sequência dos Resultados finais.

O Plano Mestre para o caso do Globo Interativo (Apêndice C) ajuda a compreender as atividades 1.3 a 16. Os Resultados finais identificados para o caso foram o programa de testes do produto final, validação dos protótipos, globo terrestre e sistema de projeção. Esses resultados foram inseridos no software na ordem apresentada, que representa a ordem de traz para frente de execução. O Globo e o Sistema de projeção possuem uma interface clara e a solução para os dois resultados deve ser analisada pelas equipes operacionais em conjunto. Deste modo, esses Resultados finais foram sequenciados em paralelo em razão da interface. A duração Globo terrestre e Sistema de projeção foi efetuada em meses, finalizando ao mesmo tempo.

A atividade 1.7 compreende na definição dos principais milestones do projeto. Por exemplo, uma feira de tecnologia para a apresentação do protótipo do produto para o público e imprensa ou a data de lançamento do produto. No caso do Globo Interativo um milestone consistiu na entrega de protótipos e do produto final.

O Plano Mestre inicial é, então, apresentado para o Product Owner, os Stakeholders e membros das equipes operacionais na atividade 1.8. Todos os envolvidos participam da apresentação e devem analisar e ajudar a validar o Plano Mestre na atividade 1.9. Já na atividade 1.10 , a equipe de planejamento e as equipes operacionais definem a 
duração dos Sprints para a execução dos work items do projeto. O resultado principal dessa etapa é o Plano Mestre do projeto.

A próxima etapa do procedimento compreende em 2. Planejar Sprint Backlog. As atividades foram adaptadas do planejamento da iteração de Cohn (2008, p.150). A Figura 32 apresenta as a sequencia de atividades dessa etapa.

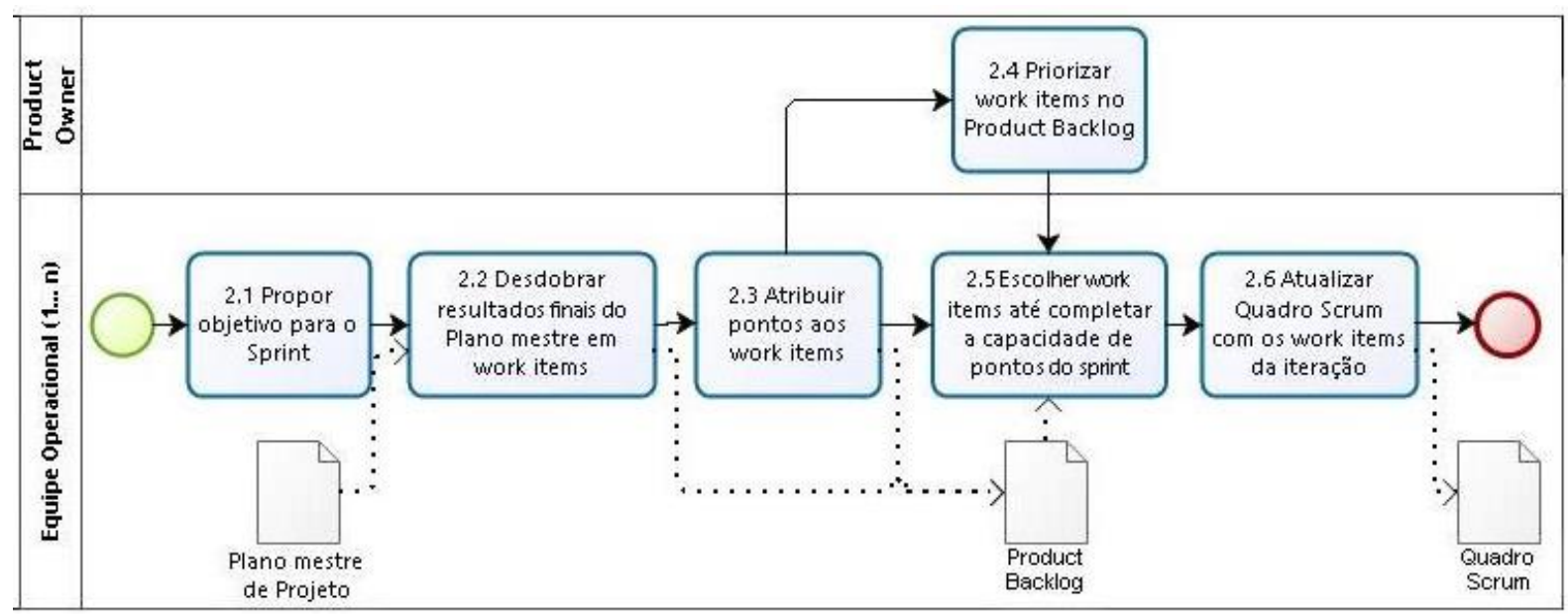

Figura 32 - Planejar Sprint Backlog

A equipe operacional inicia o planejamento do Sprint propondo um objetivo na atividade 2.1. O objetivo pode ser baseado em desenvolver uma funcionalidade específica do produto ou levar em consideração novas ideias, funcionalidades solicitadas ou capacidades organizacionais, por exemplo (COHN, 2008, p.150).

$\mathrm{Na}$ atividade 2.2, desdobra-se os resultados finais contidos no Plano Mestre em work items a serem desenvolvidos. Todos os work items devem ser inseridos e armazenados no Product Backlog. No caso do Globo Interativo, o Resultado final Globo terrestre, por exemplo, foi desdobrado nos work items "estudar tecnologias para o globo" e "preparar o protótipo do globo".

A atividade 2.3 consiste na atribuição de pontos aos work items. Os pontos são uma unidade de medida que expressa o tamanho total de um work item, sendo recomendada uma escala entre 1-10 para atribuir os pontos, conforme é apresentado no Planning Poker, subseção 2.2.2. Os pontos possibilitam verificar capacidade de execução e a velocidade da equipe operacional em um Sprint.

Por exemplo, a equipe operacional pode atribui cinco pontos para o work item “estudar tecnologias para o globo" e oito para o "protótipo do globo". Caso o Sprint tenha 
capacidade de treze pontos, a equipe executa os dois work items. Caso a equipe determinar oito pontos de execução para o Sprint, deve-se optar por estudar tecnologias ou preparar o protótipo. Ao final do Sprint, o total de pontos executados pela equipe é verificado e, assim, capacidade de pontos do próximo Sprint é ajustada de acordo com a velocidade de entrega da equipe.

O Product Owner auxilia a equipe operacional a priorizar os work items na atividade 2.4. A equipe operacional atualiza o Product Backlog com as prioridades. A priorização é levada em consideração para a escolha dos work items do próximo Sprint na atividade 2.5 .

$\mathrm{Na}$ atividade 2.6, os work items são listados no Quadro Scrum para o monitoramento, de forma visual, o progresso da equipe operacional. A etapa finaliza ao finalizar a criação do Quadro Scrum.

A terceira etapa do procedimento é 3. Executar Sprint: repetir para cada equipe operacional. A etapa consiste na execução dos work items planejados no Quadro Scrum. A Figura 33 ilustra as atividades envolvidas na etapa. Há três atividades de revisão do projeto, a Reunião diária, Sprint Review e Retrospective Review.

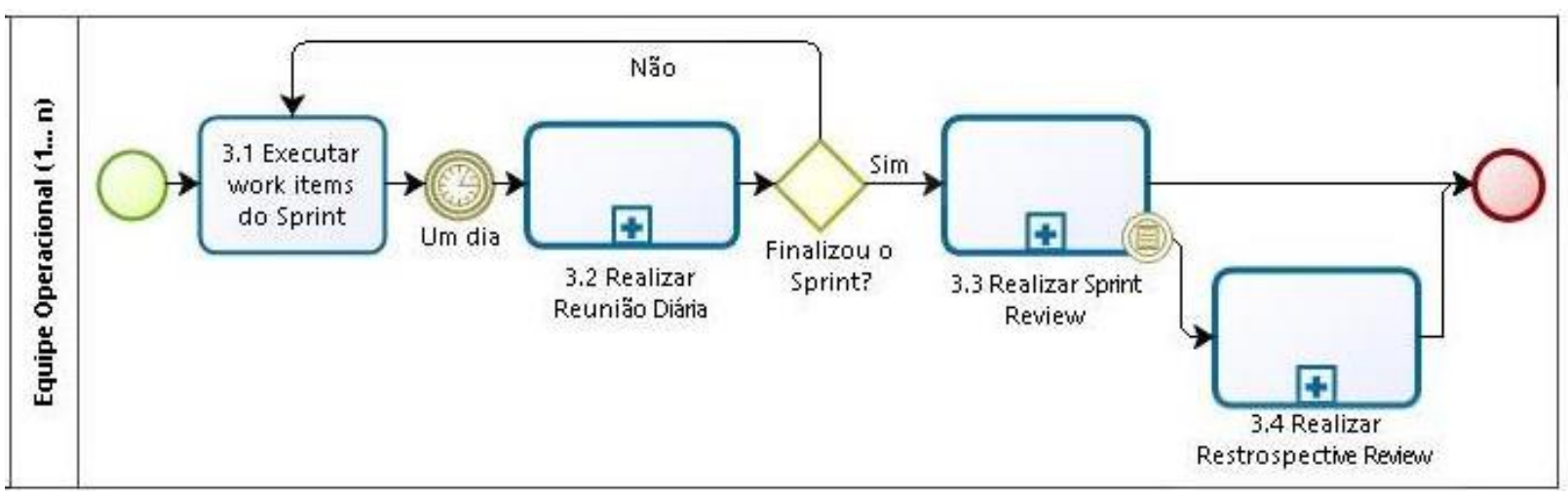

Figura 33 - Executar Sprint: repetir para cada equipe operacional $(1 \ldots \mathrm{n})$

A Reunião diária, atividade 3.2, compreende na sistematização das três perguntas características da Reunião diária do Scrum (Daily Scrum Meeting). Cada membro da equipe operacional deve responder as seguintes questões: "O que fiz?"; "O que irei fazer?”; "O que impede de fazer?" (SCHWABER, 2004, p. 135). A Figura 34 apresenta as tarefas a serem executas nessa atividade. 


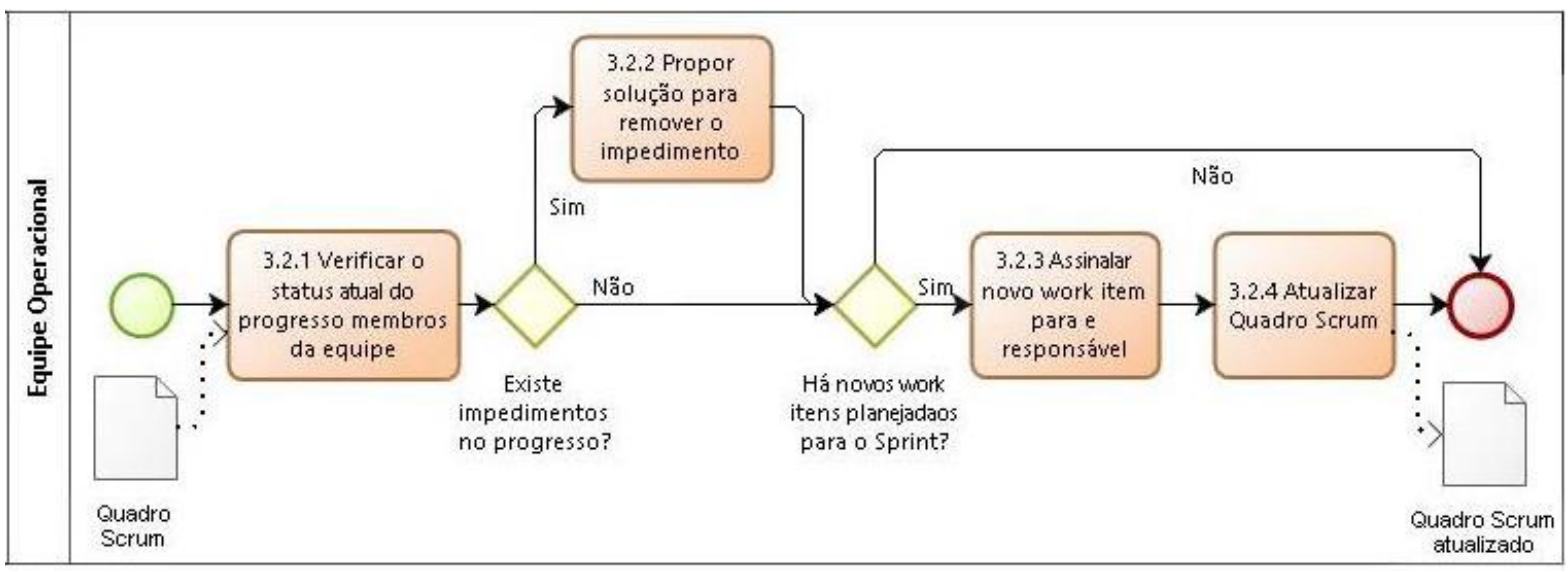

Figura 34 - Realizar reunião diária

A equipe operacional inicia a atividade executando a tarefa 3.2.1. O status de progresso dos membros da equipe operacional e a existência de work items completos são verificados. Por seguinte, cada membro reporta se há impedimentos na execução dos work items e, caso exista, discute-se como solucionar e remover o impedimento na tarefa 3.2.2. A equipe analisa o Quadro Scrum e verifica a existência de outros work items planejados para o Sprint. Na tarefa 3.2.3, um membro da equipe operacional responsabiliza-se por um novo work item. Por fim, na tarefa 3.2.4, a equipe atualiza o Quadro Scrum com as novas informações e finaliza a Reunião Diária.

A próxima atividade ocorre ao finalizar o Sprint. As equipes operacionais apresentam os resultados obtidos para o Product Owner e Stakeholders na atividade chamada de Realizar Sprint Review, que presenta a atividade 3.3 da Figura 34. A atividade adaptada de Schwaber (2004, p. 138) e é ilustrada na Figura 35.

Uma das equipes operacionais inicia a atividade apresentando o objetivo do Sprint e, em seguida, o resultado obtido na tarefa 3.3.1. Todas as equipes devem apresentar, mesmo se os resultados estiverem incompletos. O Product Owner e Stakeholders avaliam os resultados e provém feedback para as equipes operacionais na tarefa 3.3.2. O Product Owner pode solicitar mudanças no projeto ou redirecionar as equipes operacionais para outras prioridades. A equipe de planejamento analisa as mudanças no Plano Mestre e as equipes operacionais no Product Backlog nas tarefas 3.3.3 e 3.3.4. Todos os envolvidos no projeto participam das discussões sobre o impacto das mudanças. O Product Owner e Stakeholders devem então priorizar as mudanças solicitadas, executando a tarefa 3.3.5. Todas as informações geradas durante o Sprint Review são registradas pelos respectivos responsáveis. Caso não haver mudanças, a equipe de planejamento apenas atualiza o Plano Mestre com os 
dados de progresso apresentados pelas equipes operacionais na tarefa 3.3.7. Assim, finaliza-se o Sprint Review. A tarefa 3.3.6 consiste em passos para implementar as mudanças no projeto que se repetirá em outras atividades, assim, optou-se por explicá-la mais a frente no texto dessa seção em razão da importância desta para o procedimento.

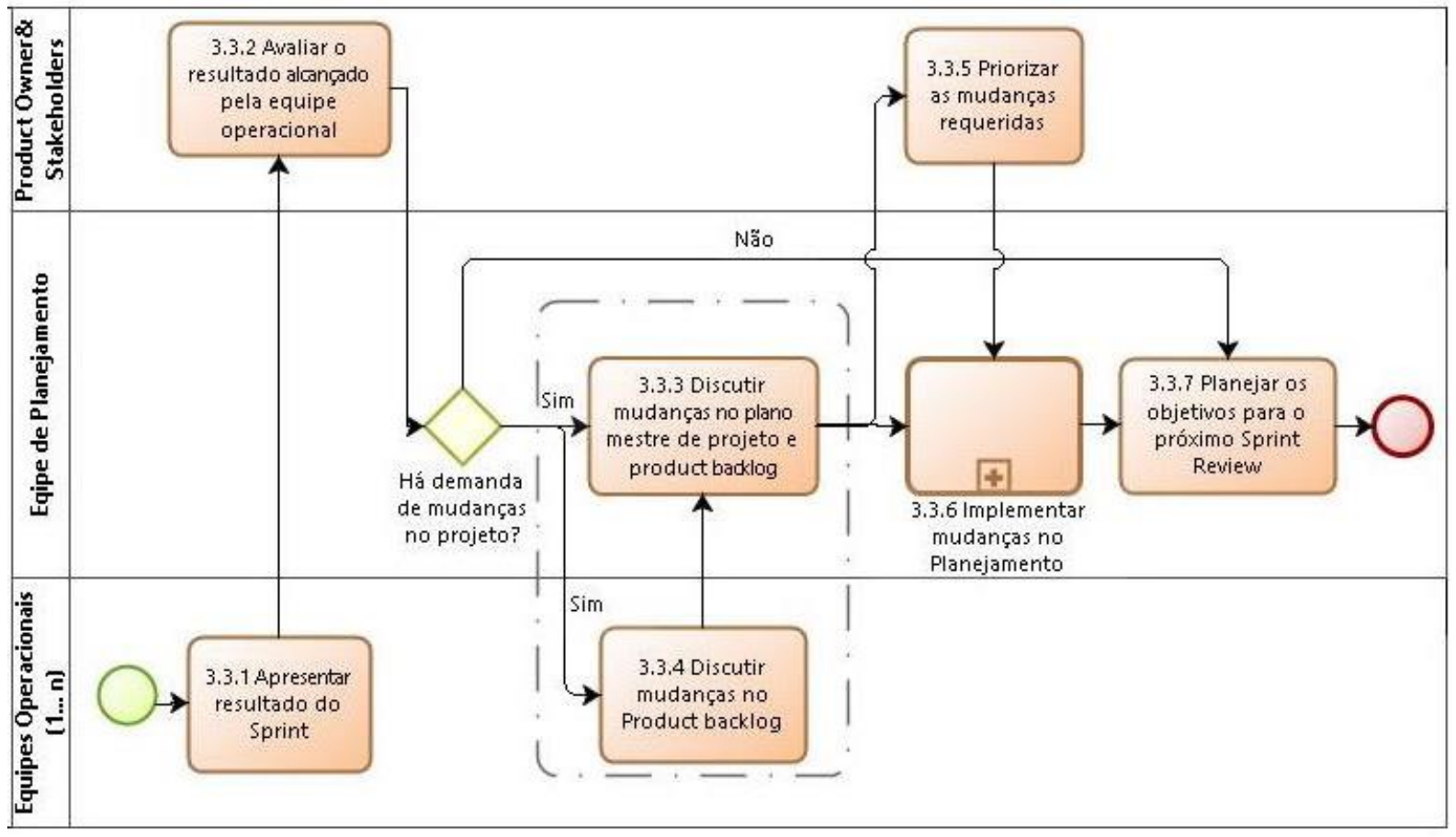

Figura 35 - Realizar Sprint Review

A próxima atividade da etapa 3 consiste em Realizar Retrospective review. A atividade 3.4 consiste em uma análise crítica realizada pela equipe operacional sobre o processo de execução do projeto. Objetiva-se a buscar por lições aprendidas que melhorem a execução do projeto. Por lições aprendidas, entende-se como o conhecimento adquirido durante o projeto que mostra como os eventos foram administrados ou como devem ser administrado no futuro com o proposito de melhorar a performance (PMI, 2013). As tarefas dessa atividade foram baseadas em Schwaber (2004, p. 138) e estão ilustradas na Figura 36.

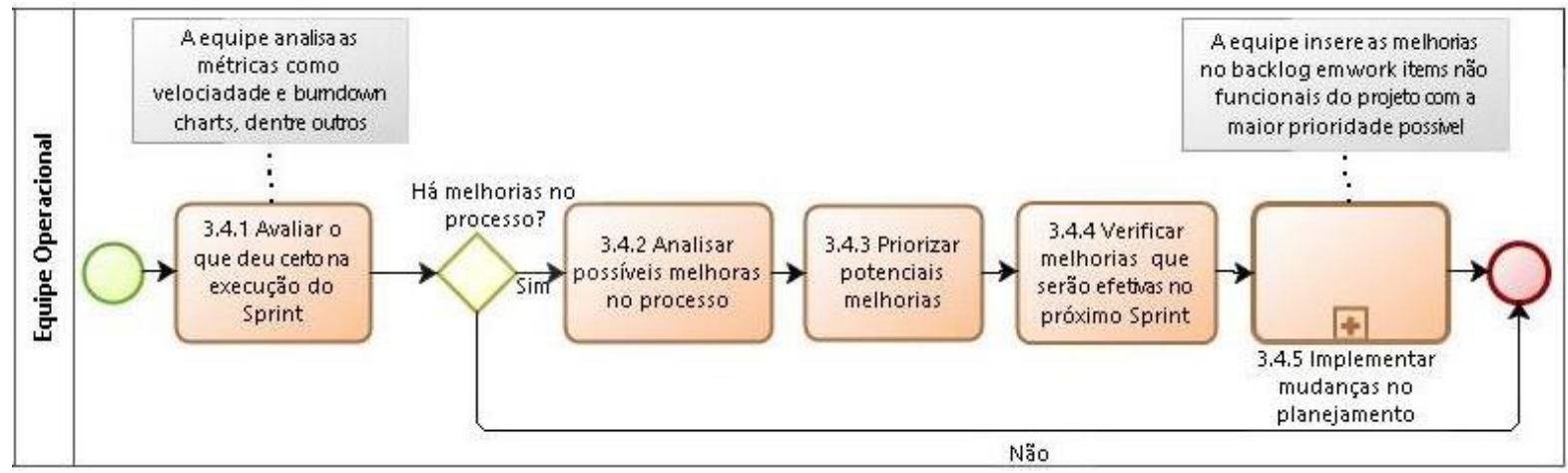

Figura 36 - Realizar Retrospective Review 
$\mathrm{Na}$ tarefa 3.4.1, a equipe operacional avalia os resultados positivos e negativos alcançados no Sprint. A equipe deve analisar as métricas, como velocidade, gráficos de desempenho, dentre outras métricas utilizadas para monitorar o progresso do projeto (LEFFINGWELL, 2011, p.168). Os resultados negativos na execução direcionam a equipe para identificar melhorias na tarefa 3.4.2. As melhorias são listadas e priorizadas na tarefa 3.4.3. A equipe verifica quais melhorias devem ser efetivas no próximo Sprint e as insere no Product Backlog como work items não funcionais com a maior prioridade possível (SCHWABER, 2004, p. 138) na tarefa 3.4.4.

O Sprint Review e o Restrospective Review possuem uma atividade de revisão dos planos que consiste em Implementar mudanças no planejamento, tarefas 3.3.6 e 3.4.5, respectivamente. A tarefa apresentada na Figura 37 objetiva-se por analisar o impacto das mudanças e implementá-las no Plano Mestre, Product Backlog e Quadro Scrum.

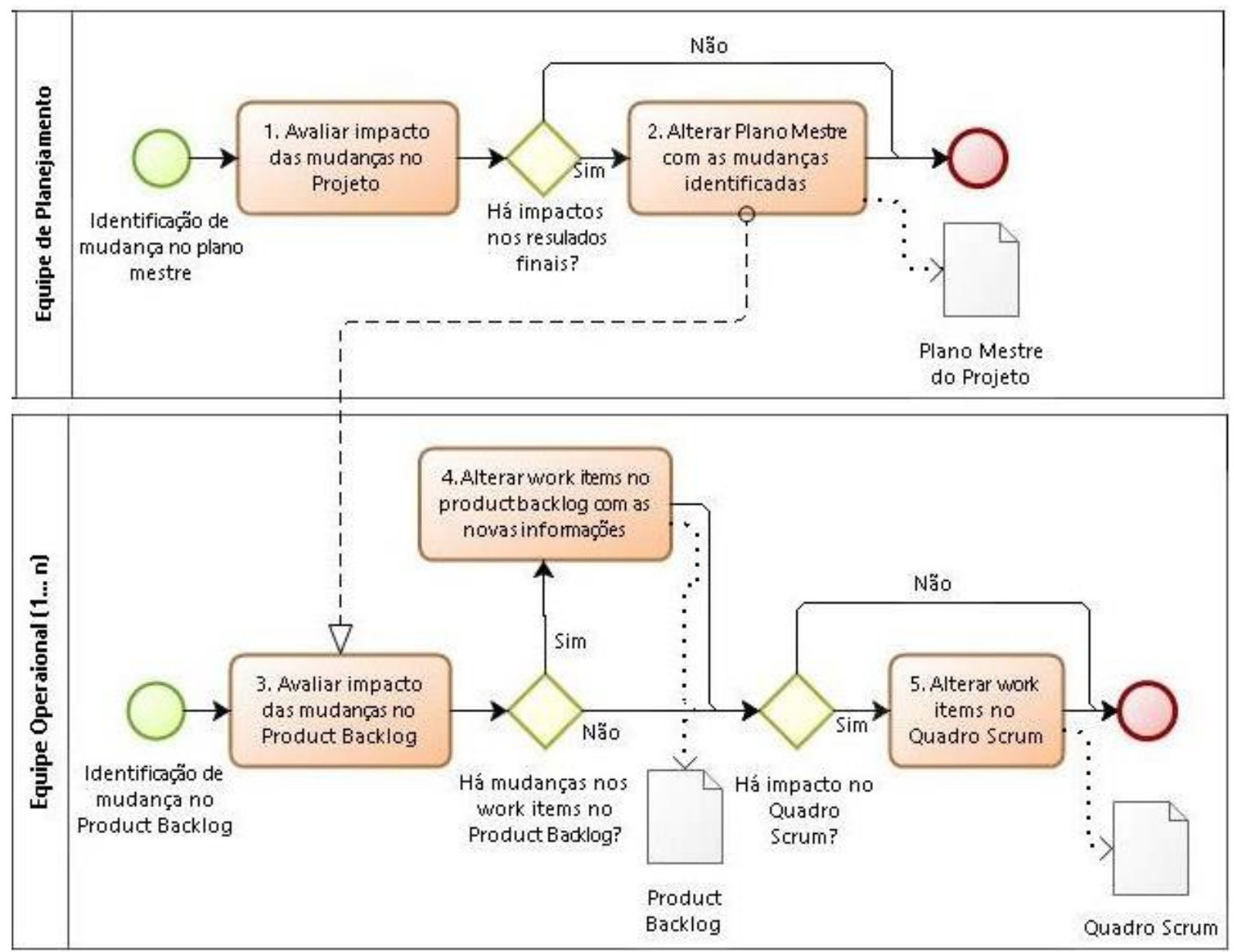

Figura 37 - Implementar mudanças no Planejamento

Caso ocorram mudanças no escopo do produto, essas podem afetar o Plano Mestre, alterando os resultados finais ou gerando novos. Por exemplo, o cliente pode solicitar 
uma nova funcionalidade para o produto. Por outro lado, pode ocorrer a descoberta de novos resultados finais com progresso do projeto e aumento de conhecimento sobre o produto. Deste modo, a equipe de planejamento deve analisar as mudanças na tarefa 1 . Se for o caso, a equipe de planejamento altera o Plano Mestre conforme as mudanças identificadas na tarefa 2. No momento de mudança e atualização do plano, o Product Owner deve ser cauteloso e levar em consideração os impactos nos milestones e prazo de entrega do projeto. Mudanças que afetem o prazo de entrega devem estar aprovadas junto aos Stakeholders principais.

As mudanças no Plano Mestre podem afetar diretamente o Product Backlog, pois a inserção de um novo resultado final gera novos work items, por exemplo. Por outro lado, novos work items podem ser descobertos e definidos pela equipe operacional. De qualquer forma, a inserção ou remoção de work items afetam a prioridade dada aos work items. Deste modo, a equipe operacional analisa o impacto da mudança no Product Backlog na tarefa 3. Se for o caso, as mudanças nos work item são implementadas na tarefa 4.

Podem existir casos em que a mudança no Product Backlog afetam os work items planejados no Quadro Scrum. Assim, a equipe operacional altera os work items planejados na tarefa 5 .

Ao final desta atividade de Implementar mudanças no planejamento todos os artefatos são atualizados. O objetivo é criar uma sistemática para atualização dos artefatos de projeto para incorporar mudanças no escopo do produto. A equipe de planejamento deve ser cautelosa com essa atividade. Ressalta-se que a execução demasiada e sem controle desta atividade pode afetar a execução do projeto. Os artefatos não devem sofrer uma de alteração completa do conteúdo em todos os Sprints. Isso resultaria em perda de foco da equipe de projeto e pode até inviabilizar o projeto.

A última etapa do procedimento consiste em executar o 4. Milestone Review. O Milestone Review pode ser uma revisão similar a um Design Review, ou mais estruturado semelhante a um Gate. A pesquisa apresenta atividades que se assemelham com o primeiro caso, porém, de forma simplificada. Uma proposta das atividades é apresentada na Figura 38. 


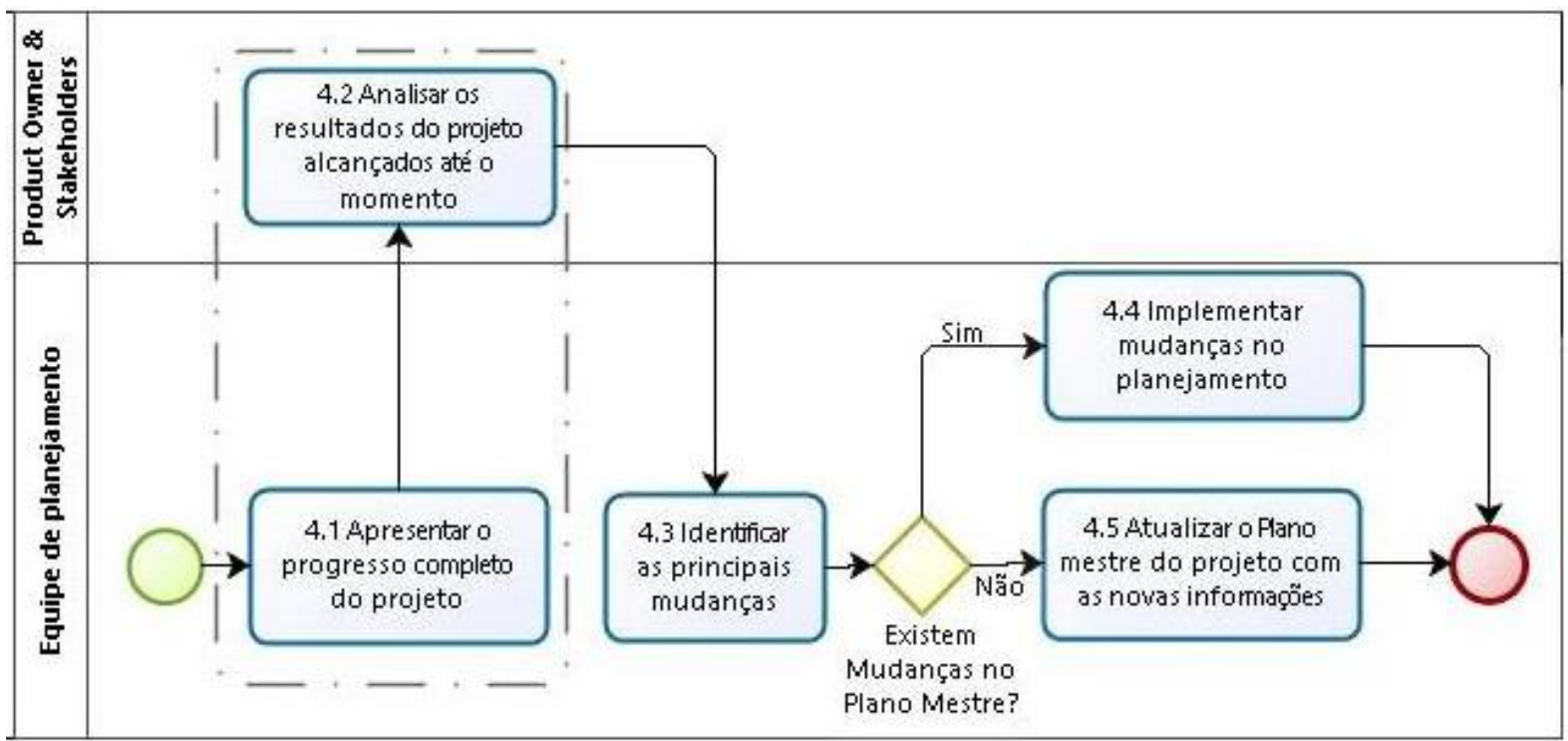

Figura 38 - Milestone Review

O objetivo do Milestone Review é apresentar para o Product Owner e Stakeholders o progresso completo do projeto na atividade 4.1, que abrange todos os Resultados finais do Plano mestre. O Product Owner e Stakeholders analisam o progresso e provêm o feedback na atividade 4.2., e podem solicitar mudanças nos resultados finais, nos work items ou nas prioridades das equipes. A equipe de planejamento analisa as solicitações e verificar os impactos das mudanças na atividade 4.3. Caso as mudanças forem aprovadas, a equipe de planejamento atualiza o Plano Mestre, executando a atividade 4.4 de Implementar mudanças no planejamento. Caso não haver mudanças, a equipe de planejamento atualiza o Plano Mestre com as novas informações na atividade 4.5 e finaliza esta etapa.

Por fim, a equipe de projeto verifica se o projeto alcançou a data de entrega e deve ser finalizado. Caso existir Sprints e work items a serem desenvolvidos, executa-se novamente a etapa de planejar Sprint Backlog e, em seguida, a executa-se o Sprint. 


\section{ESTUDO DE CASO}

\subsection{Planejamento do Caso}

O planejamento do estudo de caso envolveu três etapas: (1) Programa geral, que estabelece as informações sobre o objetivo do caso, o tempo total para execução do caso e o público alvo; (2) Cenário do treinamento, que apresenta o desafio a ser solucionado; e (3) Plano de aulas e eventos principais do treinamento. Descreve-se cada etapa nas próximas subseções.

\subsubsection{O Programa Geral}

Objetivo do caso é simular um projeto utilizando o procedimento de planejamento de tempo combinado, tradicional e ágil. O cenário de simulação consiste em um treinamento sobre APM, onde o publico é convidado a planejar um projeto utilizando o procedimento, executar o planejamento e entregar o produto ao final da simulação.

O público alvo são alunos de graduação da Universidade de São Paulo (USP) que iniciaram ou finalizaram o curso de Gestão de Projetos. Esse público foi escolhido em razão do fácil acesso aos alunos, pois o curso é administrado por um dos pesquisadores envolvido nesse trabalho. Também, porque possuem o conhecimento mínimo para participar do treinamento, aprendendo o conteúdo de forma mais rápida comparada com outros que não possuem conhecimentos em Gestão de Projetos. Além disso, estão aptos a elaborarem críticas construtivas relacionadas ao procedimento.

O tempo de duração total estimado para executar todas as atividades do treinamento foi 8 horas. As atividades abrangem desde o ensino da teoria do APM até a simulação do projeto utilizando o procedimento.

O número estabelecido de participantes por equipe são 10 pessoas. Tendo em vista a Estrutura organizacional proposta para a equipe de projetos, as dez pessoas irão desempenhar o papel de Membro, Líder ou Product Owner. O papel de Cliente será executado por um monitor do treinamento, pois, assim, garante-se que o Cliente possui o entendimento profundo sobre o produto em questão para auxiliar a equipe de projeto. 


\subsubsection{O Cenário do Treinamento}

O Cenário do treinamento consiste na criação de foguetes de água. A Figura 39 ilustra uma competição de foguetes de água. Na competição, as equipes são desafiadas a criar um foguete de propulsão a água e ar, que voe a maior distância possível. As equipes são solicitadas, também, a criar um sistema de acionamento para evitar o lançamento precoce do foguete. O lançamento ocorre quando se adiciona ar comprido no reservatório interno do foguete, que contêm água, assim eleva-se a pressão a um determinado valor e a água é ejetada e o foguete lançado. No treinamento, o Cliente solicitou para a equipe de projeto um foguete para participar da competição.
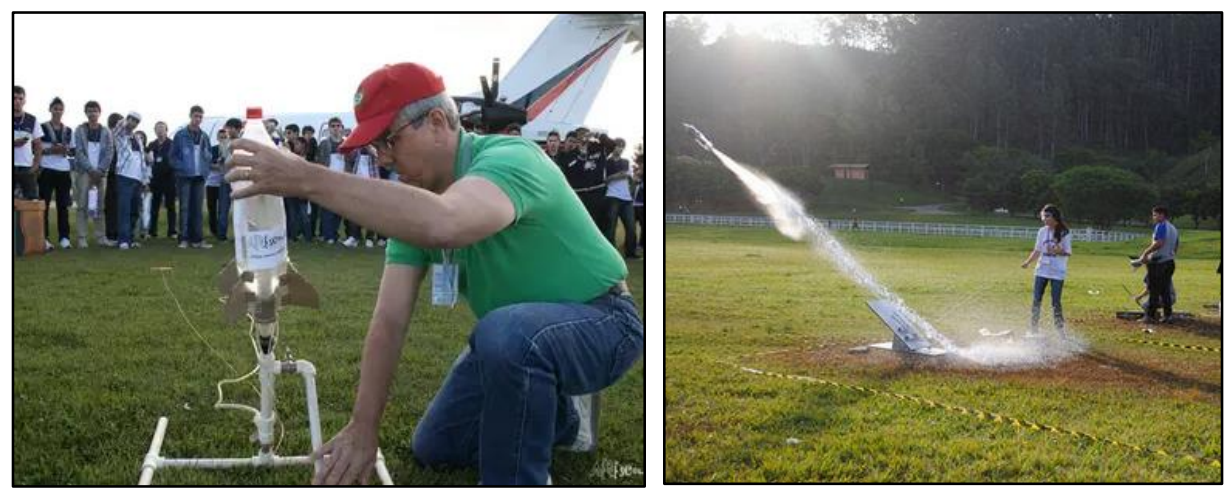

Figura 39 - Desafio do foguete de água Fonte: National Physical Laboratory (2014)

O Sistema Foguete é composto por três subsistemas, conforme apresenta a Figura 40: (A) Corpo do foguete, composto de uma garrafa Pet, e funciona como o reservatório de água e ar; (B) Mecanismo de acionamento, sistema de segurança que permite o lançamento do foguete quando acionado; e (C) Plataforma de lançamento regula o ângulo de lançamento e serve como uma base para sustentar todo o sistema.

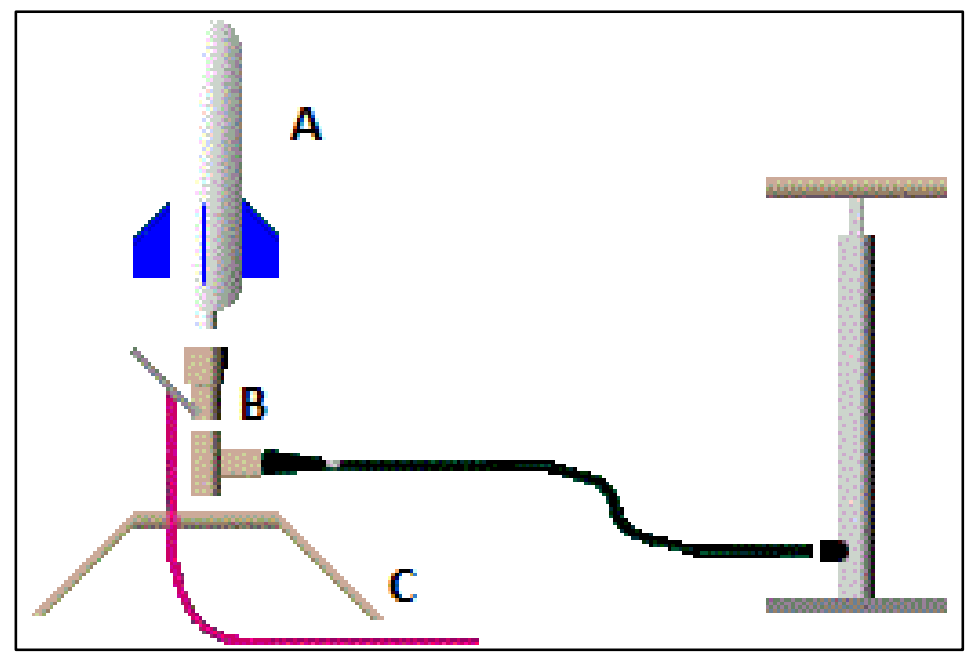

Figura 40 - Subsistemas do Foguete 
Os materiais envolvidos na construção do Foguete consistem em garrafas PET, tubos e conexões de PVC, barbante, entre outros. No site Clube de Astronomia do Colégio Estadual do Paraná (CACEP) foi encontrado o roteiro para a montagem do foguete, assim como a lista de todos os materiais envolvidos. Com isso, foi elaborada a lista de materiais para o treinamento e os detalhes desta lista podem ser consultados no Protocolo de Estudo de Caso (Apêndice G).

\subsubsection{O Plano de Aulas e eventos principais}

Quatro dias de aula foram disponibilizados pelo professor responsável pela disciplina de Gestão de Projetos para a condução do treinamento. Cada dia corresponde a uma aula com duração de duas horas, totalizando oito horas para a condução do treinamento.

Sete eventos principais do treinamento foram definidos para integrarem os quatro dias: uma aula teórica sobre APM, três Sprints, com duração de 1 hora, e dois Sprints Reviews, pontos de revisão e avaliação do projeto. A Figura 41 ilustra a divisão dos dias e a associação com os sete eventos definidos.

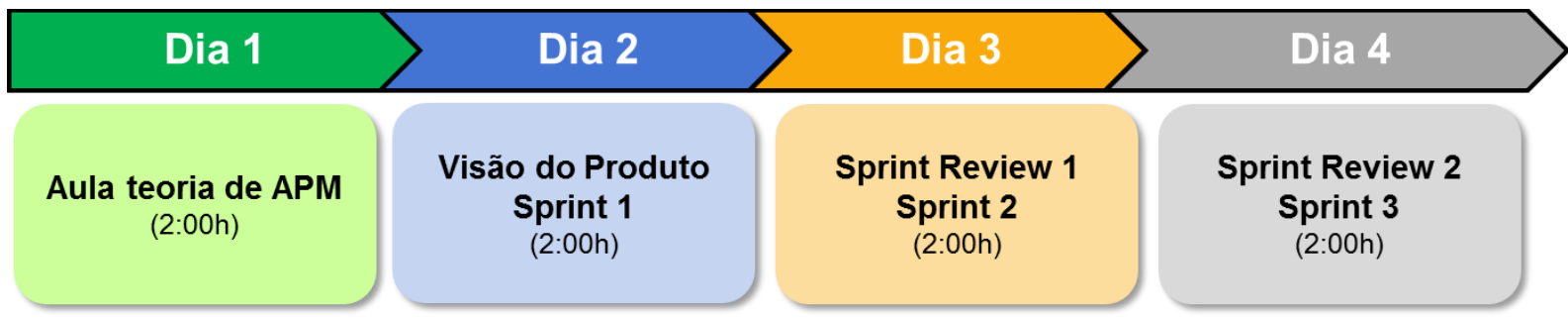

Figura 41 - Cronograma de atividades do treinamento

O Dia 1 é destinado à aula teórica sobre de Gestão Ágil de Projetos (APM). A aula foi conduzida por um monitor do treinamento e abrangeu temas como a origem do APM, os métodos ágeis, as quatro principais diferenças entre a gestão Tradicional e o Ágil, as vantagens do ágil e os desafios para projetos inovadores, como as incertezas, complexidade, várias equipes de projetos. O dia finalizou abordando a combinação das práticas e apresentando o procedimento de planejamento de tempo combinado.

O Dia 2 consistiu na organização da equipe de projeto e início do planejamento. As equipes de projeto serão organizadas e nomeadas em três por cores, Azul, Vermelha e Preta. Os membros da equipe de projeto foram escolhidos aleatoriamente e foram divididos 
em três equipes operacionais, representando os subsistemas do projeto, Foguete, Acionamento e Plataforma. As equipes operacionais foram compostas pelo Líder e os Membros. Os Líderes serão escolhidos pelos membros da equipe de projeto. Um crachá foi distribuído para cada pessoa para identificar a equipe e o papel desempenhado no treinamento visando auxiliar na análise dos registros fotográficos.

O Início do planejamento do projeto foi divido em duas partes, a apresentação da Visão do Produto e o Sprint 1. A Visão do Produto foi a apresentada utilizando o cenário do treinamento (Apêndice I). A visão foi entregue e explicada para as equipes de projeto pelo Cliente. Neste momento, o Cliente indicou a prioridade dos requisitos do produto que, em ordem de importância, e corresponderam a: (1) Ir mais longe possível; (2) Caber dentro do carro; (3) Reutilização (número de lançamentos); e (4) Não se molhar ao acionar o lançamento. No Sprint 1, os alunos entenderam o problema e iniciar o planejamento do projeto elaborando o Plano Mestre. O Cliente estava disponível para as equipes tirarem dúvidas sobre o problema. O Quadro 23 apresenta a programação das atividades planejadas para o Dia 2 e os respectivos responsáveis.

Quadro 23 - Programação planejada para o Dia 2

\begin{tabular}{|l|l|l|}
\hline Atividade & Duração & Responsável \\
\hline - Organizar a equipe de projeto & $15 \mathrm{~min}$ & Monitores \\
\hline - Distribuir o material do cenário do treinamento & $10 \mathrm{~min}$ & Monitores \\
\hline - Apresentar a Visão do produto e as prioridades & $20 \mathrm{~min}$ & Monitores \\
\hline - Explicar o funcionamento do Sprint & $10 \mathrm{~min}$ & Monitores \\
\hline - Executar o Sprint 1 & $60 \mathrm{~min}$ & Equipe de Projeto \\
\hline - Fazer o fechamento do Dia 2 & $5 \mathrm{~min}$ & Monitores \\
\hline
\end{tabular}

O Dia 3 corresponde ao início da execução do projeto. O primeiro evento do dia foi revisar o Plano Mestre elaborado pela equipe de projeto durante o Sprint Review 1 com o Cliente e a Equipe de Planejamento. Ao finalizar a revisão, as equipes planejaram as atividades a serem executas no Sprint 2 e elaborarão o Quadro Scrum para cada subsistema e iniciaram a execução do projeto. O Quadro 24 apresenta a programação das atividades planejadas para o Dia 3 e os respectivos responsáveis. 
Quadro 24 - Programação planejada para o Dia 3

\begin{tabular}{|l|l|l|}
\hline Atividade & Duração & Responsável \\
\hline - Revisar o Plano Mestre & $25 \mathrm{~min}$ & Equipe de Projeto e Cliente \\
\hline - Elaborar o Product Backlog e o Quadro Scrum & $20 \mathrm{~min}$ & Equipe de Projeto \\
\hline - Distribuir o material para construir os foguetes & $10 \mathrm{~min}$ & Monitores \\
\hline - Executar Sprint 2 & $60 \mathrm{~min}$ & Equipe de Projeto \\
\hline - Fazer o fechamento do dia 3 & $5 \mathrm{~min}$ & Monitores \\
\hline
\end{tabular}

O Dia 4 compreende na finalização do projeto. No Sprint Review 2 equipes apresentaram os resultados alcançados após a execução do Sprint 1 para a avaliação do Cliente. Logo após a revisão, as equipes planejaram as atividades do próximo a Sprint e definiram as atividades, indicando-as no Quadro Scrum. No Sprint 3, as equipes de projeto executaram as atividades e finalizaram o projeto. O Quadro 25 apresenta a programação de atividades do dia 4.

Quadro 25 - Programação planejada para o Dia 4

\begin{tabular}{|l|l|ll|}
\hline Atividade & Duração & Responsável & \\
\hline - Feedback para as equipes sobre o projeto & $25 \mathrm{~min}$ & Monitores & \\
\hline $\begin{array}{l}\text { - Executar Sprint Review 1 (simular Daily } \\
\text { Meeting) }\end{array}$ & $30 \mathrm{~min}$ & $\begin{array}{l}\text { Equipe de Projeto e } \\
\text { Monitores }\end{array}$ & \\
\hline - Executar Sprint 2 & $60 \mathrm{~min}$ & Equipe de Projeto \\
\hline - Apresentar os protótipos & $5 \mathrm{~min}$ & Equipe de Projeto \\
\hline
\end{tabular}

Todo o procedimento para a execução do treinamento e outras informações, como materiais necessários, são apresentados no Protocolo de Estudo de caso (Apêndice G).

\subsection{Execução do Caso}

A seção descreve os acontecimentos e as evidências coletadas durante o treinamento com os alunos de graduação, apresentadas na ordem dos dias 2,3 e 4, conforme o planejado na seção anterior. 


\subsubsection{Dia 2 - Planejamento do projeto}

O Dia 2 considerou o início do planejamento do projeto. A Visão do produto foi apresentada por um dos monitores, representando o Cliente do projeto, utilizando o cenário do treinamento (Apêndice I). No Sprint 1, o primeiro desafio proposto para as equipes foi o de entender a Visão do produto. Os membros das equipes se reuniram para discutir o problema e o Cliente permaneceu à disposição para ser consultado.

As equipes Preta e Vermelha perceberam logo que precisavam de informações do cliente, consultando-o no início do Sprint 1. As duas equipes questionaram o Cliente sobre a posição de lançamento, quantidade de lançamentos, necessidade de trava de segurança e transporte do produto, assim como priorizar requisitos do produto.

Com as informações do Cliente, as equipes Preta e Vermelha entenderam a visão do produto mais rapidamente do que comparado com a equipe Azul que, em contraposição, consumiu o tempo disponível em uma tarefa interna de planejando, definindo o trabalho sem questionar o cliente.

A interação com o Cliente evidência que as equipes Preta e Vermelha que focaram na compreensão dos requisitos iniciais obtiveram um ganho em conhecimento para diminuir a ambiguidade inicial do projeto e velocidade para planejamento o projeto, conforme o discutido na seção 3.4 , fatores críticos.

A próxima atividade das equipes foi preparar o Plano Mestre (PMe). Todas as equipes elaboraram o plano e definiram os Resultados finais por subsistema. Os Resultados finais foram identificados, no plano, de acordo com a cor do post-it para facilitar a visualização e sequenciados por subsistema, conforme o solicitado pelos monitores. A Figura 42 ilustra o Plano Mestre da equipe Preta.

Duas diferenças foram observadas na forma como as equipes elaboraram o PMe. A primeira diferença compreendeu a identificação dos Sprints no PMe. As equipes Preta e Azul identificaram os Sprints no PMe e a equipe Vermelha não. A segunda diferença foi a unidade de tempo apresentada no PMe. As equipes dividiram as células do PMe em unidades de tempo, que contemplava o tempo total para a execução do projeto (3 horas), mas com valores diferentes, equipe Azul 15 min, Preta 7,5 min e Vermelha 5 min. 


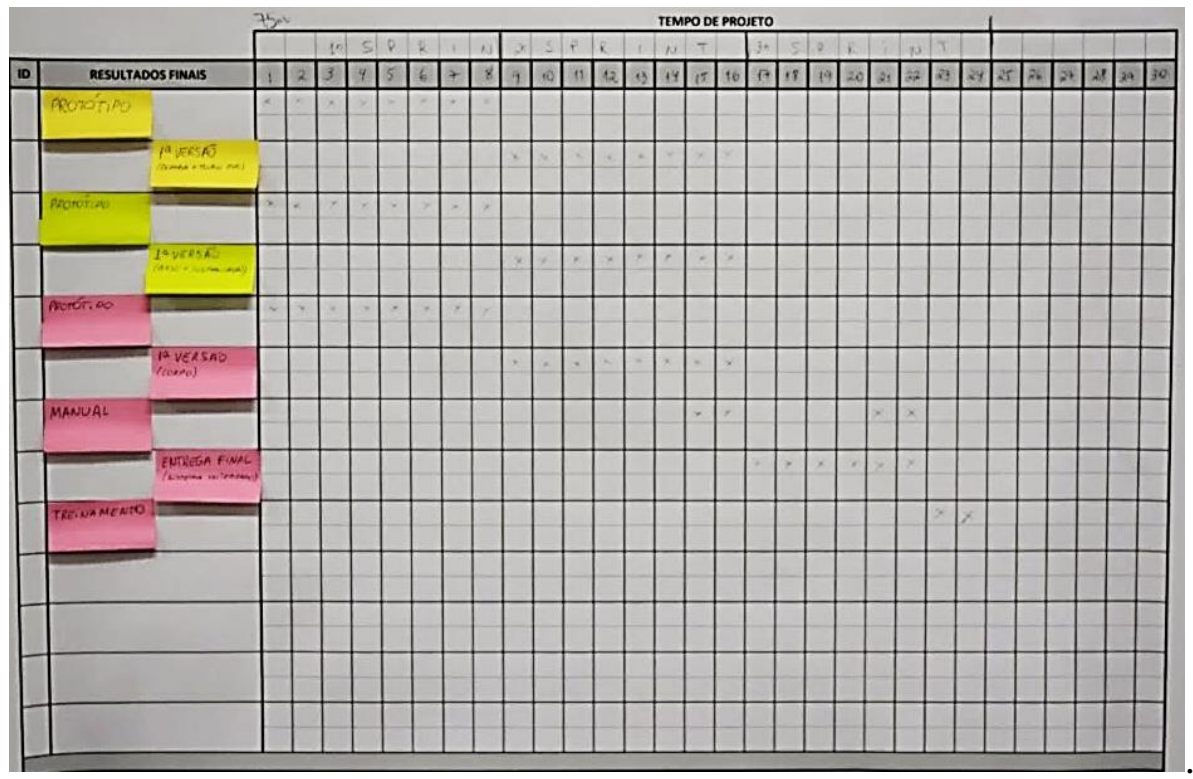

Figura 42 - Plano Mestre equipe Preta

Ao observar o progresso das equipes com o planejamento do projeto, notou-se que as equipes focaram também em solucionar o problema durante o primeiro Sprint. Por exemplo, a equipe Vermelha definiu todas as soluções para o protótipo do foguete, mesmo sem conhecer quais materiais que iriam ser disponibilizados para as equipes, resultando em perda de tempo replanejando a solução nos Sprints seguintes.

Outro destaque observado consistiu na estrutura organizacional proposta no procedimento. A Figura 43 ilustra cada subsistema da equipe Azul discutindo isoladamente quais deveriam ser os resultados finais. Momentos depois, a Figura 44 apresenta os líderes de cada subsistema criando o PMe com os inputs de cada subsistema. A equipe Vermelha seguiu o mesmo padrão da equipe Azul para a estrutura organizacional.

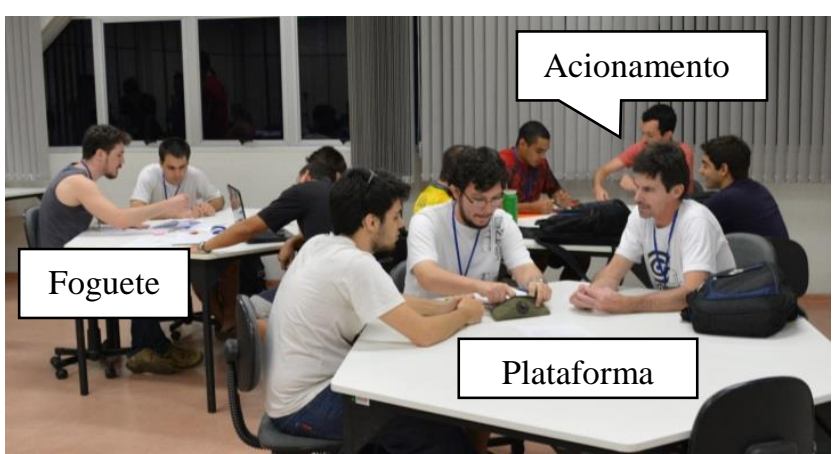

Figura 43 - Os subsistemas planejando os resultados finais.

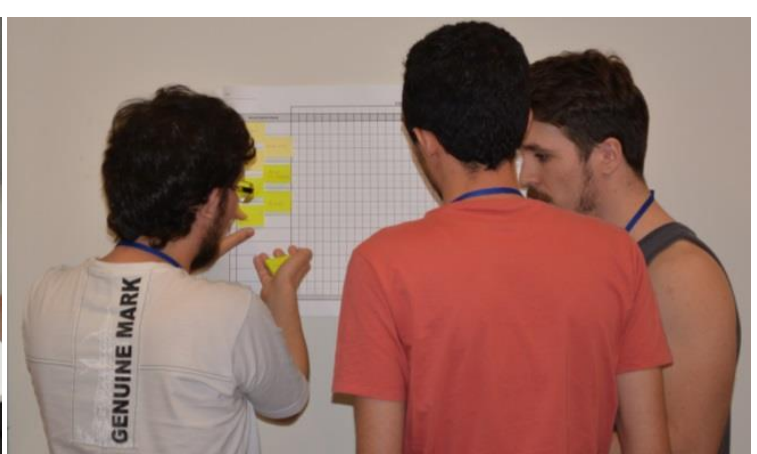

Figura 44 - Líderes criando o Plano Mestre 
A equipe Preta, ao contrário, assumiu uma estrutura única onde apenas um dos líderes comandava a discussão. A Figura 45 ilustra o evento observado. O líder atua semelhante a um gestor de projetos. Foi observado, também, que algumas pessoas não participaram ativamente do debate sobre o planejamento e os resultados finais do projeto.

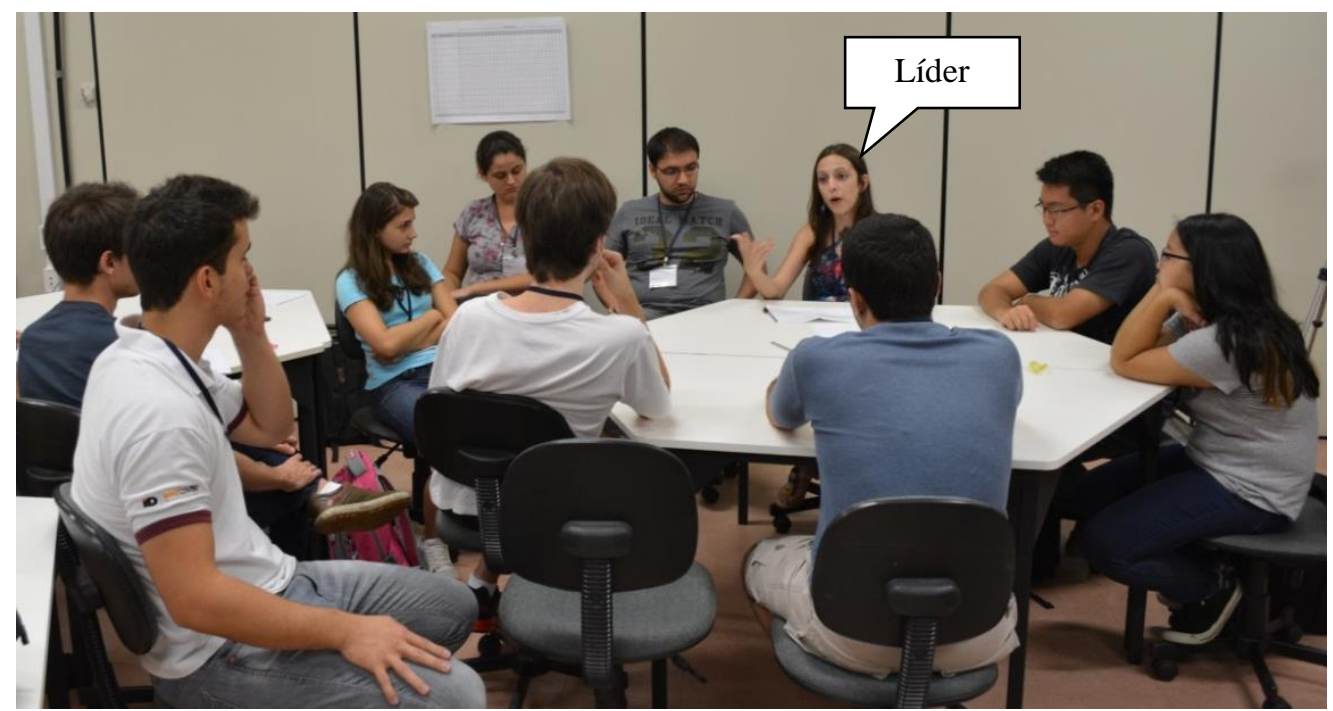

Figura 45 - Líder assumindo o papel de gerente de projetos

\subsubsection{Dia 3-Execução do projeto}

No Sprint Review 1, as equipes focaram na finalização do planejamento e criação do Plano Mestre (PMe). Depois, as equipes executaram o próximo passo do procedimento, definir os work items, elaborar o Product Backlog e criar o Quadro Scrum para cada subsistema.

Os work items foram definidos visando o horizonte de planejamento de um Sprint. As equipes estabeleceram a ordem a qual iram ser executados durante o Sprint 2. Não houve uma tentativa de hierarquização, semelhante a uma WBS, em nenhuma das equipes. As equipes seguiram a estratégia ágil de definição das atividades conforme o procedimento.

O Product Backlog $(P B)$ foi elaborado por apenas uma equipe e não há indícios que as equipes priorizaram os requisitos durante o Sprint Review 1. A equipe Azul foi a única que elaborou uma lista de work items principais, por subsistema, que se assemelhou com o PB. Embora tenham criado a lista, não há indícios que a equipe priorizou os work items. Considera-se que as equipes não utilizaram o $\mathrm{PB}$ para listar os work items necessários para o projeto. Isso pode ter ocorrido por falta de incentivo por parte do pesquisador para que os alunos a criarem o artefato e devido ao curto tempo para planejar e executar o projeto. 
O Quadro Scrum (QS) foi elaborado conforme o procedimento em duas equipes. A equipe Azul e Vermelha elaboram o QS para todos os subsistemas. A equipe Preta não elaborou, pois começou a solucionar o problema e ignorou o QS. Aparentemente, a equipe Preta pareceu ser a mais desorganizada e teve mais dificuldades em executar o Sprint 2 dentre as demais.

Foi observado que a equipe Azul fixou o QS na parede, enquanto que a equipe Vermelha deixou em cima da mesa. Não foi identificado diferenças entre as performances das equipes em razão da posição do quadro. Por outro lado, foi mais fácil identificar qual o work item que estava sendo executado em um determinado momento como o QS fixado na parede. Desde modo, o quadro funcionou como um dispositivo de gestão visual.

Ao final do Sprint Review 1, as equipes deveriam validar o PMe com o cliente antes de iniciar o Sprint 2 de acordo com o procedimento. No entanto, nenhuma equipe consultou o cliente para mostrar o PMe final. Ao analisar os artefatos físicos foram encontradas algumas inconsistências no plano, nesse sentido, a validação poderia auxiliar as equipes a revisar o PMe com o cliente, deixando-o mais robusto. As inconsistências são abordadas no Sprint Review 2.

No Sprint 2, as equipes colocaram em prática o planejamento do projeto, executando os work items estabelecidos no Quadro Scrum (QS). Dois eventos principais chamaram a atenção do pesquisado ao observar as equipes: (1) controle dos QS e (2) comunicação e organização.

Os QS foram utilizados para controlar a execução dos work items conforme o procedimento. Para exemplificar, o pesquisador analisou o quadro da equipe Azul e identificou o work item "definir design do foguete". Um membro do subsistema Foguete foi questionado sobre o que estava sendo executado no momento e a resposta coincidiu com o work item. Por outro lado, ao questionar a mesma pessoa sobre os work items de outro subsistema, ele não soube responder com precisão. O mesmo ocorreu quando foi questionado um membro de um subsistema da equipe Vermelha.

A comunicação entre os subsistemas aumentou e duas equipes adotaram uma estrutura organizacional diferente durante o Sprint 2. As equipes Vermelha e Azul assumiram uma estrutura organizacional onde os subsistemas Foguete e Acionamento ficaram reunidos para discutir as interfaces, enquanto o subsistema Plataforma permaneceu isolado. A Figura 46 ilustra a estrutura adotada na Equipe Vermelha. 


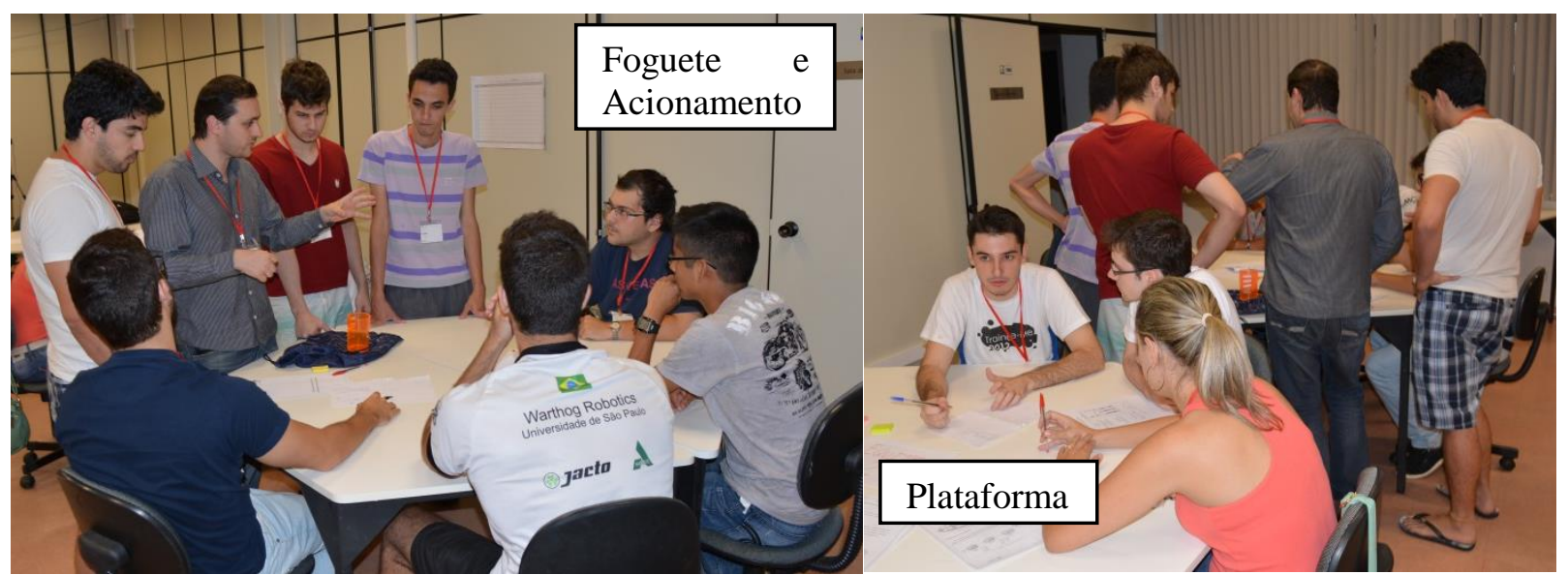

Figura 46 - Estrutura adotada pela equipe Vermelha durante o Sprint 2

De forma diferente, a equipe Preta iniciou a execução do projeto sem criar os QS e adotou a estrutura organizacional proposta no procedimento. Dificuldades com as interfaces do produto obrigaram aos líderes se comunicarem com frequência. Em destaque na Figura 47, mostra-se o plano de entrega das versões do produto, como o protótipo e as versões do produto elaborado pelos líderes da equipe. Note na figura, também, as interfaces do produto.

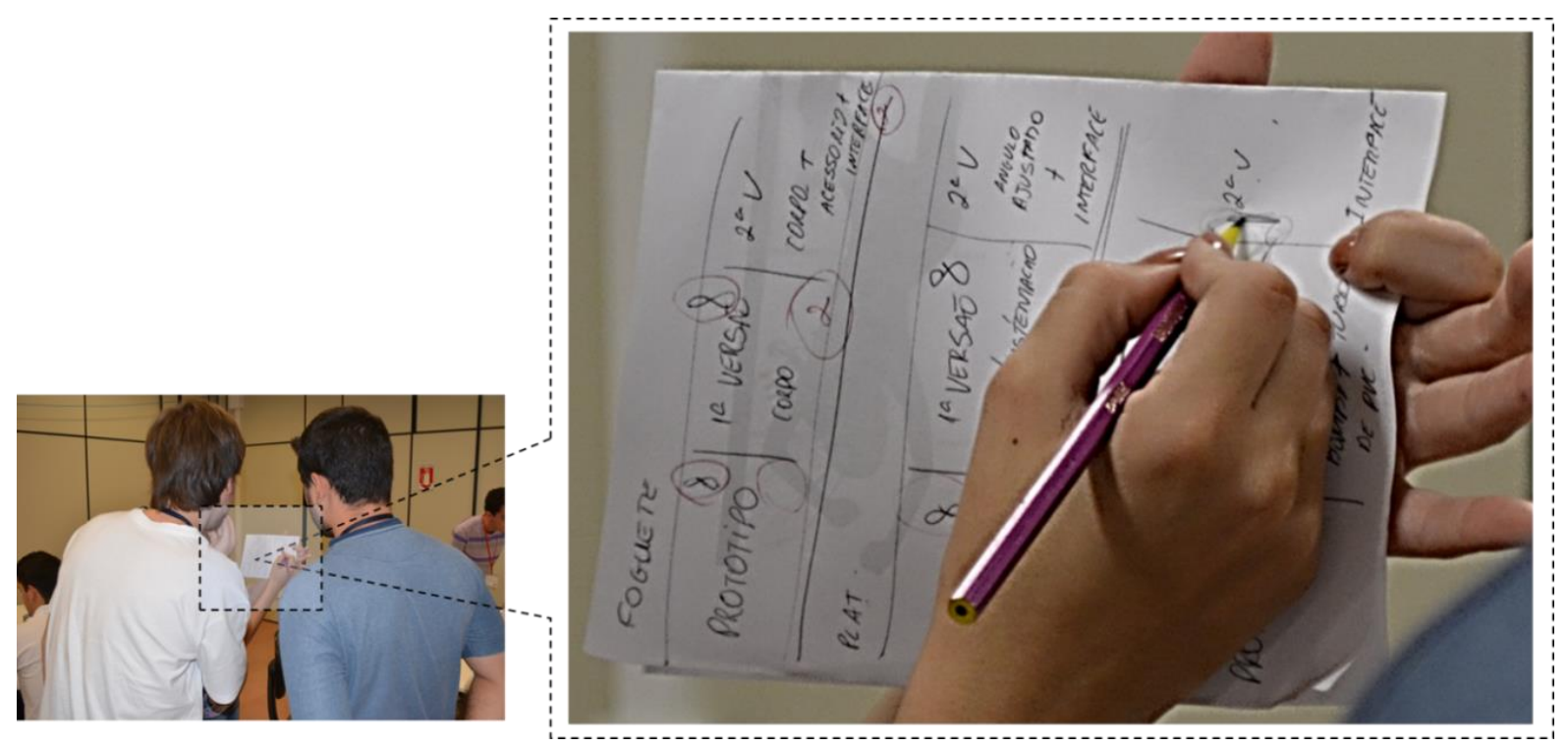

Figura 47 - Líderes da equipe Preta discutindo as interfaces do produto

Aparentemente, definir uma solução para a interface entre o foguete e o acionamento foi o desafio mais difícil para todas as equipes. As Interfaces do produto obrigaram os subsistemas a aumentar o nível de comunicação. Isso justifica a organização adotada pelas equipes Vermelha e Azul. O aspecto negativo dessa organização foi deixar de fora da discussão outra importante interface, entre a plataforma e o acionamento. Esperava-se que as duas equipes continuassem a estrutura proposta pelo procedimento, onde os 
subsistemas trabalham isoladamente e os líderes discutem entre si, conforme o observado na equipe Preta. No entanto, não foram observadas diferenças nas performances em razão da estrutura adotada.

Interfaces foram propositalmente criadas para serem dependentes para observar o comportamento das equipes. Nas equipes Vermelha e Azul, observa-se que a plataforma foi o subsistema mais independente e executou os work items de forma isolada ou pouca interação com os outros. Esse evento pode ser associado à recomendação de minimizar as dependências de atividades delegando porções independentes para um mesmo time (LEE, DELONE E ESPINOSA, 2006). Também com a decomposição do projeto em módulos de atividades independentes, e coordenar as ações dos sub-times (BARLOW et al., 2011). Logo, pode considerar-se que a dependência na interface do produto gera work items dependentes e mais interação entre os subsistemas.

\subsubsection{Dia 4 - Finalização do projeto}

O Sprint Review 2 abrangeu dois momentos distintos para direcionar as equipes a completarem o projeto. No primeiro momento foi necessário prover feedback sobre algumas falhas no planejamento das equipes. O segundo momento houve reunião entre o cliente e cada equipe para apresentação dos resultados alcançados pelas equipes até o momento.

O feedback apresentou algumas falhas na elaboração do PMe e QS, tais como: (1) falta de integridade entre os resultados finais dos subsistemas, conforme era indicado no PMe; (2) dificuldade de relacionar os work item e os resultados finais, apresentada na Figura 48; e (3) os Planos Mestres não possuíam um momento para realizar a integração entre todos os subsistemas. 

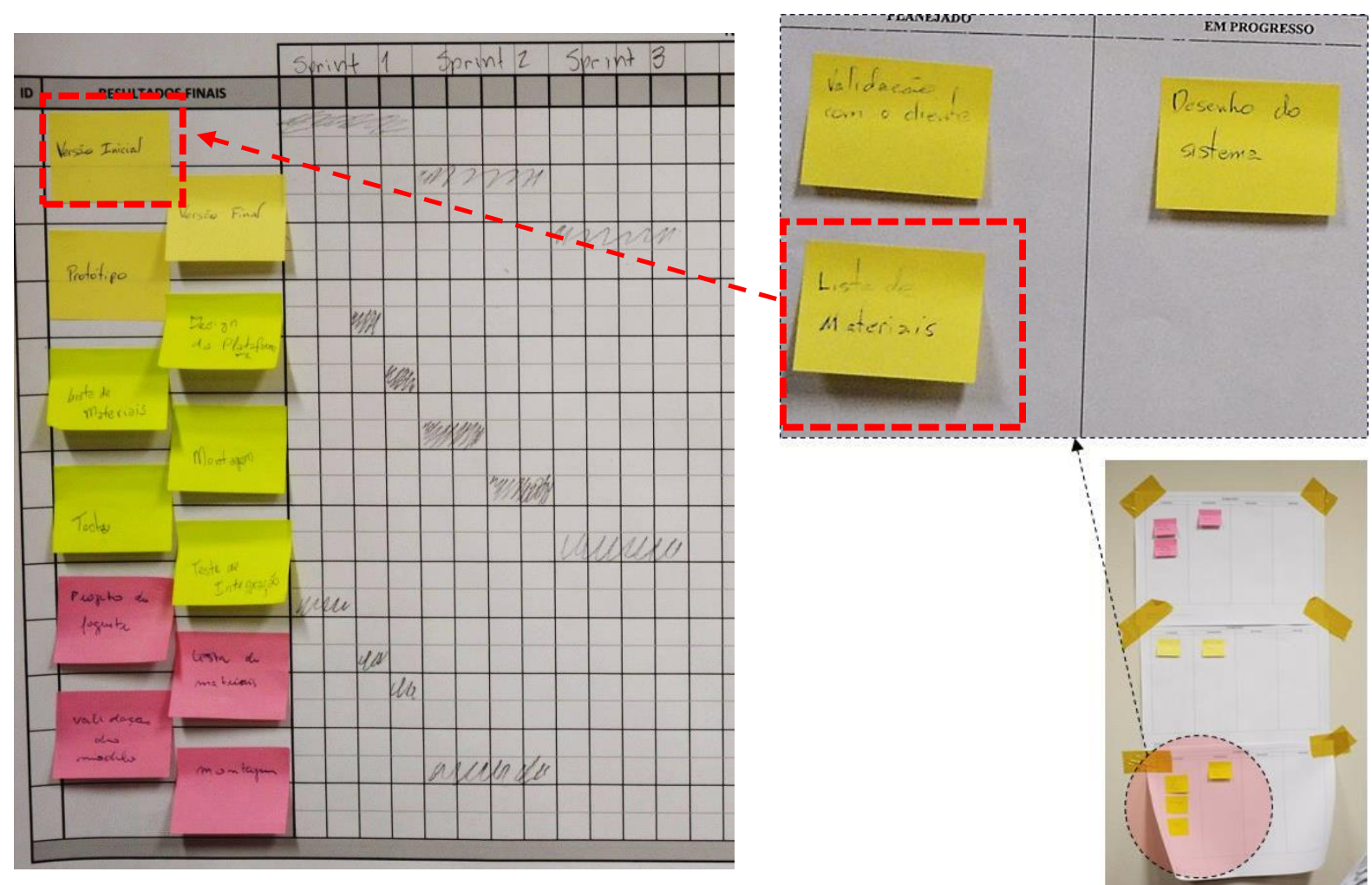

Figura 48 - Relação entre work item e resultado final, equipe Azul, Sprint 1.

Acredita-se que as falhas apresentadas poderiam ser sanadas ou evitadas com um Modelo de Referência de desenvolvimento de produtos. Por exemplo, os Planos Mestres não possuíam um momento para realizar a integração entre todos os subsistemas. A equipe Preta foi o que mais se aproximou da intenção de integrar os subsistemas. Note na Figura 49, destacada no quadro vermelho, o final do Sprint 2 onde a equipe preta planejou a entrega da $1^{\mathrm{a}}$ versão de todos os subsistemas. Nesse momento, poderia haver um milestone ou resultado final indicando a integração. Logo, o Modelo de Referência é importante para evitar falhas no planejamento, direcionando a equipe na elaboração do PMe, conforme a recomendação de AMARAL et al. (2011). 


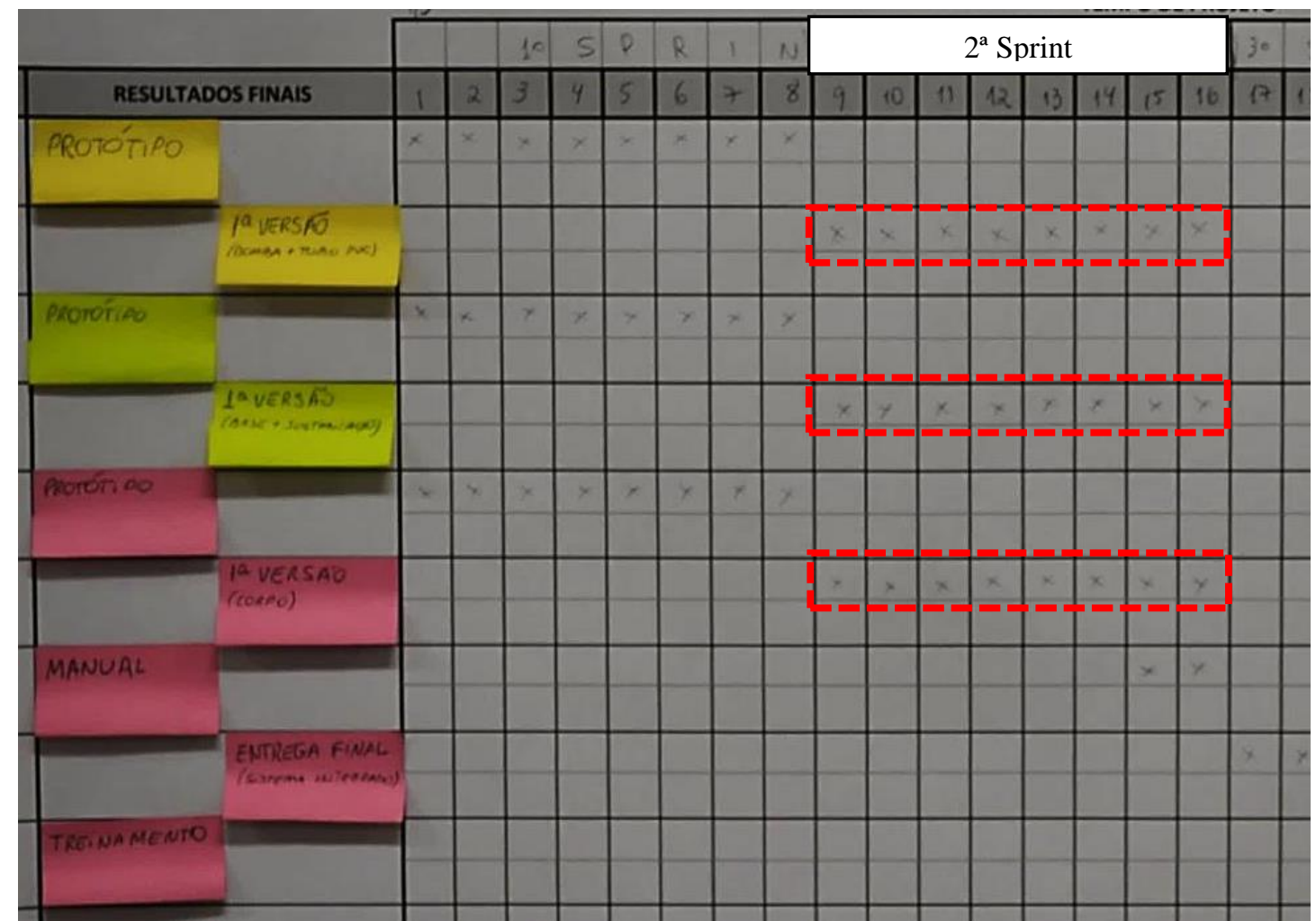

Figura 49 - PMe da equipe Preta.

No segundo momento do Sprint Review 2 foi realizada a revisão com o cliente, visando validar os resultados alcançados até o momento. A equipe Vermelha apresentou os resultados alcançados, tiraram dúvidas em relação ao design da plataforma e procuraram validar com o cliente a solução proposta. As outras equipes possuíam a apenas o corpo do foguete como resultado parcial para apresentar.

Três problemas principais foram observados durante o Sprint Review 2 e se relacionavam com os prazos de entrega, o design do produto e as estimativas dos resultados finais.

Os prazos estimados não foram respeitados e atualizados de um modo geral. $\mathrm{O}$ PMe da equipe Azul indicava ao final do Sprint 2 a entrega da versão final do sistema de acionamento, a plataforma testada e o projeto do foguete, no entanto, a equipe não apresentou esses resultados finais durante o Sprint Review 2. A equipe Preta planejou entregar a primeira versão do produto no final do Sprint 2, mas apresentou apenas o corpo do foguete. Como a equipe Vermelha não indicou os Sprints no PMe e a estimativa de tempo total estava errada, impossibilitou concluir se a equipe respeitou os prazos. 
Problemas no design do produto foram observados em duas de três equipes. $\mathrm{O}$ corpo do foguete da equipe Preta exibiu problema de excesso de material. A base da plataforma da equipe Vermelha apresentou problema na fixação da base da plataforma que poderia interferir no lançamento do foguete.

As estimativas dos resultados finais no PMe não foram atualizadas pelas equipes ao final do Sprint Review 2. Destaca-se a equipe Vermelha, ao identificar o problema de design, atualizou o PMe e o QS do subsistema Plataforma, inserindo post-it para indicar a resolução do problema, mas não atualizaram as estimativas.

O $\underline{\text { Sprint } 3}$ foi iniciado após as equipes analisarem os problemas identificados e proporem soluções. Esse Sprint era o último para as equipes executarem as últimas atividades do projeto e apresentarem o protótipo final.

As equipes atualizaram o QS durante a execução do Sprint 3. As equipes Azul e Vermelha que atualizaram todos os quadros no momento em que finalizavam algum work item. A equipe Preta não atualizou constantemente todos os QS, pois estava preocupada em terminar o projeto, uma vez que apresentaram apenas o corpo do foguete no Sprint Review 2.

Todas as equipes finalizaram o projeto e entregaram o produto ao final do Sprint 3. Destaca-se a equipe Vermelha, ao perceber que finalizaram o projeto antes acabar o tempo do Sprint 3, elaboraram um manual de uso do equipamento e, desta forma, a equipe entregou mais valor ao cliente ao adicionar mais funcionalidades do que o solicitado inicialmente. A Figura 50, Figura 51 e Figura 52 apresentam os protótipos finais da equipe Azul, Vermelha e Preta respectivamente. 


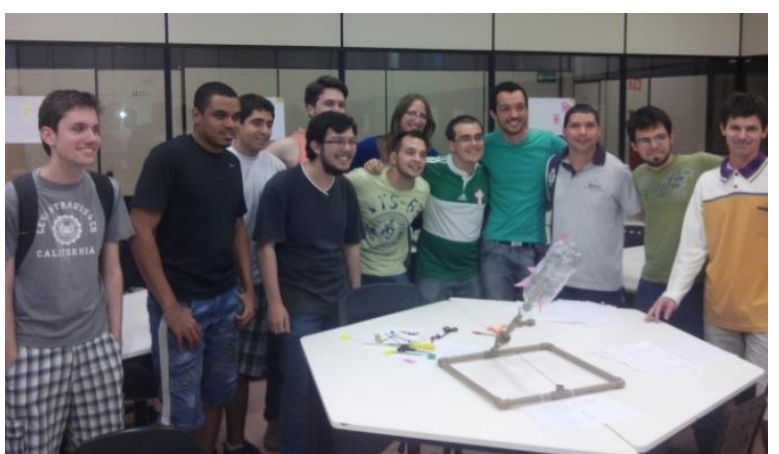

Figura 50 - Equipe Azul e protótipo final.

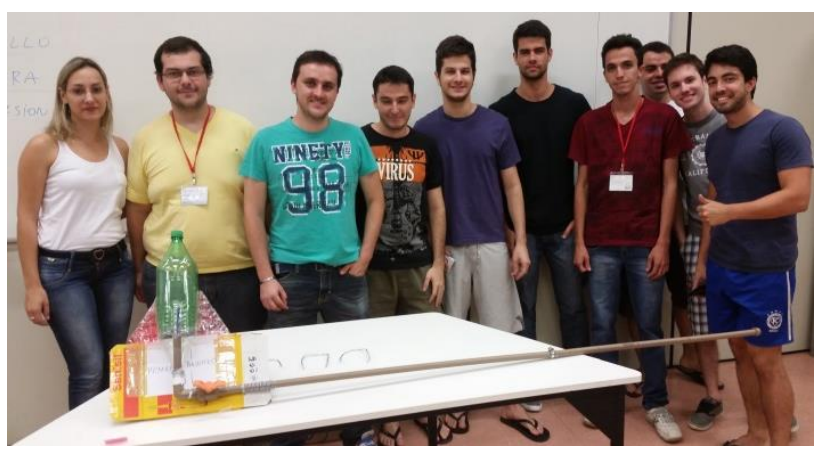

Figura 51 - Equipe Vermelha e protótipo final.

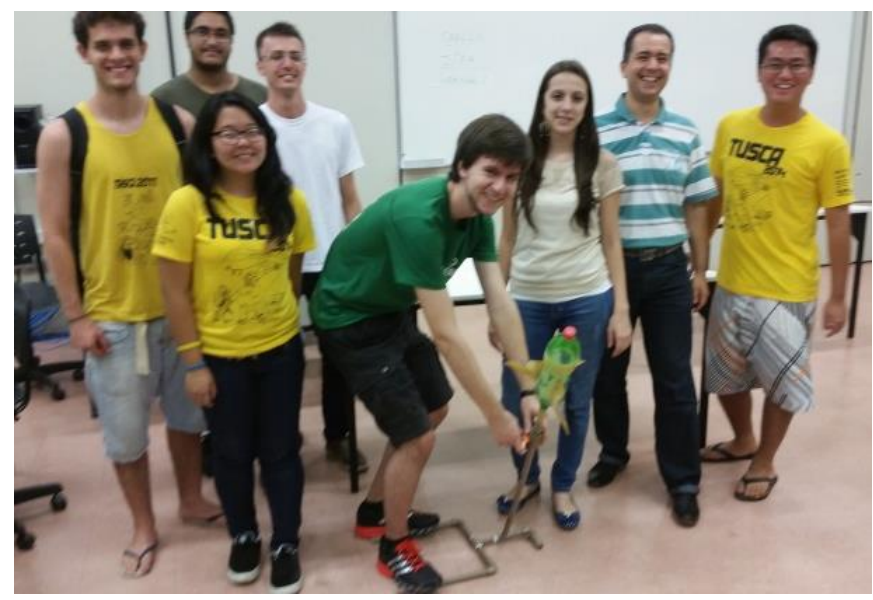

Figura 52 - Equipe Preta e protótipo final. 


\section{ANÁLISE DOS DADOS E DISCUSSÃO}

\subsection{Dimensão 1 - Combinação de práticas}

A análise apresenta a relação entre as evidências coletadas durante o treinamento e as estratégias adotadas para as variáveis da Dimensão 1: Elaboração do plano (D1.A), Descrição do escopo do projeto (D1.B), Definição as atividades (D1.C), Horizonte de planejamento das atividades (D1.D), Controle do tempo (D1.E), Verificação e controle do escopo (D1.F).

$\mathrm{Na}$ Elaboração do plano (D1.A) foi empregada a estratégia de planejamento tradicional e ágil. O Plano Mestre (PMe) representou o plano tradicional, abrangendo o tempo total do projeto e apresentando todos os resultados finais. O Quadro Scrum (QS) representou o plano ágil de curto prazo e contêm os work items referentes a um Sprint.

Todas as equipes conseguiram definir os resultados finais e elaborar o PMe. O PMe da equipe Preta foi considerado o melhor dentre as equipes, pois apresentava versionamento do produto, a intenção de integração entre os resultados finais dos subsistemas e a identificação dos Sprints. Os milestones foram à exceção em todos os $\mathrm{PMe}$, pois não foram criados em razão da simplicidade do projeto.

Cada subsistema planejou os work items para o primeiro Sprint após a definição do PMe. A equipe Azul melhor exemplifica o comportamento esperado, onde os subsistemas elaboram e fixaram os QS na parede, funcionando como um artefato de gestão visual e utilizou o QS para gerenciar visualmente a execução.

As evidências coletadas indicaram que é possível elaborar o plano do projeto utilizando práticas do plano tradicional e ágil. A decomposição dos resultados finais do em work items é semelhante a uma WBS, porém a diferença consiste em não definir todos os work items de uma única vez no início do projeto, a forma de descrição e priorização e a responsabilidade por defini-los.

Foi observado que a decomposição dos resultados finais em work items cria uma relação direta entre o PMe e QS. No entanto, não foi possível testar o fluxo inverso de atualização dos planos do procedimento. Por exemplo, as estimativas do PMe deveriam ser 
atualizadas com as informações provenientes dos QS dos subsistemas durante os Sprints Reviews.

A Definição do Escopo (D1.B) empregou a estratégia ágil utilizando a Visão do Produto, no entanto, a variável D1.B não é explorada no procedimento. Mesmo assim, apresenta-se algumas evidências e considerações importantes sobre a Visão do Produto e o procedimento.

A Visão do Produto foi apresentada por meio do Cenário do treinamento (Apêndice I). As equipes conseguiram identificar os resultados finais e elaborar o PMe, sequenciando os resultados a partir da Visão do Produto. Isso é uma evidência que é possível planejar o projeto, desdobrado resultados finais a partir da Visão. Acredita-se que exista uma possibilidade para projetos inovadores definir o escopo por meio da Visão do Produto e depois planejar o projeto utilizando o procedimento. No entanto, mais pesquisas são necessárias para analisar e comprovar essa possibilidade. A integração entre a Visão do produto entre o Plano de Projeto é discutida nas propostas de Amaral et al. (2011) e Sommer et al. (2015) e é uma etapa importante para futuras aplicações do procedimento.

A Definição das atividades (D1.C) seguiu a estratégia ágil, onde não há um padrão para descrição dos work items, podendo ser registrados como estórias, casos ou atividades. Além disso, não há uma tentativa de organização dos work items, apenas a priorização realizada pelo cliente.

Todas as equipes elaboraram os work items visando apenas um Sprint. Durante o treinamento, foi observado que interfaces obrigaram os subsistemas a executarem work items em conjunto, forçando-os a uma organização da execução do trabalho. Por exemplo, os subsistemas Foguete e Acionamento da equipe Vermelha executaram os work items em conjunto em razão da relação de dependência entre as interfaces.

Considera-se viável utilizar a estratégia ágil para a definição das atividades. No entanto, ressalta-se que as interfaces do produto devem ser analisadas para identificar work items que devem ser executados em paralelo e no mesmo Sprint. Neste caso, a análise da arquitetura de alto nível pode auxiliar as equipes a identificar as interfaces do produto, conforme o discutido para o fator crítico Arquitetura de alto nível na seção 3.4.

No Horizonte de planejamento das atividades (D1.D) foi adotada a estratégia ágil, onde as lista de work items são válidas para um Sprint e são representadas pelo Product Backlog. 
As evidências do treinamento mostram que todas as equipes definiram work items apenas para um Sprint. De outro modo, nenhuma equipe elaborou o Product Backlog. Essa prática não foi incentivada durante o treinamento em razão do tempo. Isso pode ter causado o problema de priorização das equipes, pois não ficou claro se as equipes priorizaram os requisitos do cliente.

Considera-se é viável utilizar a estratégia ágil para definir o horizonte de planejamento das atividades. Porém, mais evidências são necessárias para analisar a viabilidade de utilizar o Product Backlog em conjunto com os outros artefatos.

No Controle do tempo (D1.E) foi adotada a estratégia ágil, onde foram utilizadas reuniões frequentes (Sprint Review) para analisar o progresso das equipes utilizando o Plano Mestre e o Quadro Scrum. As evidências apresentadas no Sprint 2 e 3 indicam que as equipes não conseguiram controlar o tempo do projeto.

Ao verificar o PMe o QS não foi possível concluir se as equipes se preocuparam em controlar o tempo por meio das estimativas indicadas no PMe, por exemplo. Nenhuma equipe atualizou as estimativas durante o treinamento. A equipe Vermelha, por exemplo, não percebeu que estimaram a duração total do projeto em $1 \mathrm{~h} 15 \mathrm{~min}$, sendo que o total era de 3 horas. Além disso, não atualizaram as estimativas ao identificar o problema de design no Sprint Review 2. Embora a equipe soubesse o que deveria ser feito durante os Sprints, entende-se que eles não controlaram o tempo utilizando as estimativas do PMe.

Os prazos de entrega dos resultados finais indicados no PMe não foram respeitados pelas equipes. O fato ficou mais evidente na Azul e Preta que indicaram no PMe entregas de resultados finais e nenhuma das duas equipes entregou os resultados planejados. Os prazos poderiam auxiliar os líderes a identificar ritmo de entrega dos subsistemas e quais requisitos seriam apresentados para o cliente, mas isso não foi verificado pelas equipes.

Dois motivos ajudam explicar o porquê das equipes não terem controlado o tempo. O primeiro motivo consiste na divisão do tempo por meio dos Sprints. Um relógio virtual foi projetado na parede para controlar a duração do Sprint, deixando as equipes despreocupadas em relação ao controle do tempo. O segundo motivo é a falta de uma pessoa responsável para controlar o PMe, que deveria exigir dos líderes informações para atualizar o PMe, assumindo, assim, a função do Gerente de Projetos. 
A estratégia ágil foi utilizada para o atingimento do escopo (D1.F), onde o cliente avalia, prioriza, adiciona ou altera o produto final do projeto. Deste modo, as subequipes devem estabelecer entregas parciais para a avaliação durante os Sprints Reviews.

Todas as equipes apresentaram o corpo do foguete durante o Sprint Review 2 para a avaliação do cliente. A equipe Vermelha conseguiu ir além das outras equipes e apresentou uma primeira versão da plataforma de lançamento. O Cliente avaliou e ajudou a identificar um problema de fixação que poderia prejudicar o lançamento do sistema em qualquer tipo de superfície. A equipe adicionou fixações na plataforma para corrigir o problema apresentado. Por outro lado, a equipe Preta que planejou entregas parciais no PMe, como a primeira versão do foguete, plataforma e acionamento, mas entregou apenas o corpo do foguete. Durante a avalição, o corpo do foguete da equipe preta apresentou o problema de excesso de material. A equipe Azul apresentou apenas o corpo do foguete, que não apresentou problemas.

As evidências do treinamento mostram que apenas uma equipe apresentou alguma intenção de priorização de requisitos. A equipe Vermelha conseguiu entregar todos os requisitos que eram prioridade e, ao perceber que sobrou tempo no Sprint 3, adicionaram outro requisito ao projeto, um manual de utilização. Isso adicionou valor ao projeto e indicou que a equipe entregou mais do que o solicitado inicialmente. O corpo do foguete da equipe Preta apresentou um problema foi considerado grave, pois implicava negativamente no requisito de maior prioridade, voar mais longe, devido ao excesso de material utilizado. Isso indicou que a equipe Preta não compreendeu como utilizar os requisitos para priorizar o projeto ou faltou uma análise do líder do subsistema foguete para evitar esse problema. A equipe Azul não apresentou resultados intermediários que possibilitem afirmar se eles entenderam a priorização.

O cliente não adicionou requisitos ao produto e nem mudou as prioridades estabelecidas no início do treinamento, pois isso poderia confundir ou prejudicar os alunos na execução do projeto e dificultar a finalização do projeto no tempo disponível. Deste modo, não foi possível testar o impacto das mudanças no planejamento do projeto.

Verificando os PMe, de modo geral, não é possível concluir se as equipes se preocuparam em controlar o escopo por meio de resultados tangíveis. Apenas a equipe Preta deixou essa a intenção de planejar considerando resultados tangíveis, pois elaboraram o PMe indicando versões do produto, por exemplo, versão 1 e versão 2. Porém, a equipe não seguiu o planejamento e não apresentaram as versões durante os Sprints Reviews. 
Considera-se viável utilizar a estratégia ágil para atingimento do escopo. No entanto, ressalta-se que o cliente do treinamento conhecia profundamente o produto possibilitando, assim, uma avaliação detalha das entregas parciais das equipes, questionandoas em vários aspectos até identificar os problemas. Em casos de projetos reais, o cliente pode ter conhecimento limitado sobre o produto e dificuldades de expressar os requisitos, deste modo, dificultando o progresso da equipe de projeto.

\subsection{Dimensão 2 - Experiência do usuário.}

Essa seção apresenta a análise dos dados coletados nas duas partes do Questionário de Experiência do Usuário (Apêndice H). Na primeira parte do questionário, os usuários indicaram se concordam ou discordam sobre dez afirmações da variável usabilidade. Os dados foram analisados por meio dos Índices de Concordância (IC) e o procedimento para o cálculo do IC é apresentado no Apêndice M. Na segunda parte, a variável percepção de qualidade foi analisada por meio das respostas dos usuários sobre o planejamento do projeto e o entendimento comum do plano. As melhores respostas foram transcritas e relacionadas com os resultados encontrados para os ICs, visando para promover a discussão sobre a experiência do usuário ao utilizar o procedimento.

A Tabela 1apresenta o resultado obtido do cálculo do $r_{W G}$ e a média para as três equipes. Os resultados obtidos na Tabela 1 para as afirmações foram interpretados e sintetizados no Quadro 26 para facilitar a discussão dos resultados. Os critérios adotados para a interpretação foram adaptados de Carvalho, Costa e Amaral (2015) e correspondem:

- $\underline{\text { Totalmente atendido }}\left(r_{W G}>0.70\right.$ e $\left.\mu>3.0\right)$. Os juízes concordaram que o procedimento possui o efeito positivo;

- $\underline{\text { Ausente }}\left(r_{W G}>0.70\right.$ e $\left.\mu<3.0\right)$. Os juízes concordaram que o procedimento não possui o efeito;

- Indeterminado $\left(r_{W G}<0.70\right)$. Não há concordância e não é possível afirmar se qual é a percepção dos juízes. 
Tabela 1- Resultado do cálculo do IC para as três equipes

\begin{tabular}{ccccccc} 
& \multicolumn{2}{c}{ Equipe Azul } & \multicolumn{2}{c}{ Equipe Preta } & \multicolumn{2}{c}{ Equipe Vermelha } \\
\hline Afirmação & Média & $\boldsymbol{r}_{\boldsymbol{W G}}$ & Média & $\boldsymbol{r}_{\boldsymbol{W G}}$ & Média & $\boldsymbol{r}_{\boldsymbol{W G}}$ \\
\hline $\begin{array}{c}\text { Utilizar } \\
\text { frequentemente }\end{array}$ & 4.1 & 0.728 & 4.0 & 0.857 & 4.0 & 0.875 \\
$\begin{array}{c}\text { Desnecessariamente } \\
\text { complexo }\end{array}$ & 2.3 & 0.661 & 1.5 & 0.857 & 2.2 & 0.778 \\
$\quad$ Fácil de usar & 3.7 & 0.661 & 3.6 & 0.866 & 4.1 & 0.820 \\
Apoio do Consultor & 2.8 & 0.245 & 2.4 & 0.581 & 2.3 & 0.625 \\
$\begin{array}{c}\text { Boa integração } \\
\text { entre as funções }\end{array}$ & 4.1 & 0.728 & 4.1 & 0.938 & 4.0 & 0.625 \\
$\begin{array}{c}\text { Existência de } \\
\text { inconsistências }\end{array}$ & 1.8 & 0.800 & 2.1 & 0.795 & 1.9 & 0.570 \\
$\begin{array}{c}\text { Fácil de aprender } \\
\text { Complicado para o }\end{array}$ & 3.4 & 0.756 & 4.0 & 1.000 & 4.2 & 0.653 \\
$\quad$ uso & 1.6 & 0.867 & 1.9 & 0.509 & 1.8 & 0.528 \\
$\begin{array}{c}\text { Confiança ao } \\
\text { utilizar }\end{array}$ & 3.3 & 0.467 & 3.3 & 0.893 & 3.7 & 0.750 \\
$\begin{array}{c}\text { Aprendizado prévio } \\
\text { antes de usar }\end{array}$ & 2.2 & 0.689 & 2.0 & 0.857 & 2.4 & 0.736 \\
\hline
\end{tabular}

Quadro 26 - Avaliação da experiência do usuário para cada equipe

\begin{tabular}{|c|c|c|c|}
\hline Afirmação & Equipe Azul & Equipe Preta & Equipe Vermelha \\
\hline $\begin{array}{c}\text { Utilizar } \\
\text { frequentemente } \\
\text { complexo }\end{array}$ & $\begin{array}{c}\text { Totalmente } \\
\text { atendido } \\
\text { Fesessariamente }\end{array}$ & $\begin{array}{c}\text { Totalmente } \\
\text { atendido }\end{array}$ & $\begin{array}{c}\text { Totalmente } \\
\text { atendido }\end{array}$ \\
\hline Indeterminado & Ausente & Ausente \\
\hline Apoio do Consultor & Indeterminado & $\begin{array}{c}\text { Totalmente } \\
\text { atendido }\end{array}$ & $\begin{array}{c}\text { Totalmente } \\
\text { atendido }\end{array}$ \\
\hline $\begin{array}{c}\text { Boa integração entre } \\
\text { as funções }\end{array}$ & $\begin{array}{c}\text { Totalmente } \\
\text { atendido }\end{array}$ & $\begin{array}{c}\text { Totalmente } \\
\text { atendido }\end{array}$ & Indeterminado \\
\hline $\begin{array}{c}\text { Existência de } \\
\text { inconsistências }\end{array}$ & Ausente & Ausente & Indeterminado \\
\hline $\begin{array}{c}\text { Fácil de aprender } \\
\text { Totalmente } \\
\text { atendido }\end{array}$ & $\begin{array}{c}\text { Totalmente } \\
\text { atendido }\end{array}$ & Indeterminado \\
\hline $\begin{array}{c}\text { Complicado para o } \\
\text { uso }\end{array}$ & Ausente & Indeterminado & Indeterminado \\
\hline Confiança ao utilizar & Indeterminado & $\begin{array}{c}\text { Totalmente } \\
\text { atendido }\end{array}$ & $\begin{array}{c}\text { Totalmente } \\
\text { atendido }\end{array}$ \\
\hline $\begin{array}{c}\text { Aprendizado prévio } \\
\text { antes de usar }\end{array}$ & Indeterminado & Ausente & Ausente \\
\hline
\end{tabular}

Os dados apresentados no Quadro 26 indicam que os usuários concordaram quanto ao desejo de utilizar novamente. Essa afirmação obteve o melhor resultado dentre todas as analisadas, pois todas as equipes concordaram com a afirmação. 
O Quadro 26 também mostra que os usuários das equipes Preta e Vermelha concordaram que o procedimento fácil é de usar, estavam confiantes ao utilizar o procedimento e que não é preciso aprender muitos conceitos antes de usar o procedimento.

Os usuários das equipes Azul e Preta concordaram que as funções no procedimento estão bem integradas, discordaram que existam muitas inconsistências no procedimento e concordaram que é fácil de aprender a usar o procedimento.

Os resultados obtidos para as afirmações sobre a facilidade de uso, facilidade no aprendizado, da confiança ao utilizar o procedimento corroboram para os usuários indicarem que gostariam de utilizar o procedimento novamente.

A facilidade de uso também foi indicada em duas respostas da segunda parte do questionário. A primeira foi identificada na pergunta sobre o auxilio na elaboração do planejamento. A transcrição 1 (T.1) expressa ser mais intuitivo realizar o planejamento por equipes, onde os membros planejam as atividades, enquanto que os líderes definem as interfaces do produto, realizando, assim, atividades de planejamento paralelas. Desta forma, entende-se que o procedimento simplificou o planejamento e a elaboração dos planos. A segunda transcrição foi identificada na pergunta sobre o entendimento comum do projeto. A transcrição 2 (T.2) indica que foi possível identificar as partes dependentes e independentes entre os subsistemas ajudando, assim, no entendimento do problema.

(T.1) "Sim, a divisão do projeto em equipes responsáveis por subsistemas do projeto foi interessante, pois mesmo antes de os líderes definirem as interfaces entre os subsistemas, as equipes já poderiam pesquisar, planejar e propor coisas para os subsistemas individualmente. Além disso, fazer o planejamento por subsistema parece ser mais intuitivo do que planejar todo o projeto de uma vez". Paula - equipe Azul.

(T.2) "Sim, a divisão em subsistemas ajudou no entendimento do projeto na medida em que foi possível identificar o propósito geral e as partes dependentes e independentes entre os subsistemas." Paula Equipe Azul.

A maioria dos usuários indicou uma boa integração das funções e que não há muitas inconsistências no procedimento. Ao analisar as transcrições das respostas para a primeira pergunta, foram identificadas três opiniões que corroboram para legitimar a 
integração das funções e a baixa inconsistência. A transcrição 3 (T.3) cita que o planejamento da divisão e modularização do tempo e funções foi realizada de uma maneira eficiente. A transcrição 4 (T.4) mostra que o PMe ajuda na visão geral do projeto e a utilização dos Sprints trouxe a flexibilidade. Entende-se que o usuário quis expressar que existe flexibilidade para definir as atividades a serem executadas. A transcrição 5 (T.5) indica a integração entre o Plano Mestre e o trabalho de cada subsistema.

(T.3) "Acredito que sim, a divisão e modularização do tempo gasto e das funções a serem desenvolvidas puderam ser realizadas de uma maneira mais eficiente, embora, na execução, o planejamento não foi totalmente seguido". Giovanni - equipe Azul.

(T.4) "Sim, pois o Plano Mestre ajudou a ter uma visão geral das etapas do projeto e a utilização dos Sprints trouxe a flexibilidade necessária". Luís - equipe Azul.

(T.5) "Sim, pois o plano maior (Plano Mestre) possibilita que cada equipe veja a relação de seu trabalho com o das outras." Marcelo Equipe Vermelha.

Por outro lado, a transcrição 6 (T.6) relata que não houve entendimento para todo o projeto, ficando o entendimento limitado a parte em que o membro estava responsável. Isso indica que pode haver pontos de melhoria no procedimento em relação à integração entre os planos (PMe e QS). A integração é importante, pois todos os membros devem entender do todo, ou ter uma visão macro do projeto, para saber os impactos de seus resultados no projeto.

(T.6) "Acredito que não ajudou para o entendimento como um todo, mas sim pela parte em que estava responsável (subsistema)." William - Equipe Azul.

A maioria dos usuários discordou que precisava aprender muitos conceitos para utilizar o procedimento. Os usuários, de forma geral, estavam sendo introduzidos à Gestão de Projetos e foi necessário apresentar uma aula teórica para ensinar o APM antes de iniciar o treinamento. Ressalta-se esse resultado, pois, mesmo assim, eles discordaram com a afirmação. 
De outro modo, os resultados das outras três afirmações do Quadro 26 indicam pontos para melhoria do procedimento em relação à complexidade para o usuário, complicado para o uso e a necessidade de um consultor.

As equipes Preta e Vermelha discordaram que o procedimento é desnecessariamente complexo. Apesar das mesmas duas equipes consideraram o procedimento fácil de usar, aparentemente, o procedimento possui um nível de complexidade para os usuários, entendido como um ponto que pode ser melhorado.

Ao analisar as transições, identificou-se a transcrição 7 (T.7), que apresenta um ponto de melhoria em relação à complexidade. A T.7 comenta sobre a baixa efetividade do planejamento.

(T.7) "Em partes, pois acredito que o planejamento de tempo combinado é mais efetivo na execução do que no planejamento em si." Taís - equipe Preta.

A T.7 foi descrita por um membro da equipe Preta, onde a equipe não seguiu o planejamento do projeto durante a execução, conforme foi apresentado nas seções anteriores desse capítulo. Deste modo, isso pode ter influenciado a resposta desse membro. Mesmo assim, deve-se analisar possíveis melhorias nas etapas de planejamento via procedimento.

A equipe Azul indicou que discordou que o procedimento é complicado e nas outras duas equipes não houve consenso. A afirmação adere diretamente com a facilidade de uso, facilidade de aprender e contrasta com a complexidade. Ainda que apenas uma equipe tenha discordado a afirmação, pode-se considerar que o procedimento não é complicado.

A transcrição (T.8) relata a falta de alinhamento entre os membros dos subsistemas e, neste caso, os líderes aturam como um coordenador ou gerente de projetos. Isso pode ter causado a impressão que o procedimento é complicado para o uso e influenciado a resposta dos usuários para não haver consenso.

(T.8) "Não muito, pois a falta de alinhamento com a equipe e com o compreendimento do escopo refletiu em uma situação irreal na prática, onde sempre havia um membro da subequipe (subsistema) monitorando as outras para o alinhamento acontecer." Giovanni Equipe Azul. 
Não houve consenso nas equipes sobre a necessidade de um consultor para apoiar o uso do procedimento, mesmo que duas equipes concordarem que o procedimento é fácil de usar e aprender. Talvez por se tratar de conceitos novos para os usuários, algumas pessoas se sentiriam mais confortáveis com a presença de um consultor para auxilia-las.

A conclusão geral dessa seção é que o procedimento possui uma boa usabilidade e existe uma percepção positiva em relação à qualidade. Assim, a partir de todas as evidências apresentadas, a experiência do usuário pode ser considerada satisfatória.

\subsection{Discussão sobre outras evidências decorrentes do caso}

As evidências observadas durante a execução do treinamento permitem discutir sobre os três níveis de planejamento, estrutura organizacional, unidade de tempo de planejamento, estimativas no Plano Mestre, Problemas na atualização do Plano Mestre, complexidade versus comunicação e modelo de referência.

O procedimento é composto por três níveis de planejamento, Projeto, Sprint e Diário, representados pelos artefatos Plano Mestre (PMe), Product Backlog (PB) e Quadro Scrum (QS), respectivamente.

Foram identificados indícios durante o treinamento e discutidos nas seções anteriores que permitem considerar viável combinar os níveis de Projeto e Diário utilizando o Plano Mestre o Quadro Scrum. A equipe de planejamento (líderes das equipes) elaborou o PMe tendo em vista o tempo total permitido para a execução do projeto, os inputs das equipes operacionais (subsistemas) e os resultados finais. Depois, as equipes operacionais definiram os work items e elaboraram os Quadros Scrums. Tudo conforme o procedimento. Nenhuma equipe teve dificuldades em elaborar os planos e desdobrar os resultados finais em work items. Por esse motivo, considera-se viável combinar os nível Projeto e Diário.

Por outro lado, o Product Backlog (PB) não foi criado pelas equipes. A priori isso não dificultou a execução do projeto. Talvez, para esse caso em particular, ele não seja importante, pois o cenário do treinamento apresentou um produto relativamente simples, onde poucos work items foram definidos e executados. Contudo, não é possível fazer inferências sobre viabilidade de combinar o PB com o PMe e o QS. Uma hipótese seja analisar posteriormente se a quantidade de work items influenciaria ou não o uso do PB para o controle das atividades das equipes operacionais. 
A estrutura organizacional das equipes foi observada durante o planejamento do projeto e evidenciada no registro fotográfico. De acordo com a estrutura proposta, as equipes operacionais (subsistemas) identificaram os respectivos resultados finais do projeto. Logo depois, a equipe de planejamento (líderes dos subsistemas) construíram o PMe. Deste modo, duas equipes simularam a estrutura organizacional proposta pelo procedimento. $\mathrm{O}$ pesquisador observou que as duas equipes (Azul e Vermelha) tiveram uma maior facilidade para executar o projeto quando comparado com a outra equipe (Preta) que não seguiu a estrutura organizacional do procedimento. Assim, existe uma possibilidade de organizar a equipe utilizando a estrutura organizacional proposta pelo procedimento. $\mathrm{O}$ fato também corrobora com a estrutura descrita em Sommer, Dukovska-Popovska, Steger-Jensen (2014) e Sommer et al. (2015), que integram o Product Owner e Scrum Master a estrutura tradicional.

Critica-se a unidade de tempo de planejamento utilizada para a elaboração do PMe. Durante o planejamento do projeto, as equipes deveriam criar o PMe estabelecendo uma unidade de tempo para estimar os resultados finais. No entanto, as equipes estabeleceram uma unidade menor que o tempo para o Sprint (1h), por exemplo, equipe Azul 15 min. Isso pode ter gerado o problema de falta de controle de tempo e desatualização do PMe.

Acredita-se ser importante que a unidade de tempo presente no PMe, utilizada para estimar a duração dos resultados finais, não seja menor que o tempo definido para o Sprint, ou seja, o tempo disponível para as equipes operacionais para executar os work items.

As estimativas do PMe não foram utilizadas pelas equipes para controlar o projeto. Outros mecanismos de controle do tempo podem ser incentivados como a estimativa de pontos para os work items. No entanto, não foi possível verificar se é possível utilizar a estimativa de pontos dos work items e estimativa de tempo dos resultados finais em conjunto.

Foram observados problemas na atualização do PMe com as informações do Quadro Scrum em todas as equipes. Não foi possível realizar o fluxo inverso de atualização dos planos conforme o procedimento. O fluxo de atualização é importante, porque é o momento de atualização das estimativas com os resultados alcançados pelas equipes durante o Sprint. Com essas informações, a equipe de planejamento pode tomar decisões e direcionar o projeto.

Foi observado no treinamento que existe uma relação entre a complexidade do produto versus comunicação. Há indícios que a dependência entre interfaces do produto aumenta a necessidade de comunicação entre as equipes operacionais. Durante a execução do 
Sprint, duas equipes assumiram uma estrutura, onde os membros e líderes de dois subsistemas estavam reunidos para discutir a interface entre o sistema de acionamento e o corpo do foguete. Desta forma, foi possível para as equipes discutirem e proporem soluções para o problema. Esse indício corrobora com as recomendações da literatura, onde a divisão do projeto em entregas e atividades deve ser feita da forma mais independente possível (RAMESH et al., 2006; BARLOW et al., 2011). Caso isso não for possível, as equipes devem ser localizadas o mais próximo possível para facilitar a comunicação (RAMESH et al., 2006).

As inconsistências encontradas nos PMes durante os Sprints Reviews indicaram para o pesquisador que é importante um Modelo de Referência para auxiliar no planejamento do projeto. Por exemplo, os PMes não possuíam um momento para realizar a integração entre todos os subsistemas e faltava integração entre os resultados finais e os work items. Acreditase que o Modelo de Referência pode atuar para direcionar as equipes na elaboração do PMe e identificação de resultados finais e milestones do projeto. Isso colabora com as recomendações dos autores que defendem a necessidade de integrar o Modelo de Referencia para o desenvolvimento como Amaral et al. (2011), Ambler (2013), Seyam e Galal-Edeen (2011) e Zark e Moawad (2010). Também, utilização de um Modelo de Referência auxilia na priorização das entregas, mas pode ocasionar problemas com a prática ágil de priorização do cliente. Assim, acredita-se que é necessário mais estudos para investigar como o cliente pode auxiliar na priorização em projetos que utilizem um Modelo de Referencia e o Procedimento. 


\section{CONCLUSÕES DO TRABALHO}

A pesquisa originou três contribuições principais para o desenvolvimento do tema de combinação de práticas ágeis e tradicionais: (1) definição de combinação; (2) Análise de dez propostas de combinação; e (3) proposta e avaliação do procedimento de planejamento de tempo combinado.

A síntese da literatura permite concluir que o tema de combinação ainda está no início do desenvolvimento, motivo pelo qual a maioria das definições encontradas na literatura sobre a combinação é ampla em significado. As definições devem ser aprimoradas para indicarem os princípios e práticas ágeis e tradicionais que devem ser incorporados a possíveis propostas de combinação, assim como um objetivo.

A pesquisa indica que é preciso realizar algumas recomendações mais específicas sobre como propor modelos que combinem práticas ágeis e tradicionais. Foram analisadas dez propostas de combinação e poucas práticas tradicionais foram identificadas nas propostas. Conclui-se também que a preocupação principal dos modelos é com a documentação formal das informações projeto, no sentido de preservar o conhecimento adquirido no projeto que pode ser perdido quando é incentivada a gestão informal prescrita pela abordagem Ágil.

Apresentou-se a proposta de um procedimento de planejamento de tempo combinado e fez-se sua aplicação em um caso específico, não real, em uma disciplina de graduação. Conclui-se que o procedimento proposto funcionou em três aspectos principais: (1) Apresenta características das duas abordagens, com práticas ágeis e tradicionais; (2) Os níveis de planejamento projeto e diário; (3) Estrutura Organizacional proposta para a equipe de projeto, divida em subequipes funcionais.

Conclui-se, também, que a integração do cliente ou a representação deste por meio do Product Owner, na avaliação dos resultados auxilia na identificação e antecipação de problemas do projeto. No entanto, a condição necessária para que a avaliação seja eficaz é que o cliente seja capaz de expressar as necessidades e avaliar o projeto, ou Product Owner conheça profundamente as necessidades do cliente e conduza a equipe de projeto na avaliação.

Na dimensão usabilidade, o usuário indicou a facilidade de uso, boa integração entre as funções, baixa inconsistência, facilidade de aprendizado, confiança ao utilizar e 
pouco aprendizado prévio é necessário antes de usar. Conclui-se, assim, que a usabilidade do procedimento é considerada satisfatória para o caso.

Demonstrou-se, porém, que não foi possível observar elementos importantes que integram a proposta do procedimento. A introdução de novos requisitos ao produto e atualização das informações das subequipes após o Sprint Review permitiriam ao pesquisador observar o funcionamento do ciclo de atualização dos planos e o impactos nos Sprints seguintes. O ciclo de atualização é importante para o procedimento, pois permitiria analisar a flexibilidade do planejamento e o esforço na atualização dos planos. Também não foi possível avaliar a viabilidade da Priorização de requisitos no planejamento e como controlar a entrega dos requisitos ao final dos Sprints em razão da simplicidade do caso estudado.

As limitações da pesquisa envolvem: (1) a visão do produto utilizada para a criação do procedimento, pois foi gerada a partir de um caso não real. Em um estudo de caso posterior, recomenda-se criar também a visão do produto e utilizar o procedimento para planejar o projeto; (2) o caso do foguete de água e os quatro dias de execução não possuem representatividade com a realidade de uma empresa ou projeto. Em um projeto real, a duração das atividades são medidas em dias ou meses; (3) amostra dos alunos não representa uma equipe real de projetos com profissionais treinados e experientes em gestão de projetos; (4) aspectos não avaliados do procedimento proposto, como os benefícios esperados e os ciclos de implementação de mudanças de planejamento.

As limitações identificadas podem ser vistas como oportunidade de melhoria para aplicações futuras do procedimento. Portanto, conclui-se a pesquisa deve ter continuidade, com novos testes do procedimento capazes de aplicá-lo de maneira completa e em situações mais próximas da realidade, e por um período de tempo maior.

Acredita-se que uma aplicação futura em um caso real forneça mais detalhes sobre possíveis melhorias no procedimento e que usuários mais experientes em gestão de projetos expressem com mais detalhes as opiniões sobre as dimensões avaliadas, como gerentes e analistas de projeto, por exemplo.

No caso, também, não foram abordadas características onde é recomendada a combinação das práticas ágeis e tradicionais, como a mudanças dos requisitos e a entrega rápida na qual se recomenda combinar as práticas.

Três oportunidades de melhoraria o procedimento foram identificadas após a condução do caso. A elaboração Product Backlog e avaliar a integração deste com as outras 
práticas de planejamento, pois não foi possível observar evidências que possam determinar a viabilidade de utilizar o Product Backlog em conjunto com outros artefatos. A segunda oportunidade consiste em avaliar o controle do tempo por meio das estimativas de duração dos resultados finais e atualização do Plano Mestre. A terceira oportunidade é investigar como funcionaria a reunião de milestone e retrospectiva em conjunto com o ciclo de atualização dos planos de projeto.

Não foi avaliado nesta pesquisa se é possível alcançar os benefícios estabelecidos na definição de combinação, coesão, comunicação, satisfação do cliente, tempo, flexibilidade e controle de projeto por meio do procedimento proposto.

A pesquisa indica várias oportunidades para trabalhos futuros baseados no tema de combinação de práticas que podem ser úteis para o autor e outros pesquisadores. $\mathrm{O}$ procedimento proposto foi concebido com foco no planejamento de tempo. Futuras aplicações poderiam investigar a integração de outros processos de planejamento, como recursos, stakeholders e riscos, por exemplo. No caso específico do planejamento de recursos, recomenda-se a análise das interfaces e alocação de recursos e, também, como ponto de partida o trabalho de Sommer, Dukovska-Popovska, Steger-Jensen (2014). Outro viés de pesquisa é desenvolver procedimento considerando a estratégia bottom up que consiste em combinar a gestão ágil e um processo de desenvolvimento, contendo fases definidas e as principais entregas do projeto. 


\section{REFERÊNCIAS BIBLIOGRÁFICAS}

AMARAL, D. C.; CONFORTO, E. D.; BENASSI, J.; ARAUJO, C. Gerenciamento ágil de projetos: aplicações em projetos de produtos inovadores. São Paulo: Saraiva, 2011.

AMBLER,S. W. Going beyond scrum - disciplined agile delivery. Disciplined Agile Consortium, White paper, October 2013.

ARAUJO, C. Uma interface de painel digital interativo para planejamento de projetos. Tese (Doutorado) Escola de Engenharia de São Carlos, Universidade de São Paulo, São Carlos, 2012.

BARLOW et al. Overview and guidance on agile development in large organizations. Communications of the Association for Information Systems (CAIS), Vol. 29, Article 2, pg. 25-44, July 2011.

BATRA, D.; XIA, W.; VANDERMEER, D.; DUTTA, K.. Balancing agile and structured development approaches to successfully manage large distributed software projects: a case study from the cruise line industry. Communications of the Association for Information Systems (CAIS), Vol. 27, Article 21, 2010.

BENASSI, J. L. G. Proposta de método para criação da visão do produto no gerenciamento ágil de projetos de desenvolvimento de produtos. Tese (doutorado) - Escola de Engenharia de São Carlos, Universidade de São Paulo, São Carlos, 2013.

BINDER, J.; AILLAUD, L.; SCHILLI, L. The project management cocktail model: an approach for balancing agile and ISO 21500. 27 $7^{\text {th }}$ IPMA World Congress. Procedia - Social and Behavioral Sciences, Vol. 119, pg. 182-191, March 2014.

BIRKINSHAW, J.; HAMEL, G.; MOL, M.J. Management innovation. Academy of Management Review, Vol. 33, nº $4,825-845,2008$.

BIZAGI. Bizagi process modeler: user guide. 2013.

BODWELL, W.; E CHERMACK, T.J. Organizational ambidexterity: integrating deliberate and emergent strategy with scenario planning. Technological Forecasting e Social Change. Elsevier, 2010.

BOEHM, B. Get ready for agile methods, with care. IEEE Computer Society, Vol. 35, Issue 1, pg. 64-69, Jan 2002.

BOEHM, B.; TURNER, R.. Balancing agility and discipline: A guide for the perplexed. Addison-Wesley Professional, 2004.

BOEHM, BARRY; TURNER, RICHARD. Management challenges to implementing agile processes in traditional development organizations. IEEE Computer Society, Vol. 22, Issue 5, pg. 30-39, Sep-Oct 2005.

BOEHM, BARRY; TURNER, RICHARD. Using risk to balance agile and plan-driven methods. Computer, Vol. 36, Issue 6, Jun 2003.

BOS, E.; VRIENS, C. An agile CMM. Extreme Programming and Agile Methods-XP/Agile Universe. Springer Berlin Heidelberg, p. 129-138, 2004. 
CARVAlHO, F.H.T.; COSTA, J. H. M.; AMARAL, D. C. Envisioning products to support the agile management of innovative design. International Conference on Engineering Design (ICED), July 27 -30, 2015 (no prelo)

CARVALHO, M.M de; RABECHINI JR, R. Fundamentos em gestão de projetos: construindo competências para gerenciar projetos. São Paulo: Atlas, 2011.

CHIN, GARY. Agile Project Management: how to succeed in the face of changing project requirements. AMACOM, New York, NY, 2004.

CHOW, T; CAO, D.B. A survey of critical success factors in agile software projects. The Journal of Systems and Software, Vol. 81, Issue 6, pg. 961-971, 2008.

COBB, CHARLES G. Making sense of agile project management: balancing control and agility. Wiley, New Jersey, 2011.

COHN, M. Agile estimating and planning. Pearson Education, Inc. New Jersey, USA, $7^{\text {th }}$ priting, February, 2008.

CONFORTO, E. C. Modelo e ferramenta para avaliação da agilidade no gerenciamento de projetos. $376 f$. Tese (Doutorado) - Escola de Engenharia de São Carlos, Universidade de São Paulo, São Carlos, 2013.

CONFORTO, E. C.; AMARAL, D. C. SILVA, S. L. Roteiro para revisão bibliográfica sistemática: aplicação no desenvolvimento de produtos e gerenciamento de projetos. Anais do VIII Congresso Brasileiro de Gestão de Desenvolvimento de Produtos, Setembro, Porto Alegre, RS, 2011.

CONFORTO, E.C.; AMARAL, D.C. . Evaluating an agile method for planning and controlling innovative projects. Project Management Journal, v. 41, n. 2, p. 73-80, 2010.

CONFORTO, E.C.; REBEnTISCH, E.; AMARAL, D.C. Project Management Agility Global Survey. Massachusetts Institute of Technology, Consortium for Engineering Program Excellence (CEPE), Cambridge, Massachusetts, U.S.A. Disponível em: http://dspace.mit.edu/bitstream/handle/1721.1/88105/PM-Agility-GlobalSurvey-PMI-Executive-Report-v10.pdf?sequence=1.

CLUBE DE ASTRONOMIA DO COLÉGIO ESTADUAL DO PARANÁ (CACEP). Foguetes a água - uma atividade politicamente correta. Disponível em: http://www.cacep.com.br/node/92. Acesso em: 20 de Outubro de 2014.

DUL, J.; HAK, T. Case study methodology in business research. Elsevier, Oxford, UK, 2008.

EDER, S.; CONFORTO, E.C.; AMARAL, D.C.; SILVA, S.L. Diferenciando as abordagens tradicional e ágil de gerenciamento de projetos. Revista Produção, 2014. Disponível em: http://www.scielo.br/scielo.php?script=sci_arttext\&pid=S010365132014005000021\&lng=en\&nrm=io.

FERNANDEZ, D.; FERNANDEZ, J. Agile Project Management - agilism versus tradicional approaches. The Journal of Computer Information Systems, Winter 2008/2009, 49, 2, pg. 10. 
GALAL-EDEEN, G.H.; RIAD, A.M.; SEYAM, M.S. Agility versus Discipline: is reconciliation possible? International Conference on Computer Engineering \& Systems (ICCES), Cairo, pg.331-337, November 2007.

GOODPASTURE, J.C. Quantitative methods in project management. J. Ross Publising, 2004.

GRIFFIN, A. The effect of project and process characteristics on product development cycle time. Journal of Marketing Research, Special Issue on Innovation and New Products, Vol. 34, No. 1, pp. 24-35, February, 1997. GRIFFIN, A.; SOMERMEYER, S. The PDMA toolbook 3 for new product development. John Wiley, 2007. GRIFFITHS, M. Using agile alongside the PMBOK. PMI Global Congress Proceedings, Anaheim, CA, 2004. HIGHSMITH, J. A. Adaptive Software Development: a collaborative approach to managing complex systems. Dorset House Publishing, New York, 2000.

HOSSAIN, E.; BABAR, M.A.; PAIK, H.YE-YOUNG PAIK. Using scrum in global software development: a systematic literature review. Fourth IEEE International Conference on Global Software Engineering, 13-16 July, 2009.

HUO, M.; VERNER, J.; ZHU, L.; BABAR, M. A. Software quality and agile methods. Proceedings of the 28th Annual International Computer Software and Applications Conference (COMPSAC), 2004.

JACK, E. P.; RATURI, A. S. Lessons learned from methodological triangulation in management research. Management Research News, v. 29, n. 6, p. 345-357, 2006.

JAMES, L. R.; DEMAREE, R.G.; WOLF, G. Estimating within-group interrater reliability with and without response bias. Journal of Applied Psychology, Vol. 9, n. 1 pg. 85-89, 1984.

KÄHKÖNEN, T.; ABRAHAMSSON, P. Achieving CMMI level 2 with enhanced extreme programming approach. Product Focused Software Process Improvement. Springer Berlin Heidelberg, p. 378-392, 2004.

KARLSSON, C. Researching operations management. Routledge, Taylor \& Francis Group, New York, NY 10016, 2009.

KARLSTROM, D.; RUNESON, P. Combining agile methods with stage-gate project management. IEEE software, n. 3, p. 43-49, 2005.

KEITH, M.; DEMIRKAN, H.; GOUL, M. Service-oriented methodology for systems development. Journal of Management Information Systems, v. 30, n. 1, p. 227-260, 2013.

KERZNER, H. Gestão de Projetos: as melhores práticas. ARTMED, Porto Alegre, RS, 2a Edição, Reimpressão de 2008.

KIM, J.; WILEMON, D. Sources and assessment of complexity in NPD projects. R\&D Management, v. 33, n. 1, p. 15-30, 2003.

KOSKELA, L.; HOWELL, G. The underlying theory of project management is obsolete. Proceedings of the PMI Research Conference, 2002.pg. 293-302. 
LEBRETON, J. M.; SENTER, J. L. Answers to 20 questions about interrater reliability and interrater agreement. Organizational Research Methods, Vol. 11, n. 4, pg. 815-852, 2008.

LEE, G.; DELONE, W.; ESPINOSA, J. A. Ambidextrous coping strategies in globally distributed software development projects. Communications of the ACM, Vol. 49, Issue 10, pg. 35-40, 2006.

LEFFINGWELL, D. Agile Software Requirements: lean requirements practices for teams, programs, and the enterprise. Pearson Education, Boston, 2011.

ŁUKASIEWICZ, K.; MILER, J. Improving agility and discipline of software development with the Scrum and CMMI. IET software, v. 6, n. 5, p. 416-422, 2012.

MADACHY, Raymond; BOEHM, Barry; LANE, Jo Ann. Spiral lifecycle increment modeling for new hybrid processes. Software process change. Springer Berlin Heidelberg, p. 167-177, 2006.

MAGDALENO, A.M.; WERNER, C.M.L.; DE ARAUJO, R.M. Reconciling software development models: A quasi-systematic review. Journal of Systems and Software, v. 85, n. 2, p. 351-369, 2012.

MIGUEL, P.A.C. et al. Metodologia de pesquisa em engenharia de produção e gestão de operações. Editora Elsevier, $2^{\mathrm{a}}$ edição, 2012.

MISHRA, D.; MISHRA, A. Complex software project development: agile methods adoption. Journal of Software Maintenance and Evolution: Research and Practice, v. 23, n. 8, p. 549-564, 2011.

NAKAGAWA E.Y. Uma contribuição ao projeto arquitetural de ambientes de engenharia de software. Tese (Doutorado em Ciência da Computação), Instituto de Ciências Matemáticas e Computação, Universidade de São Paulo, 2006.

NATIONAL PHYSICAL LABORATORY. Water rocket challenge. http://www.npl.co.uk/educateexplore/water-rocket-challenge/. Acesso em: 20 de Outubro de 2014.

NAWROCKI, J. R. et al. Balancing Agility and Discipline with XPrince. Rapid Integration of Software Engineering Techniques, Lecture Notes in Computer Science, Vol. 3943, pg. 266-277, 2006.

NAWROCKI, J. R. et al. Combining extreme programming with ISO 9000. EurAsia-ICT 2002: Information and Communication Technology. Springer Berlin Heidelberg, p. 786-794. 2002.

NERUR, S., MAHAPATRA, R.; MANGALARAJ, G. Challenges of migrating to agile methodologies. Communications of the ACM, Vol. 48, Issue 5, pg. 73-78, 2005.

NERUR, S.; BALIJEPALLY, V. Theoretical reflections on agile development methodologies. Communications of the ACM, Vol. 50, No 3, March 2007.

PIECZKO, S. Agile? Warterfall? How about Wet Agile? Agile Jornal, 2010. Disponível em: http://www.agileconnection.com/article/agile-waterfall-how-about-wetagile. Acesso em: 14 de Fevereiro de 2014.

PMI. A guide to the Project Management body of knowledge (PMBoK). Project Management Institute, Inc., $5^{\text {th }}$ Edition, 2013. 
PMI. Pulse of the profession - organizational agility. 2012. Relatório disponível no site: http://www.pmi.org/ /media/PDF/Research/Organizational-Agility-In-Depth-Report.ashx

PORT, D.; BUI, T. Simulating mixed agile and plan-based requirements priorization strategies: proof-of-concept and practical implications. European Journal of Information System, Vol. 18, pg. 317-331, 2009.

RAHIMIAN, V.; RAMSIN, R. Designing an agile methodology for mobile software development: a hybrid method engineering approach. Second International Conference on Research Challenges in Information Science (RCIS), Marrakech, 3-6, pg. 337 - 342, June 2008.

RAMESH, B.; CAO, L.; MOHAN, K.; XU, P. Can distributed software development be agile? Communications of the ACM, Vol. 49, No. 10, October 2006.

RAMESH, B.; MOHAN, K.; CAO, L. Ambidexterity in agile distributed development: an empirical investigation. Information Systems Research, Vol. 23, No. 2, pp. 323-339, June 2012.

ROZENFELD, H. et al. Gestão de desenvolvimento de produtos: uma referência para a melhoria do processo. São Paulo: Saraiva, 2006.

SAUSER, B.J.; REILLY, R.R.; SHENHAR, A.J. Why projects fail? How contingency theory can provide new insights - A comparative analysis of NASA's Mars Climate Orbiter loss. International Journal of Project Management, v. 27, n. 7, p. 665-679, 2009.

SCHWABER, K. Agile project management with Scrum. Microsoft Press, Redmond, Washington, 2004.

SEYAM, M.S.; GALAL-EDEEN, G.H.; Traditional versus Agile: the Tragile framework for information systems development. International Journal of Software Engineering (IJSE), Vol 4, no 1, Jan 2011.

SHENHAR, A. J. et al. Refining the search for project success factors: a multivariate, typological approach. R\&D Management, Vol..32, n.2, pg.111-126, 2002.

SHENHAR, A. J. One size does not fit all projects: Exploring classical contingency domains. Management Science, v. 47, n. 3, p. 394-414, 2001.

SHENHAR, A. J.; DVIR, D.; LEVY, O.; MALTZ, A. C. Project success: a multidimensional strategic concept. Long range planning, v. 34, n. 6, p. 699-725, 2001.

SLIGER, M.; BRODERICK, S. The software project manager's bridge to agility. Addison-Wesley Professional, 2008.

SOMMER, A.F.; DUKOVSKA-POPOVSKA, I.; STEGER-JESEN, K. Agile product development governance on governing the emerging scrum/stage-gate hybrids. Advances in Production Management Systems. Innovative and Knowledge-Based Production Management in a Global-Local World, Vol. 438, pp 184-191, 2014.

SOMMER, A.F.; HEREGAARD, C.; DUKOVSKA-POPOVSKA, I.; STEGER-JESEN, K. Improved product development performance through agile/stage-gate hybrids: the next-generation stage-gate process? ResearchTechnology Management, v.. 58, n. 1, Jan-Feb, pp. 34-45, 2015. 
SPUNDAK, M. Mixed agile/traditional project management methodology - reality or illusion? $27^{\text {th }}$ IPMA World Congress. Procedia - Social and Behavioral Sciences, Vol. 19, pg. 939-948, 2014.

SUDDABY, ROY. Editor's Comments: construct clarity in theories of management and organization. Academy of Management Review, Vol. 35, No 3, p. 346-357, 2010.

TURK, D.; RUMPE, B. Limitations of agile software processes. University of Technology of München. Chair IV: Software \& Systems Engineering, 2009. Disponível em: http://www4.in.tum.de/publ/papers/XP02.Limitations.pdf.

VERSION ONE. $8^{\text {th }}$ Annual state of agile survey. 2014. Disponível em: www.versionone.com/pdf/2013-state-ofagile-survey.pdf. Acesso em 04 de maio de 2015.

VINEKAR, V.; SLINKMAN, C. W.; NERUR, S. Can agile and traditional systems development approaches coexist? An ambidextrous view. Information Systems Management, Vol 23, Issue 3, pg. 31-42, 2006.

VOSS, C.; TSIKRIKTSIS, N.; FROHLICH, M. Case research in operations management. International Journal of Operations \& Production Management, v.22, n. 2, p. 195-219, 2002.

WYSOCKI, R.K. Effective Project Management: Traditional, Adaptive, Extreme. Wiley, 2007.

YADAV, Vanita et al. Flexible global software development (GSD): antecedents of success in requirements analysis. Journal of Global Information Management (JGIM), v. 17, n. 1, p. 1-31, 2009.

YIN, R. K. Estudo de Caso: planejamento e métodos. $3^{\text {a }}$ Edição, Porto Alegre: Bookman, 2005.

ZAKI, K.M.; MOAWAD, R. A hybrid disciplined agile software process model. The 7th International Conference on Informatics and Systems (INFOS), 2010. 


\section{APÊNDICE A - TRABALHOS ANALISADOS PELA REVISÃO BIBLIOGRÁFICA SISTEMÁTICA}

O Quadro 27 apresenta todos os artigos lidos integralmente durante a Revisão Bibliográfica Sistemática RBS após a verificação dos critérios de inclusão. O Quadro está apresenta o conteúdo identificado nos trabalhos em relação à definição, benefícios, fatores críticos e propostas de modelos, visando, assim, auxiliar pesquisas futuras no tema de combinação de práticas de gestão de projetos.

\begin{tabular}{|c|c|c|c|c|}
\hline \multicolumn{5}{|c|}{ Quadro 27 - Artigos lidos integramente na RBS } \\
\hline Autor(es) & Definição & Benefícios & $\begin{array}{l}\text { Fatores } \\
\text { Críticos }\end{array}$ & $\begin{array}{l}\text { Proposta de } \\
\text { Modelo }\end{array}$ \\
\hline Amaral et al. (2011) & & & $\mathrm{X}$ & $\mathrm{X}$ \\
\hline Barlow et al. (2011) & $\mathrm{X}$ & & $\mathrm{X}$ & \\
\hline Batra et al. 2010 & $\mathrm{X}$ & $\mathrm{X}$ & $\mathrm{X}$ & $\mathrm{X}$ \\
\hline $\begin{array}{l}\text { Binder, Aillaud e Schilli } \\
\text { (2014) }\end{array}$ & $X$ & & & \\
\hline Boehm e Turner (2003) & $\mathrm{X}$ & & & $\mathrm{X}$ \\
\hline Boehm e Turner (2005) & $\mathrm{X}$ & & $\mathrm{X}$ & \\
\hline Bos e Vries (2004) & & & $\mathrm{X}$ & \\
\hline Chin (2004, p. 16) & $\mathrm{X}$ & & & \\
\hline Cobb $(2011$, p.69 e 87) & $\mathrm{X}$ & & $\mathrm{X}$ & \\
\hline Conforto e Amaral (2010) & & & $\mathrm{X}$ & \\
\hline $\begin{array}{l}\text { Fernandez e Fernandez } \\
(2008)\end{array}$ & $\mathrm{X}$ & & & \\
\hline $\begin{array}{l}\text { Galal-edeen, Riad } \quad \text { e } \\
\text { Seyam (2007) }\end{array}$ & $\mathrm{X}$ & & & \\
\hline Griffiths (2004) & & & $\mathrm{X}$ & \\
\hline $\begin{array}{l}\text { Kahkonen } \\
\text { Abrahamsson (2004) }\end{array}$ & & & $\mathrm{X}$ & \\
\hline $\begin{array}{l}\text { Karlstrom e Runeson } \\
\text { (2005) }\end{array}$ & & $\mathrm{X}$ & $\mathrm{X}$ & \\
\hline \multicolumn{5}{|l|}{$\begin{array}{l}\text { Keith, Demirkan e Goul } \\
\text { (2013) }\end{array}$} \\
\hline $\begin{array}{l}\text { Lee, Delone e Espinosa } \\
\text { (2006) }\end{array}$ & & & $X$ & \\
\hline $\begin{array}{l}\text { Lukasiewicz e } \\
\text { (2012) }\end{array}$ & & & & \\
\hline \multicolumn{5}{|l|}{$\begin{array}{l}\text { Madachy, Boehm e Lane } \\
\text { (2006) }\end{array}$} \\
\hline Misha e Misha (2011) & & & $\mathrm{X}$ & \\
\hline Nawroki et al (2002) & & & $\mathrm{X}$ & \\
\hline Nawroki et al. (2006) & & & $\mathrm{X}$ & $\mathrm{X}$ \\
\hline Pieczko (2010) & $\mathrm{X}$ & & & \\
\hline Port e Bui (2009) & $X$ & & & \\
\hline $\begin{array}{l}\text { Rahimian } \\
\text { (2007) }\end{array}$ & $X$ & & & \\
\hline
\end{tabular}




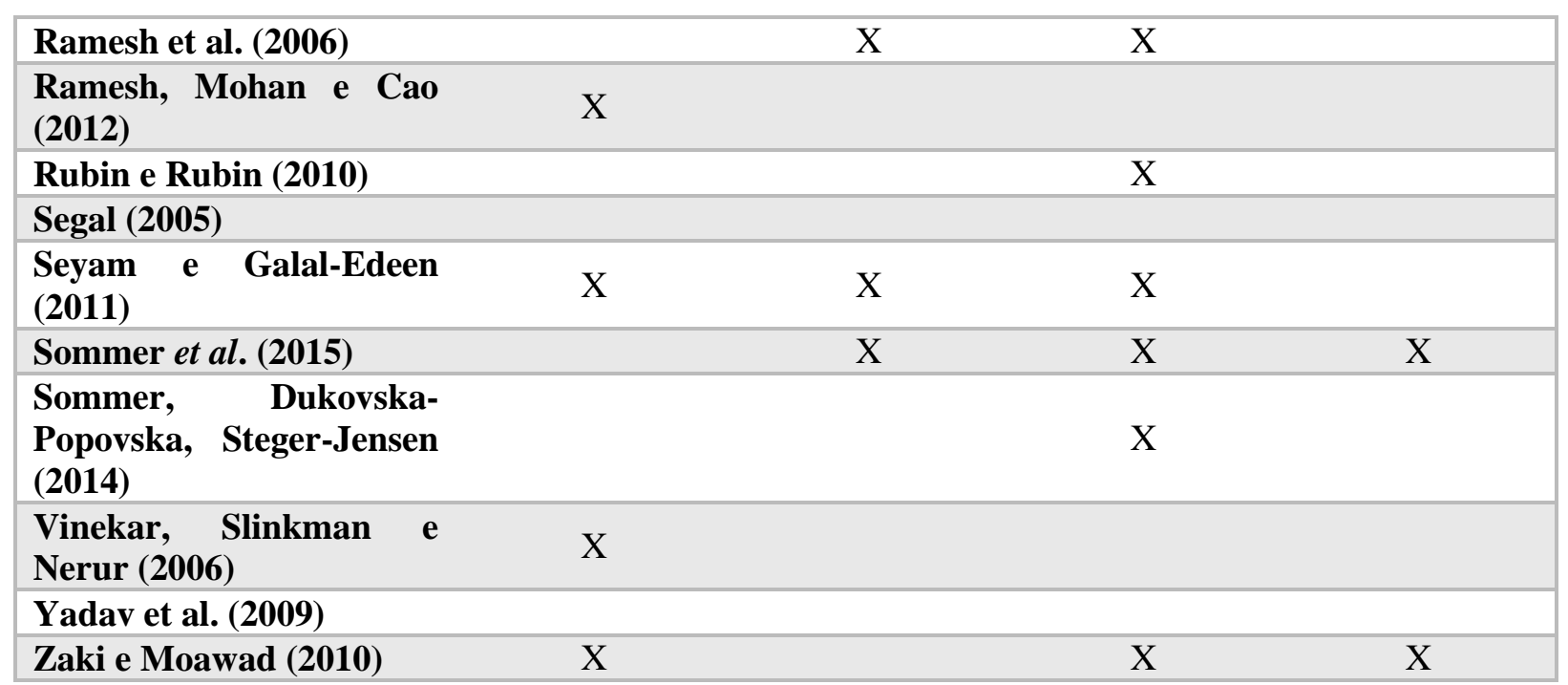




\section{APÊNDICE B - FATORES CRÍTICOS PARA A COMBINAÇÃO}

\begin{tabular}{|c|c|c|}
\hline Fatores Críticos & Sugestões/ Recomendações & Autor (es) \\
\hline \multirow[t]{2}{*}{ 1) Arquitetura de alto nível } & - Elaborar uma arquitetura de alto nível & \begin{tabular}{|c|} 
Ramesh et al. (2006) \\
Zaki e Moawad \\
(2010) \\
Seyam e Galal-Eden \\
(2011) \\
\end{tabular} \\
\hline & $\begin{array}{l}\text { - Estabelecer características e padrões que } \\
\text { permitam separar componentes estáveis } \\
\text { daqueles em evolução de requisitos e ambiente }\end{array}$ & $\begin{array}{l}\text { Boehm e Turner } \\
\qquad(2005)\end{array}$ \\
\hline \multirow{5}{*}{$\begin{array}{l}\text { 2) Up-front de } \\
\text { Desenvolvimento }\end{array}$} & $\begin{array}{l}\text { - Focar na compreensão das funcionalidades ao } \\
\text { invés de novas funcionalidades críticas }\end{array}$ & Ramesh et al. (2006) \\
\hline & $\begin{array}{l}\text { - Redução da ambiguidade no escopo do projeto } \\
\text { obtendo os requisitos do usuário da melhor } \\
\text { forma possível }\end{array}$ & Batra et al. (2010) \\
\hline & $\begin{array}{l}\text { - Incluir atividades de conhecimento e } \\
\text { entendimento }\end{array}$ & $\begin{array}{l}\text { Lee, Delone e } \\
\text { Espinosa (2006) }\end{array}$ \\
\hline & $\begin{array}{l}\text { - Desenvolver os requisitos de alto nível no up- } \\
\text { front e continuar a refinar os requisitos e os } \\
\text { planos em cada iteração }\end{array}$ & $\operatorname{Cobb}(2011, \mathrm{p} .87)$ \\
\hline & $\begin{array}{l}\text { - Utilizar a Visão do Produto para auxiliar no } \\
\text { entendimento sobre o projeto }\end{array}$ & $\begin{array}{l}\text { Amaral et al. }(2011) \\
\text { Sommer et al. }(2015)\end{array}$ \\
\hline \multirow{4}{*}{$\begin{array}{l}\text { 3) Desenvolvimento } \\
\text { iterativo }\end{array}$} & \begin{tabular}{|l} 
- Adotar ciclos de desenvolvimento curtos, mas \\
não iterativo
\end{tabular} & Ramesh et al. (2006) \\
\hline & $\begin{array}{l}\text { - Utilizar a iteração para quebrar grandes } \\
\text { projetos em partes menores }\end{array}$ & Cobb $(2011$, p.69) \\
\hline & $\begin{array}{l}\text { - Timeboxing para melhorar a produtividade do } \\
\text { desenvolvimento }\end{array}$ & Cobb $(2011$, p.69) \\
\hline & $\begin{array}{l}\text { - Iteração com duração de tempo pequena ou } \\
\text { média }\end{array}$ & Cobb $(2011, \mathrm{p} .87)$ \\
\hline \multirow{8}{*}{$\begin{array}{l}\text { 4) Documentação mínima } \\
\text { do projeto }\end{array}$} & - Documentação compreensiva e detalhada & $\begin{array}{c}\text { Lee, Delone e } \\
\text { Espinosa (2006) }\end{array}$ \\
\hline & $\begin{array}{l}\text { - Documentar apenas dos artefatos, deliveables e } \\
\text { processos críticos }\end{array}$ & Ramesh et al. (2006) \\
\hline & $\begin{array}{l}\text { - Criar a documentação ao final do ciclo de } \\
\text { desenvolvimento }\end{array}$ & Ramesh et al. (2006) \\
\hline & $\begin{array}{l}\text { - Criar práticas de documentação mínima para } \\
\text { gerenciar o conhecimento do projeto }\end{array}$ & Batra et al. (2010) \\
\hline & $\begin{array}{l}\text { - Eliminar os documentos e artefatos que não } \\
\text { provem valor para a organização }\end{array}$ & Cobb $(2011$, p.69) \\
\hline & $\begin{array}{l}\text { - Documentação de requisitos orientados ao } \\
\text { risco }\end{array}$ & Cobb $(2011$, p.87) \\
\hline & $\begin{array}{l}\text { - Utilizar templates para coletar, documentar e } \\
\text { organizar toda a informação produzida no } \\
\text { projeto. }\end{array}$ & $\begin{array}{l}\text { Conforto e Amaral } \\
\text { (2010) }\end{array}$ \\
\hline & $\begin{array}{l}\text { - Entender a documentação como uma atividade } \\
\text { de projeto }\end{array}$ & $\begin{array}{c}\text { Karlostrom e } \\
\text { Runeson (2005) }\end{array}$ \\
\hline
\end{tabular}




\begin{tabular}{|c|c|c|}
\hline Fatores Críticos & Sugestões/ Recomendações & Autor (es) \\
\hline \multirow{3}{*}{ 5) Medição do processo } & $\begin{array}{l}\text { - Utilizar métricas simples e relevantes alinhadas } \\
\text { com a meta do desenvolvimento }\end{array}$ & Griffiths (2004) \\
\hline & $\begin{array}{l}\text { - Aplicar throughput ao invés da contabilidade } \\
\text { de custos }\end{array}$ & $\begin{array}{l}\text { Boehm e Turner } \\
(2005)\end{array}$ \\
\hline & - Controlar o processo pelo valor entregado & Cobb $(2011, p .87)$ \\
\hline $\begin{array}{l}\text { 6) Melhorar a } \\
\text { produtividade do } \\
\text { desenvolvimento }\end{array}$ & $\begin{array}{l}\text { - Utilizar técnicas ágeis como programação em } \\
\text { pares, a integração contínua, code refactoring e } \\
\text { o para melhorar a produtividade do } \\
\text { desenvolvimento. }\end{array}$ & Cobb $(2011$, p.69) \\
\hline \multirow{2}{*}{ 7) Milestones } & $\begin{array}{l}\text { - Realinhar ou redefinir os milestones para } \\
\text { melhor ajustar com a abordagem iterativa. }\end{array}$ & $\begin{array}{l}\text { Boehm e Turner } \\
\text { (2005) }\end{array}$ \\
\hline & $\begin{array}{l}\text { - Elaborar pontos de revisão e balanço para } \\
\text { garantir que o projeto está sobre controle }\end{array}$ & Ramesh et al. (2006) \\
\hline \multirow{3}{*}{$\begin{array}{l}\text { 8) Gestão dos requisitos do } \\
\text { produto }\end{array}$} & $\begin{array}{l}\text { - Desenvolver primeiramente os requisitos mais } \\
\text { importantes }\end{array}$ & $\begin{array}{c}\text { Karlostrom e } \\
\text { Runeson (2005) }\end{array}$ \\
\hline & $\begin{array}{l}\text { - Priorizar os requisitos para acelerar a entrega } \\
\text { dos mais essenciais }\end{array}$ & Cobb (2011, p.69) \\
\hline & $\begin{array}{l}\text { - Os requisitos do usuário devem ser } \\
\text { gerenciados, caso contrário haverá implicações } \\
\text { significantes no custo e cronograma do projeto }\end{array}$ & Batra et al. (2010) \\
\hline 9) Qualidade & $\begin{array}{l}\text { - Incorporar o QA para testes e inspeção de } \\
\text { qualidade }\end{array}$ & $\begin{array}{c}\text { Ramesh et al. (2006) } \\
\text { Cobb (2011) } \\
\end{array}$ \\
\hline \multirow{2}{*}{$\begin{array}{l}\text { 10) Divisão de atividades } \\
\text { de projeto }\end{array}$} & $\begin{array}{l}\text { - Minimizar as dependências de atividades } \\
\text { delegando porções independentes para um } \\
\text { mesmo time. }\end{array}$ & $\begin{array}{l}\text { Lee, Delone e } \\
\text { Espinosa (2006) }\end{array}$ \\
\hline & $\begin{array}{l}\text { - Decompor o projeto em módulos de atividades } \\
\text { independentes, e coordenar as ações das sub- } \\
\text { equipes de projeto. }\end{array}$ & Barlow et al. (2011) \\
\hline \multirow{3}{*}{$\begin{array}{l}\text { 11) Estrutura } \\
\text { organizacional }\end{array}$} & $\begin{array}{l}\text { - Três níveis: Alta administração (gerentes e } \\
\text { stakeholders principais); Intermediário (gerente } \\
\text { de projetos e scrum master); Equipes de projeto } \\
\text { auto-geridas }\end{array}$ & $\begin{array}{l}\text { Sommer, Dukovska- } \\
\text { Popovska, Steger- } \\
\text { Jensen (2014); } \\
\text { Sommer et al. (2015) }\end{array}$ \\
\hline & $\begin{array}{l}\text {-Três níveis: Alta administração (gerentes } \\
\text { sêniores); Intermediário (gerente de projetos); } \\
\text { Equipes de projeto }\end{array}$ & Batra et al. (2010) \\
\hline & $\begin{array}{l}\text { - Três níveis: Alta administração (usuário sênior, } \\
\text { executivo e fornecedor sênior); Intermediário } \\
\text { (gerente de projeto e arquiteto); Equipe de } \\
\text { projeto. }\end{array}$ & Nawrocki et al. \\
\hline \multirow{4}{*}{ 12) Comunicação } & $\begin{array}{l}\text { - Balancear a coordenação por meio de estrutura } \\
\text { formal de responsabilidade e relatórios }\end{array}$ & Ramesh et al. (2006) \\
\hline & - Utilizar vários canais de comunicação & Ramesh et al. (2006) \\
\hline & $\begin{array}{l}\text { - Entender como a comunicação ocorre entre os } \\
\text { Times de projeto }\end{array}$ & $\begin{array}{l}\text { Boehm e Turner } \\
\text { (2005) }\end{array}$ \\
\hline & $\begin{array}{l}\text { - Colaboração multigrupos por meio de } \\
\text { frequentes checkpoints }\end{array}$ & Cobb $(2011$, p.87) \\
\hline
\end{tabular}




\begin{tabular}{|c|c|c|}
\hline Fatores Críticos & Sugestões/ Recomendações & Autor (es) \\
\hline \multirow{3}{*}{$\begin{array}{l}\text { 13) Gerenciamento da } \\
\text { mudança }\end{array}$} & $\begin{array}{l}\text { - Gerenciar as mudanças culturais e os } \\
\text { comportamentos dos indivíduos com a nova } \\
\text { abordagem }\end{array}$ & $\begin{array}{l}\text { Boehm e Turner } \\
\qquad(2005)\end{array}$ \\
\hline & $\begin{array}{l}\text { - Ao propor um processo que integre o ágil e o } \\
\text { tradicional, conduzir uma análise significativa } \\
\text { nos processos existentes para identificar } \\
\text { incompatibilidades nos requisitos e expectativa } \\
\text { do processo proposto } \\
\end{array}$ & $\begin{array}{l}\text { Boehm e Turner } \\
\text { (2005) }\end{array}$ \\
\hline & $\begin{array}{l}\text { - Treinar gerentes e equipe de projeto na Gestão } \\
\text { Ágil de projetos }\end{array}$ & $\begin{array}{c}\text { Karlostrom e } \\
\text { Runeson (2005) }\end{array}$ \\
\hline \multirow{7}{*}{$\begin{array}{l}\text { 14) Processo de } \\
\text { Desenvolvimento }\end{array}$} & $\begin{array}{l}\text { - Ajustar o processo continuamente para atender } \\
\text { às necessidades do projeto }\end{array}$ & Ramesh et al. (2006) \\
\hline & $\begin{array}{l}\text { - Construir o processo gradualmente ao invés de } \\
\text { implementá-lo }\end{array}$ & $\begin{array}{l}\text { Boehm e Turner } \\
\text { (2005) }\end{array}$ \\
\hline & $\begin{array}{l}\text { - Implementar praticas ágeis que suportem os } \\
\text { processos existentes ou as novas prioridades } \\
\text { organizacionais }\end{array}$ & $\begin{array}{l}\text { Boehm e Turner } \\
\qquad(2005)\end{array}$ \\
\hline & $\begin{array}{l}\text { - Testes funcionais contínuos, maior parte } \\
\text { automatizado }\end{array}$ & Cobb $(2011$, p.87) \\
\hline & - Escolhas de design orientado ao risco e valor & Cobb $(2011$, p.87) \\
\hline & - Manter um repositório de informações comum & $\begin{array}{l}\text { Ramesh et al. (2006) } \\
\text { Lee, Delone e } \\
\text { Espinosa (2006) } \\
\text { Conforto e Amaral } \\
\quad(2010) \\
\text { Amaral et al. }(2011)\end{array}$ \\
\hline & $\begin{array}{l}\text { - Utilizar modelo de referência para guiar o } \\
\text { desenvolvimento }\end{array}$ & $\begin{array}{l}\text { Conforto e Amaral } \\
\qquad(2010) \\
\text { Amaral } \text { et al. }(2011) \\
\text { Sommer } \text { et al. }(2015) \\
\end{array}$ \\
\hline
\end{tabular}




\section{APÊNDICE C - Artefatos criados para o caso exemplo do Capítulo 5}

\begin{tabular}{|c|c|c|c|c|c|c|c|c|c|}
\hline \multirow{10}{*}{$\begin{array}{l}\text { Matriz } \\
\text { Item - Entrega }\end{array}$} & \multirow{2}{*}{ ID } & \multirow{2}{*}{$\begin{array}{c}\text { Item } \\
\text { ( Entregas orientadas ao } \\
\text { produto) }\end{array}$} & \multirow{2}{*}{ Responsável } & \multicolumn{6}{|c|}{ Iteração } \\
\hline & & & & 7 & 8 & 9 & 10 & 11 & 12 \\
\hline & 1 & Globo & EF e FS & & & v.1 & v.1 & & v.fin \\
\hline & 2 & $\begin{array}{l}\text { Sistema de projeção e } \\
\text { cameras (SPC) }\end{array}$ & $J B$ e LF & & & & v.1 & & v.fin \\
\hline & 3 & Totem & DA & & & & & & v.fin \\
\hline & 4 & Modulo central do software & GS e CA & & v. 1 & & & & v.fin \\
\hline & 5 & Aplicação Web & GS e CA & & & v.1 & & & \\
\hline & 6 & $\begin{array}{l}\text { Módulo de interação com } \\
\text { usuário }\end{array}$ & GS e CA & & & v.1 & & & \\
\hline & 7 & & & & & & & & \\
\hline & 8 & & & & & & & & \\
\hline $\begin{array}{l}\text { Legenda } \\
\text { Item de Hardware }\end{array}$ & 9 & & & & & & & & \\
\hline $\begin{array}{l}\text { Item de Software } \\
\text { Item de... }\end{array}$ & ID & $\begin{array}{l}\text { Pacotes de Trabalho } \\
\text { (Entregas orientadas à ação) }\end{array}$ & Responsável & & & & & & \\
\hline Versão 1 & 1 & Testes de integração & Todos & & & & & $x$ & \\
\hline Versão final & 2 & Documentação & Todos & & & & $x$ & & $x$ \\
\hline \begin{tabular}{|l|} 
Equipe \\
Responsável
\end{tabular} & 3 & $\begin{array}{l}\text { Análise de viabilidade do } \\
\text { Globo }\end{array}$ & EF e FS & $x$ & $x$ & & & $x$ & \\
\hline Camila Araujo & 4 & Codificação do software & GS e CA & & & $x$ & $x$ & & $x$ \\
\hline Edvandro Conforto EC & 5 & & & & & & & & \\
\hline \begin{tabular}{|l|} 
Daniel Amaral \\
\end{tabular} & 6 & & & & & & & & \\
\hline $\begin{array}{l}\text { Felipe Silva } \\
\text { João Benassi }\end{array}$ & 7 & & & & & & & & \\
\hline Guilherme & 8 & & & & & & & & \\
\hline Luke Ferreira & 9 & & & & & & & & \\
\hline
\end{tabular}

Figura 53 - Matriz Item - Entrega do exemplo

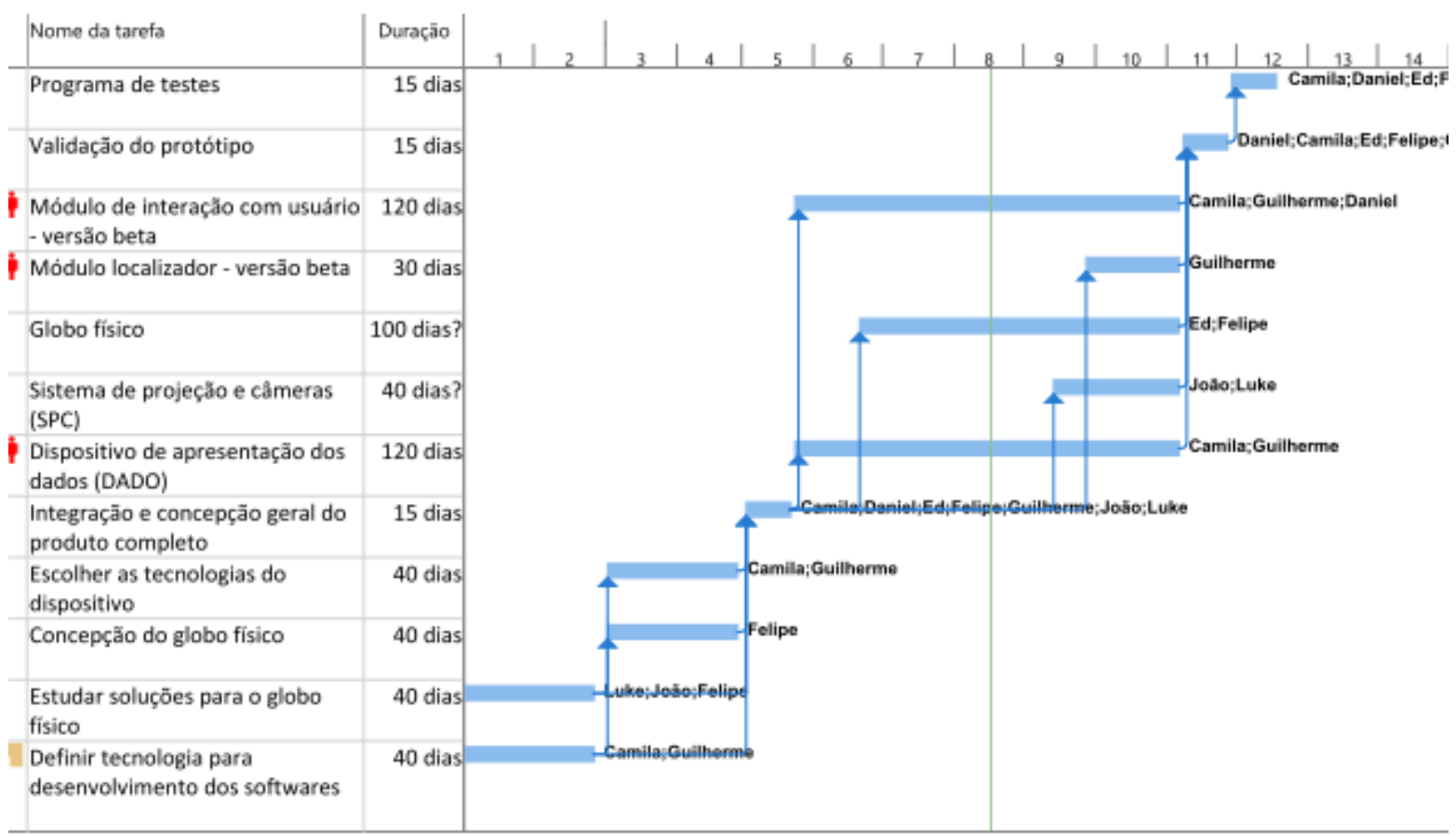

Figura 54- Plano do projeto para o exemplo 


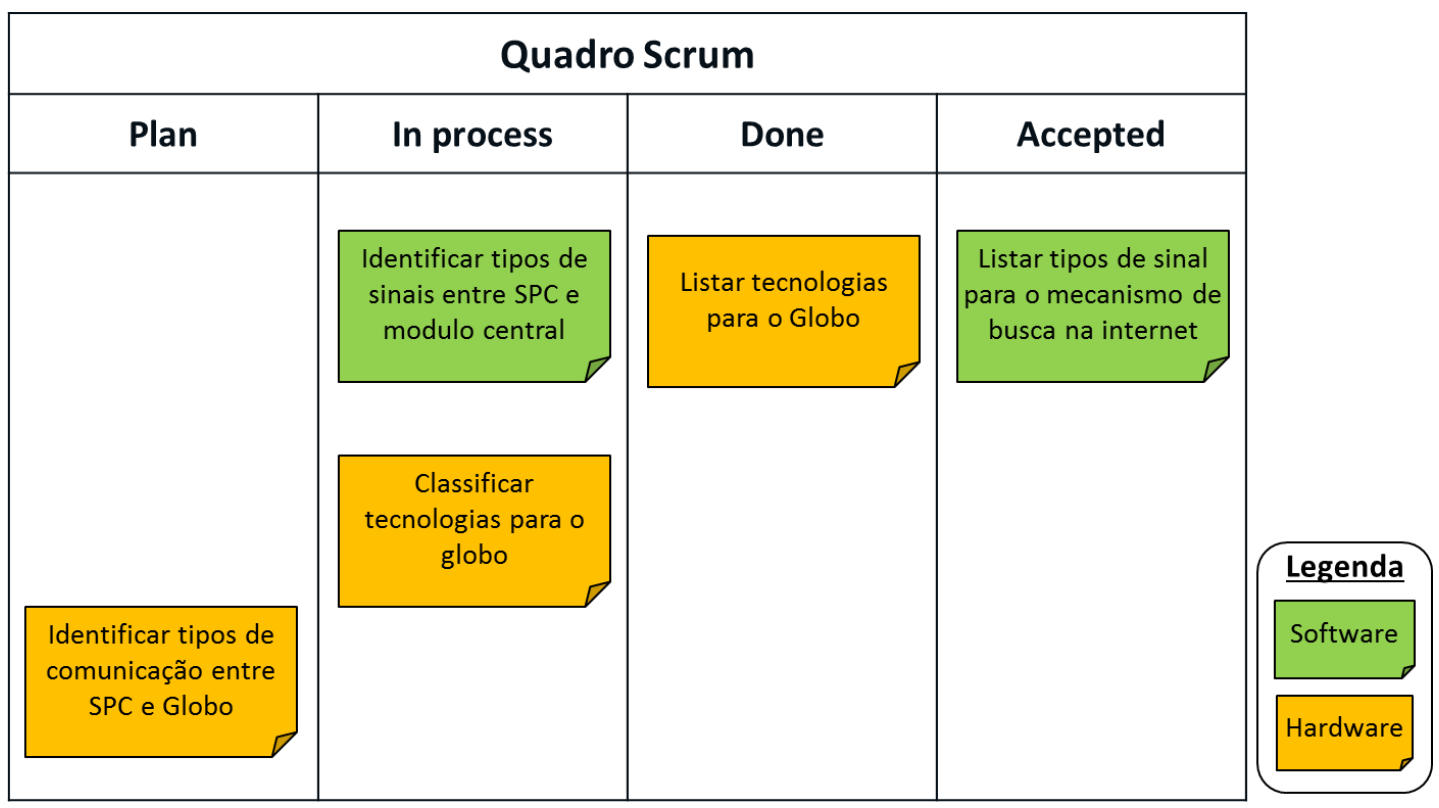

Figura 55 - Quadro Scrum e as atividades do $1^{\text {a }}$ Sprint para o exemplo 


\section{APÊNDICE D - Quadro de equivalência}

\begin{tabular}{|c|c|c|c|c|c|c|}
\hline & \multicolumn{2}{|c|}{ Tradicional } & \multicolumn{4}{|c|}{ Ágil } \\
\hline $\begin{array}{l}\text { Nível de } \\
\text { Planejamento }\end{array}$ & PMI (2013) & Wysocki (2004) & Schwaber (2004) & Leffingwell (2011) & Cohn (2008) & Amaral et al. (2011) \\
\hline Projeto & $\begin{array}{l}\text { Master Schedule } \\
\text { (p.313) - cronograma } \\
\text { sumarizado do projeto } \\
\text { que identifica as } \\
\text { principais entregas e } \\
\text { componentes dos } \\
\text { marcos do cronograma. }\end{array}$ & $\begin{array}{l}\text { Project Schedule (p.38) } \\
\text { - inclui as relações de } \\
\text { dependências entre as } \\
\text { atividades. A sequência } \\
\text { de atividades, quando } \\
\text { estabelecida, é formado } \\
\text { o cronograma. Para } \\
\text { construir o Project } \\
\text { Schedule o autor } \\
\text { recomenda diagramas } \\
\text { de rede. }\end{array}$ & -- & $\begin{array}{l}\text { Roadmap (p.272) - } \\
\text { consiste em conjuntos } \\
\text { de requisitos do } \\
\text { produto, priorizados e } \\
\text { organizados em datas } \\
\text { planejadas de releases }\end{array}$ & $\begin{array}{c}\text { Release Plan (p.134) - } \\
\text { simples lista de user } \\
\text { stories que serão } \\
\text { desenvolvidas durante } \\
\text { o projeto. (p.145) } \\
\text { Release plan é uma } \\
\text { visão geral de como o } \\
\text { time pretende entregar } \\
\text { o maior valor possível. } \\
\text {-- }\end{array}$ & $\begin{array}{c}\text { Painel Visual de } \\
\text { Planejamento e } \\
\text { Controle de Projeto } \\
\text { (PVPCP) (p.155) - } \\
\text { Painel visual físico que } \\
\text { contempla o } \\
\text { planejamento e controle } \\
\text { das entregas do projeto, } \\
\text { aquelas definidas na } \\
\text { Matriz Item-Entrega e } \\
\text { no Plano de Projeto } \\
\text { Ágil. }\end{array}$ \\
\hline $\begin{array}{l}\text { Sprint } \\
\text { (Iteração) ou }\end{array}$ & -- & -- & $\begin{array}{l}\text { Sprint Backlog (p.142) } \\
\text { - lista de atividades que } \\
\text { define o trabalho do } \\
\text { time no Sprint. Cada } \\
\text { atividade identifica o } \\
\text { responsável em realiza- } \\
\text { la e a quantidade } \\
\text { estimada de trabalho } \\
\text { restante dado um dia } \\
\text { dentro do Sprint. }\end{array}$ & $\begin{array}{l}\text { Iteration Plan (p.163) - } \\
\text { resultado do } \\
\text { planejamento e contêm: } \\
\text { objetivo da iteração; } \\
\text { lista priorizada de } \\
\text { stories a serem } \\
\text { trabalhadas; as } \\
\text { atividades estimadas e } \\
\text { os responsáveis; o } \\
\text { compromisso do time } \\
\text { para o objetivo; e, } \\
\text { documentação do plano } \\
\text { em local visível ou } \\
\text { acessível para todos. }\end{array}$ & $\begin{array}{l}\text { Iteration Plan (p.145) - } \\
\text { resultado do iteration } \\
\text { planning. Pode ser uma } \\
\text { planilha ou um } \\
\text { conjunto de cards ou } \\
\text { post-it com atividades } \\
\text { escritas à mão. As } \\
\text { atividades devem ser } \\
\text { organizadas de acordo } \\
\text { com a estória a ser } \\
\text { implementada ao final } \\
\text { da iteração. }\end{array}$ & $\begin{array}{l}\text { Quadro de } \\
\text { Planejamento Fino } \\
\text { Semanal (QPFS) } \\
\text { (p.158) - Quadro com } \\
\text { cartões que contribui } \\
\text { para melhorar a } \\
\text { interação entre os } \\
\text { membros da equipe de } \\
\text { projeto e decomposição } \\
\text { das entregas, definidas } \\
\text { no PVPCP, em } \\
\text { atividades ou pacotes de } \\
\text { trabalho que possam ser } \\
\text { concluídos no intervalo } \\
\text { de uma semana. }\end{array}$ \\
\hline
\end{tabular}




\begin{tabular}{|c|c|c|c|c|c|c|}
\hline \multirow[b]{2}{*}{$\begin{array}{l}\text { Nível de } \\
\text { Planejamento }\end{array}$} & \multicolumn{2}{|c|}{ Tradicional } & \multicolumn{4}{|c|}{ Ágil } \\
\hline & PMI (2013) & Wysocki (2004) & Schwaber (2004) & Leffingwell (2011) & Cohn (2008) & Amaral et al. (2011) \\
\hline Diário & -- & -- & $\begin{array}{l}\text { Daily Scrum Meeting } \\
\text { (p.142) - reunião de } \\
\text { status de curta duração, } \\
\text { realizada todos os dias, } \\
\text { com o objetivo de } \\
\text { sincronizar o trabalho e } \\
\text { progresso de todos os } \\
\text { membros do time e } \\
\text { reportar os } \\
\text { impedimentos. }\end{array}$ & $\begin{array}{l}\text { Daily Stand-Ups } \\
\text { (p.165) - reunião diária, } \\
\text { com duração de } 15 \\
\text { minutos, onde todos os } \\
\text { membros do time } \\
\text { participam. O propósito } \\
\text { é compartilhar } \\
\text { informações sobre o } \\
\text { progresso, comunicar e } \\
\text { coordenar atividades } \\
\text { diariamente. }\end{array}$ & $\begin{array}{l}\text { Daily Stand-up } \\
\text { Meeting (p.29) - } \\
\text { reunião para coordenar } \\
\text { o trabalho e os esforços } \\
\text { diários. Os times } \\
\text { fazem, avaliam e } \\
\text { revisam os planos. O } \\
\text { horizonte de } \\
\text { planejamento é o } \\
\text { próximo dia. }\end{array}$ & -- \\
\hline
\end{tabular}




\section{APÊNDICE E - ENVISIONING}

Antes de iniciar o procedimento de planejamento, recomenda-se, para produtos inovadores a criação da Visão do Produto. $\mathrm{Na}$ pesquisa foram adotadas as atividades e os artefatos necessários para criar a visão do produto apresentado por Benassi (2013). Deste modo, foi possível compor o fluxo de atividades para a descrição da visão do produto apresentada Figura 56 e chamada de Envisioning.

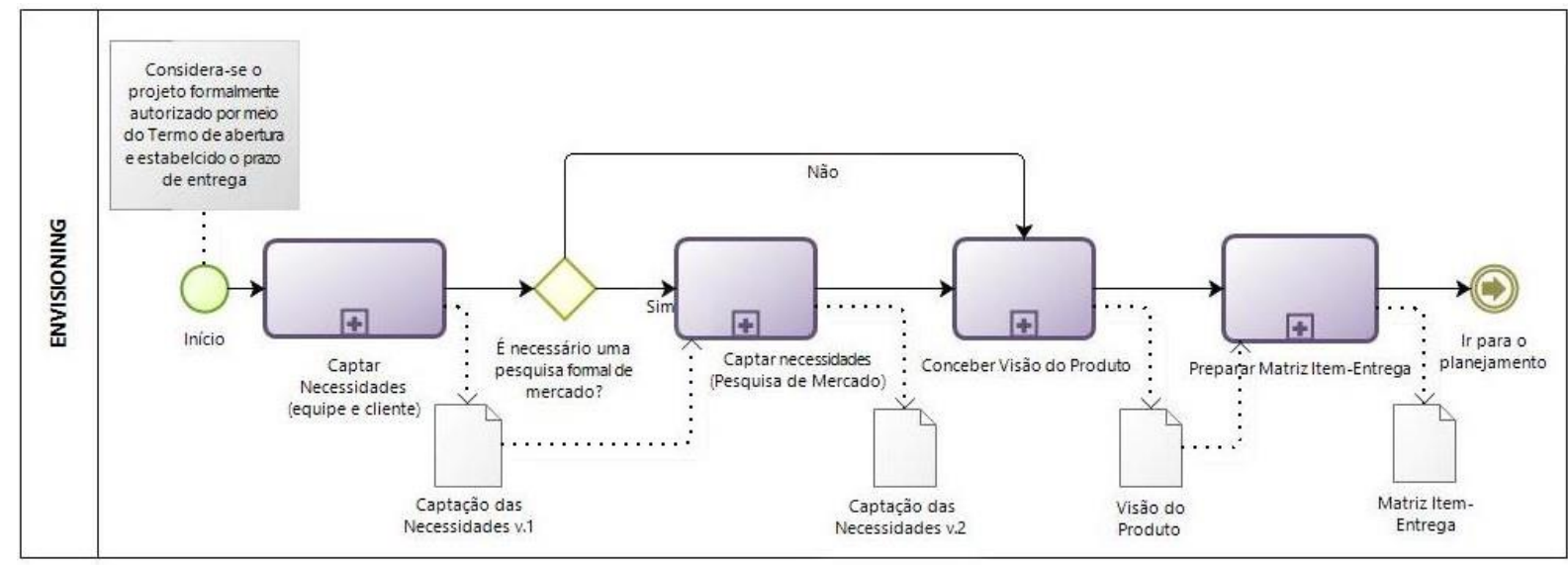

Figura 56 - Visão geral do Envisioning

O Envisioning compreende a macro atividades de iniciação do projeto. Objetivase a aumentar o conhecimento do time de desenvolvimento do problema do projeto a ser solucionado. Existem quatro macro atividades principais: Captar necessidades (equipe e cliente); Captar necessidades (pesquisa de mercado); Conceber Visão do Produto; e, Preparar matriz Item-Entrega. E os respectivos artefatos: Captação das necessidades v.1; Captação das necessidades v.2; Visão do produto; e, Matriz Item-entrega.

Parte-se do pressuposto que o projeto já foi aprovado para iniciação por meio de um Termo de Abertura por motivos de simplificação. O Termo de Abertura consiste em um artefato onde são explicitados os stakeholders e a data de entrega do projeto, dentre outras informações necessárias para iniciar o projeto.

Captar necessidades (equipe e cliente) consiste em levantar necessidades dos clientes e equipes do projeto e aprimorar o entendimento do time de desenvolvimento sobre o problema de projeto. As atividades desta estão ilustradas na Figura 57. 


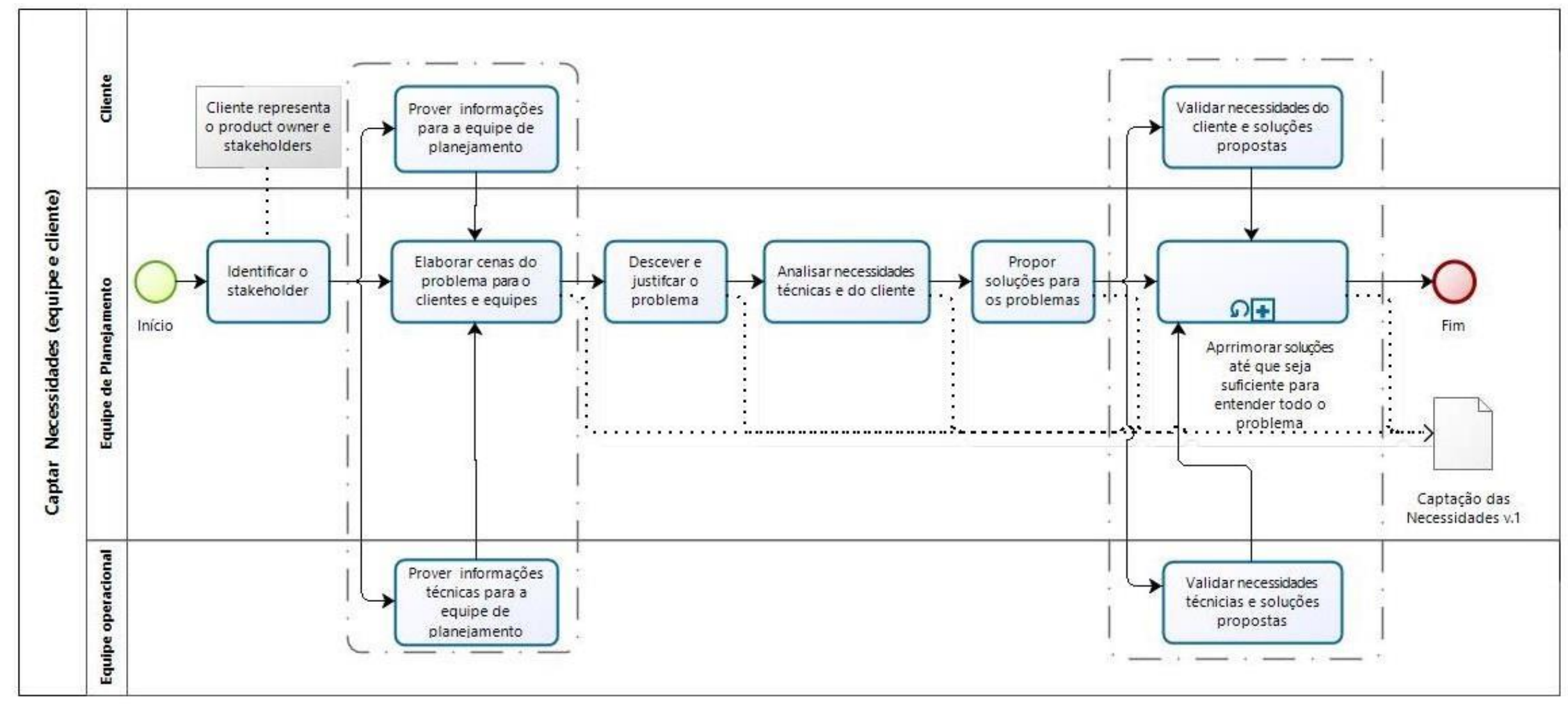

Figura 57 - Captar necessidades (equipe e cliente) 
A equipe de planejamento é a responsável por explorar detalhadamente os problemas, oportunidades e necessidades do projeto. As informações iniciais são provenientes dos clientes e membros das equipes operacionais. Benassi (2013) recomendada à técnica de desdobramento de cenas para explorar essas informações. As cenas são utilizadas para identificar respostas para as perguntas Quando? Como? Onde? O que? Por quê? Quem? (5W1H) (BENASSI, 2013, p.114).

A equipe de planejamento descreve e justifica os problemas, oportunidades e necessidades levantados em forma textual e por meio de imagens representativas. Cada um é analisado no viés do cliente e técnico da equipe operacional. A equipe de planejamento elabora propostas de soluções e os apresenta aos clientes e membros das equipes operacionais. Todos colaboram com opiniões para validar as soluções. Finaliza-se quando todos concordam que as soluções estão maduras e são suficientes para entender o problema.

Todas as informações geradas nessa atividade são documentadas no formulário de Captação das Necessidades v.1, apresentado no Anexo C.

O time de desenvolvimento pode optar por realizar a pesquisa de mercado quando for conveniente levantar informações. As atividades de Captar necessidades (pesquisa de mercado) são ilustradas na Figura 58. A equipe de planejamento analisa todos os possíveis concorrentes no mercado, em busca de informações sobre características, funcionalidades e preços praticados, dentre outras necessárias. Por exemplo, um produto similar ao Globo Iterativo do exemplo é o Smart Globe®. Esse produto interage com o usuário provendo informações sobre os países ao encostar uma caneta no país desejado. Essas informações auxiliam a equipe de planejamento na análise dos princípios de soluções. A equipe finaliza a atividade propondo um custo-meta para o produto a ser desenvolvido. $\mathrm{O}$ formulário de Captação das Necessidades v.1 é atualizado com todas as informações levantadas compondo a segunda versão desse documento. 


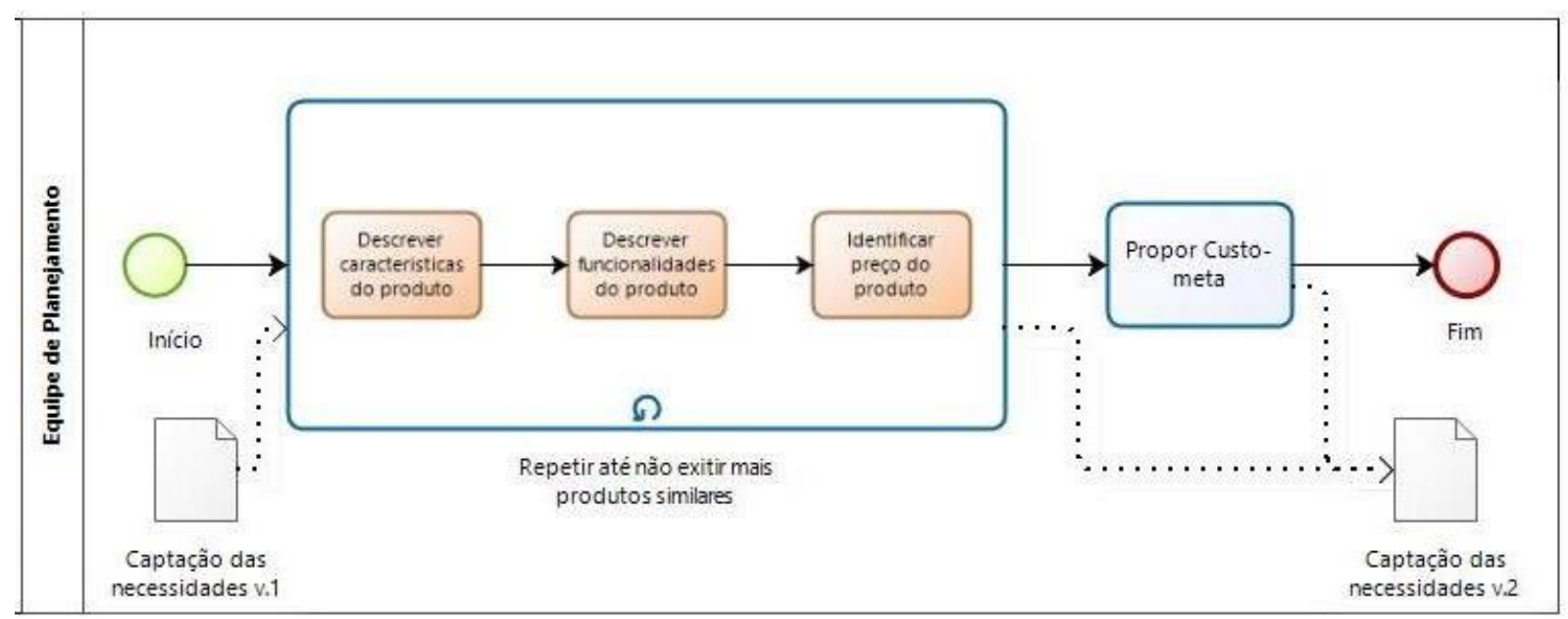

Figura 58 - Captar necessidades (Pesquisa de mercado)

A próxima macro atividade consiste em Elaborar Pré-concepção do produto, ilustrada na Figura 59. O input inicial são as cenas presentes no documento de Captação das necessidades. A equipe de planejamento conduz os clientes e membros das equipes operacionais na exploração das cenas representativas para transformá-las em pré-concepções. Uma pré-concepção exprime um desenho materializado em um artefato, ao mesmo tempo em que é ambígua em alguns pontos, pode conter detalhes de soluções ou partes específicas do produto (BENASSI, 2013, p.115).

As melhores pré-concepções são selecionadas pela equipe de planejamento. Segundo Benassi (2013, p.118), a seleção leva em consideração as pré-concepções que estão mais alinhas aos objetivos do projeto e, portanto, devem ser mais exploradas e priorizadas. Essas são aprimoradas por meio da discussão entre a equipe de planejamento, clientes e membros das equipes operacionais. 


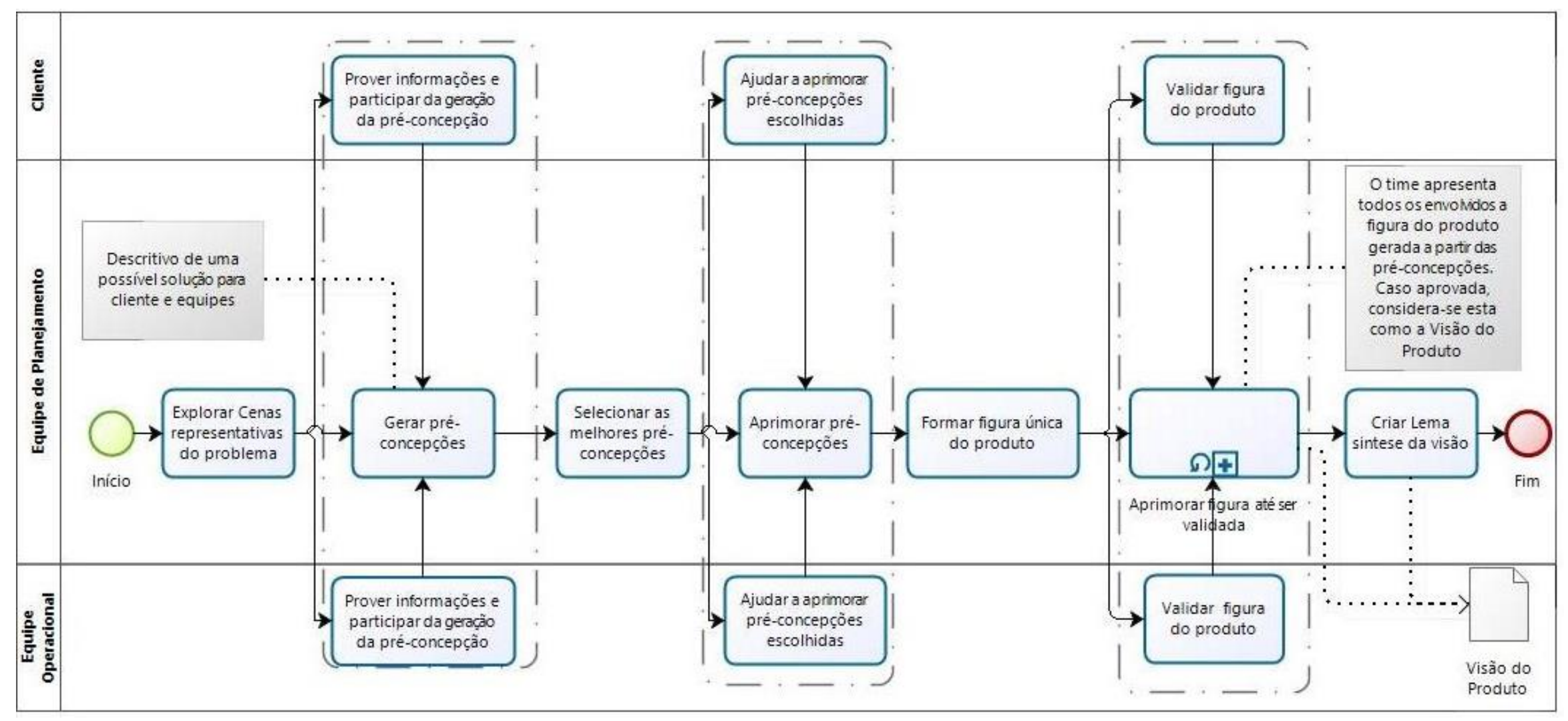

Figura 59 - Elaborar Pré-concepção do produto 
A próxima atividade é formar uma figura representativa do produto tendo como base as melhores pré-concepções. A figura passa uma ideia geral da expectativa do produto, porém não pode ser completa ao ponto da equipe não poder mais continuar sendo desafiada ou o produto não poder mais ser mudado a cada iteração (BENASSI, 2013, p.118). Após ser forma, essa é apresentada à todos os envolvidos que discutem até valida-la.

A última atividade é criar um lema síntese para a visão do produto. Benassi (2013, p.118) define o lema como uma frase concisa que ao mesmo tempo exprima com ambiguidade uma possível solução e crie motivação na equipe. Dessa forma, o artefato Visão do produto gerado nessa atividade contem a figura representativa do produto e o lema síntese.

Preparar Matriz Item-Entrega compreende na última macro atividade, representada na Figura 60. A Matriz Item-Entrega visa auxiliar os membros da equipe a desdobrar figura representativa do produto em itens a serem desenvolvidos e pacotes de trabalho orientados às ações a serem realizados no projeto (BENASSI, 2013, p.118).

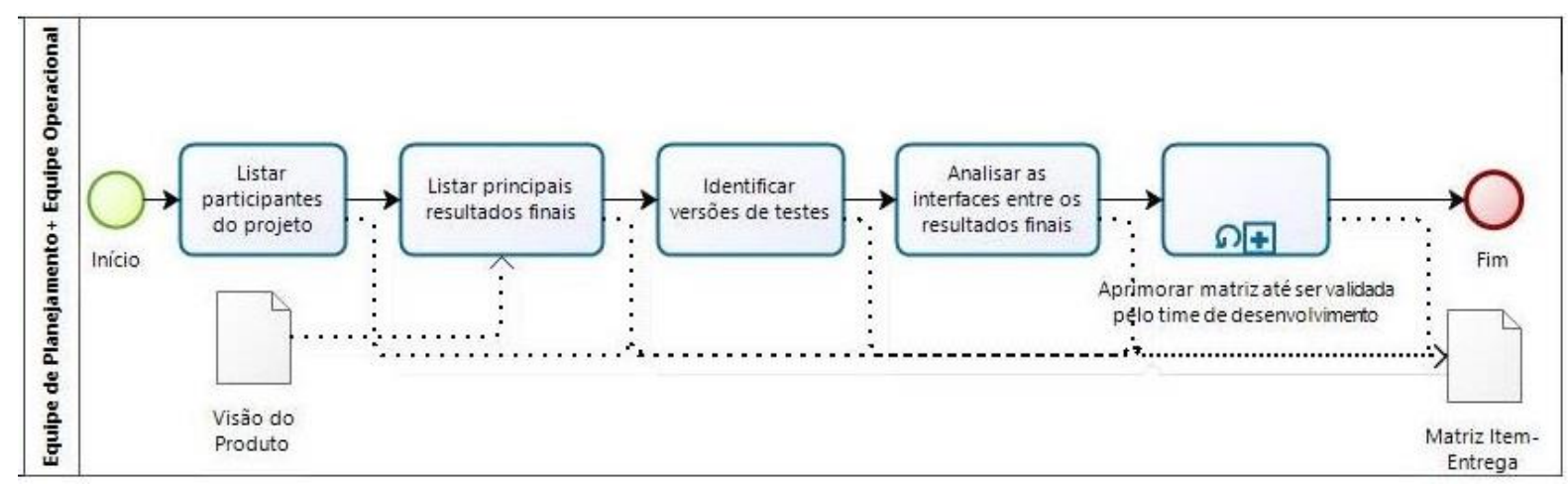

Figura 60 - Preparar Matriz Item-entrega

É necessário listar os participantes do projeto, principais resultados finais e versões de testes, por exemplo, protótipos funcionais. O time de desenvolvimento analisa as interfaces do produto entre resultados finais e membros das equipes operacionais. Por fim, há apresentação final, onde o time discute todas as informações presentes na matriz, aprimorando-a até esta ser validada por todos. Recomenda-se a leitura do exemplo de matriz Item-entrega para o caso do Globo Interativo, apresentada no Apêndice C. 


\section{APÊNDICE F - Dicionário de dados do procedimento}

\section{Elemento}

\begin{tabular}{ll}
\hline 1. Envisioning & $\begin{array}{l}\text { Etapa de iniciação do projeto com o objetivo de aumentar o } \\
\text { entendimento sobre o produto a ser desenvolvido no } \\
\text { projeto. }\end{array}$ \\
\hline
\end{tabular}

Captar Necessidades

Pro

Cenas do Problema

Cenas do Problema

Proveniente da técnica desenvolvida por Ohfuji, Ono \& meio de respostas as perguntas Quando? Como? Onde? O que? Por quê? Quem? (5W1H) (BENASSI, 2013, p.114)

Objetiva-se captar dos stakeholders as necessidades em relação ao produto (AMARAL et al., 2011, p.89) Akao (1997) e consiste em identificar possíveis cenas por

Conjunto de artefatos que descrevem o resultado esperado de um projeto de produto, por meio de elementos visuais e textuais, que devem ser elaborados de maneira concisa,

Visão do Produto coletiva (por membros da equipe de projeto e do cliente), alinhados com a estratégia apoiada pelo projeto e capaz de desafiar a equipe em busca de soluções inovadoras (BENASSI, 2013, p.100)

Exprime um desenho materializado em um artefato (documento), ao mesmo tempo em que é ambígua em alguns pontos, pode conter detalhes de soluções ou partes

Pré-concepção específicas do produto na qual os membros da equipe já conseguem prever e conhecer de antemão. Difere-se da concepção por ser criada na fase inicial de planejamento do projeto (BENASSI, 2013, p.115)

Artefato do metodo Involvision com o objetivo de

Matriz Item-entrega descrever os resultados/entregas do projeto e esclarecer para todos os membros da equipe a relação entre eles (BENASSI, 2013, p.118)

\section{Planning}

Etapa de planejamento do procedimento

Plano que apresenta as principais entregas, os milestones

Plano mestre de projeto fundamentais, baseado nas necessidades do cliente, visão do produto e cronograma de alto nível (BINDER; AILLAUD; SCHILLI, 2014).

Product Backlog Consiste na lista de todos os work items identificados pela equipe de projeto (LEFFINGWELL, 2011, p.56)

Resultado Final Compreende as entregas e pacotes de trabalho identificados pelo time e presentes no Macro Plano

Conjunto de todas as atividades do projeto, funções,

Work items requisitos do produto e user stories, identificados ou coletados pelo time de projeto, necessários para o desenvolvimento do projeto 


\begin{tabular}{ll}
\hline Sprint & É a denominação de iteração na metodologia Scrum \\
\hline Quadro Scrum & $\begin{array}{l}\text { Quadro vísivel para todos do time onde estão representadas } \\
\text { as atividades a serem desenvolvidas na iteração. As } \\
\text { atividades apresentam quatro status: Not started (não } \\
\text { iniciado); in process (executando); Done (concluído); } \\
\text { Accepted (Aprovado) (LEFFINGWELL, 2011, p. 165). }\end{array}$ \\
& $\begin{array}{l}\text { Consiste na Daily Scrum Meetin, reunião de status de curta } \\
\text { duração, realizada todos os dias, com o objetivo de }\end{array}$ \\
& sincronizar o trabalho e progresso de todos os membros do \\
time e reportar os impedimentos (SCHWABER, 2004, & p.142) \\
\hline Reunião Diária & Reunião com o propósito do time apresentar para o \\
& Product Owner e stakeholders funcionalidade \\
potencialmente entregável ou implementável \\
(SCHWABER, 2004, p.137). O product owner e \\
stakeholders são chamados de Clientes no procedimento \\
híbrido.
\end{tabular}




\section{APÊNDICE G - PROTOCOLO DO ESTUDO DE CASO}

\section{Seção 1 - Visão geral do estudo de caso}

1.1 Objetivo do estudo de caso

Avaliar o procedimento de planejamento de tempo combinado por meio de um treinamento didático.

\section{Seção 2 - Procedimentos de campo}

2.1 - O Layout da sala para aplicação do treinamento deve ser preparado antecipadamente ao início das atividades. A Figura 61 ilustra o posto de trabalho da equipe de projeto que deve ser organizado em três mesas, uma para cada subsistema. As mesas devem estar próximas à parede para fixação dos artefatos.

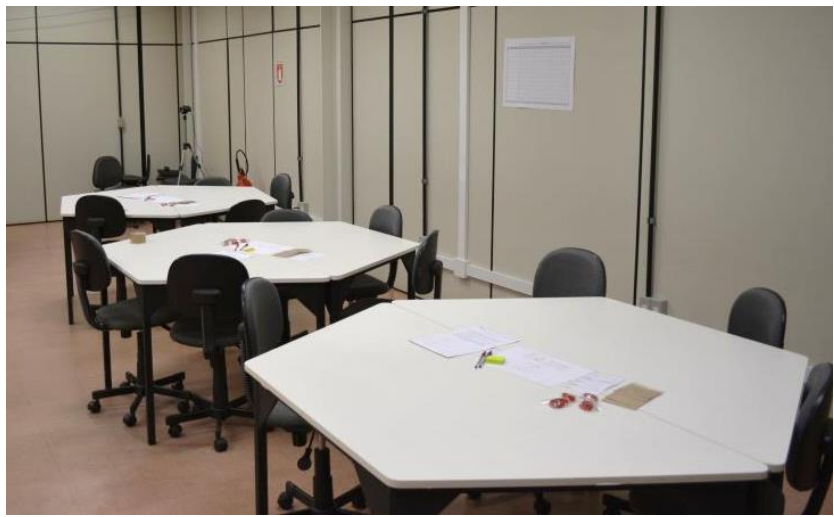

Figura 61 - Layout da sala de treinamento

2.2 - O material para deve ser disponibilizado para cada equipe deve estar disposto em cima da mesa conforme mostra a Figura 62. Os materiais consistem no crachá de identificação dos alunos, canetas, post-it e Carta de consentimento (Apêndice J).

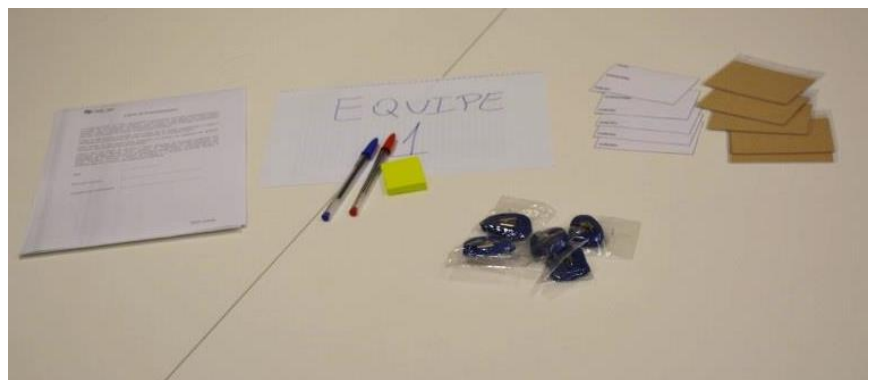

Figura 62 - Materiais disponibilizados

2.3 - O alunos devem ser previamente distribuídos aleatoriamente em grupos com pelo menos 9 pessoas. Três pessoas devem ser escolhidas para assumirem o papel de líderes do 
projeto e as outras exercem o papel de membros das equipes.

2.4- Materiais necessários para a construção do foguete e condução do treinamento são apresentados no Quadro 28.

\begin{tabular}{|lcc|}
\hline \multicolumn{2}{|c|}{ Quadro 28 - Materiais para a construção do foguete } \\
\hline Item & Tipo & $\begin{array}{c}\text { Quantidade por } \\
\text { equipe }\end{array}$ \\
\hline Corpo do Foguete & und & 2 \\
Garrafas PET (Iguais) & caixa & 1 \\
Papelão & m & 3 \\
Arame Galvanizado No 18 Gerdau & & \\
& & \\
Acionamento & rolo & 1 \\
Barbante & und & 1 \\
Válvula de pneu sem câmara & und & 8 \\
Abraçadeira de Nylon & und & 1 \\
Registro Esf Vs Soldável 20 MM TIGRE & und & 1 \\
CAP Soldável 20 MM TIGRE & und & 3 \\
Abraçadeira de ferro 19/25 3/4X1 COFEMA & & \\
& & \\
Plataforma de Lançamento & metro & 2 \\
Tubo Soldável 20 MM TIGRE & und & 4 \\
Joelho Soldável 45 graus, 20 MM TIGRE & und & 4 \\
Joelho Soldável 90 graus, 20 MM TIGRE & und & 4 \\
TE 90 graus Soldável 25 MM TIGRE & und & 4 \\
Ponteiras de borracha de 1" & und & 1 \\
Luva de Correr Soldável 32 MM TIGRE & und & 1 \\
Mini Arco de Serra Tramontina & und & 1 \\
Fita adesiva & & \\
\hline
\end{tabular}

2.5 - O diário de bordo registra os acontecimentos ocorridos durante o treinamento. Recomenda-se utilizar uma prancheta com folhas A4, uma para equipe. Os acontecimentos devem ser codificados conforme o ID apresentado no quadro da seção 3 deste protocolo.

2.6 - O pesquisador deve carregar previamente todos os equipamentos eletrônicos a serem utilizados no treinamento, dentre máquina fotográfica, filmadoras, laptops, outros dispositivos eletrônicos necessários para a condução do treinamento. 
2.7 - Agenda para a execução do treinamento

\begin{tabular}{|c|c|c|c|}
\hline Dia 1 & Dia 2 & Dia 3 4 \\
\hline $\begin{array}{c}\text { Aula teoria de APM } \\
(2: 00 \mathrm{~h})\end{array}$ & $\begin{array}{c}\text { Visão do Produto } \\
\text { Sprint 1 } \\
(2: 00 \mathrm{~h})\end{array}$ & $\begin{array}{c}\text { Sprint Review 1 } \\
\text { Sprint 2 } \\
(2: 00 \mathrm{~h})\end{array}$ & $\begin{array}{c}\text { Sprint Review 2 } \\
\text { Sprint 3 } \\
(2: 00 \mathrm{~h})\end{array}$ \\
\end{tabular}

2.8 - Atividades específicas para cada dia do treinamento.

Dia 2 - Planejamento do projeto.

\begin{tabular}{|l|l|l|}
\hline Atividade & Duração & Responsável \\
\hline - Organizar a equipe de projeto & $15 \mathrm{~min}$ & Monitores \\
\hline - Distribuir o material do cenário do treinamento & $10 \mathrm{~min}$ & Monitores \\
\hline $\begin{array}{l}\text { - Apresentar a Visão do produto e as prioridades do } \\
\text { cliente }\end{array}$ & $20 \mathrm{~min}$ & Monitores \\
\hline - Explicar o funcionamento do Sprint & $10 \mathrm{~min}$ & Monitores \\
\hline - Executar o Sprint 1 & $60 \mathrm{~min}$ & Equipe de Projeto \\
\hline - Fazer o fechamento do Dia 2 & $5 \mathrm{~min}$ & Monitores \\
\hline
\end{tabular}

Dia 3 - Execução do projeto

\begin{tabular}{|l|l|l|}
\hline Atividade & Duração & Responsável \\
\hline - Revisar o Plano Mestre & $25 \mathrm{~min}$ & $\begin{array}{l}\text { Equipe de Projeto e } \\
\text { Cliente }\end{array}$ \\
\hline $\begin{array}{l}\text { - Elaborar o Product Backlog e o Quadro } \\
\text { Scrum }\end{array}$ & $20 \mathrm{~min}$ & Equipe de Projeto \\
\hline $\begin{array}{l}\text { - Distribuir o material para construir os } \\
\text { foguetes }\end{array}$ & $10 \mathrm{~min}$ & Monitores \\
\hline - Executar Sprint 2 & $60 \mathrm{~min}$ & Equipe de Projeto \\
\hline - Fazer o fechamento do dia 3 & $5 \mathrm{~min}$ & Monitores \\
\hline
\end{tabular}




\section{Dia 4 - Finalização do projeto}

\begin{tabular}{|l|l|l|}
\hline Atividade & Duração & Responsável \\
\hline - Feedback para as equipes sobre o projeto & $25 \mathrm{~min}$ & Monitores \\
\hline $\begin{array}{l}\text { - Executar Sprint Review 1 (simular Daily } \\
\text { Meeting) }\end{array}$ & $30 \mathrm{~min}$ & $\begin{array}{l}\text { Equipe de Projeto e } \\
\text { Monitores }\end{array}$ \\
\hline - Executar Sprint 2 & $60 \mathrm{~min}$ & Equipe de Projeto \\
\hline - Apresentar os protótipos & $5 \mathrm{~min}$ & Equipe de Projeto \\
\hline
\end{tabular}

2.8 - O questionário de avaliação da experiência do usuário (Apêndice $\mathrm{H}$ ) deve ser entregue para os participantes do treinamento, no último dia, após a conclusão do debate sobre o procedimento.

2.9 - Todos os artefatos gerando durante a execução do treinamento, Plano Mestre, Quadro Scrum, entre outros, devem ser devidamente armazenados para a análise posterior.

2.10 - Após o treinamento, os dados coletados via diário de bordo devem ser transcritos para a tabela no seguinte formato para facilitar a análise posterior dos dados:

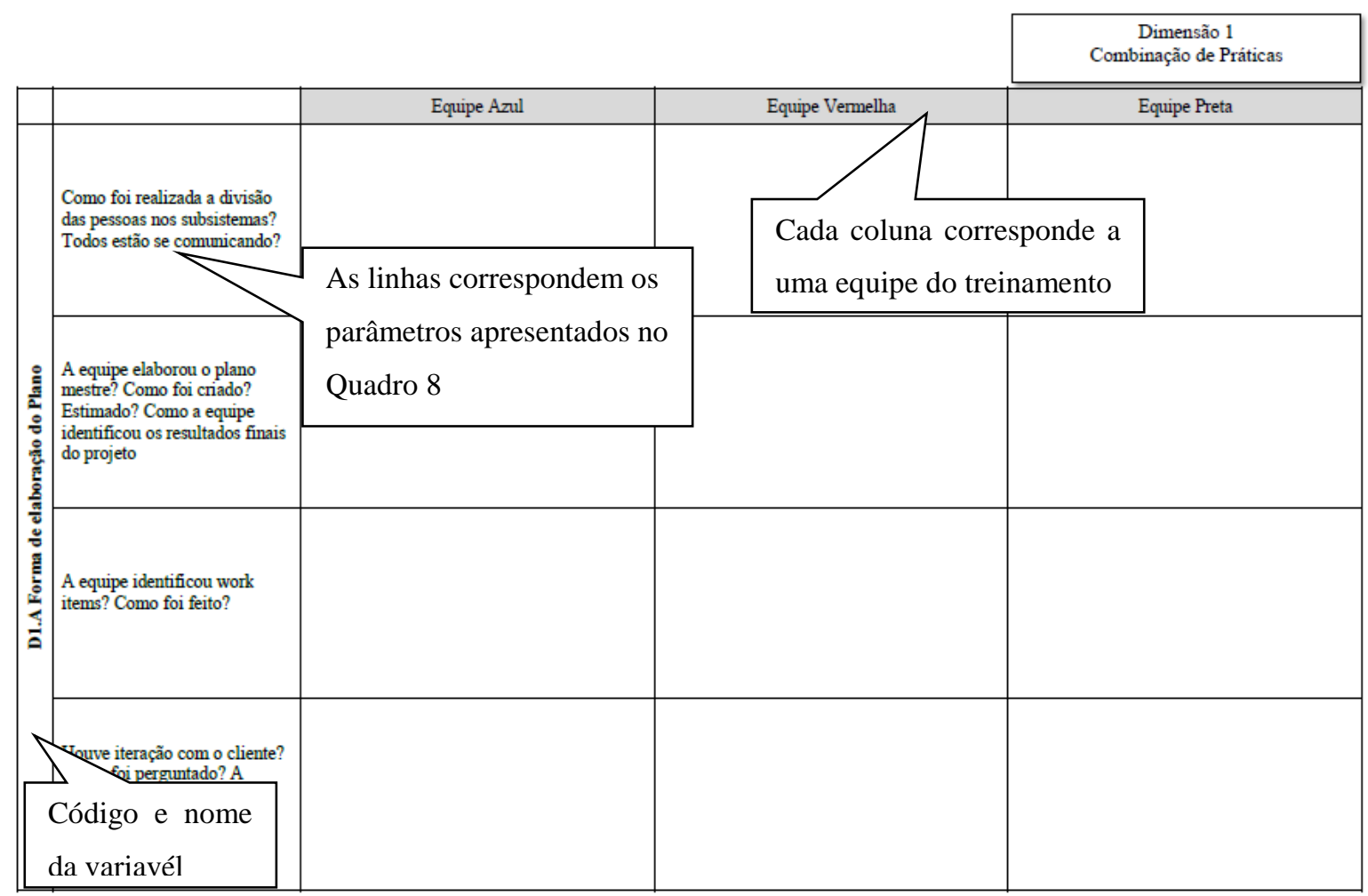




\section{Seção 3 - Questões de estudo}

As questões específicas do estudo referentes às variáveis da Diminsão 1 (Combinação de Práticas) estão desdobradas em parâmetros a serem observados, ou perguntas direcionadoras, para auxiliar o pesquisador na coleta de dados durante a execução dos Sprints pelos alunos.

\begin{tabular}{|c|c|c|}
\hline ID & racterística & Parâmetros a serem observados \\
\hline D1.A & $\begin{array}{l}\text { Forma de elaboração } \\
\text { do Plano }\end{array}$ & $\begin{array}{l}\text { - Nível de detalhe nos planos de projeto } \\
\text { - O plano mestre foi elaborado para todo o projeto de uma única } \\
\text { vez } \\
\text { - A equipe priorizou as entregas mais importantes? } \\
\text { - O Quadro Scrum elaborado/ atualizado sucessivas vezes? } \\
\end{array}$ \\
\hline D1.B & jeto & $\begin{array}{l}\text { - A equipe conseguiu definir asentregas finais a partir da visão } \\
\text { do produto? }\end{array}$ \\
\hline D1.C & $\begin{array}{l}\text { Forma como se define } \\
\text { as atividades }\end{array}$ & $\begin{array}{l}\text { - Foi criada uma lista de atividades (Backlog)? } \\
\text { - As atividades foram organizadas de forma hierárquica } \\
\text { semelhante à WBS? } \\
\text { - Foi realizado o sequenciamento das entregas principais no } \\
\text { plano mestre? }\end{array}$ \\
\hline D1.D & $\begin{array}{l}\text { brizonte de } \\
\text { anejamento das } \\
\text { vidades }\end{array}$ & $\begin{array}{l}\text { - O plano mestre foi elaborado para todo o horizonte de tempo } \\
\text { do projeto de uma única vez? } \\
\text { - O quadro scrum foi detalhado/atualizado para o curto horizonte } \\
\text { de tempo? ( } 1 \text { sprint) }\end{array}$ \\
\hline D1.E & $\begin{array}{l}\text { Estratégia de controle } \\
\text { do tempo }\end{array}$ & $\begin{array}{l}\text { - O progresso foi direcionado para resultados tangíveis? } \\
\text { - As equipes solicitaram o feedback dos líderes? (Comunicação) } \\
\text { - O cliente participou da discussão ou auxiliou o time de } \\
\text { desenvolvimento? } \\
\text { - Foi utilizado algum indicado de tempo? (Exemplo: Escopo } \\
\text { entregue ou atividades concluídas) }\end{array}$ \\
\hline D1.F & $\begin{array}{l}\text { Verificação e controle } \\
\text { do Escopo }\end{array}$ & $\begin{array}{l}\text { - Priorização do cliente auxiliou na entrega do escopo? } \\
\text { - Foram realizadas verificações para controlar o escopo } \\
\text { estabelecido no inicio do projeto }\end{array}$ \\
\hline \multicolumn{3}{|c|}{ Seção 4 - Guia para o relatório do estudo de caso } \\
\hline \multicolumn{3}{|c|}{$\begin{array}{l}\text { - O código, apresentado na coluna ID do quadro na seção anterior, deve ser utilizado para } \\
\text { classificar os parâmetros observados em campo. Por exemplo: "D1.A - A equipe } 1 \text { elaborou o } \\
\text { plano mestre, identificando os Sprints."; D1.D - A equipe } 2 \text { não atualizou o quadro Scrum } \\
\text { durante o Sprint". } \\
\text { - O registro fotográfico deve ser realizado capturando cenas que retratem as variáveis da } \\
\text { Dimensão } 1 \text {, por exemplo, da equipe elaborando o plano mestre. O pesquisador também deve } \\
\text { estar atento a possíveis erros na execução da atividade, como por exemplo, registrar os } \\
\text { quadros não atualizados pela equipe } 2 \text {. }\end{array}$} \\
\hline
\end{tabular}




\section{APÊNDICE H - QUESTIONÁRIO DE AVALIAÇÃO DA EXPERIÊNCIA DO USUÁRIO}

Nome:

Equipe:

Data:

1

A. Indique com "X", na escala de 1 a 5, o quadro que reflete a sua opinião sobre as questões referentes ao procedimento de planejamento de tempo combinado.

$\begin{array}{cccc}\text { Discordo } & \text { Discordo Indiferente Concordo } & \begin{array}{c}\text { Concordo } \\ \text { totalmente }\end{array}\end{array}$

Eu acho que eu gostaria de utilizar esse procedimento frequentemente

2 Achei o procedimento desnecessariamente complexo

3 Eu achei o procedimento fácil de usar

Eu acho que eu iria necessitar do apoio de

4 um consultor para poder utilizar esse procedimento

5

Achei que as várias funções neste procedimento foram bem integradas

6 Eu achei que havia muita inconsistência nesse procedimento

Eu imagino que a maioria das pessoas iria

7 aprender a usar esse procedimento muito rapidamente

8

Achei o procedimento muito complicado para uso

9

Senti-me muito confiante usando o procedimento

Eu precisava aprender um monte de coisas antes de poder usar esse procedimento
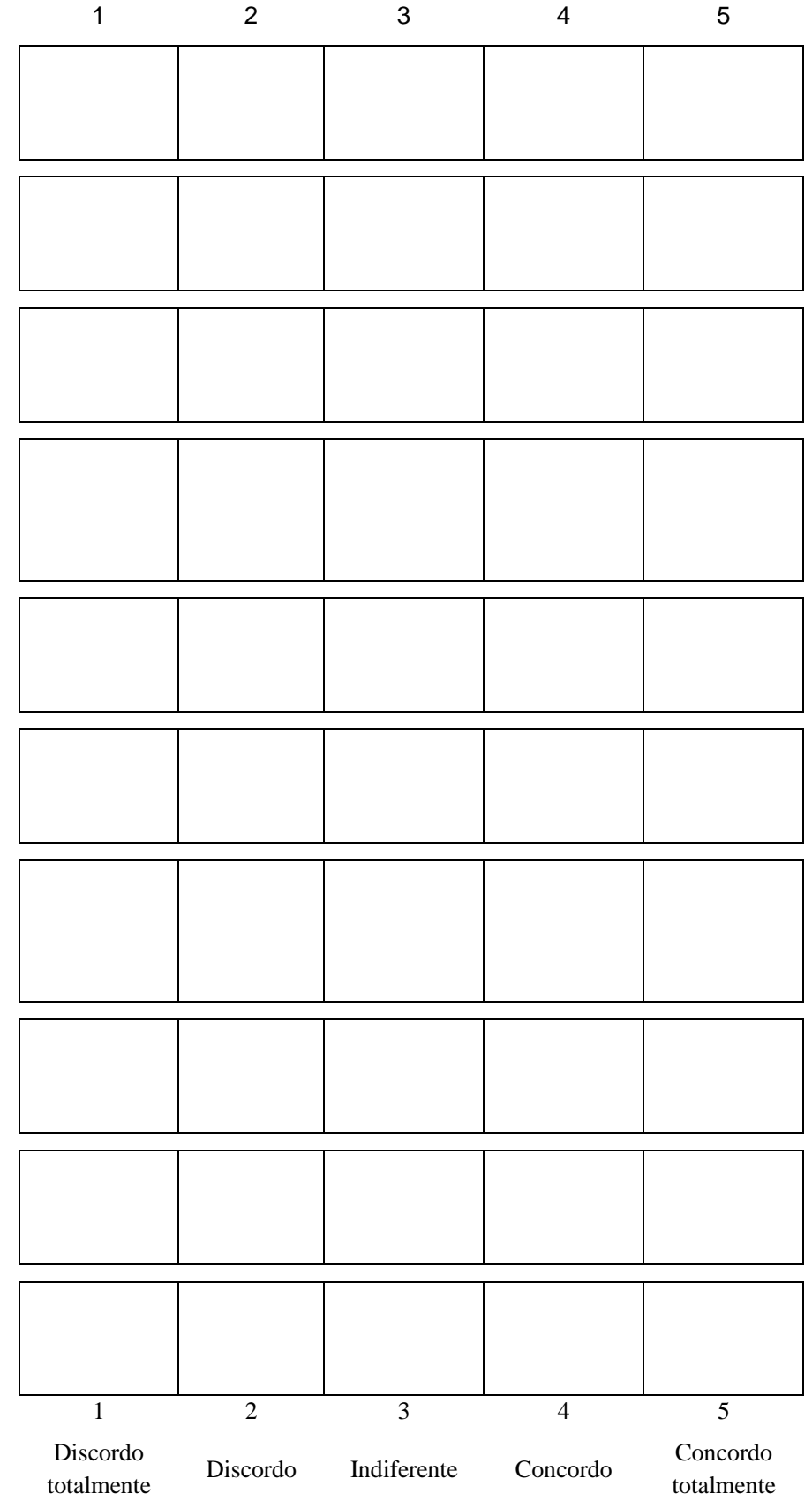
B. Você acredita que o procedimento de planejamento de tempo combinado ajudou na elaboração do planejamento do projeto? Por favor, justifique sua resposta.

Justificativa:

C. Você acredita que o procedimento de planejamento de tempo combinado ajudou no entendimento comum do plano do projeto? Por favor, justifique sua resposta.

Justificativa: 


\section{APÊNDICE I - CENÁRIO DO TREINAMENTO (VISÃO DO PRODUTO)}

Vocês fazem parte da equipe de projeto da "V8 Rocket Enterprise", empresa especializada em construção de foguetes.

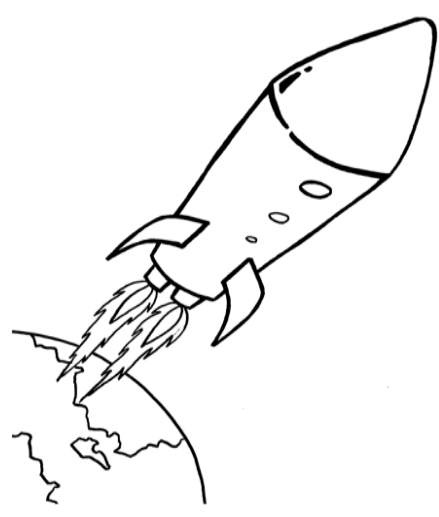

Existe uma competição de foguetes de água e ar comprimido que a empresa gostaria de participar. A competição que possui as seguintes características:

1) Utilizar a menor quantidade possível de materiais recicláveis na elaboração do design do foguete.

2) Possua um mecanismo de acionamento confiável.

3) Utilizar uma plataforma de lançamento que permita a regulagem do ângulo de lançamento.

O presidente da empresa, visando direcionar os esforços do projeto, solicitou a construção de um protótipo desse novo foguete ao final de duas semanas. O protótipo deve ser construído a partir do material fornecido para o treinamento e, ao final, vocês devem apresentar o protótipo na última reunião do projeto.

A missão da equipe é:

1. Planejar o projeto utilizando o procedimento combinado proposto.

2. Executar o projeto.

3. Acompanhar o projeto utilizando o procedimento e atualizando o plano.

4. Encerrar o projeto apresentando aos stakerholders o foguete construído 


\section{DICAS PARA A CONSTRUÇÃO DO FOGUETE}

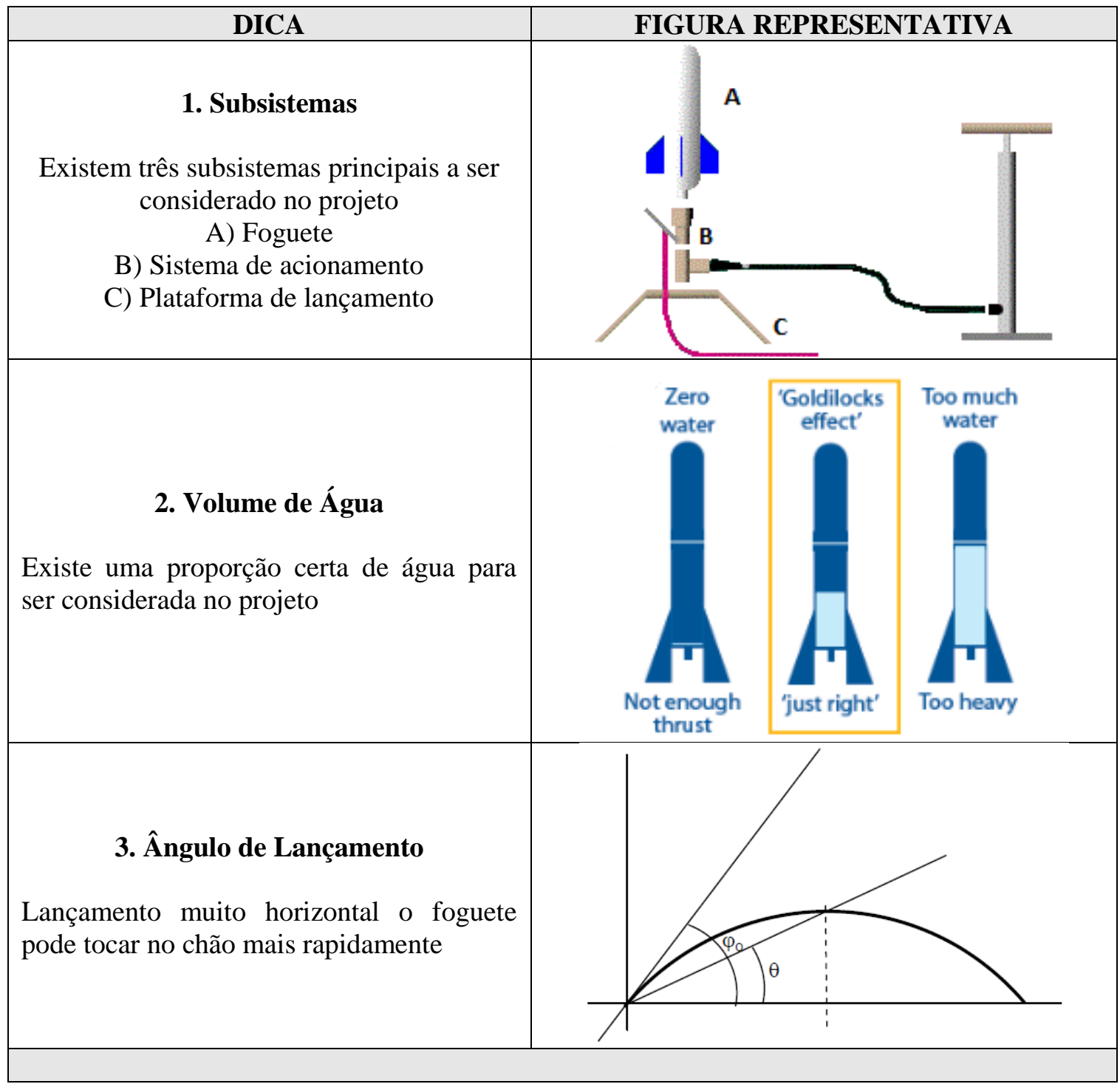




\section{APÊNDICE J - CARTA DE CONSETIMENTO}

\section{Carta de Consentimento}

A coleta de dados via vídeo, fotografias e questionário visa obter informações sobre a execução do procedimento proposto, assim como as percepções dos entrevistados durante e após a dinâmica. As informações coletadas serão utilizadas exclusivamente para fins de avaliação do método e publicações científicas.

Todas as informações coletadas neste estudo são de caráter confidencial e o nome e identidade dos participantes não serão identificados em momento algum.

Estou ciente de que posso fazer perguntas ou desistir de colaborar em qualquer momento, sem qualquer tipo de penalidade.

Afirmo que sou maior de 18 anos e desejo participar da pesquisa conduzida pelo mestrando Felipe Barreto Silva, membro do Programa de Pós-Graduação em Engenharia de Produção da Escola de Engenharia de São Carlos - Universidade de São Paulo. Também, concedo o direito de imagem e o material produzido durante a dinâmica para uso exclusivo de publicações científicas.

Data:

Nome por extenso:

Assinatura do participante: 


\section{APÊNDICE L - TABELA COM O REGISTRO DOS DADOS COLETADOS}

Apresenta os dados brutos coletados na pesquisa referentes às observações de campo e o registro fotográfico.

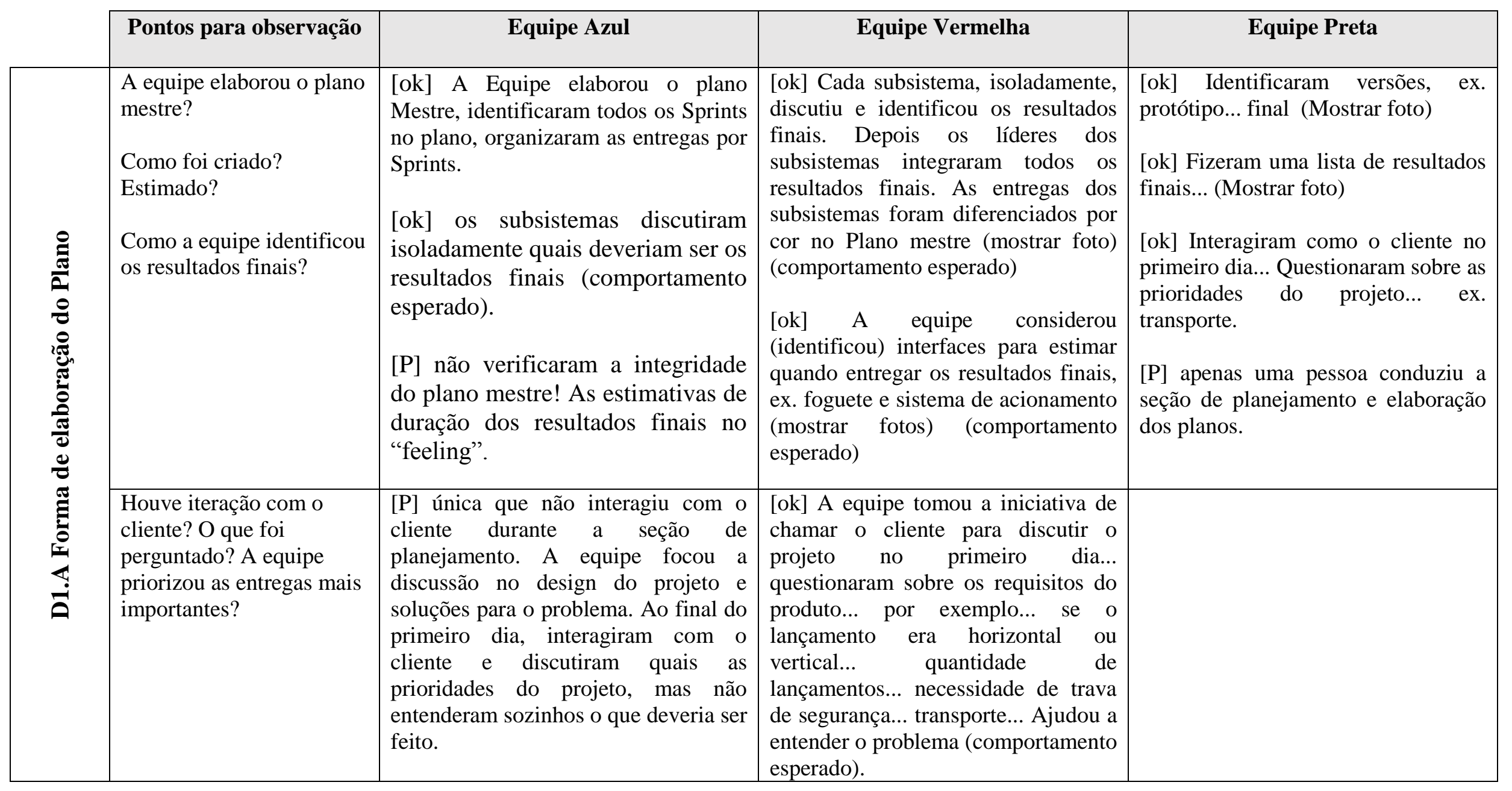




\begin{tabular}{|c|c|c|c|c|}
\hline \multirow{3}{*}{ 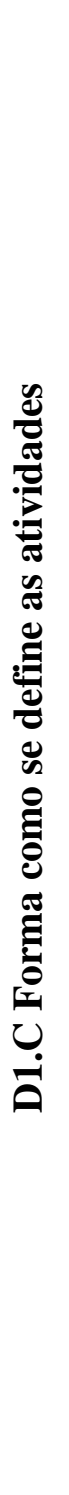 } & $\begin{array}{l}\text { Foi criada uma lista de } \\
\text { atividades (Backlog)? } \\
\text { A equipe está atualizando a } \\
\text { lista com as prioridades e } \\
\text { pontos? }\end{array}$ & $\begin{array}{l}\text { [ok] Durante a seção de } \\
\text { planejamento (1 a dia) não } \\
\text { identificaram work items. } \\
\text { [ok] No segundo dia, a equipe } \\
\text { elaborou uma lista de atividades, } \\
\text { semelhante a um backlog, onde } \\
\text { indicava alguns work items que } \\
\text { deveriam ser executados, mas apenas } \\
\text { para o primeiro Sprint... A lista } \\
\text { contemplou as atividades de todos os } \\
\text { subsistemas... A lista auxiliou no } \\
\text { planejamento do Sprint e as } \\
\text { atividades foram adicionadas ao } \\
\text { Quadro Scrum. } \\
\text { [ok] A discussão para a criação da } \\
\text { lista envolveu todos os membros da } \\
\text { equipe azul, onde os lideres } \\
\text { comandavam a discussão } \\
\text { (comportamento esperado). }\end{array}$ & $\begin{array}{l}{[\mathrm{P}] \text { Fizeram uma lista com os }} \\
\text { componentes do produto, ex. rolha } \\
\text { para vedar a boca da garrafa pet, o } \\
\text { planejamento foi realizado tendo em } \\
\text { vista a solução final discutida } \\
\text { inicialmente pela equipe. } \\
\text { [ok] No segundo Sprint cada } \\
\text { subsistema, isoladamente, identificou } \\
\text { os work items e iniciaram a execução } \\
\text { das atividades... } \\
\text { [P] deixaram o quadro scrum em } \\
\text { cima das mesas. Dificultou a } \\
\text { visualização das atividades por } \\
\text { outros subsistemas... } \\
\text { [ok] No terceiro Sprint atualizaram o } \\
\text { quadro scrum conforme a entrega dos } \\
\text { work itens. }\end{array}$ & $\begin{array}{l}\text { [P] Não priorizaram os work items } \\
\text { inicialmente, começaram a execução, } \\
\text { cada subsistema isoladamente, } \\
\text { tiveram dificuldades com as } \\
\text { interfaces e, a partir disso, os } \\
\text { subsistemas começaram a se } \\
\text { comunicar. } \\
\text { [P] Não identificaram work items no } \\
\text { segundo dia. } \\
\text { [P] Não fizeram o quadro scrum no } \\
\text { segundo dia. } \\
\text { [P] no terceiro dia não atualizaram o } \\
\text { quadro constantemente durante a } \\
\text { execução do Sprint... um subsistema } \\
\text { durante o sprint }\end{array}$ \\
\hline & $\begin{array}{l}\text { As atividades (work items) } \\
\text { foram organizadas de } \\
\text { forma hierárquica } \\
\text { semelhante à WBS? }\end{array}$ & $\begin{array}{l}\text { [ok] Não organização dos work } \\
\text { items. }\end{array}$ & $\begin{array}{l}\text { [ok] Não organização dos work } \\
\text { items. }\end{array}$ & $\begin{array}{l}\text { [ok] Não organização dos work } \\
\text { items. }\end{array}$ \\
\hline & $\begin{array}{l}\text { O Quadro Scrum } \\
\text { elaborado? Este foi } \\
\text { atualizado durante as } \\
\text { Sprints? }\end{array}$ & $\begin{array}{l}\text { [ok] No segundo sprint... a equipe } \\
\text { identificou work items... colaram o } \\
\text { quadro scrum na parede... } \\
\text { atualizaram os quadros conforme os } \\
\text { subsistemas foram finalizando as } \\
\text { atividades... veracidade do plano... } 1^{\text {a }} \\
\text { work item era desenhar a solução e a } \\
\text { equipe estava executando } \\
\text { (comportamento esperado). }\end{array}$ & & \\
\hline
\end{tabular}




\begin{tabular}{|c|c|c|c|c|}
\hline 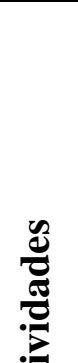 & $\begin{array}{l}\text { O Plano Mestre foi } \\
\text { elaborado para todo o } \\
\text { horizonte de tempo do } \\
\text { projeto de uma única vez? }\end{array}$ & $\begin{array}{l}\text { [ok] No Plano Mestre a unidade de } \\
\text { planejamento correspondia a } 15 \mathrm{~min} . . . \\
\text { tempo total } 3 \mathrm{~h} \text { disponível... Os } \\
\text { resultados finais foram estimados no } \\
\text { feeling, os membros da equipe não } \\
\text { tinham ideia de quanto tempo iria ser } \\
\text { gasto na execução dos resultados } \\
\text { finais. }\end{array}$ & $\begin{array}{l}\text { [ok] O Plano Mestre foi elaborado } \\
\text { para todo o horizonte de tempo. A } \\
\text { unidade de tempo utilizada foi } 5 \text { min. } \\
\text { [P] duração de tempo total do projeto } \\
\text { 1h15min. Inconsistência no Plano } \\
\text { mestre. }\end{array}$ & $\begin{array}{l}\text { [ok] O Plano Mestre foi elaborado } \\
\text { para todo o horizonte de tempo. A } \\
\text { unidade de tempo utilizada foi } 7,5 \\
\text { min, identificaram os sprints. Tempo } \\
\text { total 3h... igual tempo disponível } \\
\text { para executar. }\end{array}$ \\
\hline
\end{tabular}




\begin{tabular}{|c|c|c|c|c|}
\hline 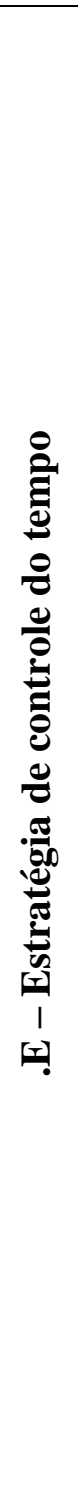 & $\begin{array}{l}\text { O progresso foi direcionado para } \\
\text { resultados tangíveis? } \\
\text { As equipes solicitaram o feedback } \\
\text { dos líderes? Ou os líderes } \\
\text { espontaneamente davam o } \\
\text { feedback? (Comunicação) } \\
\text { O cliente participou da discussão } \\
\text { ou auxiliou o time de } \\
\text { desenvolvimento? } \\
\text { Foi utilizado algum indicado de } \\
\text { tempo? (Exemplo: Escopo } \\
\text { entregue ou atividades concluídas) }\end{array}$ & $\begin{array}{l}{[\mathrm{P}] \text { Não possível observar os }} \\
\text { feedbacks entre membros das } \\
\text { equipes. } \\
\text { [P] Não se percebeu que a equipe } \\
\text { direcionou o progresso para } \\
\text { resultados tangíveis (Rever Plano } \\
\text { da Equipe)... ex. estabelecendo } \\
\text { entregas parciais... } \\
\text { [P] Não chamaram o cliente para } \\
\text { ajudar a validar o plano ou mostrar } \\
\text { entregas parciais durante o segundo } \\
\text { dia... e estava planejado no quadro } \\
\text { scrum... } \\
\text { [P] No terceiro dia não tinham nada } \\
\text { para apresenta ao cliente... Durante } \\
\text { a seção de revisão com o cliente... } \\
\text { [P] Não utilizaram o Plano mestre } \\
\text { para controlar o tempo... Faltou } \\
\text { atualização das estimativas. } \\
\text {. } \\
\text { [P] Os prazos para entregas não } \\
\text { respeitados..., ex. atividade de } \\
\text { revisão não tinham nada para } \\
\text { entregar para o cliente avaliar... } \\
\text { Falhas nas estimativas do plano } \\
\text { mestre, não atualizaram o Plano } \\
\text { mestre... apenas os quadros } \\
\text { scrums... as entregas do } 1^{\text {a }} \text { Sprint } \\
\text { não estavam completas, ex. } \\
\text { desenhos do projeto... }\end{array}$ & $\begin{array}{l}{[\mathrm{P}] \text { Não possível observar os }} \\
\text { feedbacks entre membros das } \\
\text { equipes. } \\
{[\mathrm{P}] \text { No } 2^{\mathrm{a}} \text { dia, o subsistema da }} \\
\text { plataforma ficou isolado da } \\
\text { discussão... (mostrar foto) } \\
{[\mathrm{P}] \text { No } 3^{\mathrm{a}} \text { dia, todos os subsistemas }} \\
\text { estavam em volta da mesma } \\
\text { mesa... Abandonaram a divisão de } \\
\text { subsistemas... Os membros do } \\
\text { subsistema foguete terminaram a } \\
\text { execução dos work items e não } \\
\text { fizeram mais nada } \\
\text { [ok] Cliente ajudou a identificar } \\
\text { um problema no projeto... Explicar } \\
\text { o problema de fixação da } \\
\text { plataforma } \\
\text { [P] Falhas nas estimativas do plano } \\
\text { mestre, não atualizaram as } \\
\text { estimativas de tempo do Plano } \\
\text { mestre... [ok] atualizaram todos os } \\
\text { quadros scrums. } \\
\text { [ok] (comportamento esperado) } \\
\text { entregas parciais... foi possível o } \\
\text { cliente avaliar e encontrar um } \\
\text { problema de projeto... isso foi } \\
\text { planejado, executado e entregue no } \\
\text { momento certo. }\end{array}$ & $\begin{array}{l}\text { [P] Não possível observar os } \\
\text { feedbacks entre membros das } \\
\text { equipes. } \\
\text { [ok] Os líderes conversaram muito } \\
\text { entre si para discutir a solução do } \\
\text { problema... (Mostrar foto) } \\
\text { [ok] No terceiro dia o cliente } \\
\text { também ajudou a identificar um } \\
\text { problema no subsistema foguete... } \\
\text { excesso de material utilizado... [P] } \\
\text { mas não atualizaram os planos. } \\
\text { [P] Falhas nas estimativas do plano } \\
\text { mestre. } \\
\text { [P] não atualizaram o Plano } \\
\text { mestre, apenas os quadros } \\
\text { scrums... } \\
\text { [P] não seguiram o planejamento... } \\
\text { não entregas parciais... }\end{array}$ \\
\hline
\end{tabular}




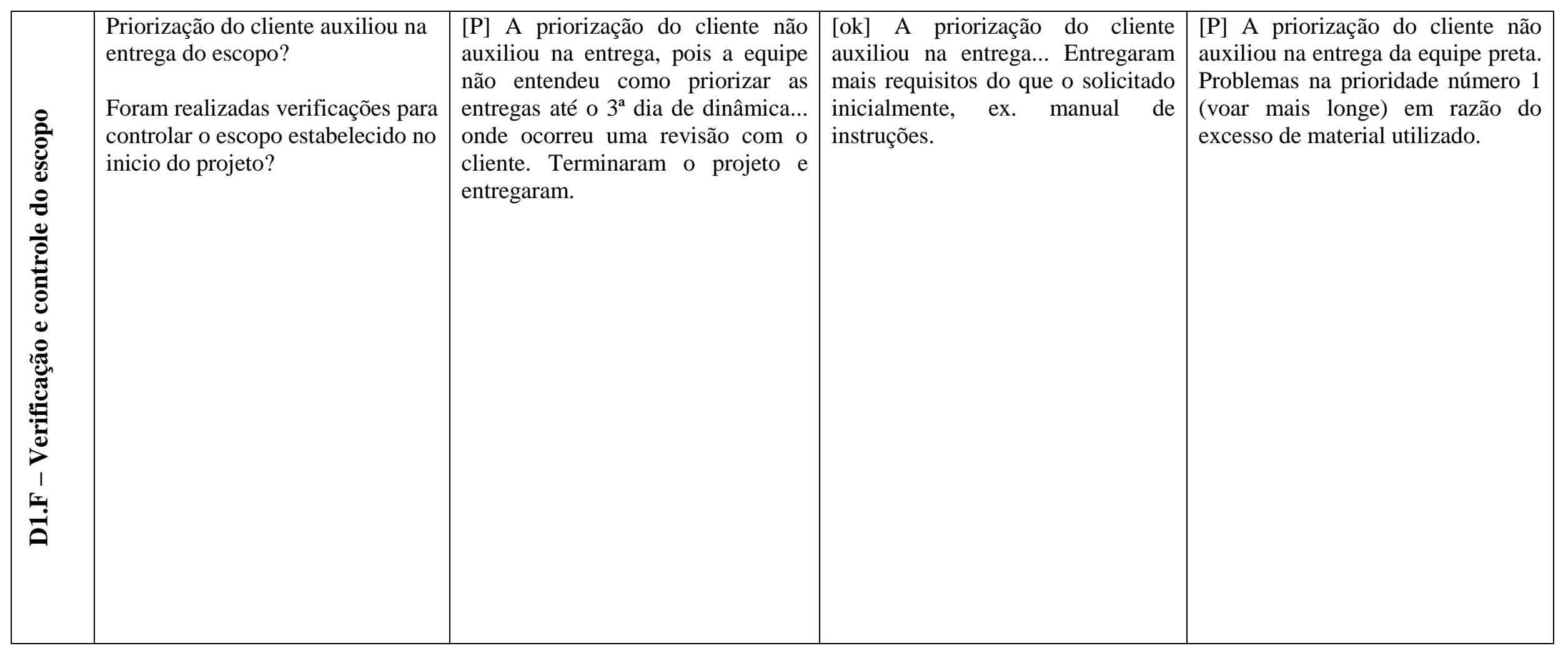




\section{APÊNDICE M - CÁLCULO DO ÍNDICE DE CONCORDÂNCIA}

A literatura apresenta vários métodos para calcular o Índice de Concordância (IC). A escolha por um método em particular para estimar o índice leva em consideração apenas questões pessoais do pesquisador, pois todos tendem a apresentar resultados convergentes (LEBRETON; SENTER, 2008). Por esse motivo, pesquisa calculou o IC por dois métodos para verificar a convergência dos métodos e, assim, optar por um método especifico para apresentar a análise dos dados. Dentre os métodos mais utilizados (LEBRETON; SENTER, 2008), a pesquisa escolheu o $r_{W G}$ e o $a_{W G}$, pois apresentam formas diferentes de calcular o índice, no entanto, apresentam os valores em uma escala entre 0 e 1, onde valor 1,0 significa total concordância entre os juízes, permitindo a comparação entre os resultados obtidos pelo dois métodos.

No método $r_{W G}$ os juízes avaliam um único alvo em uma única variável usando uma escala de intervalo de medição, que define o índice de concordância em termos de redução proporcional na variância do erro, conforme ilustra a equação 1 (LEBRETON; SENTER, 2008).

$$
r_{W G}=1-\frac{S_{X}^{2}}{\sigma_{E}^{2}},
$$

Onde: $S_{X}^{2}$ representa a variância observada de X, $\sigma_{E}^{2}$ é a variância esperada quando há completa falta de concordância entre os juízes.

Para calcular a $\sigma_{E}^{2}$ (variância esperada) é necessário assumir uma distribuição de probabilidade. Essa variância é obtida teoricamente da distribuição nula (null), representando a variância esperada se todos os juízes responderem aleatoriamente uma métrica, e é considerado o fator que mais complica o uso do $r_{W G}$ (LEBRETON; SENTER, 2008).

$\mathrm{O}$ método $a_{W G}$ foi criado para superar a dependência do $r_{W G}$ em relação à distribuição escolhida (LEBRETON; SENTER, 2008). No $a_{W G}$, leva-se em consideração o intervalo da escala de medição para calcular o índice a partir do julgamento de múltiplos juízes, conforme é apresentado na equação 2 (LEBRETON; SENTER, 2008). O método foi criado para superar a dependência do $r_{W G}$ em relação à distribuição escolhida, ao intervalo de medição e ao numero. 


$$
a_{W G}=1-\frac{2 * S_{X}^{2}}{\left[(H+L) * \bar{X}-\left(\bar{X}^{2}\right)-(H * L)\right] *\left[\frac{K}{K-1}\right]}
$$

Onde: X é a média dos valores atribuídos pelos juízes, H é o valor máximo possível da escala, L é o valor mínimo possível da escala, K é o numero de juízes, $S_{X}^{2}$ representa a variância observada de X.

O foco de análise para a variável usabilidade é avaliar individualmente as 10 métricas, presente no questionário de experiência do usuário, e não fazer inferências sobre o constructo usabilidade. Neste caso, adota-se o cálculo simples do índice de concordância para o $r_{W G} \mathrm{e} o$ $a_{W G}$. Caso for objetivo fazer inferências sobre o constructo usabilidade, é necessário calcular o índice agregado o $r_{W G(J)}$ e o $a_{W G(J)}$ para as das 10 métricas. Recomenda-se a leitura do trabalho de LeBreton e Senter (2008) para maiores informações sobre os indicies agregados.

O cálculo da variância e a média para cada uma das 10 métricas, categorizadas por equipe, foi efetuado por meio do software estatístico SPSS®, versão 17.0, e seguiu o tutorial apresentado por LeBreton e Senter (2008). Em um segundo momento, o Microsoft Excel® foi utilizado para organizar os dados e calcular o IC pelos dois métodos utilizando a equação 1 e 2 . Para o $r_{W G}$ foi adotado a distribuição de probabilidade igual ou retangular, onde o valor do $\sigma_{E}^{2}$ assume o valor dois, representando que os juízes não tinham tendências ou viés de respostas. (LEBRETON; SENTER, 2008).

A análise de dados apresentada no Capítulo 7 optou por apresentar apenas o $r_{W G}$ em razão da convergência dos resultados encontrados pelos dois métodos e simplificação da análise.

Quatro passos principais foram executados para calcular os ICs descritos de forma didática para ensinar de forma simples e direta como calcular os ICs utilizando o procedimento de LeBreton e Senter (2008).

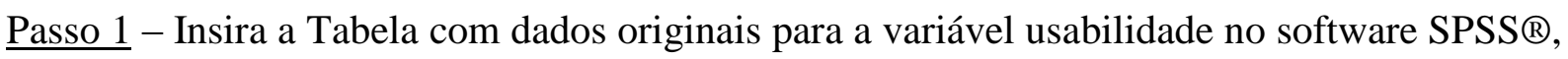
versão 17.0, onde item representa a métrica do questionário de experiência do usuário. 


\begin{tabular}{ccccccccccc}
\hline Grupo & Item 1 & Item 2 & Item 3 & Item 4 & Item 5 & Item 6 & Item 7 & Item 8 & Item 9 & Item 10 \\
\hline Azul & 4 & 2 & 4 & 2 & 4 & 2 & 4 & 1 & 4 & 2 \\
Azul & 4 & 2 & 4 & 3 & 4 & 2 & 3 & 2 & 4 & 3 \\
Azul & 4 & 2 & 5 & 1 & 3 & 2 & 3 & 2 & 4 & 2 \\
Azul & 5 & 2 & 3 & 4 & 4 & 2 & 3 & 2 & 4 & 2 \\
Azul & 3 & 4 & 2 & 5 & 5 & 1 & 3 & 2 & 3 & 2 \\
Azul & 4 & 1 & 4 & 2 & 5 & 1 & 4 & 1 & 4 & 2 \\
Azul & 5 & 3 & 4 & 2 & 5 & 1 & 4 & 1 & 3 & 1 \\
Azul & 5 & 3 & 3 & 3 & 4 & 2 & 2 & 2 & 1 & 4 \\
Azul & 3 & 2 & 4 & 4 & 3 & 3 & 4 & 2 & 3 & 2 \\
Azul & 4 & 2 & 4 & 2 & 4 & 2 & 4 & 1 & 2 & 2 \\
Preto & 5 & 1 & 4 & 1 & 4 & 2 & 4 & 2 & 4 & 2 \\
Preto & 4 & 1 & 3 & 2 & 4 & 1 & 4 & 1 & 3 & 2 \\
Preto & 4 & 2 & 3 & 3 & 4 & 2 & 4 & 2 & 3 & 1 \\
Preto & 4 & 2 & 4 & 2 & 4 & 2 & 4 & 2 & 4 & 2 \\
Preto & 4 & 2 & 4 & 2 & 4 & 2 & 4 & 1 & 3 & 2 \\
Preto & 4 & 1 & 4 & 3 & 5 & 2 & & 4 & 3 & 2 \\
Preto & 3 & 2 & 4 & 2 & 4 & 3 & 4 & 1 & 3 & 2 \\
Preto & 4 & 1 & 3 & 4 & 4 & 3 & 4 & 2 & 3 & 3 \\
Vermelho & 4 & 2 & 4 & 1 & 3 & 2 & 4 & 1 & 3 & 2 \\
Vermelho & 4 & 2 & 4 & 3 & 4 & 2 & 4 & 2 & 4 & 3 \\
Vermelho & 4 & 1 & 4 & 3 & 5 & 1 & 5 & 1 & 4 & 2 \\
Vermelho & 4 & 3 & 5 & 3 & 4 & 2 & 5 & 2 & 3 & 2 \\
Vermelho & 4 & 2 & 3 & 2 & 4 & 1 & 3 & 2 & 4 & 3 \\
Vermelho & 3 & 2 & 4 & 2 & 3 & 2 & 3 & 1 & 3 & 2 \\
Vermelho & 4 & 2 & 5 & 1 & 5 & 1 & 5 & 1 & 4 & 4 \\
Vermelho & 5 & 3 & 4 & 3 & 5 & 4 & 5 & 4 & 5 & 2 \\
Vermelho & 4 & 3 & 4 & 3 & 3 & 2 & 4 & 2 & 3 & 2 \\
\hline & & & & & & & & & & \\
\hline
\end{tabular}

$\underline{\text { Passo } 2}$ - Identifique e clique na aba Variable View, canto esquerdo inferior. Defina o tipo de variável (Type) e um valor para os dados que faltam (Missing). LeBreton e Senter (2008) recomendam inserir o valor 999, deste modo O SPSS $®$ ignora valores que faltam para gerar os resultados. 


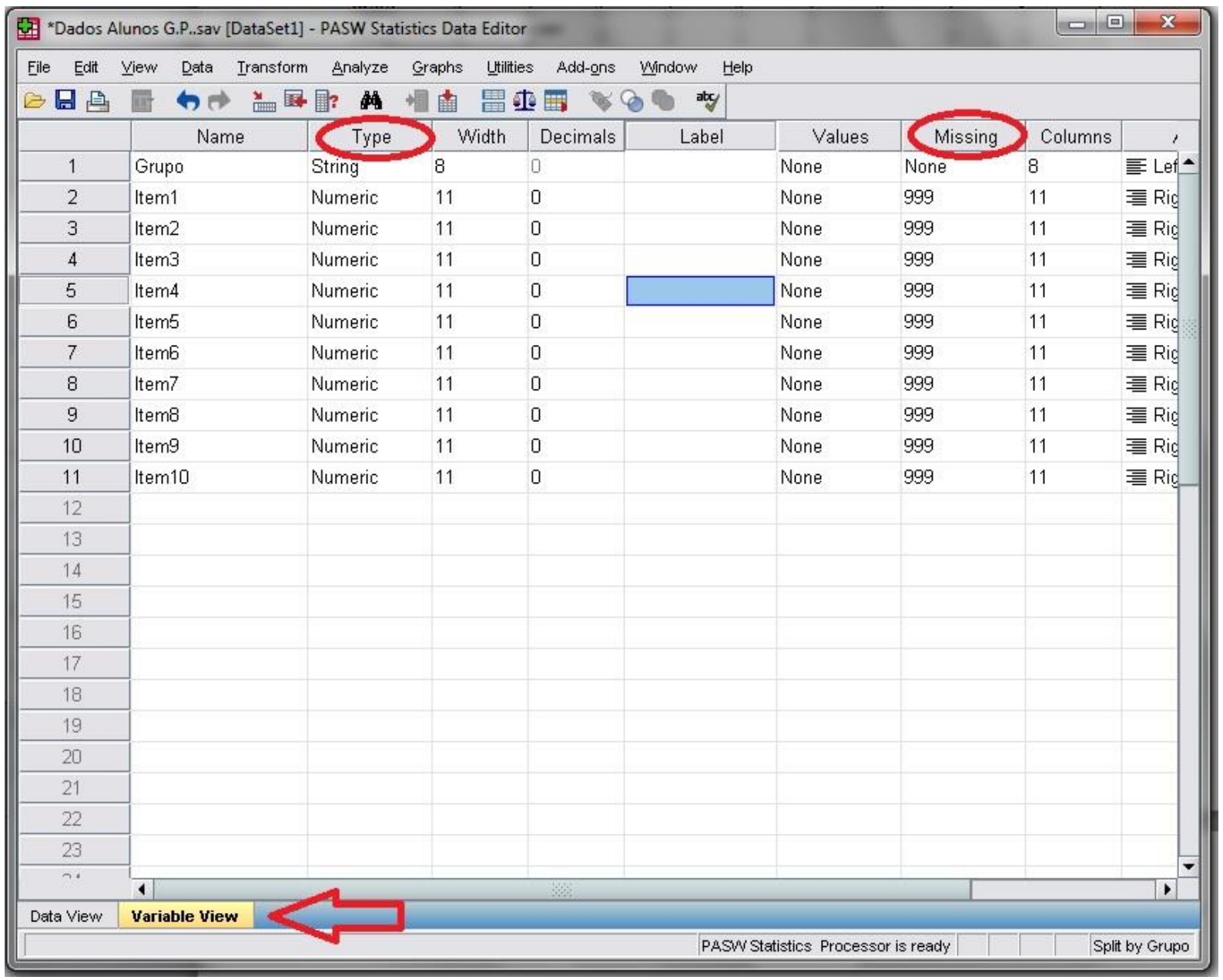

$\underline{\text { Passo } 3}$ - Inserir a sintaxe no software SPSS $®$, versão 17.0 , para o cálculo da variância e média por item (métrica) para cada equipe.

SORT CASES BY Grupo.

SPLIT FILE

SEPARATE BY Grupo.

DESCRIPTIVES

VARIABLES $=$ Item 1

/STATISTICS = MEAN STDDEV VARIANCE MIN MAX.

DESCRIPTIVES

VARIABLES $=$ Item 2

/STATISTICS $=$ MEAN STDDEV VARIANCE MIN MAX.

DESCRIPTIVES

VARIABLES $=$ Item 3

/STATISTICS $=$ MEAN STDDEV VARIANCE MIN MAX.

DESCRIPTIVES

VARIABLES $=$ Item 4

/STATISTICS $=$ MEAN STDDEV VARIANCE MIN MAX.

DESCRIPTIVES

VARIABLES $=$ Item 5

ISTATISTICS = MEAN STDDEV VARIANCE MIN MAX.

DESCRIPTIVES

VARIABLES $=$ Item 6 


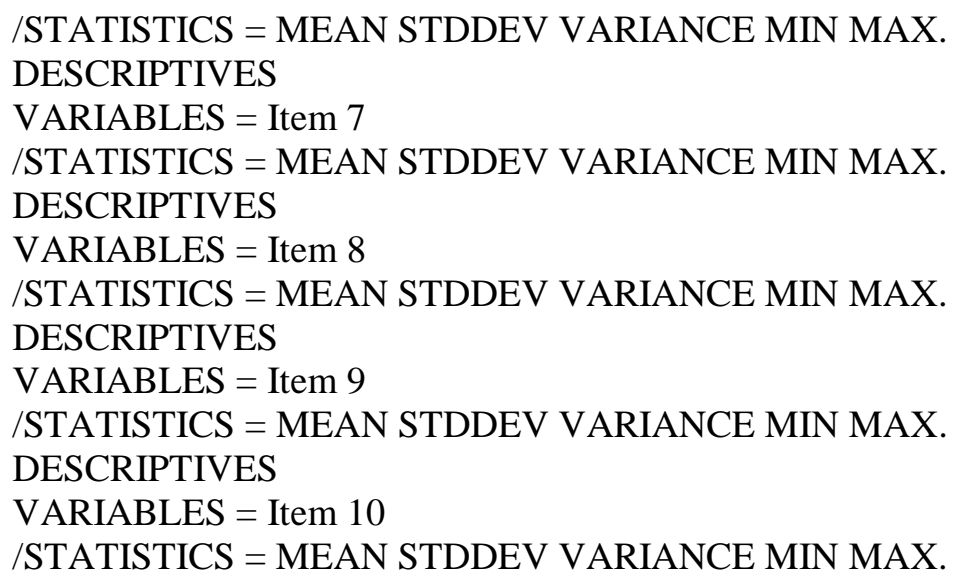

Passo 4 - No Microsoft Excel, organize o dado referente à média e variância calculadas no SPSS®. Utilize as formulas para calcular $r_{W G}$ e o $a_{W G}$. As tabelas apresentam os resultados dos cálculos para cada equipe.

Equipe Azul

\begin{tabular}{|c|c|c|c|c|}
\hline Afirmação & Média & Variância & Rwg & Awg \\
\hline $\begin{array}{c}\text { Utilizar } \\
\text { frequentemente }\end{array}$ & 4,1 & 0,544 & 0,728 & 0,649 \\
\hline $\begin{array}{l}\text { Desnecessariamente } \\
\text { complexo }\end{array}$ & 4,0 & 0,678 & 0,661 & 0,593 \\
\hline Fácil de usar & 3,7 & 0,678 & 0,661 & 0,652 \\
\hline Apoio do Consultor & 2,8 & 1,511 & 0,245 & 0,313 \\
\hline $\begin{array}{l}\text { Boa integração } \\
\text { entre as funções }\end{array}$ & 4,1 & 0,544 & 0,728 & 0,649 \\
\hline $\begin{array}{l}\text { Existência de } \\
\text { inconsistências }\end{array}$ & 1,8 & 0,400 & 0,800 & 0,719 \\
\hline Fácil de aprender & 4,0 & 0,489 & 0,756 & 0,707 \\
\hline $\begin{array}{l}\text { Complicado para o } \\
\text { uso }\end{array}$ & 1,6 & 0,267 & 0,867 & 0,764 \\
\hline $\begin{array}{c}\text { Confiança ao } \\
\text { utilizar }\end{array}$ & 3,2 & 1,067 & 0,467 & 0,515 \\
\hline $\begin{array}{l}\text { Aprendizado prévio } \\
\text { antes de usar }\end{array}$ & 2,2 & 0,622 & 0,689 & 0,667 \\
\hline
\end{tabular}




\section{Equipe Preta}

\begin{tabular}{|c|c|c|c|c|}
\hline Afirmação & Média & Variância & Rwg & Awg \\
\hline $\begin{array}{c}\text { Utilizar } \\
\text { frequentemente }\end{array}$ & 4,0 & 0,286 & 0,857 & 0,828 \\
\hline $\begin{array}{c}\text { Desnecessariamente } \\
\text { complexo }\end{array}$ & 2,0 & 0,286 & 0,857 & 0,828 \\
\hline Fácil de usar & 3,6 & 0,268 & 0,866 & 0,866 \\
\hline Apoio do Consultor & 2,4 & 0,839 & 0,581 & 0,582 \\
\hline $\begin{array}{l}\text { Boa integração } \\
\text { entre as funções }\end{array}$ & 4,1 & 0,125 & 0,938 & 0,917 \\
\hline $\begin{array}{l}\text { Existência de } \\
\text { inconsistências }\end{array}$ & 2,1 & 0,411 & 0,795 & 0,772 \\
\hline Fácil de aprender & 4,0 & 0,000 & 1,000 & 1,000 \\
\hline $\begin{array}{c}\text { Complicado para o } \\
\text { uso }\end{array}$ & 1,9 & 0,982 & 0,509 & 0,356 \\
\hline $\begin{array}{c}\text { Confiança ao } \\
\text { utilizar }\end{array}$ & 3,3 & 0,214 & 0,893 & 0,902 \\
\hline $\begin{array}{l}\text { Aprendizado prévio } \\
\text { antes de usar }\end{array}$ & 2,0 & 0,286 & 0,857 & 0,828 \\
\hline
\end{tabular}

Equipe Vermelha

\begin{tabular}{|c|c|c|c|c|}
\hline Afirmação & Média & Variância & Rwg & Awg \\
\hline $\begin{array}{c}\text { Utilizar } \\
\text { frequentemente }\end{array}$ & 4,0 & 0,250 & 0,875 & 0,850 \\
\hline $\begin{array}{c}\text { Desnecessariamente } \\
\text { complexo }\end{array}$ & 3,0 & 0,444 & 0,778 & 0,800 \\
\hline Fácil de usar & 4,1 & 0,361 & 0,820 & 0,765 \\
\hline Apoio do Consultor & 2,3 & 0,750 & 0,625 & 0,620 \\
\hline $\begin{array}{l}\text { Boa integração } \\
\text { entre as funções }\end{array}$ & 4,0 & 0,750 & 0,625 & 0,550 \\
\hline $\begin{array}{l}\text { Existência de } \\
\text { inconsistências }\end{array}$ & 1,9 & 0,861 & 0,570 & 0,440 \\
\hline Fácil de aprender & 4,2 & 0,694 & 0,653 & 0,503 \\
\hline $\begin{array}{c}\text { Complicado para o } \\
\text { uso }\end{array}$ & 1,8 & 0,944 & 0,528 & 0,323 \\
\hline $\begin{array}{c}\text { Confiança ao } \\
\text { utilizar }\end{array}$ & 3,7 & 0,500 & 0,750 & 0,747 \\
\hline $\begin{array}{l}\text { Aprendizado prévio } \\
\text { antes de usar }\end{array}$ & 2,4 & 0,528 & 0,736 & 0,742 \\
\hline
\end{tabular}


ANEXO A - Lista de classificação de práticas de gestão de projetos

\section{Classificação das práticas conforme Eder et al. (2014)}

\begin{tabular}{|l|c|}
\hline \multicolumn{1}{|c|}{ Ações } & Fontes \\
\hline Adding Detail to User Stories Sooner & Ágil \\
\hline Ask for a Time Commitment & Ágil \\
\hline Coletar requisitos & Tradicional \\
\hline Controlar Escopo & Tradicional \\
\hline Controlar o plano do projeto & Ambas \\
\hline Controlar Mudanças do Escopo & Ágil \\
\hline Termo de abertura do projeto & Ágil \\
\hline $\begin{array}{l}\text { Identificar o trabalho necessário para } \\
\text { o projeto (produto, entregas, etc..) }\end{array}$ & Ambas \\
\hline Declarar o Problema/Oportunidade & Ambas \\
\hline Definir as Atividades & Tradicional \\
\hline Definir Escopo do Projeto & Ambas \\
\hline Desenvolver o cronograma & Tradicional \\
\hline $\begin{array}{l}\text { Determine Target Velocity / } \\
\text { Estimating Velocity / Velocity }\end{array}$ & Ágil \\
\hline Estimar as durações das atividades & Ambas \\
\hline Estimar os recursos das atividades & Ambas \\
\hline Identificar e dimenionar folgas & Ágil \\
\hline Finalizar o Plano do Projeto & Tradicional \\
\hline Priorizar requisitos & Ágil \\
\hline Priorizar o trabalho necessário & Ágil \\
\hline Sequenciar as atividades & Tradicional \\
\hline Medir a complexidade & Ágil \\
\hline Verificar Escopo & Tradicional \\
\hline Definir Escopo do Produto & Tradicional \\
\hline
\end{tabular}

\begin{tabular}{|l|c}
\hline \multicolumn{1}{|c|}{ Ferramenta } & Fonte \\
\hline Apresentação de Slides & Ambas \\
\hline Ata de Reunião & Ambas \\
\hline Banco de dados & Tradicional \\
\hline Cartão / Recados Autoadesivos (Sticky Notes) & Ambas \\
\hline Cartaz & Ambas \\
\hline Checklist & Ambas \\
\hline Contrato & Tradicional \\
\hline Desenho / Esboço & Ambas \\
\hline Diagrama / Apresentação gráfica / Gráfico & Ambas \\
\hline Roteiros & Ambas \\
\hline E-mail & Ambas \\
\hline Lista & Ambas \\
\hline Manual de qualidade & Tradicional \\
\hline Maquetes & Ágil \\
\hline Mental models / Mandala / Process Maps & Ambas \\
\hline Modelos / Protótipo / Template & Ambas \\
\hline Planilha / Tabela & Ambas \\
\hline Quadro / Mural & Ambas \\
\hline Relatório & Tradicional \\
\hline Questionário & Ambas \\
\hline Software de gerenciamento de projetos & Ambas \\
\hline
\end{tabular}

\begin{tabular}{|c|c|}
\hline Técnicas & Fonte \\
\hline Planning Poker & Ágil \\
\hline Ajuste de antecipações e esperas & Tradicional \\
\hline Análise de alternativas & Tradicional \\
\hline Análise de produto & Tradicional \\
\hline Análise de reservas & Tradicional \\
\hline Análise do desempenho & Tradicional \\
\hline Árvore de Decisão & Tradicional \\
\hline Balanced Scorecard & Ambas \\
\hline Business problem definition & Tradicional \\
\hline Case point estimates & Ágil \\
\hline Chartering & Tradicional \\
\hline Compressão de cronograma & Tradicional \\
\hline Critical Path Method & Tradicional \\
\hline Delphi Technique & Tradicional \\
\hline Dinâmica de grupo & Tradicional \\
\hline Duration and Total Work Effort & Tradicional \\
\hline Earned Value Analysis & Tradicional \\
\hline Entrevista & Tradicional \\
\hline Estimar por analogia & Tradicional \\
\hline Estimar por comparação & Ágil \\
\hline Estimativa paramétrica & Tradicional \\
\hline Bill of Material & Ágil \\
\hline Experimento & Ágil \\
\hline Feature cards & Ágil \\
\hline Estimativa Análoga & Tradicional \\
\hline Inspeção / Observação & Tradicional \\
\hline Método da corrente crítica & Tradicional \\
\hline Event on node diagram & Tradicional \\
\hline Modelo / Template & Tradicional \\
\hline Nivelamento de recursos & Tradicional \\
\hline Opinião especializada / Oficina & Tradicional \\
\hline Planejamento em ondas sucessivas & Ambas \\
\hline Product Backlog & Ágil \\
\hline Program Evaluation and Review Technique & Tradicional \\
\hline Reunião & Ambas \\
\hline Simulação & Tradicional \\
\hline Stoplight Reports & Tradicional \\
\hline Técnica de Estimativa dos Três Pontos & Tradicional \\
\hline Técnicas de criatividade em grupo & Tradicional \\
\hline Customer Focus Groups & Ágil \\
\hline Daily Scrum Meetiing & Ágil \\
\hline Product Architecture & Ágil \\
\hline Product Feature List & Ágil \\
\hline Product Vision Box & Ágil \\
\hline Project Data Sheet & Ágil \\
\hline Reunião de Retrospectiva do Scrum (Sprint Retrospective Meeting) & Ágil \\
\hline Reunião de Revisão do Sprint (Sprint Review Meeting) & Ágil \\
\hline Sprint Backlog & Ágil \\
\hline Business case & Tradicional \\
\hline Comparing Pairs & Ambas \\
\hline Dot Voting & Ambas \\
\hline Intervalos de medida & Ágil \\
\hline WBS / Decomposição & Ambas \\
\hline Gantt & Tradicional \\
\hline
\end{tabular}


ANEXO B - Pré-concepção do produto e arquitetura de software para o exemplo

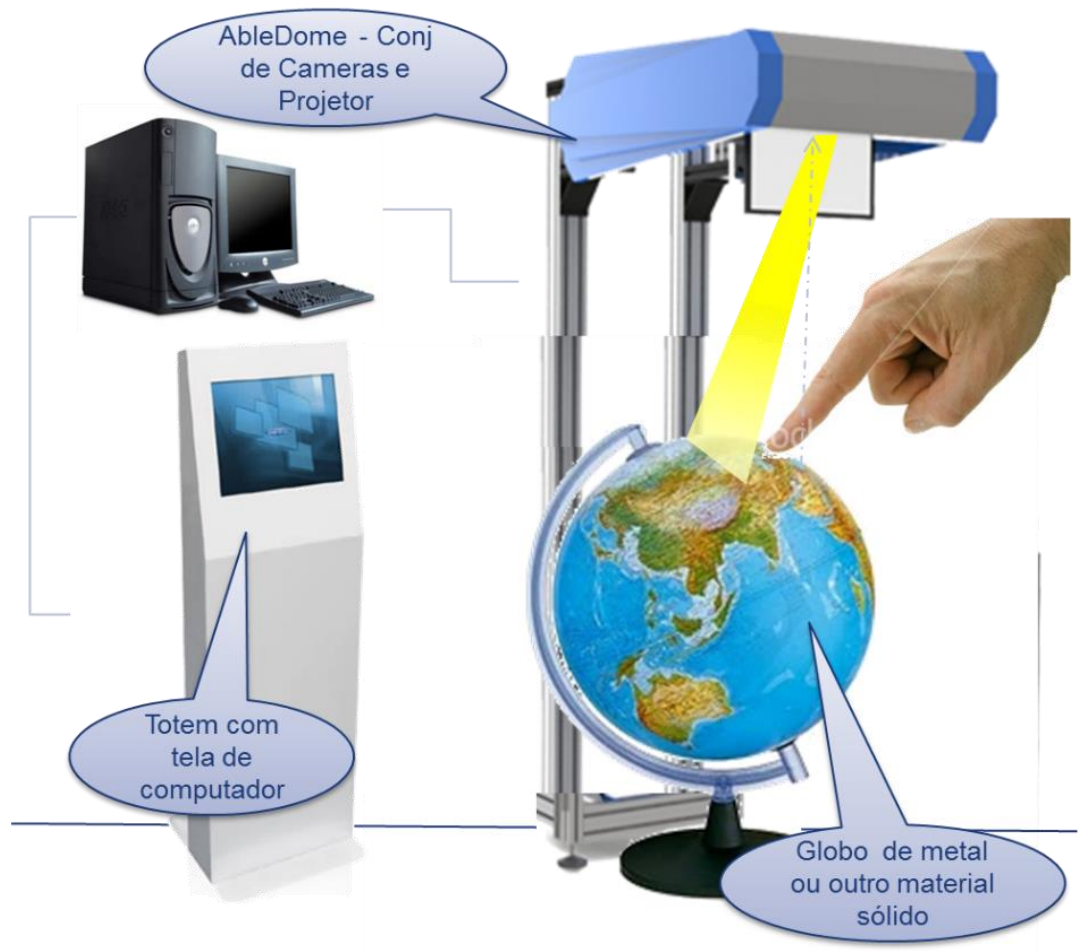

Figura 63 - Pré-concepção do Globo Interativo Fonte: Araujo (2012)

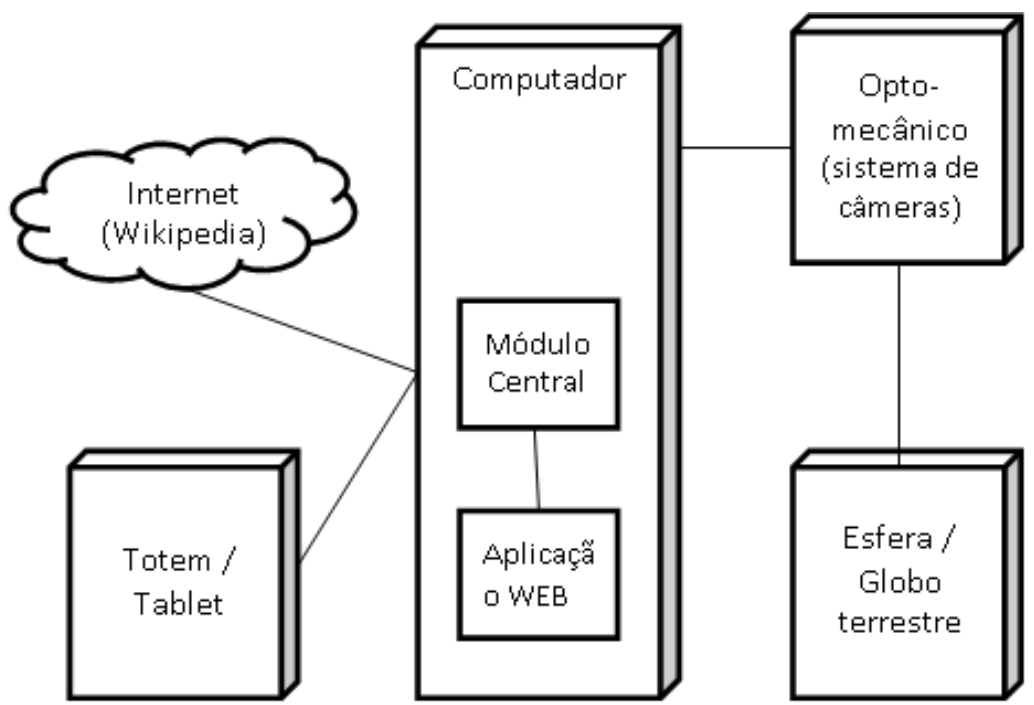

Figura 64 - Arquitetura do Software para o Globo Interativo Fonte: Araujo (2012) 


\section{ANEXO C - Captação das necessidades do cliente}

Formulário para a captação de necessidades dos clientes apresentado por Araujo (2012).

\begin{tabular}{|c|c|c|c|c|c|c|}
\hline \multicolumn{7}{|c|}{ Captação de necessidades do produto } \\
\hline \multicolumn{2}{|c|}{ Nome do projeto } & \multicolumn{3}{|l|}{\begin{tabular}{|l|} 
Globo interativo \\
\end{tabular}} & Data & \\
\hline \multicolumn{2}{|c|}{ Apelido } & & & & & \\
\hline \multicolumn{7}{|c|}{ Nome do Produto } \\
\hline \multirow{2}{*}{\multicolumn{2}{|c|}{$\begin{array}{l}\text { Autores } \\
\text { O produto possui similar? }\end{array}$}} & \multirow{2}{*}{\multicolumn{5}{|c|}{$\begin{array}{l}\text { Camila de Araujo e Ramon Faganello Fachini } \\
\begin{array}{l}\text { (X) Sim ( ) Não - Vide Smart Globe na ID } 4 \text { e documento Produtos-Base }\end{array}\end{array}$}} \\
\hline & & & & & & \\
\hline ID & Cenas & \multicolumn{2}{|c|}{ Problemas } & Sugestões & \multicolumn{2}{|r|}{ Necessidades } \\
\hline 01 & & $\begin{array}{l}\text { A falta de recursos } \\
\text { que viabilizem uma } \\
\text { maior interatividade a } \\
\text { uma aula de geografia } \\
\text { convencional. }\end{array}$ & $\begin{array}{l}\text { Uma aula, por exempaa } \\
\text { a divisão, soblitica de qualquer } \\
\text { parte do planeta trata de um } \\
\text { grande volume de } \\
\text { informações. } \\
\text { Uma aula expositiva pode ser } \\
\text { maçante e prejudicar o } \\
\text { aprendizado dos alunos. } \\
\text { O uso de mapas planos ou } \\
\text { globo na exposição de tais } \\
\text { informações não permite a } \\
\text { interação dos alunos. Além } \\
\text { disso, tais artefatos não } \\
\text { permitem a associação de } \\
\text { informações a esses. }\end{array}$ & $\begin{array}{l}\text { - Desenvolvimento de um } \\
\text { globo interativo para que o } \\
\text { aluno possa consultar as } \\
\text { informaçōes passadas durante } \\
\text { a aula, associando a parte } \\
\text { visual do globo com as } \\
\text { demais informaçōes sobre } \\
\text { determinados espaços (tais } \\
\text { como paises ou regiōes). O } \\
\text { uso do globo facilitaria o } \\
\text { entendimento das posições e } \\
\text { dimensões geográficas }\end{array}$ & $\begin{array}{l}\text { - Um globo interativ } \\
\text { que o mesmo estimu } \\
\text { - Um globo interativ } \\
\text { forma a poder ser us } \\
\text { pessoas, ou seja, est } \\
\text { reduzidas; } \\
\text { - Um globo interativ } \\
\text { interações variadas, } \\
\text { informaçōes que ou }\end{array}$ & $\begin{array}{l}\text { o deve possuir algum apelo para } \\
\text { le a criatividade dos alunos; } \\
\text { o tem de ser dimensionado de } \\
\text { ado no ensino de um grupo de } \\
\text { não deve ter dimensões muito } \\
\text { o deve oferecer formas de } \\
\text { de forma a apresentar as } \\
\text { suário solicitar. }\end{array}$ \\
\hline 02 & & $\begin{array}{l}\text { Há uma carência de } \\
\text { recursos tecnológicos } \\
\text { que promovam o } \\
\text { ensino da geografia } \\
\text { em aulas (ensino } \\
\text { básico e médio), assim } \\
\text { como em centros de } \\
\text { divulgação científica. } \\
\end{array}$ & $\begin{array}{l}\text { Muitas feiras de conhecimento } \\
\text { promovem conhecimentos e } \\
\text { disciplinas com o apoio de } \\
\text { tecnologias inovadoras que } \\
\text { chamam a atenção do público, } \\
\text { porém não existem muitas } \\
\text { iniciativas neste sentido que } \\
\text { abordem a geografia. }\end{array}$ & $\begin{array}{l}\text { - Desenvolvimento de } \\
\text { produtos com uso de } \\
\text { tecnologia de ponta para a } \\
\text { área de geografia, tal como } \\
\text { um globo interativo. }\end{array}$ & $\begin{array}{l}\text { - Utilização de uma } \\
\text { recente, porém ainda } \\
\text { apresentação de con }\end{array}$ & $\begin{array}{l}\text { nova tecnologia ou tecnologia } \\
\text { pouco conhecida, aplicando-a na } \\
\text { hecimentos da área de geografia. }\end{array}$ \\
\hline
\end{tabular}


ANEXO D - Legenda do procedimento

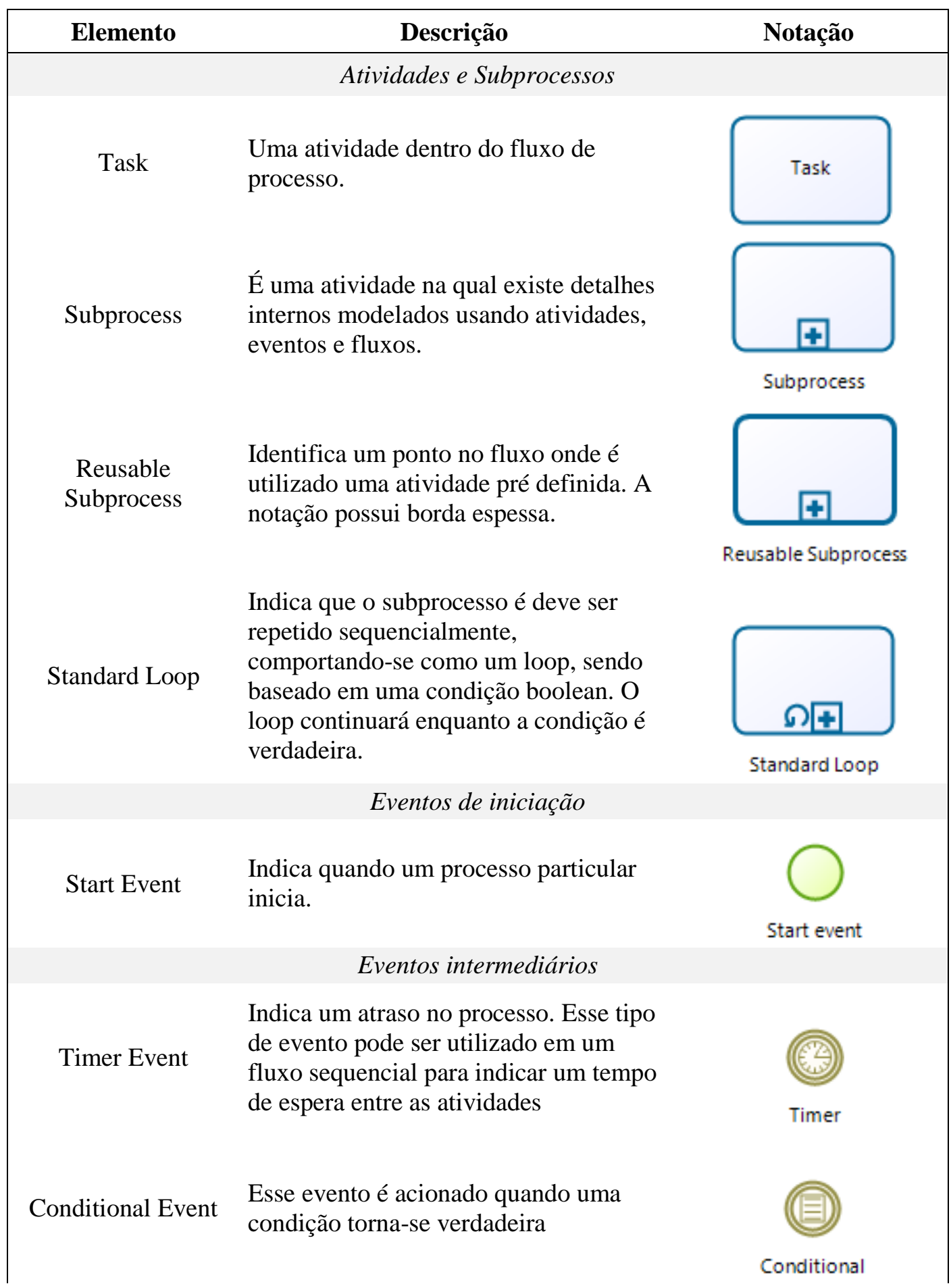




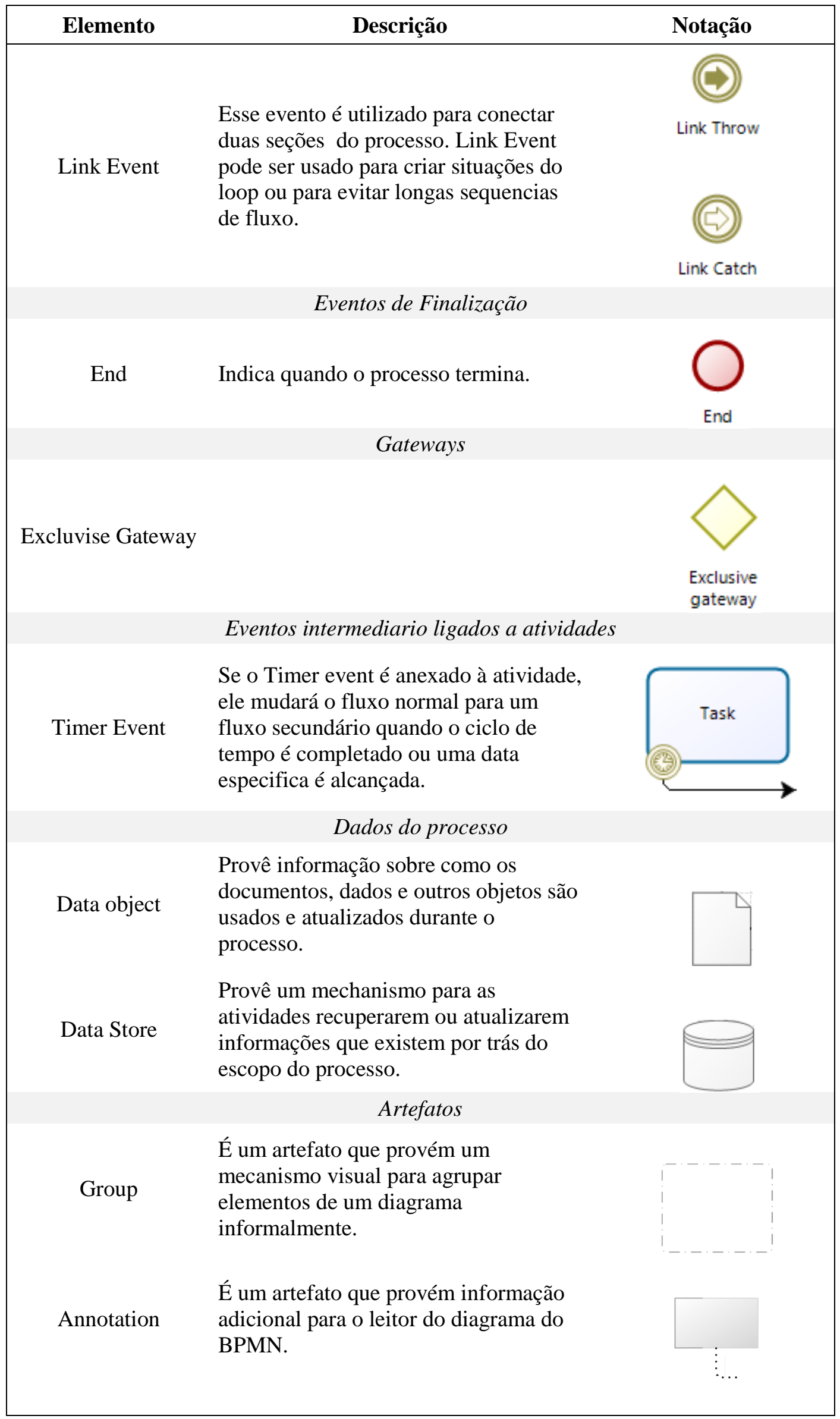




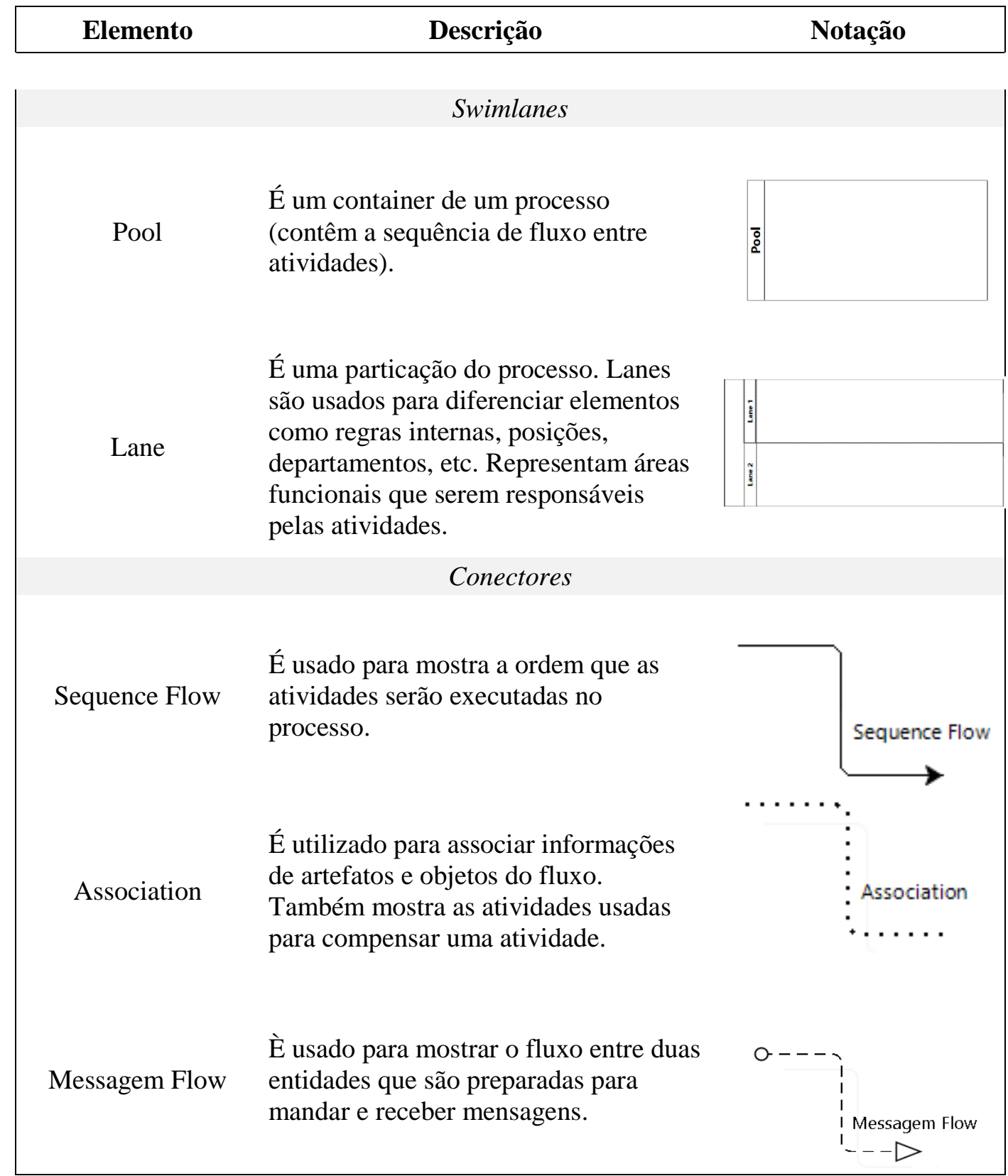


ANEXO E - Questionário de usabilidade

\section{System Usability Scale}

(1) Digital Equipment Corporation, 1986.

1. I think that I would like to use this system frequently

2. I found the system unnecessarily complex

3. I thought the system was easy to use

4. I think that I would need the support of a technical person to be able to use this system
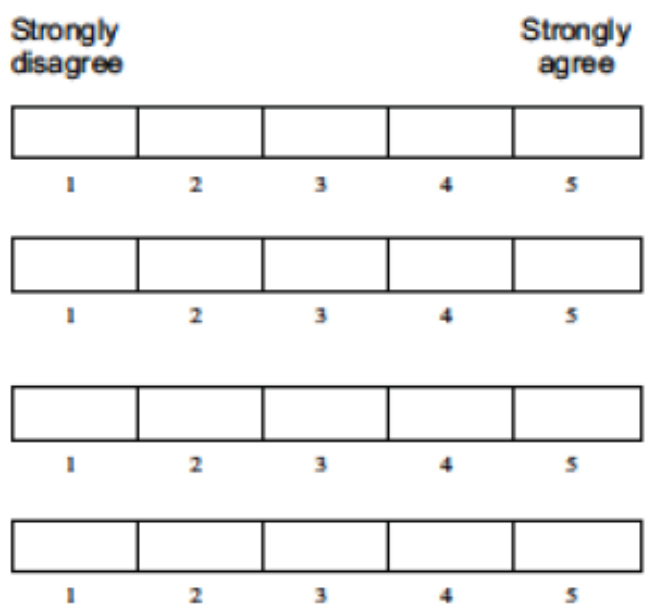

5. I found the various functions in this system were well integrated

6. I thought there was too much inconsistency in this system

7. I would imagine that most people would leam to use this system very quickly
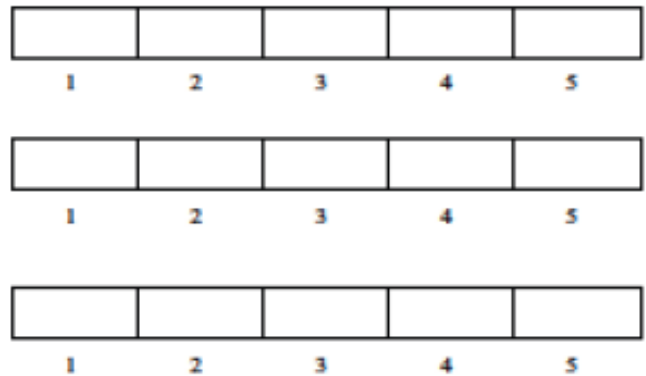

8. I found the system very cumbersome to use

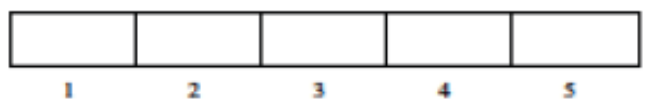

9. I felt very confident using the system

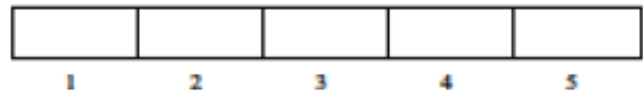

10. I needed b leam a lot of things before I could get going with this system

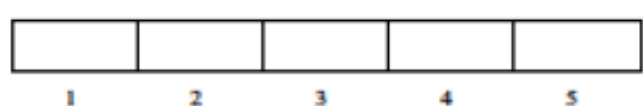

